\title{
CONTEXTUALIZACIÓN Y ARMONIZACIÓN JURÍDICA DEL CONVENIO 189 EN COLOMBIA
}

\author{
AUTOR \\ Jorge Alberto Lamo Tapias
}

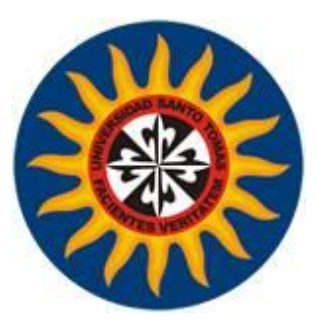

División de Ciencias Humanas

Facultad de Derecho

Universidad Santo Tomás,

Floridablanca, Colombia 


\title{
CONTEXTUALIZACIÓN Y ARMONIZACIÓN JURÍDICA DEL CONVENIO 189 EN COLOMBIA
}

\author{
AUTOR \\ Jorge Alberto Lamo Tapias
}

Presentado a

Dr. Pedro Antonio García Obando

Asesor

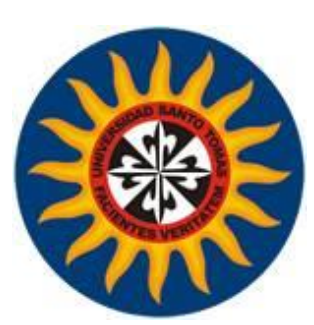

División de Ciencias Humanas

Facultad de Derecho

Universidad Santo Tomás,

Floridablanca, Colombia.

2016 


\section{Tabla de Contenido}

Pág.

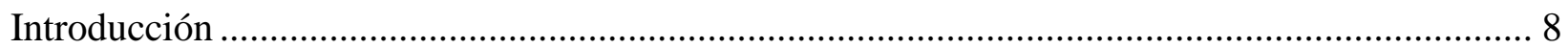

Contextualización Y Armonización Jurídica Del Convenio 189 En Colombia .......................... 11

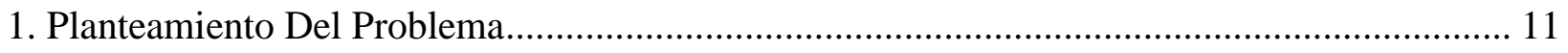

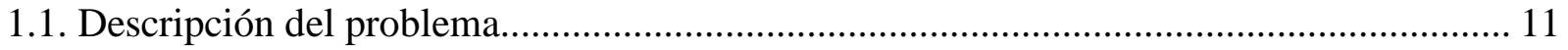

1.2. Formulación de pregunta de investigación........................................................... 17

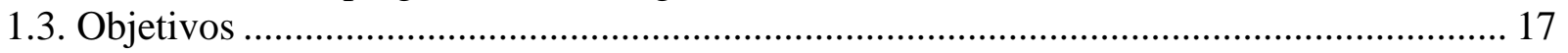

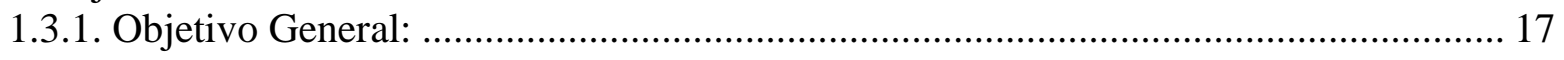

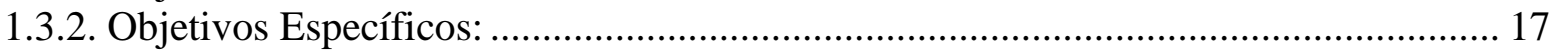

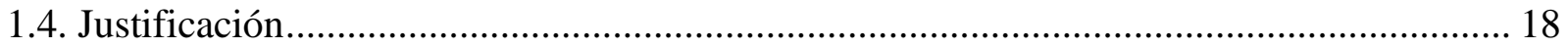

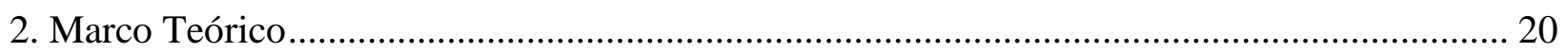

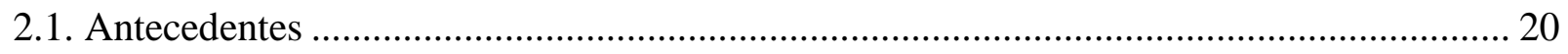

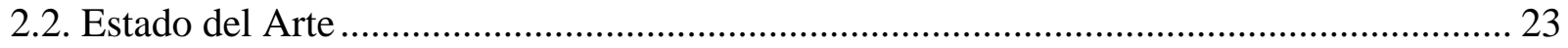

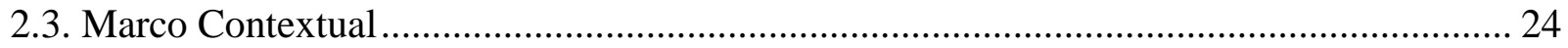

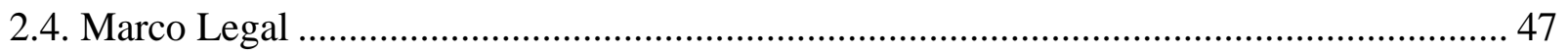

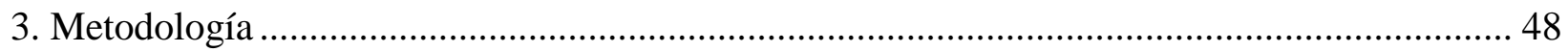

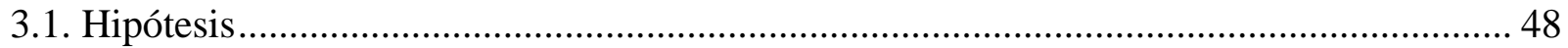

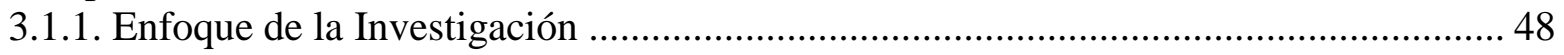

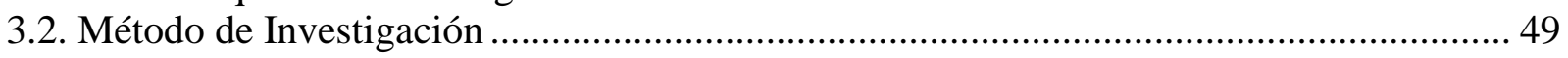

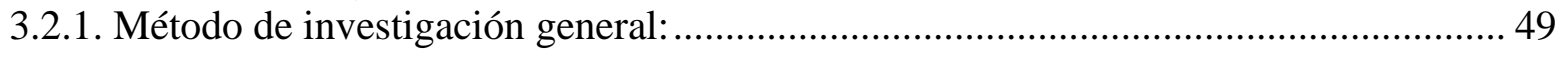

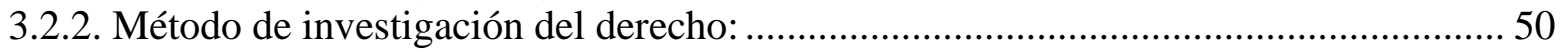

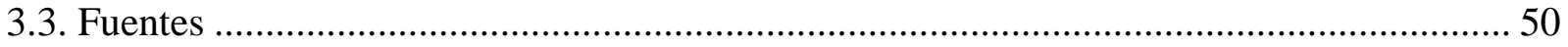

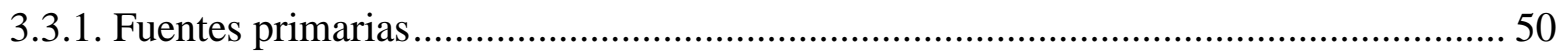

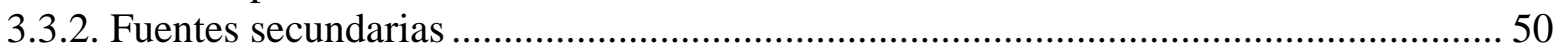

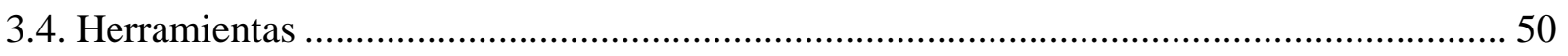

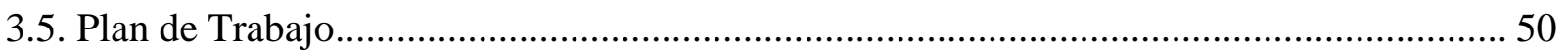

4. Contextualización Histórica Del Trabajo Decente Para Los Trabajadores Del Servicio Doméstico .............................................................51

4.1. El Trabajo Doméstico en la Edad Media: ................................................................ 52

4.2. El Trabajo Doméstico en la Colonia ......................................................................... 54

4.3. El trabajo Doméstico en la Independencia............................................................. 59

4.4. Esclavitud y el contrato de arrendamiento de servicio doméstico: ................................ 61

4.5. El Trabajo Doméstico y las teorías económicas y sociológicas .................................... 65

4.6. Mundialización y Globalización de los Derechos Laborales ......................................... 66

4.7. Regulación y Reivindicación de los Derechos de los Trabajadores Domésticos............... 70 
5. Armonización del Convenio 189 en la Legislación Colombiana ......................................... 79

5.1. Convenio 189 de la OIT: Origen, desarrollo y entrada en vigor.................................... 80

5.2. Armonización del Convenio 189 al Bloque de Constitucionalidad Colombiano .............. 82

5.3. Derecho al Trabajo Decente de los Trabajadores del Servicio doméstico en Colombia. . 85

5.4. Desarrollo Jurisprudencial del Trabajo Decente para los Trabajadores Domésticas en las

Cortes Constitucional y Suprema de Justicia de Colombia. 120

5.4.1. Línea Jurisprudencial Trabajo Decente para los Trabajadores Domésticas en la Corte

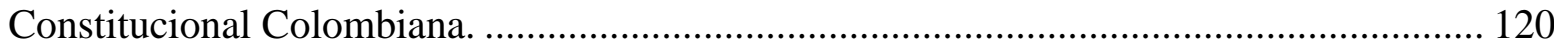

5.4.2. Línea Jurisprudencial Trabajo Decente para los Trabajadores Domésticos en la Corte

Suprema de Justicia ....................................................................................... 143

5.4.3. Confrontación del Análisis Jurisprudencial Corte Constitucional y Corte Suprema de

Justicia

6. Las Políticas Públicas y la Reivindicación de los Derechos Laborales para los Trabajadores del Servicio Doméstico.

6.1. Propuesta final: Desarrollo profesional de los trabajadores domésticos para un Trabajo

Decente 156

6.1.1. Esquema del Programa de Formación Académica de Entrenamiento Doméstico. ... 159

7. Conclusiones 165

Referencias. 170

Anexos 183 


\section{Lista de tablas}

Pág.

Tabla 1. Estimaciones a nivel regional y mundial del número de trabajadores domésticos en 2010, por sexo ................................................................................................................... 26

Tabla 2. Estimaciones del número de niños en trabajo doméstico por edad y sexo, 2008........... 29

Tabla 3. Población ocupada según sexo y posición ocupacional, promedio anual 2012 Total

Nacional ........................................................................................................................... 35

Tabla 4.Avella cita a Silva Romero. 2010 (p. 62) .................................................................. 72

Tabla 5.Porcentaje de trabajadores domésticos que cotizan a la seguridad social en años

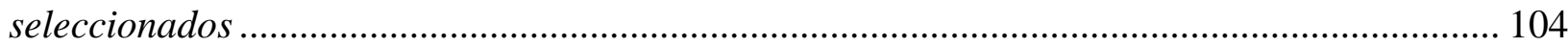

Tabla 6.Rastreo Jurisprudencial Trabajadores Servicio Doméstico...................................... 121 


\section{Lista de Figuras}

Pág.

Figura 1. Distribución de trabajadores domésticos por sexo y región, estimaciones 2010 ......... 27 Figura 2. Distribución porcentual de la población ocupada según posición ocupacional total

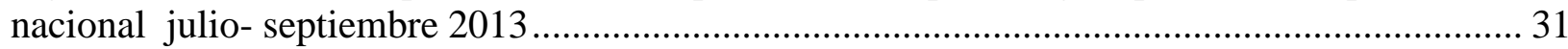
Figura 3. Proporción de la población de 5 a 17 años que realiza oficios en el hogar según sexo y el tipo de oficio que realiza total nacional 2012 (octubre - diciembre)....................................... 33 Figura 4. Población ocupada por posición ocupacional, 2012 (cifras en porcentaje)..................... 34

Figura 5. Línea Jurisprudencial.......................................................................................... 142

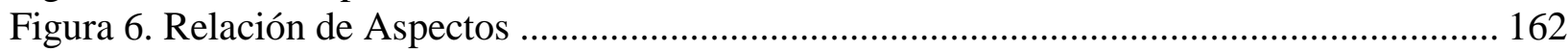

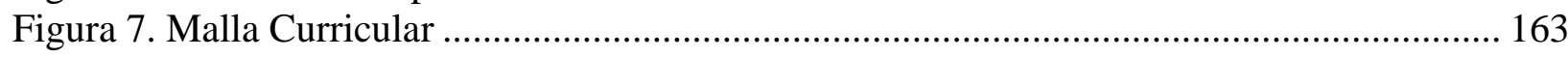




\section{Lista de anexos}

Pág.

Anexo A. Entrevistas a Organizaciones que trabajan en pro de los derechos de los trabajadores del hogar.

Anexo B. Análisis Jurisprudencial Sentencia C-616 de 2013 Sobre la Exequibilidad de la Ley 1595 de 2012 Por Medio de la Cual se Aprueba El Convenio 189. Anexo C. Análisis Jurisprudencial Sentencias de la Corte Constitucional Colombiana para establecer la Línea Jurisprudencial del Trabajo Decente para los Trabajadores del Servicio Doméstico.

Anexo D. Análisis Jurisprudencial Sentencias de Tutela de la Corte Suprema de Justicia Colombiana para establecer la Línea Jurisprudencial del Trabajo Decente para los Trabajadores del Servicio Doméstico 


\section{Introducción}

La presente investigación está dirigida a la Contextualización y armonización en Colombia del Convenio 189 sobre Trabajo Decente para los trabajadores y las trabajadoras del servicio doméstico, el tema clave al que se hace referencia en el presente documento es el concepto de Trabajo Decente, por cuanto este abarca una serie de principios básicos adoptados por la OIT, los cuales surgen de la necesidad de protección y promoción del trabajo bajo unos parámetro de decencia en un mundo globalizado y regido por un modelo económico agresivo e inequitativo que profundiza las brechas sociales; razones por las cuales la OIT, se ha venido pronunciando:

Conseguir un trabajo decente y productivo en condiciones de libertad, equidad, seguridad y dignidad humana. El trabajo decente es el punto de convergencia de cuatro objetivos estratégicos: la promoción de los derechos fundamentales en el trabajo; el empleo; la protección social y el dialogo social. (OIT, 1999,)

La OIT en el año 2011 por medio de sus análisis para la creación del Convenio 189, y en búsqueda de la protección jurídica a este grupo de trabajadores, encontró que ya algunos países contaban con herramientas jurídicas que buscaban salvaguardar determinados derechos fundamentales en materia laboral, como es el caso de Estados Unidos, Reino Unido, Francia y España, donde los trabajadores inmigrantes vieron vulnerados sus derechos laborales debido a su condición extranjera. Para el caso de Colombia, si bien los trabajadores de este sector marginado contaban con algunas herramientas jurídicas para su protección, no existía el concepto de Trabajo Decente, bajo el cual cambian los paradigmas socio-jurídicos para la garantía de derechos fundamentales.

Con esta nueva directiva emanada de este organismo supra nacional (OIT), se empiezan a establecer lineamientos para la protección efectiva de sus derechos y dicha situación permite que se visualice la importancia de un trabajo que a lo largo de la historia se ha subvalorado y relegado. En consecuencia, con la adopción de este Convenio por parte del Gobierno Colombiano, el país adquiere una serie de compromisos que deben asumir las partes 
involucradas (Estado, empleadores y trabajadores) con el fin de mejorar la calidad de vida de los trabajadores domésticos.

Es importante resaltar que los motivos que conllevaron al desarrollo de la investigación se dieron en desarrollo de la labor desarrollada por parte del autor como docente investigador dentro del semillero de investigación IUSLABORUM, del Módulo de Derecho Laboral de la Universidad Santo Tomás. Allí, el tema de esta investigación surgió como un contenido de interés para el grupo por las características especiales de los trabajadores domésticos, aunado esto al ámbito privado en el cual se desarrolla la relación laboral y a la subvaloración e indiferencia con la que la sociedad contempla esta importante labor, todo ello con fundamento en que este trabajo no requiere mayores estudios ni conocimientos para su desarrollo.

Siglos de indiferencia, apatía y desprecio de la labor remunerada que se desarrolla en el hogar, producto de la historia de servilismo y esclavismo, reclaman poner fin a este precedente y para ello se tiene como objetivo primordial de esta investigación lograr el cambio de paradigma jurídico dentro del ordenamiento jurídico colombiano, para con ello brindar a los trabajadores del servicio doméstico una mejor calidad de vida y contribuir a la reducción de las brechas sociales por medio de la adopción y cumplimiento del Convenio 189 de la OIT.

En cuanto a la finalidad de la presente investigación es establecer el avance, progreso y adopción en Colombia del Convenio 189 "Sobre el Trabajo Decente para las Trabajadoras y los Trabajadores Domésticos" adoptado en Ginebra en la 1OOa Reunión de la Conferencia Internacional del Trabajo en 2011, aprobado en Colombia mediante Ley 1595 de 2012, declarado Exequible por la Corte Constitucional Colombiana en sentencia C-616 de septiembre de 2013, depositado ante las Naciones Unidas en mayo de 2014 y ratificado a través del Decreto 325 de 2016.

Teniendo en cuenta lo anterior, se tiene que esta investigación parte del análisis histórico de la labor doméstica en Colombia y los avances jurídicos en la protección de este grupo de trabajadores, para luego establecer el origen del Convenio, el cual confluye en el análisis del articulado de éste en atención a la sentencia C-616 de 2013, donde la Corte Constitucional realiza el estudio de constitucionalidad, al tiempo que se observa las normas vigentes y algunos pronunciamientos que se vinculan al tema. Lo anterior nos remite al estudio de las líneas jurisprudenciales de trabajo decente para los trabajadores del servicio doméstico, desde los enfoques de la Corte Constitucional y de la Corte Suprema de Justicia, con el fin de corroborar 
el avance jurisprudencial para salvaguardar los derechos de quienes laboran en el servicio domésticos, para finalmente constituir una propuesta que brinde mayores y mejores oportunidades a este grupo de trabajadores, en atención a las necesidades de promoción, control y profesionalización del trabajo doméstico en Colombia. 


\section{Contextualización Y Armonización Jurídica Del Convenio 189 En Colombia}

\section{Planteamiento Del Problema}

\subsection{Descripción del problema}

El trabajo como elemento esencial de la economía es tema prioritario en las agendas de los entes gubernamentales, que en su deber social han de crear condiciones dignas y decentes para el desarrollo de las actividades laborales. Cabe resaltar que el concepto de trabajo decente es adoptado por la OIT a partir de 1999 y surge de la necesidad de protección y promoción del trabajo decente en un mundo globalizado y regido por un modelo económico agresivo e inequitativo que profundiza las brechas sociales.

Los cambios demográficos, como el envejecimiento de la población, la merma de la prestación de bienestar, la creciente participación de la mujer en la fuerza de trabajo y los retos que plantea armonizar la vida laboral y la vida familiar en las zonas urbanas y los países desarrollados propician una mayor demanda de personal doméstico (D’Souza, 2010, p. V).

Este incremento de oferta y demanda de servicios domésticos en la economía global, unido a la escasa reglamentación en algunos países y la vulnerabilidad de quienes realizan labores remuneradas en el hogar, llamó la atención de la Organización Internacional del Trabajo y en el 2008 se incluyó en la agenda de trabajo el estudio de las diferentes perspectivas con el fin de garantizar y promover el trabajo decente para los trabajadores domésticos.

A lo largo de la historia el trabajo en el hogar ha transmutado atendiendo a los cambios socioculturales, pero en cuanto a la relación laboral actual persisten características de rango o posición social propias del esclavismo y el servilismo. La brecha socio-económica entre el empleador y el trabajador genera espacios propicios para la precarización de los derechos de quienes desempeñan labores domésticas y aspectos tales como la raza, la edad, el sexo, la etnia, la nacionalidad, son factores determinantes que debilitan al trabajador al momento de llevar a cabo la negociación laboral con el empleador. 
Asha D’Souza(2010) en su informe Camino del trabajo decente para el personal del servicio doméstico: panorama de la labor de la OIT, indica que a nivel mundial se observa que el trabajo doméstico se desarrolla mayormente de forma clandestina o irregular, así mismo, la falta de estadísticas de algunos gobiernos o el hecho de incluir el trabajo doméstico dentro de otros tipos de prestación de servicios, unido a la falta de registro de los trabajadores en seguridad social impide establecer la cantidad de personas que desarrollan esta actividad laboral, más aún establecer las condiciones en que la desarrollan.

Los diferentes fenómenos que se presentan en las regiones en cuanto a las tendencias de los trabajadores domésticos evidencia que la inmigración, la migración rural, el desplazamiento forzado y el trabajo infantil, son los más frecuentes y donde se presenta la mayor vulneración de los derechos no solo laborales sino humanos. Con el Convenio 189 sobre las trabajadoras y los trabajadores domésticos adoptado por la Organización Internacional del Trabajo el 16 de junio de 2011 en la $100^{\mathrm{a}}$ Conferencia Internacional del Trabajo, se pretende, como indica Hodges en el prefacio del documento "Camino al Trabajo Decente":

El compromiso por parte de Gobiernos y agentes sociales a la hora de poner de relieve este sector en la Conferencia Internacional del Trabajo ofrece la gran esperanza de que puede ser transformado en uno que ofrece mayores oportunidades para el trabajo decente para los millones de mujeres y hombres que trabajan como trabajadores domésticos en todo el mundo. (Hodges, 2010)

Para fines de esta investigación se entenderá por trabajo doméstico lo referido en los literales a y b del Artículo 1 del Convenio 189 que expresa:

(a) La expresión trabajo doméstico designa el trabajo realizado en un hogar u hogares o para los mismos;

(b) La expresión trabajador doméstico designa a toda persona, de género femenino o género masculino, que realiza un trabajo doméstico en el marco de una relación de trabajo.

Mediante la expedición del Convenio 189 la OIT pretende que se valore la labor que desempeñan los Trabajadores Domésticos en la sociedad, el aporte que hace a la economía global así como al desarrollo de las naciones. Por lo tanto, se tienen en cuenta temas fundamentales de los derechos de quienes desempeñan labores domésticas como es la ampliación 
de protección de la seguridad social para las trabajadoras domésticas remuneradas, lo que constituye un punto fundamental para el cumplimiento de los principios de dignidad y derechos humanos, así mismo se estudian temas como el trabajo infantil doméstico, la jornada laboral, la protección a la maternidad, la libertad de asociación y el derecho a la negociación colectiva. Al respecto la OIT expresa:

Un paso fundamental para el reconocimiento y la protección social de las trabajadoras domésticas... es su plena inclusión en los sistemas de seguridad social de los países. En la actualidad ellas tienen muy baja cobertura de los sistemas de protección. En algunos casos, la legislación nacional no permite su afiliación a los sistemas de pensiones y en unos pocos países las excluye incluso de los sistemas de salud para trabajadores. En otros casos, la afiliación es voluntaria y queda a criterio del empleador. Por último, en los países en que la ley obliga a formalizar la relación laboral y aportar a la seguridad social, el grado de evasión es muy alto.

Los sistemas de seguridad social protegen a las personas frente a situaciones que les impiden trabajar, por causa de una enfermedad o el nacimiento de un hijo, por haber llegado a una edad avanzada o por haber perdido su trabajo. Así, se refieren a tres ámbitos básicos que son la salud, las pensiones y la cesantía. (Nota 4, OIT, 2011d, p.1)

Atendiendo a la necesidad de salvaguardar los derechos de los niños y niñas y propender por su desarrollo, es vital el rechazo a la explotación así como al trabajo infantil doméstico. A este punto se debe agregar los peligros a los cuales se expone un niño, como lo es a la trata de personas, esclavitud, violencia y acoso sexual. La OIT indica al respecto:

El trabajo infantil doméstico (TID) en casa de terceros es una de las formas más comunes y tradicionales de trabajo infantil. Son "trabajadores invisibles", ya que sus labores son efectuadas al interior de casas que no son las suyas, sin ningún sistema de control y lejos de su propia familia. Este grupo es probablemente el más vulnerable y explotado así como el más difícil de proteger. Trabajo infantil es toda actividad económica realizada por niños y niñas que están por debajo de la edad mínima permitida por la legislación nacional. Para el caso de adolescentes (sobre la edad mínima pero menores de 18 años) son consideradas como trabajo 
infantil las actividades que interfieren con su educación, que se realizan en ambientes peligrosos y/o en condiciones que afecten su desarrollo psicológico, físico, social y moral, es decir, todo trabajo que les priva de su infancia, su educación y su dignidad. (Nota 3, OIT, 2011c, p.1)

Otro factor fundamental que requiere regulación es la jornada laboral, es parte fundamental para el trabajo decente que los trabajadores domésticos cuenten con un espacio para su desarrollo personal:

Uno de los grandes ejes de la calidad del empleo es la duración de la jornada laboral. Su reglamentación, así como de los períodos de descanso, incluidos los días festivos y las vacaciones son fundamentales para el bienestar y la seguridad de las personas que laboran. Para las trabajadoras domésticas son indispensables, pues sus jornadas de trabajo son generalmente largas e intensas, a menudo sin reglas que las limiten. (OIT, 2011a, p.1)

Por su parte, es de vital importancia abordar el contenido expuesto por la OIT frente a la Protección a la maternidad, pues en Colombia un gran número de trabajadoras domésticas son cabeza de familia por lo tanto es esencial: "La protección a la maternidad como uno de los derechos más importantes para las trabajadoras domésticas pues les permite desarrollarse como trabajadoras y como madres, de una forma sana y sin discriminaciones.” (OIT, 2011b)

Frente al tema particular de la libertad de asociación, se tiene que uno de los grandes retos es, sin dudas, la necesidad de conformar organizaciones sindicales que propendan por la promoción del trabajo decente y la protección de los derechos de los trabajadores domésticos, es esencial para el desarrollo social.

A las trabajadoras domésticas les resulta particularmente difícil organizarse. Esto se debe principalmente a sus condiciones laborales bastante particulares, como el aislamiento en domicilios privados, largas jornadas laborales y la débil organización sindical. Además, en varios de los países del continente no existe la posibilidad de que las asociaciones u organizaciones de trabajadoras domésticas adquieran personería jurídica como sindicato ni cuentan con el derecho de afiliación directa a federaciones o confederaciones sindicales. 
Otro factor que influye en la posibilidad de este sector de negociar colectivamente es la dificultad que enfrentan los empleadores y las empleadoras de trabajadoras domésticas para organizarse. El diálogo social y las negociaciones colectivas no son posibles sin la participación de organizaciones. (Nota 7, OIT, 2011e, p.1)

Para Colombia es un reto suscitar trabajo decente para los trabajadores domésticos como se observa en el documento de la Procuraduría General de la Nación: “Trabajo Digno y Decente en Colombia Seguimiento y Control Preventivo a las Políticas Públicas", si bien esta investigación no es directamente sobre el trabajo doméstico, es consecuente con las investigaciones de la OIT sobre trabajo decente, pues contextualiza la problemática que se presenta a la hora de proteger este sector laboral, en particular se resalta del documento el siguiente aparte:

En Colombia, la persistencia de tasas de desempleo superiores al 10\%; la existencia de un sector informal que genera alrededor de la mitad de los empleos; la discriminación que el mercado laboral efectúa contra las mujeres, los jóvenes, las personas en situación de discapacidad, los desplazados, entre otros; el incumplimiento de los estándares laborales; el abuso de figuras como las cooperativas de trabajo asociado; las bajas tasas de sindicalización; la precariedad de los mecanismos de negociación colectiva y la baja proporción de cotizantes en el sistema de seguridad social, revelan la complejidad de los problemas asociados al mundo del trabajo y ponen de presente la insuficiencia de los esfuerzos que el Estado ha invertido para superarlos. Estos fenómenos evidencian que el desempeño actual del mercado laboral en Colombia no permite un salto cualitativo en términos del desarrollo económico y social del país. En la medida en que se perpetúe este panorama desolador en materia laboral, el trabajo continuará siendo un motivo de frustración y no una fuente de realización personal de los trabajadores y trabajadoras colombianos. (2011, p. 16)

Lo anterior remite a los documentos de la OIT donde se indica precisamente que el trabajo doméstico es clasificado como trabajo informal, esto lleva a la subvaloración por parte del Estado en cuanto a su participación en el PIB, debido a su bajo impacto en la economía general del país y estar ligado simplemente a la economía de un pequeño sector, así mismo este tipo de labor no es valorado apropiadamente por la sociedad, pues en la mayoría de los casos el servicio 
es prestado por el sector social menos favorecido, por mujeres cabeza de hogar, en algunos casos, víctimas de la violencia y del desplazamiento, de grupos étnicos o del sector rural que migra a las ciudades en busca de mejores oportunidades económicas.

Laís Abramo en el documento para la OIT “Trabajo decente y equidad de género en América Latina" en el año 2006 indica que:

La calidad del empleo de las mujeres al interior de la economía informal es inferior comparada a la de los hombres, según lo indican los diversos indicadores considerados. Sus ingresos son más bajos, cuentan con menor cobertura de seguridad social y están sobrerepresentadas en los segmentos más precarios, como el servicio doméstico y los trabajadores familiares no remunerados. (Abramo, 2006, p.46)

Aun cuando se habla de forma general de trabajadores domésticos, se resalta que es un trabajo realizado en su mayor parte por mujeres, las cuales se encuentran desprotegidas, el informe indica que:

La mitad (50.1\%) de la ocupación femenina en América Latina se concentra en tres segmentos del empleo caracterizado, en general, por bajas remuneraciones y bajo grado de protección social: el trabajo por cuenta propia (23.2\%), la microempresa (11.4\%) y el servicio doméstico (15.5\%). Para los hombres esas proporciones correspondían, respectivamente, a $24.0 \%, 19.3 \%$ y menos del $0.7 \%$. La calidad de los empleos de las mujeres al interior de esos segmentos en comparación a la de los hombres no mejora en América Latina entre 1990 y 2003: crece el porcentaje de empleadas en el servicio doméstico (1.5 puntos porcentuales); asimismo, la tasa de crecimiento de las ocupadas en la microempresa (1.0 puntos porcentuales) fue inferior a la observada para los hombres (2 puntos porcentuales). (Abramo, 2006, p. 47)

Atendiendo a los datos del informe de Abramo se observa que en Colombia el trabajo informal de los hombres alcanza el $59 \%$ de los cuales el $0.5 \%$ son trabajadores domésticos mientras que del $64.2 \%$ del total de trabajadoras informales el $12.8 \%$ son trabajadoras domésticas. Se resalta del informe que la mayoría de los empleos generados en los años 
anteriores son del sector informal de la economía y el servicio doméstico aporta el $22 \%$ de los empleos. Es esta aceleración del crecimiento del empleo doméstico lo que ha prendido las alarmas de la Organización Internacional del Trabajo, para fomentar el trabajo decente y brindar protección a los trabajadores y las trabajadoras del servicio domésticos.

El extracto de la procuraduría es un claro indicador de la falta de políticas públicas que fomenten el trabajo decente, es por tal razón que la investigación se enfoca en analizar como por intermedio de las sentencias de las cortes nacionales se ha fortalecido y se ha protegido el trabajo decente de los trabajadores domésticos.

\subsection{Formulación de pregunta de investigación}

¿De qué manera es posible contextualizar el Convenio 189 de la OIT en Colombia por medio de políticas públicas que promuevan el trabajo decente en los trabajadores domésticos?

\subsection{Objetivos}

\subsubsection{Objetivo General:}

Establecer la materialización del Convenio 189 de la OIT en el ámbito socio-jurídico Colombiano.

\subsubsection{Objetivos Específicos:}

a) Investigar el desarrollo histórico, social y jurídico de los trabajadores del servicio doméstico en Colombia.

b) Analizar el desarrollo jurídico colombiano de los derechos laborales de los trabajadores del servicio doméstico en atención a la sentencia C-616 del 2013.

c) Desarrollar las líneas jurisprudenciales de la Corte Constitucional y la Corte Suprema de Justicia para determinar su posición frente al trabajo decente en el contrato laboral del servicio doméstico en Colombia. 
d) Identificar y formular una política pública pertinente para la reivindicación del trabajo decente para los trabajadores del servicio doméstico.

\subsection{Justificación}

Con la creación del Convenio 189, su posterior aprobación mediante Ley 1595 de 2012 por el Congreso de la República, el respectivo control ejercido por la Corte Constitucional en Colombia en Sentencia C-616 de 2013 y su promulgación por Decreto 325 de 2016, no conlleva al punto final para detener la vulneración de los derechos de los trabajadores del servicio domésticos, ni el inicio de la plena protección de este grupo de trabajadores; por el contrario, es el primer paso para el reconocimiento de sus derechos. El Convenio 189 de la OIT surge como un instrumento que contiene los fundamentos jurídicos que permiten asegurar un trabajo decente para quienes desarrollan labores remuneradas en los hogares, si bien, ha sido un oficio subvalorado por la sociedad, más allá de ser un trabajo informal, es una labor que al igual que todas las demás profesiones u oficios, hace parte del desarrollo económico del mundo.

La disminución de las brechas sociales, de los índices de pobreza y el mejoramiento de la calidad de vida de la población, son fundamentales para el desarrollo social, económico y cultural de los Estados. La OIT en sus notas sobre Trabajo Decente para las trabajadoras y los trabajadores domésticos indica que:

Es una de las ocupaciones con peor calidad del empleo: extensas jornadas de trabajo, bajas remuneraciones, escasa cobertura de seguridad social y alto nivel de incumplimiento de las normas laborales. El trabajo doméstico remunerado es uno de los trabajos con mayor déficit de trabajo decente. (Nota 1 OIT, 2010, p.1)

Aún cuando algunos Estados continúan enmarcándola como una labor informal "el trabajo doméstico remunerado aporta una contribución significativa a la economía mundial, que incluye, además, el aumento de oportunidades de empleo remunerado para los trabajadores y trabajadoras con responsabilidades familiares.” (OIT, 2012. Preámbulo, Convenio 189) Así mismo, frente al tema de la importancia de la educación en la desigualdad social, la OIT ha expresado: 
La relación que existe entre trabajo doméstico, desigualdad social, de género, de raza o etnia y pobreza es persistente y enfrentar este fenómeno requiere aumentar el grado de escolaridad y formación técnica de las trabajadoras, mejorar sus condiciones de trabajo, promover en todos los ámbitos la igualdad de derechos entre hombres y mujeres (y las reformas necesarias para asegurarlos). Pero, además, se requiere valorizar el trabajo de la mujer, las tareas domésticas y el trabajo de cuidado de los hogares y de los seres humanos. (Nota 1, OIT, 2010b, p.4)

Es labor de los Estados procurar la disminución de las brechas sociales y la protección de la parte débil dentro de las relaciones laborales, es fundamental que las normas existentes tengan una fuerte coherencia con políticas públicas que reivindiquen el trabajo doméstico y que permitan un proceso de formación y educación de calidad para la población vulnerable.

El aumento de la demanda de trabajadores en los hogares y la necesidad de políticas públicas: ha propiciado espacios para la discusión de medidas legales y de políticas públicas para avanzar hacia el trabajo decente para trabajadoras domésticas. Además, la situación relativamente favorable de las economías latinoamericanas, especialmente frente a la crisis económica mundial, ha generado un ambiente propicio para la adopción de medidas necesarias para dotar el trabajo doméstico remunerado de condiciones más equitativas. (Nota 1, OIT, 2010b, p.3)

Es vital que los Estados reivindiquen el trabajo doméstico que si bien es una labor desempeñada en menor proporción por hombres, es la mujer la que netamente realiza este oficio, ellas:

Son especialmente vulnerables a los abusos y la explotación. Las violaciones de sus derechos humanos y laborales que con tanta frecuencia denuncian los medios de comunicación exigen la intervención urgente de los gobiernos, los sindicatos, las asociaciones de empleadores y las organizaciones de la sociedad civil interesadas. (D’Souza, 2010, p. 19)

Mediante este trabajo de investigación se busca analizar las políticas estatales para la promoción y protección del trabajo decente para las trabajadoras y los trabajadores domésticos y la contextualización del Convenio 189 en las políticas públicas. Por otra parte se ha de examinar como la justicia colombiana, como rama del poder público, ha reivindicado los derechos de este 
grupo de trabajadores por medio de sus providencias. Finalmente se analizará casos específicos de reivindicación de los derechos de los trabajadores domésticos.

\section{Marco Teórico}

\subsection{Antecedentes}

Como la mayoría de figuras jurídico-sociales que hay en la actualidad, para hacer un estudio profundo del tema, el investigador se debe remitir a la historia para establecer los fenómenos socio-culturales que han dado forma a los mismos. Ahora bien, al abordar el estudio del trabajo doméstico, las referencias históricas se hacen importantes e imprescindibles ya que éstas ilustran y ayudan a la comprensión de la sub valoración de la labor doméstica en la sociedad.

Al respecto se puede iniciar en la sociedad victoriana, donde la mujer desempeñaba labores domésticas, se le instruía y la sociedad la confinaba al hogar, de hecho fueron varios los textos que se escribieron en distintos idiomas que enseñaba a las mujeres como comportarse y como desarrollar cada una de las tareas del hogar. Otro referente histórico de cómo la mujer fue segregada a labores de servicio doméstico lo podemos encontrar durante la industrialización europea, en la cual los hombres eran los únicos que desempeñaban labores en la industria, mientras la mujer se encargaba de labores domésticas a las que se creía que por naturaleza estaba preparada para desempeñar. Pero si el estudio del trabajo doméstico se remite siglos más allá, podemos encontrar referencias al servilismo, en donde se aprecia que:

La servidumbre fue un puente entre el hogar de los patrones y el mundo externo, sobre todo, el mundo de la pobreza de la ciudad. Los lacayos y los cocheros eran escudos entre sus amos y la muchedumbre de la ciudad. La cocinera, la galopina o el mozo trataban con los vendedores del mercado, los lecheros y los aguadores. El portero o el mozo eran responsables por las puertas al hogar.

Con el tiempo, las características del servicio doméstico han ido cambiando. Ya a finales de la Colonia, la mayoría de personas que llevaban a cabo labores domésticas recibían algún tipo de pago; paulatinamente, la remuneración monetaria ha ido cobrando mayor importancia. 
El trabajo doméstico mismo se ha transformado y durante las décadas recientes de una manera más notoria: el consumo más amplio de aparatos domésticos, el creciente uso de alimentos industrializados y otros productos tales como pañales desechables, biberones y artículos de limpieza han dejado su huella.

Hay oficias del servicio doméstico que han disminuido en relevancia, o inclusive, desaparecido, tales como la dama de compañía, mayordomo, galopina, costurera, nodriza o portero. Esto ha llevado al empleo de un número más reducido de trabajadoras en una casa y a la realización de actividades más diversificadas por una persona. (Goldsmith, 1998, p. 88)

En Colombia la lucha de las trabajadoras inicia a principio de los años ochenta como se indica en el proyecto de investigación-acción: Trabajo doméstico y servicio doméstico en Colombia:

La transformación de la legislación o las reformas al Código Sustantivo del Trabajo se pensaron poco menos que imposibles. Sin embargo, ante una coyuntura favorable, se estudiaron los temas más importantes para una reforma de la legislación laboral que, al tiempo que representara reivindicaciones sentidas por el gremio, tuvieran viabilidad. En esencia, se buscó el reconocimiento de la igualdad de derechos con otros trabajadores. Este proyecto naufragó por el cambio en el Ministerio de Trabajo de la funcionaria interesada en promover ésta y otras reformas en favor de la mujer trabajadora.

Luego se priorizaron la reforma de la legislación sobre la afiliación a la seguridad social y el impulso de la afiliación (León 1988 y 1987). Desde 1977, la seguridad social era obligatoria para la empleada doméstica, pero no se cumplía esta disposición. En la que llamamos "lucha por la seguridad social", o por la reforma de la norma y su aplicación, confluyeron las acciones directas con empleadas y las acciones de multiplicación del proyecto. Ésta fue una lucha desde la cotidianidad, que llegó a la esfera político-pública en forma diversa y heterogénea, e irrumpió en el Estado para dar respuesta a la reclamación. Su punto de partida fue la condición de salud vivida como una carencia y registrada en la vida personal de la empleada. Esta necesidad fue impulsada por el conocimiento de las normas y el atropello que las patronas y el Estado ejercían sobre sus derechos, en razón de que, si bien existían, eran 
limitados o no se cumplían. Comúnmente, enfermarse, quedar embarazada o envejecer era sinónimo de pérdida de empleo. La asistencia médica era considerada como un favor patronal y entraba como "salario en especie" y variaba según las diferencias patronales. Así, un derecho se convertía en elemento para reforzar los lazos de dependencia de las empleadas hacia sus patronas.

Desde 1985, el proyecto promovió la afiliación de la empleada a la seguridad social. Los trámites eran confusos y casi imposibles, y era casi nulo el número de empleadas afiliadas. La batalla por la afiliación se promovió en los niveles individual y colectivo y en el espacio público, con demandas masivas en el ámbito callejero, como mítines y la "Marcha Nacional por la Seguridad Social", que, con la presencia de más de 1.000 empleadas de todo el país, tuvo lugar en Bogotá el 5 de abril de 1987. Se diseñó un volante con la información básica de los trámites por seguir y los beneficios esperados, y se repartió en los cursos y en la asesoría legal a patronas y empleadas.

Las dificultades mayores para la afiliación a la seguridad social fueron la no existencia de sanciones por incumplimiento, la inestabilidad laboral de una parte del sector, que hacía difíciles los registros de afiliación, y la falta de reglamentación para la afiliación de la empleada de por días que tenía coexistencia de contratos. La seguridad social no se vio como una solución mágica a los problemas de salud del gremio, por la falta de eficiencia en la prestación de los servicios; sin embargo, ante los graves problemas de invalidez y vejez, la seguridad social representaba un gran avance.

Ante la ineficiencia de la norma existente, el proyecto impulsó y acompañó la lucha por la reforma como parte del proceso de investigación-acción. Después de intentos no convenientes de aplicación de la norma por el Gobierno, el proyecto preparó el articulado de reforma, lo discutió con las bases, con el sindicato y con el Comité de Empleadas que surgió en Bogotá y que lideró el proceso de cambio. Se divulgó en los medios masivos de comunicación y se presentó al Congreso de la República para su discusión y aprobación. El 16 de diciembre de 1987, con una opinión pública sensibilizada, se aprobó la Ley 11, la cual fue sancionada por la Presidencia, en enero de 1988. El logro más significativo fue conseguir un régimen de excepción mediante el cual la cotización para la afiliación de la empleada doméstica se permitía sobre una base inferior a la de otros trabajadores o por debajo del salario mínimo. Por otra parte, el Decreto 824 de 1988 planeaba una subvención del Estado 
para llenar la deficiencia de estas cotizaciones y garantizar plena cobertura social y pensión no inferior al salario mínimo. Esta excepción al régimen general constituyó un gran logro de las empleadas movilizadas y del proyecto. El proyecto, junto con el Comité de Bogotá, orgulloso de su triunfo y dispuesto a no dar pie atrás, siguió impulsando el proceso de afiliación a la seguridad social hasta el final de sus labores. La Ley 100 de 1993 ratificó este logro, el cual fue derogado en 2003. Lo irónico es que el mismo político que defendió la

norma en 1988, el senador Álvaro Uribe Vélez, fue quien la enterró en 2003, con la Ley 797 , como presidente.

La Oficina de Trabajo del Ministerio de Trabajo era la instancia administrativa para dirimir los conflictos obrero-patronales. En la interpretación de la norma, el inspector de trabajo desempeñaba un papel fundamental, y por ello, el proyecto promovió con estos funcionarios la correcta interpretación de la norma. (León, 2013, p. 207)

Con la creación del convenio 189 y su ratificación por el Estado Colombiano, se espera que verdaderas políticas públicas protejan los derechos de las trabajadoras domésticos y que brinde trabajo decente y digno a este grupo en particular.

\subsection{Estado del Arte}

Respecto al trabajo decente para las trabajadoras y los trabajadores domésticos, se ubican una serie de investigaciones realizadas por la Organización Internacional del Trabajo como lo son "Camino del trabajo decente para el personal del servicio doméstico: panorama de la labor de la OIT” (2010), “Trabajo decente y equidad de género en América Latina” (2006), “Trabajo decente para los trabajadores domésticos" (2010), estos documentos de la OIT son a grandes rasgos, una visión del Trabajo Decente para los Trabajadores Domésticos, pero ninguno de ellos profundiza el caso colombiano.

En cuanto a investigaciones netamente colombianas entorno al Trabajo Decente de los Trabajadores Domésticos, se lograron ubicar las siguientes, que si bien no investigan el tema en particular, si desarrollan en parte algunos de los temas que se abordan en esta investigación: Proyecto de Investigación-acción: Trabajo Doméstico y Servicio Doméstico en Colombia, (2013), en este Documento la Autora Magdalena León efectúa un análisis de "la relación del 
servicio doméstico con el trabajo doméstico de la mujer ama de casa”, este estudio ofreció a la investigación una perspectiva de la historia y el desarrollo de los derechos de las trabajadoras del servicio doméstico en el país; Trabajo digno y decente en Colombia. Seguimiento y control preventivo a las políticas públicas y el Informe Nacional del Trabajo Decente en Colombia del 2012, este documento de la Procuraduría General de la Nación, proporcionó a la investigación el conocimiento básico del término "trabajo decente" y su relación con el concepto de trabajo digno que se estaba implementando en la rama judicial.

Como se puede observar el tema a tratar en esta investigación es de gran relevancia, atendiendo las directrices de la OIT, así mismo es un tema que poco se ha profundizado en Colombia, debido a su reciente aparición en el campo de investigación socio-jurídica.

\subsection{Marco Contextual}

Aun cuando es una de las labores más antiguas realizadas por el hombre, el trabajo doméstico nunca ha recibido la importancia que merece tanto en contexto familiar, social y económico. La creación de políticas públicas de trabajo decente para los trabajadores domésticos es necesaria para garantizar la protección y valoración del trabajo doméstico, así mismo es vital para el desarrollo social, el mejoramiento de la calidad de vida de los trabajadores y la disminución de la desigualdad social.

Al realizar la búsqueda de estadísticas del trabajo decente para los trabajadores domésticos, en la mayoría de los documentos se explica que aun cuando se trate de obtener cifras reales del fenómeno del trabajo doméstico, en todo caso estas han de ser estimatorias, esto debido a que algunos países no cuentan con cifras, en otros la labor en el hogar es incluida en sectores como el informal y en algunos casos los datos entregados por los Estados distan de los otorgados por entes no gubernamentales, lo que impide obtener datos reales de cuantos trabajadores domésticos existen. Mediante LABORSTA (sistema de estadísticas y datos de la OIT) se logró encontrar datos estimatorios del trabajo doméstico. En el documento informativo No. 4 de Trabajo Doméstico del cual se obtuvo los datos se indica al respecto:

En total, se incluyeron datos de 117 países y territorios en las estimaciones mundiales y regionales 11. A pesar de que estos 117 países representan sólo dos tercios de todos los países en nuestro universo de muestra, ellos representan 88,7 por ciento del empleo total fuera de 
China. Para China, se utilizó una combinación de fuentes oficiales para generar una estimación tentativa. En resumen, la nueva base de datos posee la cobertura suficiente para producir estimaciones mínimas confiables, a nivel mundial y regional. (2011d, p.4)

Así mismo, para efecto de las estadísticas en el informe se expone que se entiende por trabajo doméstico y cuales labores son desarrolladas por las personas que prestan el servicio:

Al disponerse a estimar el número de trabajadores domésticos, es importante traducir lo que entendemos por trabajador doméstico a una definición estadística operativa que permita compilar datos comparables de un amplio rango de países. Este no es un emprendimiento menor, debido a que los trabajadores domésticos no son un grupo homogéneo, sino que desempeñan labores tan variadas como aseo, cuidado de personas ancianas o niños, resguardo de la casa, acompañamiento de niños a la escuela, jardinería o cocina, entre otras. (Nota de Trabajo No. 4 de la OIT, 2011d, p.2)

Para comprender la urgencia y la necesidad de crear un sistema jurídico que brinde Trabajo Decente y digno a los trabajadores domésticos, se deben observar y analizar las estadísticas que indican la aceleración y aumento de demanda que ha tenido la sociedad de trabajadores domésticos; este incremento y la falta de regulación en algunos países, genera fenómenos sociales de desigualdad y aumento de los índices de pobreza.

Tal es el caso de los migrantes para "quienes las circunstancias y condiciones de su empleo equivalen a las del trabajo forzoso, donde los empleadores les prohíben abandonar la casa, les retienen o no les pagan el salario, recurren a la violencia o a amenazas de violencia, les retienen el pasaporte o documento de identidad, les limitan sus posibilidades de contactar a su familia o les engañan con respecto a sus derechos con el fin de obligarles a trabajar. (CSI, 2010)

La estadísticas a continuación son del documento de la OIT “Trabajadores domésticos: estimaciones a nivel mundial y regional (2011d) que como el título indica son estimaciones del panorama del trabajo doméstico en el mundo: 
Tabla 1.

Estimaciones a nivel regional y mundial del número de trabajadores domésticos en 2010, por sexo

\begin{tabular}{|l|r|r|r|}
\hline \multicolumn{1}{|c|}{ Ranel A. Ambos sexos } & $\begin{array}{c}\text { Trabajadores } \\
\text { domésticos }\end{array}$ & $\begin{array}{c}\text { Trabajadores } \\
\text { domésticos en \% del } \\
\text { empleo total }\end{array}$ & $\begin{array}{c}\text { Trabajadores domésticos en \% } \\
\text { de trabajadores remunerados }\end{array}$ \\
\hline $\begin{array}{l}\text { PaísesAvanzados } \\
\text { (Seleccionados) }\end{array}$ & $3,555,000$ & $0.8 \%$ & $0.9 \%$ \\
\hline Europa del Este y CEI & 595,000 & $0.3 \%$ & $0.4 \%$ \\
\hline Asia & $21,467,000$ & $1.2 \%$ & $3.5 \%$ \\
\hline \multicolumn{1}{|c|}{ Asia excluido China } & $12,077,000$ & $1.2 \%$ & $4.7 \%$ \\
\hline América Latina y el Caribe & $19,593,000$ & $7.6 \%$ & $11.9 \%$ \\
\hline África & $5,236,000$ & $1.4 \%$ & $4.9 \%$ \\
\hline Oriente Medio & $2,107,000$ & $5.6 \%$ & $8.0 \%$ \\
\hline Total & $\mathbf{5 2 , 5 5 3 , 0 0 0}$ & $\mathbf{1 . 7} \%$ & $\mathbf{3 . 6 \%}$ \\
\hline
\end{tabular}

\begin{tabular}{|l|c|c|c|}
\hline Panel B. Mujeres & $\begin{array}{c}\text { Mujeres trabajadoras } \\
\text { domésticas }\end{array}$ & $\begin{array}{c}\text { Mujeres trabajadoras } \\
\text { domésticas en \% del } \\
\text { empleo femenino total }\end{array}$ & $\begin{array}{c}\text { Mujeres trabajadoras } \\
\text { domésticas en \% de mujeres } \\
\text { trabajadoras remuneradas }\end{array}$ \\
\hline $\begin{array}{l}\text { PaísesAvanzados } \\
\text { (Seleccionados) }\end{array}$ & $2,597,000$ & $1.3 \%$ & $1.4 \%$ \\
\hline Europa del Este y CEI & 396,000 & $0.4 \%$ & $0.5 \%$ \\
\hline Asia & $17,464,000$ & $2.5 \%$ & $7.8 \%$ \\
\hline Asia excluido China & $9,013,000$ & $2.6 \%$ & $11.8 \%$ \\
\hline América Latina y el Caribe & $18,005,000$ & $17.4 \%$ & $26.6 \%$ \\
\hline África & $3,835,000$ & $2.5 \%$ & $13.6 \%$ \\
\hline Oriente Medio & $1,329,000$ & $20.5 \%$ & $31.8 \%$ \\
\hline Total & $\mathbf{4 3 , 6 2 8 , 0 0 0}$ & $\mathbf{3 . 5} \%$ & $\mathbf{7 . 5 \%}$ \\
\hline
\end{tabular}

\begin{tabular}{|l|c|c|c|}
\hline Panel C. Hombres & $\begin{array}{c}\text { Hombres trabajadores } \\
\text { domésticos }\end{array}$ & $\begin{array}{c}\text { Hombres trabajadores } \\
\text { domésticos en \% del } \\
\text { empleo masculino }\end{array}$ & $\begin{array}{c}\text { Hombres trabajadores } \\
\text { domésticos en \% de hombres } \\
\text { trabajadores remunerados }\end{array}$ \\
\hline $\begin{array}{l}\text { PaísesAvanzados } \\
\text { (Seleccionados) }\end{array}$ & 958,000 & $0.4 \%$ & $0.5 \%$ \\
\hline Europa del Este y CEI & 199,000 & $0.2 \%$ & $0.2 \%$ \\
\hline Asia & $4,003,000$ & $0.4 \%$ & $1.0 \%$ \\
\hline Asia excluido China & $3,064,000$ & $0.5 \%$ & $1.7 \%$ \\
\hline América Latina y el Caribe & $1,588,000$ & $1.0 \%$ & $1.6 \%$ \\
\hline África & $1,400,000$ & $0.6 \%$ & $1.8 \%$ \\
\hline Oriente Medio & 778,000 & $2.5 \%$ & $3.5 \%$ \\
\hline Total & $\mathbf{8 , 9 2 5 , 0 0 0}$ & $\mathbf{0 . 5} \%$ & $\mathbf{1 . 0 \%}$ \\
\hline
\end{tabular}

Fuente: Estimación OIT basada en daos de fuentes oficiales

El análisis que realizan los investigadores del documento relativo a la proporción de trabajadores domésticos en el mundo sugiere: 
Las estimaciones indican un mínimo de 52,6 millones de trabajadores domésticos en todo el mundo... Dado que existen razones para creer que las fuentes de datos subestiman el número de trabajadores domésticos, el número efectivo de trabajadores domésticos podría estar cercano a la estimación de 100 millones de trabajadores en todo el mundo, previamente citado por la OIT. Sin embargo, con la actual disponibilidad de datos resulta difícil determinar el rango del valor "efectivo" y las cifras presentadas en esta Nota son las mínimos estimaciones más confiables que se encuentran disponibles.

Incluso con estas advertencias en mente, las estimaciones muestran que el trabajo doméstico es una fuente significativa de empleo: representa el 1,7 por ciento del empleo mundial total, y 3,6 por ciento del empleo asalariado. Mientras que el trabajo doméstico es de menor incidencia en países avanzados (0,9 por ciento del empleo asalariado total) y en Europa del Este y países de la Comunidad de Estados Independientes (CEI) (0,4 por ciento), representa un porcentaje de participación mucho mayor del empleo asalariado en varios países en desarrollo y emergentes: en América Latina y el Caribe, 11,9 por ciento del empleo asalariado se encuentra en servicios domésticos, seguido por Oriente Medio (8,0 por ciento), África (4,9 por ciento) y Asia (3,5 por ciento). (Nota 4, OIT, 2011d)

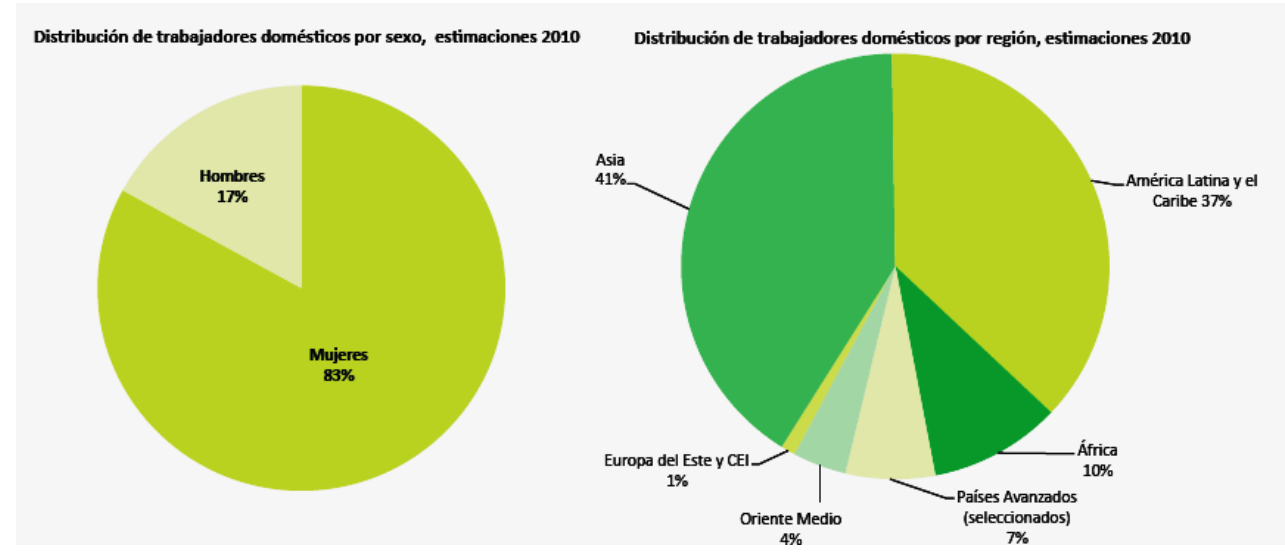

Figura 1. Distribución de trabajadores domésticos por sexo y región, estimaciones 2010.

Fuente: Estimaciones OIT basadas en datos de fuentes oficiales

El trabajo doméstico es predominantemente realizado por mujeres, quienes representan 83 por ciento de todos los trabajadores domésticos a nivel mundial. La composición por género fluctúa entre regiones, y la participación femenina varía de aproximadamente 64 por ciento en 
Oriente Medio y 67 por ciento en Europa del Este y los países CEI a 92 por ciento en América Latina y el Caribe. Con una participación femenina de entre 70 y 80 por ciento, las regiones restantes se encuentran entre ambos extremos (no tabulado). Debido a que las mujeres a menudo enfrentan obstáculos específicos para obtener un empleo remunerado, cerca del 7,5 por ciento de todas las trabajadoras asalariadas son de hecho trabajadoras domésticas (en comparación al 1,0 por ciento de los trabajadores asalariados masculinos), lo cual refleja la importancia del trabajo doméstico como fuente de trabajo para mujeres alrededor del mundo. Este hecho se acentúa especialmente en América Latina y el Caribe, donde el trabajo doméstico remunerado representa más de un cuarto (26,6 por ciento) del empleo asalariado femenino, y en Oriente Medio, donde prácticamente un tercio (31,8 por ciento) de las trabajadoras asalariadas son trabajadoras domésticas.

Esto se debe a la generalmente baja participación de mujeres nativas en la fuerza de trabajo y al hecho que una gran proporción de las trabajadoras inmigrantes trabajan en servicios domésticos. Como se muestra en el Gráfico, las dos regiones con el mayor número de trabajadores domésticos son Asia y América Latina y el Caribe. En Asia, al menos 21,5 millones de mujeres y hombres trabajan en hogares privados (o 40,8 por ciento de todos los trabajadores domésticos del mundo), mientras que 19,6 millones de trabajadores domésticos viven en América Latina y el Caribe (un 37,3 por ciento del total mundial). África y los países avanzados siguen en el ranking, con 5,2 millones y 3,6 millones de trabajadores domésticos respectivamente, mientras que Oriente Medio (2,1 millones de trabajadores domésticos) y Europa del Este y los países CEI (595.000 trabajadores domésticos) contribuyen en menor medida al total mundial. (OIT, 2011d, p.7)

Uno de los fenómenos que más profundiza la desigualdad y agudiza la pobreza en el mundo es el trabajo doméstico infantil, este vulnera derechos laborales, los derechos humanos y la declaración de los derechos del niño. Por medio del convenio 189 se busca reafirmar el compromiso de los Estados contra la explotación infantil no solo mediante la creación de sistemas jurídicos que proporcionen herramientas sino mediante la implementación de políticas de prevención del trabajo infantil, programas de concientización de la sociedad y la protección del menor trabajador. Tal y como se observa en las cifras estimadas por la OIT: 
Son miles los niños que trabajan en hogares de terceros o de un empleador, realizando tareas como limpiar, planchar, cocinar, la jardinería, recolectar agua, cuidar de otros niños o de los ancianos. Vulnerables a la violencia física, psicológica y sexual, y expuestos a condiciones de trabajo abusivas, con frecuencia están aislados de sus familias, ocultos a la mirada pública y llegan a ser muy dependientes de sus empleadores. Muchos corren el riesgo de terminar siendo explotados sexualmente con fines comerciales.(1)"La situación de muchos niños trabajadores domésticos no sólo constituye una violación grave de los derechos de los niños, pero sigue siendo un obstáculo al logro de muchos objetivos nacionales e internacionales de desarrollo", dijo Constance Thomas, Directora del Programa Internacional para la Erradicación del Trabajo Infantil de la OIT (IPEC).(1)

Tabla 2.

Estimaciones del número de niños en trabajo doméstico por edad y sexo, 2008

\begin{tabular}{|c|c|c|c|}
\hline $\begin{array}{l}\text { Grupo de edad y } \\
\text { sexo }\end{array}$ & $\begin{array}{c}\text { Trabajo doméstico } \\
\text { infantil }\end{array}$ & Niños en empleo & $\begin{array}{c}\text { Trabajo doméstico infantil en } \\
\text { \% del niños en empleo }\end{array}$ \\
\hline $\mathbf{5 - 1 1}$ años & $\mathbf{3 , 5 1 4 , 0 0 0}$ & $\mathbf{9 1 , 0 2 4 , 0 0 0}$ & $\mathbf{3 . 8}$ \\
\hline Niños & $1,430,000$ & $49,490,000$ & 2.9 \\
\hline Niñas & $2,084,000$ & $41,534,000$ & 5.0 \\
\hline $\mathbf{1 2 - 1 4}$ años & $\mathbf{3 , 8 8 0 , 0 0 0}$ & $\mathbf{8 5 , 4 2 8 , 0 0 0}$ & $\mathbf{4 . 4}$ \\
\hline Niños & $1,069,000$ & $49,679,000$ & 2.2 \\
\hline Niñas & $2,811,000$ & $35,749,000$ & 7.9 \\
\hline $\mathbf{1 5 - 1 7}$ años & $\mathbf{8 , 1 3 1 , 0 0 0}$ & $\mathbf{1 2 9 , 2 1 7 , 0 0 0}$ & $\mathbf{5 . 9}$ \\
\hline Niños & $\mathbf{1 , 6 9 4 , 0 0 0}$ & $76,608,000$ & 2.2 \\
\hline Niñas & $6,436,000$ & $52,609,000$ & $\mathbf{4 . 8}$ \\
\hline Total 5-17 años & $\mathbf{1 5 , 5 2 5 , 0 0 0}$ & $\mathbf{3 0 5 , 6 6 9 , 0 0 0}$ & 2.4 \\
\hline Niños & $4,193,000$ & $175,777,000$ & 8.6 \\
\hline Niñas & $11,331,000$ & $129,892,000$ & \\
\hline
\end{tabular}

Fuente: Programa de información estadística y Seguimiento en Materia de Trabajo infantil de la OIT (IPECISIMPOC)

Las cifras que se observan nunca dejan de lado a los países latinoamericanos, por el contrario, Latinoamérica aporta el $37 \%$ de trabajadores domésticos en el mundo. Atendiendo que Colombia es el objeto de la presente investigación, que busca contextualizar y armonizar el convenio 189 a la realidad social, jurídica y de políticas públicas, que permita establecer el grado de trabajo decente para los trabajadores domésticos. 
De acuerdo al artículo 1 del Decreto 824 de 1988 en Colombia se entiende por trabajador del servicio doméstico:

La persona natural que a cambio de una remuneración presta su servicio personal en forma directa, de manera habitual, bajo continuada subordinación o dependencia, residiendo o no en el lugar del trabajo, a una o a varias personas naturales, en la ejecución de tareas de aseo, cocina, lavado, planchado, vigilancia de niños y demás labores inherentes al hogar.

Para efectos del presente reglamento se denominarán "internos", los trabajadores que residan en el lugar o sitio de trabajo. Los demás, se denominarán "por días"." (Negrilla por fuera del texto original)

En la sentencia C-616 de 2013 el Magistrado ponente Dr. Luis Ernesto Vargas Silva hace alusión a la intervención del Ministro del trabajo, quien en su intervención deja en claro la necesidad de Ratificar el convenio 189:

Expresa el Ministerio que esta conformación tripartita llegó a la conclusión que era necesario ratificar el Convenio, puesto que sus prescripciones están dirigidas a proteger a los trabajadores y trabajadoras domésticos, los cuales conforman un grupo laboral tradicionalmente sometido a abusos y violaciones de sus derechos laborales. Agrega, en ese sentido, que el Estado colombiano es “... conocedor de las dificultades y condiciones adversas que a nivel mundial enfrenta esta población, entendiendo que por décadas en muchos países han sido notorios los eventos de trato discriminatorio y de explotación hacia personas contratadas para cumplir labores domésticas como aseo, cocina, lavado y planchado de ropa y demás actividades propias de un hogar, que habían encontrado tradicional materialización, connivencia e indiferencia, en un rezago de la esclavitud y la servidumbre del pasado a través del mantenimiento de la segregación social y las diferencias en las condiciones laborales”. En ese sentido, la ratificación del Convenio se muestra útil para insertar a dichos trabajadores en los estándares internacionales del trabajo decente. Esto, a su vez, tendría un impacto significativo en la población laboral colombiana, pues los trabajadores y trabajadores domésticos ascienden a 500.000 personas en el país. (Corte Constitucional, Sent. C-616, 2013) 
Las estadísticas del Departamento Administrativo Nacional de Estadísticas indican que en la actualidad del $78.7 \%$ del total de personas que estaban ocupadas en el periodo de julio a septiembre de 2013, el 3,4\% desempeñaba labores de empleado doméstico. Cabe resaltar que en la actualidad se realiza la distinción de los empleados domésticos como una fuerza laboral independiente dentro de la economía, esto atendiendo a la Resolución de la OIT sobre la Clasificación Internacional de la Situación en el Empleo (CISE),adoptada por la decimoquinta Conferencia Internacional de Estadísticos del Trabajo de enero de 1993, así como a las recomendaciones "formulada por el Grupo de Expertos en Estadísticas del Sector Informal (Grupo de Delhi), en su Quinta Reunión, que indica que la definición y medición del empleo en el sector informal debe complementarse con una definición y medición del empleo informal". (0IT, 2003, Recuperado de: http://www.ilo.org/public/spanish/bureau/stat/download/guidelines/defempl.pdf)

En una de las recomendaciones que realiza el Grupo de Expertos Delhi se encuentra que:

Según las relaciones de empleo y los tipos de contrato, las personas que trabajan en el hogar pueden, pertenecer a cualquier categoría de situación en el empleo. Por lo tanto, deben identificarse por medio de la variable "lugar de trabajo", en conjunción con otras clasificaciones existentes, como las industriales y ocupacionales, en lugar de formar una categoría separada de situación en el empleo.(2)

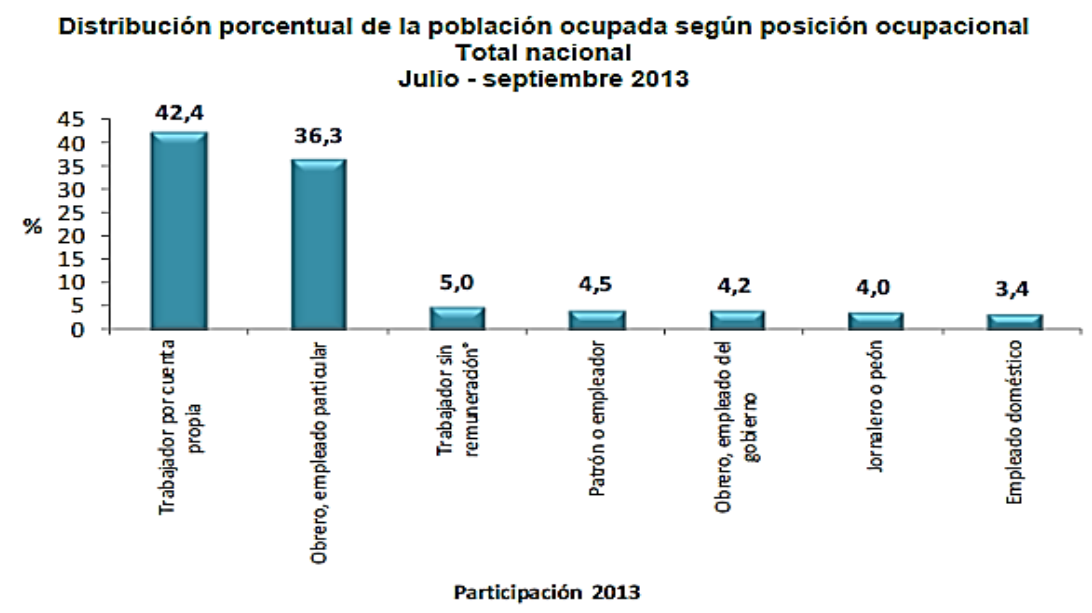

Figura 2. Distribución porcentual de la población ocupada según posición ocupacional total nacional julio-septiembre 2013 
Aunque para el informe presentado en el 2004 por el DANE correspondiente a los periodos del 2001 al 2003, se observa que el trabajo doméstico se sigue incluyendo como trabajo informal, en el informe se indica que en el caso de los empleados domésticos y de los trabajadores familiares sin remuneración, la participación femenina es superior a la masculina y de acuerdo a las cifras del DANE para este periodo se presentó una caída de 3.4 de los trabajadores domésticos.

Arango y Posada (2003) en el documento "Determinantes de la probabilidad de tener servicio doméstico en Colombia” expresan que "el uso de servicio doméstico en Colombia ha decaído de manera prácticamente continua en los últimos 20 años. Así, en 1984, 8\% de los hogares contaban con servicio doméstico y ahora sólo 3,7\% de estos".

Arango y Posada concluyen con dos teorías sobre la disminución de la demanda de trabajo doméstico en Colombia:

Sólo hay dos que podrían explicar la evolución de largo plazo de la frecuencia declinante de la tenencia de servicio doméstico: la caída del nivel de educación de los jefes de hogar con respecto al de las trabajadoras de servicio doméstico y la reducción del número relativo de personas que requieren cuidados especiales (básicamente niños menores de seis años).

La mayor educación (relativa) del servicio doméstico con respecto a la de los jefes de hogar hace más costoso el servicio doméstico. Esta es la causa principal de la tendencia negativa de la proporción de hogares con servicio doméstico durante los dos últimos decenios.

Por lo demás, en períodos cortos o medios, la tasa de desempleo ha mostrado alteraciones significativas. Si, como sucedió entre 1994 y 2000, la tasa de desempleo aumenta, aumentará también la frecuencia de hogares con uno o más miembros desempleados. En tal caso operará otro factor de reducción de la probabilidad de contar con servicio doméstico en un hogar, no obstante el efecto positivo que pudiese tener el mayor desempleo de personal femenino de baja calificación sobre la oferta laboral para desempeñar actividades de servicio doméstico. (Arango y Posada, 2003, p.18)

Si bien, de acuerdo a la investigación efectuada por Arango y Posada se observa una reducción de la demanda de trabajo doméstico, presentando una baja en el mercado laboral, lo anterior no exhorta al gobierno nacional a crear políticas que protejan el trabajo decente para los 
trabajadores domésticos. Más aún cuando dentro de la población que presta este servicio se encuentran menores de edad, el Boletín de Prensa Bogotá, D. C., 22 de abril de 2013 Trabajo Infantil Octubre - diciembre 2012 indica:

- En el período de referencia, 55,0\% de la población de 5 a 17 años realizó oficios del hogar en el total nacional. Los principales oficios que desarrollaron los hombres fueron: hacer mandados y/o mercados $(88,2 \%)$ y limpieza y mantenimiento del hogar $(84,6 \%)$. Por su parte, los principales oficios que ejecutaran las mujeres fueron: limpieza y mantenimiento del hogar $(93,3 \%)$ y hacer mandados y/o mercados $(76,2 \%)$.

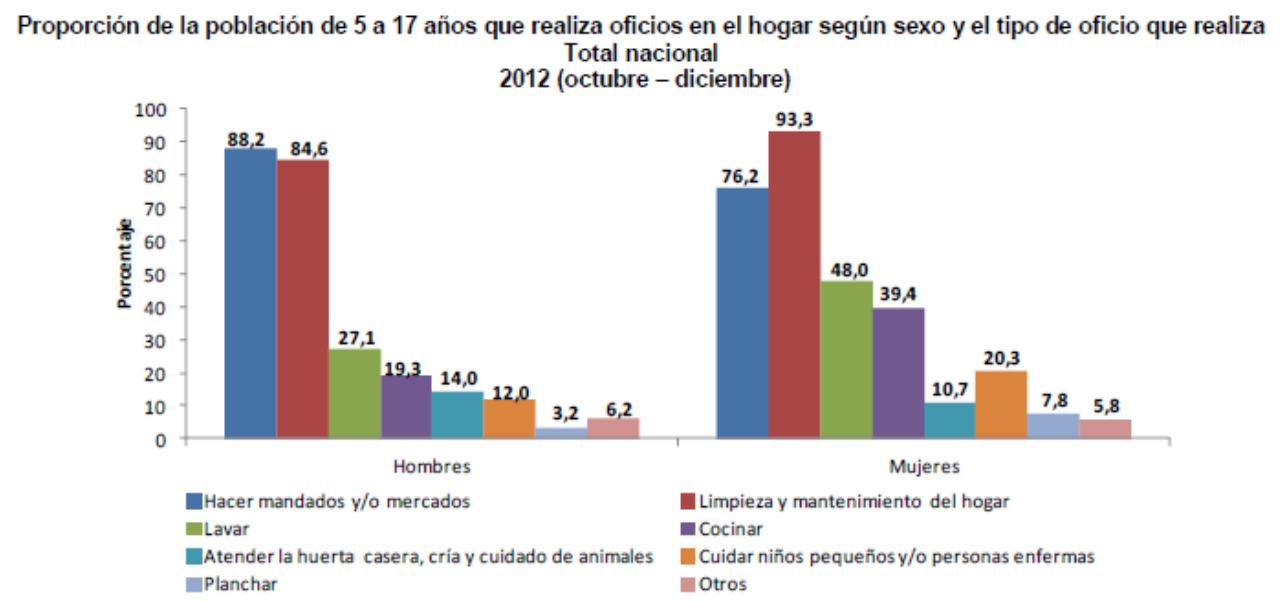

Figura 3. Proporción de la población de 5 a 17 años que realiza oficios en el hogar según sexo y el tipo de oficio que realiza total nacional 2012 (octubre-diciembre)

Fuente: DANE-GEH- Módulo de trabajo infantil 2012

En el Informe Nacional del Trabajo Decente en Colombia del 2012, de Vázquez Fernández (2013) se realizó un estudio de la realidad de los trabajadores en Colombia, así mismo se analizaron los datos ofrecidos por los entes gubernamentales, con el fin de determinar el verdadero alcance de las políticas del Estado y si estas se ajustan a las necesidades.

Este informe parte enfatizando, que aun cuando Colombia es la cuarta nación que se encuentra entre las denominadas "economías emergentes" de Latinoamérica, las condiciones laborales en el país, atendiendo a las estadísticas, son propias de un "país del tercer mundo"; el Informe Nacional del Trabajo Decente en Colombia del 2012, cita documento de la OIT de 2013, e indica que las anteriores afirmaciones se deben a que: 
- En el 2012, la tasa de desempleo fue del 10,4\%, mientras que la tasa promedio para América Latina se situó en el 6,5\%;

- La tasa de subempleo fue del $32 \%$;

- La tasa de informalidad fue del $68 \%$, la cuarta más alta de toda la región, después de países como, Perú, Bolivia y Paraguay

- La tasa de desempleo juvenil de Colombia fue del 19\%, mientras que en América Latina es del $14,3 \%$;

- La tasa de desempleo de las mujeres en Colombia fue del 13,7\%, en tanto que en América Latina es del 7,7\%;

- Y respecto del nivel de protección social, apenas 36 de cada 100 trabajadores cuentan con una relativa protección social: 46 en salud, 40 en riesgos profesionales, 36 en cesantías y 31 en pensiones. (Vásquez, 2013, p. 11)

En el informe se realiza la discriminación de cada uno de las ocupaciones, caso contrario en las estadísticas del DANE presentadas anteriormente, lo cual deja ver correctamente los porcentajes y la participación de cada una de las ocupaciones en las estadísticas y se observa en la Gráfica extraída del informe, el análisis permite inferir que la informalidad en Colombia es aproximadamente del $80 \%$ y es la "única alternativa frente al desempleo y la pobreza, y frente a la ausencia de políticas públicas que protejan a los desempleados de la amenaza de verse reducidos a la condición de indigencia por falta de ingresos”. (Vásquez, 2013, p. 19)

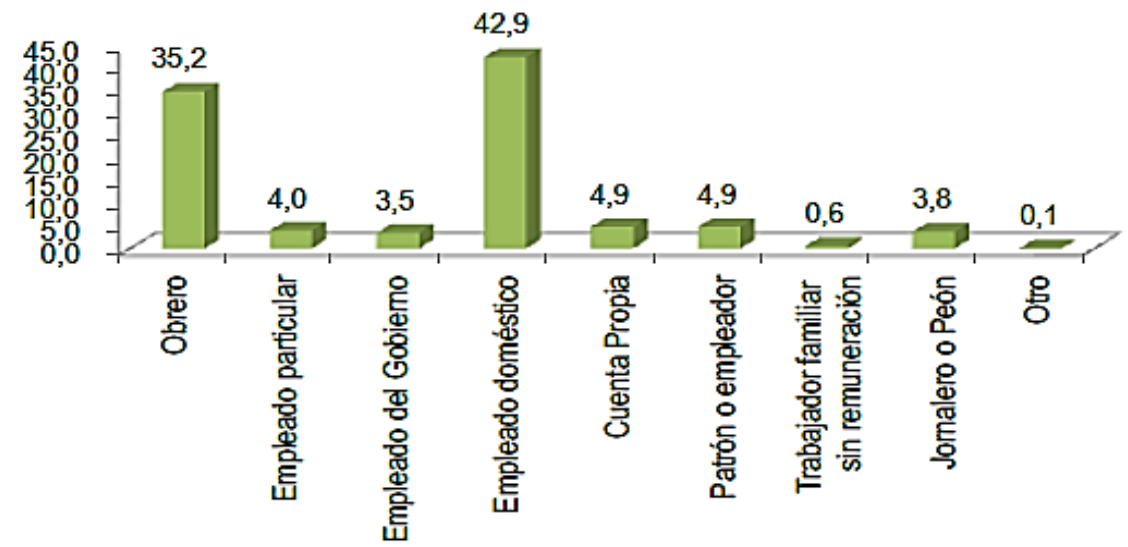

Figura 4. Población ocupada por posición ocupacional, 2012 (cifras en porcentaje)

Fuente: DANE (2012) Gran Encuesta Integrada de Hogares 
Al observar directamente el número de personas que desempeñan trabajo doméstico en Colombia se observa que son personas del género femenino quienes desarrollan este tipo de labores, así mismo los trabajadores familiares sin remuneración en su gran mayoría corresponden igualmente a mujeres, como se expone en el Informe Nacional del Trabajo Decente en Colombia del 2012 lo anterior es analizado y expuesto Vásquez quien indica que:

La prevalencia de factores socioculturales que señalan como actividad natural para las mujeres el trabajo doméstico y aquellas labores ligadas al cuidado, que por lo general no son pagas. Ambos aspectos contribuyen a la dependencia económica de las mujeres que reduce el espectro de oportunidades de crecimiento personal y laboral, y restringe su participación en la construcción de agendas para el desarrollo. El rol de cuidadora que se ha asignado tradicionalmente a las mujeres y el mínimo valor económico atribuido a tales labores, ha generado diversas barreras para desarrollar otro tipo de oficios o profesiones y roles que impliquen liderazgo o autoridad. (Vásquez, 2013, p. 66)

Tabla 3.

Población ocupada según sexo y posición ocupacional, promedio anual 2012 Total Nacional

\begin{tabular}{|l|r|r|r|}
\hline \multicolumn{1}{|c|}{ Concepto } & Total & Hom bres & Mujeres \\
\hline Ocupados Total Nacional & 20.696 & 12.149 & 8.547 \\
\hline Obrero, empleado particular & 7.282 & 4.452 & 2.830 \\
\hline Obrero, empleado del gobierno & 838 & 441 & 397 \\
\hline Empleado doméstico & 730 & 37 & 693 \\
\hline Trabajador por cuenta propia & 8.883 & 5.276 & 3.608 \\
\hline Patrón o empleador & 1.017 & 764 & 253 \\
\hline Trabajador familiar sin remuneración* & 1.138 & 444 & 694 \\
\hline Jornalero o Peón & 783 & 726 & 57 \\
\hline Otro & 26 & 10 & 16 \\
\hline
\end{tabular}

Fuente: (Vásquez, 2013, p. 66)

En el proceso de investigación y desarrollo del Convenio 189, fue la Oficina para la Igualdad de Género la encargada de realizar los estudios tendientes a examinar el ámbito laboral de los 
trabajadores domésticos en el mundo, advirtiendo que el trabajo doméstico era ejecutado básicamente por mujeres, la mayoría en estado de pobreza y vulnerabilidad, seguido de los niños y en menor medida por hombres. Es así que para buscarla reivindicación de los derechos humanos del niño y de la mujer, así como la valoración del trabajo doméstico, resulta prioritario fomentar el trabajo decente y la dignidad, lo que constituye razón del convenio.

Respecto al tema en contexto colombiano el Informe coordinado por Vásquez Fernández expone:

Desde el punto de vista de la rama económica, las mujeres se concentran en comercio, hoteles y restaurantes y en el sector de servicios comunales, sociales y personales. Esta distribución en las actividades económicas muestra una concentración del 64\% en trabajos asociados al cuidado y el servicio a otros, persistiendo así la asociación de las mujeres con lo doméstico que se extiende al trabajo productivo, donde los estereotipos tradicionales de género se reproducen: las mujeres tienen del deber natural del servicio y los cuidados y su trabajo no es generador de riqueza y como tal no tiene el mismo valor que el de los hombres. (Negrilla fuera del texto original) (Vásquez, 2013, p. 69)

Lo anterior deja ver la segregación ocupacional que impide a las mujeres posicionarse laboralmente en Colombia, la discriminación por razones de sexo, etnia y nivel sociocultural en Colombia es aún muy arraigada, por lo tanto es vital que en el marco de los Principios y Convenios de la OIT se dé aplicabilidad plena y real por medio de políticas públicas y mediantes el compromiso por parte de las diferentes instituciones estatales. Cabe resaltar sobre el particular el documento de la OIT: "Igualdad de género y trabajo decente. Convenios y recomendaciones claves para la igualdad de género”, que expresa:

Desde la creación de la Organización Internacional del Trabajo (OIT) en 1919, la no discriminación y la promoción de la igualdad constituyen principios fundamentales que sustentan la labor de la institución. Estos principios también forman parte integrante del Programa de Trabajo Decente de la OIT: Promover el trabajo decente y productivo en condiciones de libertad, igualdad, seguridad y dignidad de la persona humana. Todos los trabajadores tienen derecho a tener un trabajo digno, no sólo quienes trabajan en la economía 
formal sino quienes trabajan de forma independiente, eventual y en la economía informal, así como quienes trabajan en el área de la prestación de cuidados y en el ámbito privado de los hogares, áreas en las que predominan las mujeres. (OIT, 2006, p.V)

El aparte anterior pone en contexto el trabajo decente como elemento fundamental para la consecución de las metas de la OIT.

El concepto de trabajo decente surge en 1999 en 87ª reunión en Ginebra y reza:

Actualmente, la finalidad primordial de la OIT es promover oportunidades para que los hombres y las mujeres puedan conseguir un trabajo decente y productivo en condiciones de libertad, equidad, seguridad y dignidad humana Tal es la finalidad principal de la Organización hoy en día. El trabajo decente es el punto de convergencia de sus cuatro objetivos estratégicos: la promoción de los derechos fundamentales en el trabajo; el empleo; la protección social y el dialogo social. Esto debe orientar las decisiones de la Organización y definir su cometido internacional en los próximos años.(3)

Como se observa el concepto de trabajo decente es relativamente nuevo y su desarrollo en principio es de carácter doctrinario. Al respeto la Procuraduría General de la Nación se pronuncia con el fin de establecer el contexto socio-jurídico en el cual se ha de aplicar el Trabajo Decente en Colombia, en el documento "Trabajo digno y decente en Colombia. Seguimiento y control preventivo a las políticas públicas", profundiza acerca de los cuatro objetivos que hacen parte del concepto de Trabajo decente y expresa:

El concepto de trabajo decente tiene poco fundamento normativo pero amplia base doctrinaria, por ese motivo la descripción de sus componentes se desarrollará por completo a partir de definiciones doctrinarias. Además, como el contenido específico de cada uno de los componentes es objeto de discusión por parte de los distintos doctrinantes que han tratado el tema, en esta descripción se incluyen únicamente los puntos en los que hay relativo consenso. Adicionalmente, se hace referencia a los indicadores que se han propuesto para medir el comportamiento de cada uno de los cuatro elementos en los distintos países. 
a. Oportunidades de empleo e ingresos: partiendo de que para poder hablar de trabajo decente hay que contar, en primer lugar, con trabajo, este componente contiene un análisis de distintas condiciones relativas a la suficiencia de empleo en los países y la remuneración de los trabajadores.

Estas condiciones de empleo varían de país en país de acuerdo a distintos factores tales como el nivel de desarrollo, el ingreso per cápita, la distribución de recursos y la existencia de políticas económicas y laborales de distintas clases (Ghai, 2003, p. 128).

El Centro de Investigaciones Sociojurídicas de la Universidad de Los Andes (Cijus), presentó al Viceministerio de Relaciones Laborales del Ministerio de la Protección Social, una "Propuesta sobre la definición de política pública para la generación de trabajo digno y decente en el país" (Cijus, 2008). A través de esa propuesta el Cijus, como lo había dicho antes DharamGhai (2006), afirmó que para poder medir el componente empleo del trabajo decente era necesario tener en cuenta los siguientes tres aspectos:

i. Las oportunidades de empleo

ii. La aceptabilidad de la remuneración

iii. Las condiciones de trabajo: como se había afirmado antes, el concepto de trabajo decente no se refiere únicamente a la cantidad sino también a la calidad de las condiciones de empleo. De tal forma que para examinar estas condiciones hay que tener en cuenta factores como la duración de las jornadas de trabajo, el descanso, la existencia de medidas de protección a la salud ocupacional, entre otros.

b. Derechos de los trabajadores: en palabras de DharamGhai (2003, Pág.28) este componente "constituye el marco ético y legal para todos los elementos del trabajo decente. $\mathrm{Su}$ objetivo es asegurar que el trabajo se asocie con la dignidad, equidad, libertad, remuneración adecuada, seguridad social y voz, representación y participación para todas las clases de trabajadores".

En términos más concretos, como elemento constitutivo del trabajo decente, los derechos de los trabajadores están referidos principalmente al conjunto de normas laborales de protección a las libertades básicas de los trabajadores, o derechos fundamentales del trabajo (Rodgers, 2007). Por este motivo DharamGhai (2006) señala que el principal ámbito de operación de este componente del trabajo decente está en el campo normativo, así su reconocimiento y 
aplicación efectiva dependa más de la capacidad institucional y de los recursos que asignen los Estados a este fin.

La Declaración sobre los principios y derechos fundamentales en el trabajo, aprobada por la OIT en 1998, y que reúne ocho convenios sobre los derechos de los trabajadores, puede ser considerada como una de las consagraciones normativas que de manera más integral presenta los derechos a los que aquí se hace referencia. Específicamente, esas convenciones se refieren a la libertad sindical, al derecho de sindicación y de negociación colectiva, a la abolición del trabajo forzoso, al trabajo infantil y a la no discriminación e igualdad entre el trabajo de mujeres y hombres. Además, esta Declaración ha servido de marco de referencia para las normas sobre esos mismos temas adoptadas por los Estados.

c. Protección social: este componente del trabajo decente se refiere a la seguridad social de los trabajadores, es decir, al objetivo de brindarles una salvaguarda, a ellos y a sus familias, en los casos en que se presenten contingencias como la enfermedad o los accidentes laborales, la maternidad, la muerte, la vejez, el desempleo y la invalidez. Relacionado con este mismo componente, algunos autores como Anker (2003) señalan también a las condiciones físicas de seguridad del lugar de trabajo; hablan entonces de "las condiciones que preservan y fomentan la integridad física y psicológica de los trabajadores", y señalan que para que esas condiciones puedan ser alcanzadas es necesario que los Estados sigan la recomendación del Convenio número 155 de la OIT, sobre Seguridad y salud de los trabajadores, de acuerdo con la cual las políticas que implementaran en esta materia deberían "prevenir los accidentes y los daños para la salud que sean consecuencia del trabajo, guarden relación con la actividad laboral o sobrevengan durante el trabajo, reduciendo al mínimo, en la medida en que sea razonable y factible, las causas de los riesgos inherentes al medio ambiente de trabajo" (Ibid Pág. 180)

d. Diálogo social: es una manifestación de la democracia que se expande hasta el ámbito del trabajo. Este componente supone que los actores con intereses en los asuntos del trabajo puedan dar a conocer su punto de vista directamente o a través de sus representantes y así influir en la toma de las decisiones que les conciernen. Estas decisiones giran en torno a aspectos específicos de la relación con un determinado empleador, pero también a temas más generales tales como las políticas laborales, económicas y sociales que determinan las condiciones de empleo (Ghai, 2003, p. 146). 
En este diálogo están llamados a participar no solo los trabajadores, que de manera más frecuente se agrupan en organizaciones sindicales, sino también los empleadores y el Estado. Se trata de una comunicación tripartita que utiliza la misma estructura organizativa adoptada por la OIT. Tras la exposición de las justificaciones aportadas por cada una de las partes interesadas, el diálogo social que hace parte del trabajo decente debe conducir al encuentro de soluciones negociadas que gocen de una amplia aceptación por parte de todos los actores. De esa manera se logra que la voz de los trabajadores sea escuchada y tomada en consideración con tanta importancia como la de los sectores económicamente más influyentes." (Procuraduría General de la Nación, 2011, p. 26)

Es esencial comprender que el trabajo decente y los derechos del trabajador no se deben contraponer a la productividad y el desarrollo económico, por el contrario como se expresa en cita de la OIT en el documento de la Procuraduría en el que se expresa:

El paradigma del trabajo decente bien podría inscribirse dentro del tipo de enfoques que comparten esta segunda actitud, pues se basa en la creencia de que el respeto a los derechos laborales no es incompatible con la generación de empleo y con el desarrollo nacional, sino que antes bien, podría reforzar y acelerar la consecución de estos objetivos. Precisamente, uno de los principales desafíos de los defensores del trabajo decente siempre ha sido intentar demostrar el impacto positivo que su cumplimiento tiene sobre el crecimiento y el desarrollo económico (OIT, 2011, p.31).

Ahora bien, que el concepto de Trabajo Decente sea nuevo en Colombia, no por esto se han dejado de promover y proteger los derechos de los trabajadores. En el desarrollo constitucional del derecho de los trabajadores la Corte Constitucional parte del principio de dignidad como bien se expone en el documento de la Procuraduría:

El trabajo digno, puede encontrarse por dos vías. Por un lado, a través de la referencia a la dignidad humana, que como principio fundante del Estado social de derecho debe reflejarse en todo el ordenamiento jurídico, y de manera concreta, sobre las distintas dimensiones del trabajo. Por el otro, acudiendo a la referencia expresa de los art. 25 y 53 de la C.P. que dan 
muestra de la relevancia que la Constitución le otorga a las condiciones en las que se desempeña el trabajo. (Procuraduría General de la Nación, 2011, p. 35).

A partir de estos conceptos la Corte Constitucional Colombiana desarrolla a partir de la Sentencia T-457 de 1992, elementos constitutivos de las condiciones dignas y justas del trabajo del artículo 25 de la C.P, como lo expone el documento de la Procuraduría:

\section{El trabajo en condiciones dignas y justas del artículo 25 de la Constitución}

Como se ha afirmado, desde muy temprano la Corte Constitucional se encargó de señalar por medio de su jurisprudencia cuáles eran las condiciones dignas y justas del trabajo de las que se habla en el artículo 25 C.P. En las primeras sentencias que se refirieron a que el derecho constitucional al trabajo debía desarrollarse en determinadas condiciones (como lo ordena el artículo 25 C.P.), la Corte se limitó a decir que "La Constitución Nacional prevé en normas posteriores [al artículo 25] los parámetros que fijan las condiciones del derecho al trabajo (art. 52, a 58 y 64)”. (Procuraduría Cita la Corte Constitucional, Sent. T- 451, 1992)

En el mismo año, sin embargo, la Corte Constitucional indicó, a través de la Sentencia T-457 de 1992, que las condiciones que debían estar presentes en la relación laboral para poder afirmar que la misma se desarrollaba en condiciones dignas y justas (como lo ordena el artículo 25 C.P.) eran las mencionadas en el artículo 53 de la Constitución. Dijo adicionalmente que dichas condiciones deberían ser reconocidas como parte del derecho al trabajo de todos los trabajadores, independientemente del tipo de relación laboral que tuvieran, ya fuera ésta entre particulares, o entre la administración y sus servidores. Se ha afirmado incluso, que los que actualmente no trabajan y los desempleados también son sujetos del derecho al trabajo en condiciones dignas y justas. (Procuraduría Cita la Corte Constitucional, Sent. C-531, 2005)

Los principios del artículo 53 son los siguientes: "Igualdad de oportunidades para los trabajadores; remuneración mínima vital y móvil, proporcional a la cantidad y calidad de trabajo; estabilidad en el empleo; irrenunciabilidad a los beneficios mínimos establecidos en normas laborales; facultades para transigir y conciliar sobre derechos inciertos y discutibles; situación más favorable al trabajador en caso de duda en la aplicación e interpretación de las fuentes formales de derecho; primacía de la realidad sobre formalidades establecidas por los 
sujetos de las relaciones laborales; garantía a la seguridad social, la capacitación, el adiestramiento y el descanso necesario; protección especial a la mujer, a la maternidad y al trabajador menor de edad.

A continuación se mostrará brevemente la manera en que la jurisprudencia de la Corte Constitucional ha dado aplicación a los principios del artículo 53 como componentes del trabajo en condiciones dignas. Se presentarán, además, algunas de las subreglas constitucionales que la Corte ha creado mediante la resolución de casos concretos, en los que su decisión ha estado fundamentada en la protección de uno o varios de los principios del artículo 53 de la C.P., como condiciones del trabajo en condiciones dignas.

a. Igualdad de oportunidades para los trabajadores: este principio es un desarrollo del mandato más general del artículo 13 de la Constitución que, por un lado, establece que a los iguales se les dé igual protección y tratamiento y que a los diferentes se les trate distinto en razón de esas diferencias, y por el otro, prohíbe la discriminación con base en los llamados criterios sospechosos (esto son: sexo, raza, origen nacional o familiar, lengua, religión, opinión política o filosófica).

Como se sabe, pretender aplicar este principio puede ser difícil en ocasiones en las que no es claro si el tratamiento diferenciado que se le da a alguien está razonablemente justificado por condiciones especiales de esa persona (como sería el caso, por ejemplo, de las acciones afirmativas para asegurar que la contratación de un número de hombres y de mujeres sea equilibrada) o si, por el contrario, obedece a razones típicamente discriminatorias (como cuando, por ejemplo, se despide a alguien únicamente por razón de su situación de discapacidad). En los casos en los que resulta dudoso si la diferenciación se constituye en discriminación o no, la Corte ha señalado la necesidad de aplicar el método argumentativo del test de proporcionalidad, a partir del cual es posible saber si, razonablemente, el trato diferenciado en un caso determinado constituye discriminación o no.(Procuraduría Cita la Corte Constitucional, T-230, 1994)

Cuando el derecho que está en juego en un caso específico es el derecho al trabajo, la determinación razonable y objetiva de que hubo un tratamiento discriminatorio significa el reconocimiento de una violación a las condiciones dignas y justas del trabajo. (Procuraduría Cita la Corte Constitucional, T-677, 2001) En palabras más generales, se debe decir que se presentó un atentado en contra del trabajo digno. 
La discriminación como desconocimiento del principio de igualdad, en el ámbito laboral, suele presentarse con mayor frecuencia bajo las formas de segregación por sexo(Procuraduría Cita la Corte Constitucional, T-026, 1996; T-326, 1995; T-624, 1995), por orientación sexual (Procuraduría Cita la Corte Constitucional, C-481, 1998), y por discapacidad(Procuraduría Cita la Corte Constitucional, C-531, 2000; T-792, 2004; T-434, 2008). Las cuales suelen presentarse en dos momentos diferentes: cuando se pretende acceder a un cargo y cuando se lleva a cabo la fijación salarial (Procuraduría Cita la Corte Constitucional, SU-519, 1997; SU547, 1997). En este último caso, el del salario, la Corte ha precisado que las condiciones particulares del patrono no pueden traducirse en un tratamiento diferenciado en el momento de establecer los salarios de los trabajadores (Procuraduría Cita la Corte Constitucional, C051, 1995).

b. Remuneración mínima vital y móvil: las condiciones de dignidad y justicia de que habla el artículo 25 de la C.P. imponen que el salario que se le dé a un trabajador por utilizar su fuerza a favor de su patrono sea, en primer lugar, proporcional o equivalente a la cantidad y calidad del trabajo. Adicionalmente, implican que esa remuneración sea mínima vital y móvil. El carácter de vital hace alusión a que la fuerza que el trabajador utiliza en beneficio de su patrón debe ser compensada a través de una remuneración que le permite llevar una vida digna, pues es ésta la forma en que el trabajador se asegura un sustento para él mismo y para su familia. La movilidad, por su parte, ha sido entendida como el derecho que le asiste al trabajador para que el poder adquisitivo de sus salarios se mantenga en el tiempo, lo cual no implica que siempre se le deba hacer un incremento salarial (Procuraduría Cita la Corte Constitucional, C-851, 1999; C-1433, 2000; C-1064, 2001; C-1017, 2003; C-931, 2004).

Un empleo, entonces, en el que el salario no cumpla con alguna de estas características, sería un empleo con condiciones contrarias a las del trabajo digno, pues la compensación que recibe el trabajador por la realización de sus labores no le permitiría "satisfacer las necesidades - materiales, sociales y culturales - vida social y familiar normal" (Procuraduría Cita la Corte Constitucional, C-252, 1995).

En relación con este componente del trabajo en condiciones dignas y justas, ha precisado la Corte que también supone que esa remuneración se lleve a cabo de manera oportuna, pues un pago tardío puede ser tan perjudicial para el mantenimiento de las condiciones de vida del trabajador y su familia, como el mismo no pago. Ha afirmado la Corte incluso que el pago de 
la incapacidad durante la enfermedad es equivalente al pago del salario mientras se está sano (Procuraduría Cita la Corte Constitucional, T-311, 1996; T-680, 2008), de manera que se constituye también en una condición del trabajo digno.

c. Estabilidad en el empleo: la consagración de la estabilidad laboral como condición de dignidad en el trabajo, les da a los trabajadores la confianza en que por el correcto desempeño de sus labores conservarán sus puestos de trabajo y las condiciones que desde el principio han sido establecidas para que desarrollen sus tareas.

Si se tiene en cuenta que dentro de las potestades patronales se encuentra el iusvariandi, que consiste en la capacidad del empleador de modificar las condiciones de modo, tiempo y lugar en que el trabajador debe desempeñar sus funciones, podría pensarse en que esa estabilidad se encuentra amenazada por las facultades con que cuentan los empleadores. Sin embargo, tan pronto como en la jurisprudencia de la Corte Constitucional se ha hecho referencia a las condiciones de trabajo dignas y justas, se ha dejado también en claro que la potestad del iusvariandi está limitada por las condiciones del trabajo digno (Procuraduría Cita la Corte Constitucional, T-457, 1992; T, 407, 1992), y por otras normas como las que se encuentran en el Código Sustantivo del Trabajo a través del artículo 23 y siguientes.

De esta manera, aunque en principio el empleador tenga el poder para cambiarle al trabajador las condiciones inicialmente pactadas, los cambios siempre tienen que hacerse de acuerdo a unas condiciones; en concreto esos cambios tienen que ser razonables, temporales y justificados, pues de lo contrario se verían como resultado del puro capricho del empleador, como una violación al trabajo en condiciones dignas, y no contarían con ningún sustento constitucional.

Por otra parte, hay que considerar también que además de esa protección general a la estabilidad, en la Carta se habla de manera concreta de una estabilidad laboral reforzada para los sujetos en condiciones de debilidad manifiesta. En esta situación se encontrarían, por ejemplo, las personas en condición de discapacidad, las mujeres embarazadas (Procuraduría Cita la Corte Constitucional, C-470, 1997), los trabajadores con fuero sindical y las personas con VIH.

Para el caso de las personas en condición de discapacidad, la Corte ha manifestado que la garantía de estabilidad reforzada pone en cabeza del empleador la obligación de reubicar a los trabajadores con discapacidad parcial, pues de esa estabilidad depende que puedan vivir en 
condiciones dignas y justas (Procuraduría Cita la Corte Constitucional, T-434, 2008; T-1040, 2001; T-434, 2008).

Adicionalmente, la Corte Constitucional ha afirmado que la potestad del iusvariandi del empleador está condicionada también por las características particulares del empleado de que se trate, de manera pues que no podrán señalarse a priori las facultades que por el iusvariandi podría tener un empleador, sino que el establecimiento de éstas depende en gran medida de la situación de la persona a quien se le quieran modificar las condiciones de empleo(Procuraduría Cita la Corte Constitucional, C-531, 2005). Esto significa que la estabilidad laboral como componente de las condiciones dignas de trabajo es subjetiva (porque se establece en relación con cada persona y no en abstracto).

d. Irrenunciabilidad a los beneficios mínimos establecidos en normas laborales: como se tiene que las normas de derecho laboral son de interés público y establecen puntos mínimos, resulta por definición contrario a las condiciones de trabajo digno que se renuncie a esos puntos mínimos establecidos justamente como señal de lo que resulta inaceptable en términos de condiciones laborales.

e. In dubio pro operario: es uno de los principios rectores del derecho laboral, según el cual debe optarse por la interpretación más favorable al trabajador de entre varias posibles, o por la norma que beneficie más al trabajador cuando varias sean aplicables.

f. Primacía de la realidad sobre las formas: es otro principio del derecho laboral que tiene por fin el evitar que por medio de formalidades se desconozcan los derechos de los trabajadores. En concreto, como componente del trabajo digno significa que resulta en contra de las condiciones dignas en el trabajo el hecho de establecer formalidades que desfiguran la realidad de las relaciones laborales.

g. Garantía a la seguridad social, la capacitación, el adiestramiento y el descanso: los elementos de capacitación y adiestramiento del trabajo en condiciones dignas suponen que se reconoce el valor que tiene la persona por ella misma, de tal forma que se vea como valioso capacitarla para que esté mejor preparada, y no simplemente descartarla cuando no cuente con todos los conocimientos deseados.

La Corte ha señalado, en relación con este punto, que es parte del trabajo en condiciones dignas el "tener una clara apreciación del cargo que va a desempeñar y las funciones que debe realizar en el mismo" (Procuraduría Cita la Corte Constitucional, T-084, 1994). Algunas 
veces, para alcanzar esa clara apreciación del cargo y de las funciones es necesaria alguna capacitación inicial. Por otra parte, como ya se había mencionado antes, este elemento del trabajo en condiciones dignas y justas en conjunción con el primero mencionado de la estabilidad laboral, pone en cabeza del empleador la obligación de reubicar al trabajador en condición de discapacidad parcial. Esa reubicación, en muchos casos, requiere de alguna capacitación o adiestramiento para la nueva tarea por realizar.

Por su parte, la seguridad social está incluida como un elemento del trabajo en condiciones dignas y justas, pues "la vida, la integridad física y la salud, son derechos indispensables para hacer efectivo el derecho al trabajo, el sistema público de seguridad social busca entonces que el Estado dignifique y otorgue justicia a las condiciones en que se ejerce el trabajo" (Procuraduría Cita la Corte Constitucional, C-425, 2005, T-013, 2005).

Asimismo, el descanso supone reconocer al trabajador como ser humano, que necesita reponerse de las jornadas de trabajo.

Por otra parte, la Corte también ha afirmado(Procuraduría Cita la Corte Constitucional, C898, 2006) que como el artículo 25 de la Constitución consagra el derecho al trabajo en condiciones dignas y justas sin establecer límites, la protección no solo se extiende a los principios dispuestos en el artículo 53 de la Carta Política sino que además comprende la garantía de otros derechos fundamentales en el ámbito laboral como son el derecho a la integridad física y moral, el derecho a la igualdad, a la intimidad, al buen nombre, y a la libertad sexual, entre otros.” (Procuraduría, 2011, p. 36)

Atendiendo al desarrollo conceptual tanto de Trabajo Decente como de Trabajo Digno se puede indicar que:

El concepto de trabajo decente pone su atención en dos dimensiones adicionales del mundo del trabajo; esto es, en la relativa a los efectos que el mismo fenómeno del trabajo puede tener sobre la economía, y en la dimensión de la democracia en el terreno laboral. Y es justamente esa visión más amplia la que le otorga algún valor adicional al concepto de trabajo decente. En esta última noción entonces habría que reconocer el valor que le otorga el hecho de contar con una mirada más interdisciplinaria. (Procuraduría General de la Nación, 2011, p. 47) 
Mediante el trabajo digno, en Colombia se hacen efectivos los derechos de los trabajadores, mediante el concepto de Trabajo Decente, se busca el compromiso de los entes gubernamentales para que cree políticas públicas y económicas, que brinde a los trabajadores la protección y garantías necesarias para su desarrollo laboral y personal.

Como se observa a lo largo del desarrollo de la investigación, aun cuando se encuentran documentos que analicen el trabajo decente en Colombia, estos no profundizan en el trabajo doméstico, por lo tanto con la presente investigación se pretende no solo analizar las políticas públicas del Estado colombiano con respecto al trabajo decente para los trabajadores domésticos, sino que de igual forma se busca establecer como mediante desarrollo jurisprudencial se ha procedido a garantizar y proteger el trabajo doméstico y por último se ha de realizar el estudio de casos concretos de desarrollo del Convenio 189.

\subsection{Marco Legal}

Las normas manejadas en la investigación comprenden aquellas normas cuyo contenido atienden al derecho laboral de los trabajadores domésticos:

- Ley 11 de 1988 Por lo cual se consagran unas excepciones en el régimen del Seguro Social para los trabajadores del servicio doméstico.

- Decreto Número 824 de 1988 (abril 29) El Presidente de la República de Colombia, en ejercicio en la facultad otorgada en el parágrafo del artículo $3^{\circ}$ de la Ley 11 de 1988.

- Decreto Ley 2663 del 5 de agosto de 1950 "Sobre Código Sustantivo del Trabajo", publicado en el Diario Oficial No 27.407 del 9 de septiembre de 1950, en virtud del Estado de Sitio promulgado por el Decreto Extraordinario No 3518 de 1949.

- Ley 50 de 1990 (diciembre 28) por la cual se introducen reformas al Código Sustantivo del Trabajo y se dictan otras disposiciones.

- Ley 100 de 1993 (Diciembre 23) Por la cual se crea el sistema de seguridad social integral y se dictan otras disposiciones.

- Ley 1496 de 2011 (Diciembre 29) 'Por medio de la cual se garantiza la igualdad salarial y de retribución laboral entre mujeres y hombres, se establecen mecanismos para erradicar cualquier forma de discriminación y se dictan otras disposiciones. 
- Ley 1595 de 2012 (Diciembre 21) Por medio de la cual se aprueba el "Convenio Sobre el Trabajo Decente Para las Trabajadoras y los Trabajadores Domésticos, 2011 (número 189)", adoptado en Ginebra, Confederación Suiza, en la 100ª reunión de la Conferencia Internacional del Trabajo el 16 de 2011.

\section{Metodología}

\subsection{Hipótesis}

Las políticas públicas existentes y erigidas por el Estado colombiano, son insuficientes para la materialización del convenio 189 (trabajo decente para los trabajadores domésticos) adoptado mediante Ley 1595 de 2012.

\subsubsection{Enfoque de la Investigación}

La metodología empleada en la presente investigación es de enfoque cualitativo, debido a que el proceso de investigación está caracterizado por la observación, descripción y la exploración hecha al control de convencionalidad, en donde se vincula el ordenamiento jurídico colombiano y la aplicación del Convenio 189 de la OIT. Así mismo, corresponde a una investigación cualitativa, toda vez que ésta se basa en una estrategia para tratar de conocer los hechos, procesos, estructuras y personas en su totalidad, y no a través de la medición de algunos de sus elementos. La misma estrategia indica el empleo de procedimientos que dan un carácter único a las observaciones, produciendo datos descriptivos y conduciendo la investigación de forma inductiva. De igual manera, los elementos que componen el objeto de estudio no están operacionalizados desde el principio de la investigación, es decir, no están definidos desde el inicio los indicadores que se tomarán en cuenta durante el proceso de investigación.

Entendido lo anterior, la presente investigación tiene como objetivo el estudio de la contextualización del convenio 189 de la OIT al sistema socio-jurídico colombiano. Para ello, se parte del análisis de la jurisprudencia de las Cortes Constitucional y Suprema de Justicia, la cual tiene como sujeto a los trabajadores del servicio doméstico, atendiendo a lo anterior se corrobora 
el enfoque CUALITATIVO, puesto se busca estudiar los fenómenos sociales del trabajo decente para los trabajadores del servicio doméstico mediante el análisis y creación de las correspondiente líneas jurisprudenciales de las Cortes Colombianas, así como el estudio del desarrollo que han presentado las políticas públicas con el fin de crear trabajo decente para este grupo de trabajadores.

Por su parte, el tipo de investigación se concibe como hermenéutico, que hace referencia al intercambio frecuente entre observaciones, presunciones, interpretaciones tentativas y verificaciones de datos nuevos. De la misma manera, permite el acceso a nuevas interpretaciones que comprenden más datos. Así mismo se entiende como un método dialéctico que incorpora el análisis de varios fenómenos y tiene como fin establecer relaciones entre estos. (Méndez, 2003)

El presente trabajo de investigación se concibe como de tipo hermenéutico en la medida en que consiste en una constante disertación sobre las relaciones existentes entre los pronunciamientos de las Cortes Colombianas y las disposiciones planteadas por la OIT en el Convenio 189, todo esto alrededor del concepto de trabajo decente para los trabajadores domésticos. Así mismo, se pretende describir y analizar minuciosamente el contenido de la legislación y jurisprudencia colombiana al respecto, para posteriormente llevar a cabo una intervención propositiva en la medida en que se intentará sugerir de qué manera se puede contextualizar el Convenio 189 en el ordenamiento jurídico colombiano para que cumpla con lo dispuesto por los preceptos internacionales de trabajo decente.

\subsection{Método de Investigación}

\subsubsection{Método de investigación general:}

En la presente investigación se recurre a un método de análisis, porque se observa un objeto específico, como lo es el Convenio 189, y se realiza una observación detallada de sus características aplicadas a un escenario concreto, como lo es el ordenamiento jurídico colombiano, mediante una descomposición de las partes que integran su estructura. Así mismo, el análisis también se aplica en la recolección de información aportada desde la jurisprudencia, las normas y la doctrina colombiana. 


\subsubsection{Método de investigación del derecho:}

La presente investigación corresponde a un método sistemático porque se desarrolla mediante un proceso en el cual se relacionan hechos aislados y se pretende formular una teoría unificada compuesta por diferentes elementos del objeto de estudio. Así mismo se hace la reunión racional de los elementos dispuestos en una nueva totalidad para presentar el planteamiento de la hipótesis. Por último mediante el método sistemático, según un conjunto de órdenes y reglas se permite llegar a la comprensión sistemática de la situación dada.

\subsection{Fuentes}

\subsubsection{Fuentes primarias}

Trabajo de Campo a través de entrevistas a asociaciones de trabajadoras del servicio doméstico y organizaciones que trabajen por los derechos de este grupo de trabajadores.

\subsubsection{Fuentes secundarias}

Internet, Doctrina jurídica, artículos jurídicos de investigación, jurisprudencia, normatividad vigente y artículos pedagógicos.

\subsection{Herramientas}

En la presente investigación se utilizan instrumentos tales como entrevistas a grupos focales, análisis de datos y recolección de documentos de diversa clase relacionados con el tema objeto de estudio.

\subsection{Plan de Trabajo}

1. Planeación y administración del proyecto de Investigación

2. Revisión documental y seguimiento de antecedentes

3. Procesamiento de Información y orientación de la investigación 
4. Planteamiento de hipótesis

5. Presentación primer informe (anteproyecto)

6. Segundo Informe (propuesta de investigación) importancia, viabilidad y factibilidad del proyecto (con correcciones de anteproyecto)

7. Recolección de datos estadísticos y de información relacionados con el tema de investigación

8. Análisis e interpretación de la información seleccionada

9. Presentación del Proyecto

10. Ejecución, presentación del trabajo final y resultados

\section{Contextualización Histórica Del Trabajo Decente Para Los Trabajadores Del Servicio Doméstico}

\section{"Los pueblos que olvidan su historia están condenados a repetirla" \\ George Santayana}

En el presente capitulo se busca establecer el contexto histórico en el que se desarrolló el trabajo doméstico en Colombia, para obtener una mejor comprensión de su influencia en la sociedad actual y en el marco jurídico del Convenio 189. El estudio se realiza en atención a la herencia socio-cultural española y se aborda desde el trabajo doméstico en la edad media europea, la evolución que esta labor tiene en la España colonial hasta su paso por la independencia y la creación de la República.

Así mismo, es fundamental el estudio de los antecedentes jurídicos del contrato de trabajo de los trabajadores del servicio doméstico y realizar el correspondiente análisis de los avances de los organismos internacionales que influenciaron el cambio de paradigma y la necesidad de la regulación particular que propenda una protección eficiente, equitativa y eficaz de los derechos de este grupo de trabajadores. 


\subsection{El Trabajo Doméstico en la Edad Media:}

Al momento de considerar los orígenes del Trabajo doméstico y su reglamentación en Colombia, la historia nos remite directamente al Continente Europeo, ya que como indica Romano "la organización del mundo del trabajo en América se hizo alrededor del pensamiento medieval europeo y más precisamente del pensamiento de Santo Tomás de Aquino y de sus discípulos". Es por esto que al exponer la idea de trabajo en América, Romano adopta el término de idea <medieval> del trabajo, cuyos orígenes los ubica en el pensamiento aristotélico, considerando la distinción que Aristóteles realizó en su libro La Política, diferenciando entre seres naturalmente libres y seres naturalmente siervos. (1996, p. 199)

Al mirar y abordar el contexto laboral en las colonias españolas, se observa cómo mientras la evolución del sistema del trabajo en Europa pasó del servilismo feudal a la libertad de trabajo, trayendo consigo el iluminismo (sistema que se perpetuó en las colonias, mediante la mita y la encomienda y se trasladó a las Américas, por intermedio de la conquista y la colonización; figuras sostenidas por la distinción aristotélica, pero para preservar este pensamiento en el cristianismo, se requería tal y como expone Romano:

Resolver un problema fundamental: para el cristianismo todos los hombres son iguales ante Dios por lo menos por un carácter común: el pecado original. Una vez superado este escollo, la distinción aristotélica funciona bien y sin ella sería totalmente imposible comprender una institución como la encomienda que es muy representativa del trabajo compulsivo. (Romano, 1996, p. 200)

Se considera, por ende, que es fundamental comprender la procedencia y el trasfondo real de la figura de la encomienda para establecer su función durante la colonia, Romano aborda su investigación desde la antigua Roma al examinar la formula latina "ego me commendo tibi (yo me encomiendo a ti). Naturalmente, esta fórmula individual no tenía ninguna influencia sobre los hijos del individuo que se había encomendado a otro; a la muerte del padre, los hijos no tenían ninguna obligación hacia el encomendado del padre.” Los cambios que los hechos históricos consignaron sobre la figura dieron como resultado la encomienda de tipo colectiva en los pueblos barbáricos, "que se encomendaban a un señor para que los protegiera de mil peligros. La 
encomienda colectiva determina, inevitablemente, su carácter hereditario. Y además, progresivamente, de acto de pedido de una protección se transforma en acto de imposición de esta misma protección”. (Romano, 1996, p. 200)

La evolución histórica de las sociedades europeas partió de pequeños grupos de terratenientes a monarquías absolutas que controlaban vastas extensiones de tierra:

Con el desarrollo de las ciudades europeas, resultado del aumento del comercio y el triunfo de la economía monetaria, y en consecuencia el debilitamiento de la economía señorial y el retroceso del fenómeno de la dispersión feudal, Europa asistió al proceso de consolidación de la unidad nacional y de la formación de la monarquía absoluta como sustituto del autonomismo medieval. Países como Francia, Inglaterra y España, vieron desarrollarse el nuevo estilo de gobierno y Estado. Junto con esto, la época renacentista vio el surgimiento del espíritu científico y la aparición de nuevas corrientes de pensamiento que interpretaron las necesidades de la época en términos de individualismo político, religioso, artístico y lingüístico. Sin embargo, la evolución de los diferentes países europeos, seguirá una dirección de acuerdo con las especificidades de cada uno de ellos. Italia y Alemania no lograrán su unidad nacional sino ya avanzado el siglo XIX, en tanto que España, por ejemplo, consolidará una monarquía absoluta en la cual jugarán rol determinante los sectores terratenientes y la Iglesia católica, luego del quebrantamiento del poder de las ciudades en la batalla de Villalar en $1520(4)$.

Los cambios sociales y culturales, que llegaron con el Renacimiento a finales del siglo XVI, brindaron a Europa un nuevo aire ideológico y económico, así mismo se dieron los primeros avances tecnológicos en materia de comunicaciones; sin embargo, como afirma Sena:

España era una sociedad básicamente campesina, que no había entrado dentro del proceso de modernización capitalista - es decir, la servidumbre campesina continuaba y era un supuesto de la estructura latifundista; de otro lado, la iglesia ejercía un control semejante en la sociedad, y que, además, representaba un papel similar al del sector agrario laico. En otro aspecto los sectores medios -mercaderes, comerciantes- no constituían ya la vanguardia del proceso modernizante- podemos, pues, comprender, la naturaleza de lo que va a ser y los 
rasgos que habrán de caracterizar el proceso de conquista y colonización en el Nuevo Mundo. Todos estos elementos van a constituirse en lo que podemos denominar la estructura señorial, fuertemente cerrada y conservadora de la España de las primeras décadas de los siglos XVI y XVII y en el porqué de su reproducción en la sociedad hispanoamericana colonial, conforme a las peculiares condiciones que se habrán de desarrollar en el continente latinoamericano.(4)

\subsection{El Trabajo Doméstico en la Colonia}

Las guerras sostenidas dentro y fuera del territorio español, habían empobrecido a la naciente monarquía española, que en búsqueda de nuevas rutas comerciales se aventuró a un viaje que cambiaría el mundo tal como era concebido. Al poco tiempo que Cristóbal Colón presentara su propuesta a los reyes españoles, se creó el Derecho Indiano mediante las Capitulaciones de Santa Fe del 17 de abril de 1492, que tenía como fin establecer las bases jurídicas con las cuales iba a gobernar un mundo desconocido. Al respecto, Bernal indica:

El derecho indiano ha sido definido como el conjunto de disposiciones legislativas: pragmáticas, ordenanzas, reales cédulas, provisiones, instrucciones, capítulos de carta, auto acordados, capitulaciones, decretos, reglamentos y todo tipo de mandamientos de gobernación que promulgaron los monarcas españoles o sus autoridades delegadas, así mismo las leyes supletorias y costumbres indígenas que se incorporaron y que se mantuvieron vigentes en América durante los siglos de dominación española. (Bernal, 2007, p. 1)

Estas primeras normas que llegaron al nuevo mundo exhortaban al Almirante Cristóbal Colón a someter a la autoridad de los Reyes Católicos, las islas y tierras, junto con sus habitantes, en el camino a una nueva ruta que les condujera a la India, esto concordaba no solo con las capitulaciones, sino también con el viejo derecho internacional del medioevo, como expone Bernal en su estudio sobre el derecho indiano (2007, p. 1). Pero lo que no se advirtió fueron los atropellos y malos tratos de los conquistadores contra los aborígenes y que generó el reproche de la reina Isabel la Católica, situación que llevó a un nuevo ordenamiento jurídico en donde la Monarca Española, declaró como libres y vasallos de la corona, a los indígenas que habían sido esclavizados y trasladados a la península ibérica por los conquistadores. 
La polémica que se desató, como lo sostiene Bernal:

Sobre la legalidad de los títulos que tenía España para detentar la posesión de las tierras americanas, así como la guerra y los problemas relativos a la libertad, la condición jurídica y el buen tratamiento que debía darse a los indígenas o naturales, estuvieron bajo el escrutinio público; llevándose a cabo análisis y efectuándose reuniones donde los más brillantes y combativos teólogos y juristas de la época discutieron estos temas. (Bernal, 2007, p. 1)

Si bien se tocaba el tema jurídico de los habitantes de las tierras colonizadas por España, fue con la expedición de las Leyes de Burgos en 1512, que se llevó a cabo la transformación del repartimiento de los indios en la encomienda y se instauró el requerimiento (que es la legalización española de los actos de guerra contra los nativos) (2007, p. 3).

Consecuente con el nuevo orden jurídico, social, económico y político, la encomienda indiana adquirió:

Rasgos distintivos en las diferentes regiones de la colonia, pero con un elemento particular en común y es la función <protectora> con la cual se implementaron las primeras encomiendas en la época de la conquista, esta función traía inmersa un rasgo fuertemente distintivo que se difundiría en todo el continente: la evangelización de los indios. Misión evangélica muy noble, sin lugar a duda. Pero -nobleza o menos- el carácter coactivo de la encomienda indiana es mucho más fuerte, más pesado, que la encomienda española. (Romano, 1996, p. 200)

La misión de evangelizar los pueblos indígenas contrasta con la segunda función que contenía la encomienda, la recompensa a los méritos de los conquistadores y pobladores, o sus descendientes. Si bien mediante la promulgación de las Leyes Nuevas en 1542, Carlos V, intentó suprimir la encomienda, "en uno de sus capítulos restableció de forma estricta la prohibición de hacer cautivos a los indios, ni por guerra de conquista ni por rebelión, pues se les debía tratar como vasallos libres" (Domínguez, 1998, p. 512); y la Ley de Sucesión (con la cual los herederos del encomendero adquirían el derecho de continuar su explotación por dos generaciones). 
Los encomenderos hicieron revivir la Ley de sucesión en 1545 y las circunstancias llevaron a prolongar la existencia de la encomienda hasta el siglo XVIII, como lo indica Molino en su investigación donde cita a Colmenares (1973), quien al respecto expone la existencia de varios intereses en fricción:

Por una parte, la Corona necesitaba una fuente de ingresos a la que había renunciado en favor de los conquistadores, como recompensa a su esfuerzo privado; por otra, los sucesores de aquellos querían procurárselos alegando la ascendencia como título para una herencia legítima; así mismo, los recién llegados, muchos de ellos pertenecientes a la Audiencia, hacían uso de sus influencias para conseguir algunas encomiendas, y los mestizos, llevando en sus venas sangre de conquistadores, aspiraban a que su sucesión fuera reconocida. (1976, p. 5)

Se observa como el descubrimiento del nuevo mundo y su sometimiento por parte de la Corona española truncó su proceso de ascenso capitalista en lo que se refiere a técnicas en el desarrollo industrial, ya que a fines del siglo XVI, España se encontraba atrasada industrialmente frente a la evolución del resto de Europa, situación que se agudiza con los fenómenos que se originan por efecto del mismo descubrimiento de las zonas coloniales del Nuevo Mundo. Lo anterior se vio reflejado en la consolidación de una mentalidad parasitaria por parte de los sectores dominantes (explotación campesina por parte del señor, por ejemplo) que encontraron su expresión ideológica y económica en el culto al oro y, posteriormente, en el Descubrimiento se va a cristalizó en la obsesión por el Tesoro Americano.(4)

Es importante examinar como Felipe II, durante su reinado atendiendo la problemática social y política en torno a las colonias delegó a Juan Ovando los asuntos del Nuevo Mundo, Ovando trabajó como Visitador del Real y Supremo Consejo de Indias en 1566 y con su labor pudo concluir sobre la problemática en las colonias se debía a varias razones:

1. La desinformación o información defectuosa y contradictoria a lo que acontecía en las colonias, como consecuencia de los intereses disímiles de los informantes (conquistadores, colonizadores, funcionarios y clérigos) y de la lejanía de los territorios. 2. La excesiva legislación y el desconocimiento que de ella tenían tanto las autoridades que la dictaban en la 
Metrópoli, como los funcionarios que la aplicaban en las indias, y, 3. La extensión de los territorios y la variedad de unos pueblos que se encontraban en diferentes estadios de desarrollo. (Bernal, 2007, p. 4)

Ovando, en cuanto a los resultados arrojados, establece tres procedimientos que se deben llevar a cabo para dar solución a las principales problemáticas que se presentan en las Colonias Españolas. La primera de ellas es la realización de una encuesta a los pueblos aborígenes con el fin de conocer su verdadera situación, la segunda, consiste en adoptar medidas eficaces para dar solución a los pobladores nativos y la tercera y no menos importante, la compilación de la normatividad vigente expedida tanto por los gobernadores de las indias, como la legislación emitida por el gobierno central, para organizar jurídicamente las colonias, esta última solución presentada lleva a la elaboración de la Recopilación de las Leyes de Indias y posteriormente a la Novísima Recopilación de las Leyes de España. (Bernal, 2007, p. 4)

Con la expedición y promulgación de las normas se pretendió establecer tasas tributarias que los grupos aborígenes debían pagar a los encomenderos, quienes abusaban de los mandatos, infringiendo ultrajes a los aborígenes al aumentar no solo el tiempo que debían laborar sino que incrementaban la cantidad de trabajadores que podían tener a su disposición, la corona se vio en la obligación de enviar misiones verificadoras para establecer las condiciones de estas comunidades, y tratar de evitar los abusos que generaron pobreza, altas tasas de mortalidad y por lo tanto deducción en la población indígena.

En lo concerniente a los africanos que llegaron esclavizados por los colonos y sus descendientes, se debe tener clara la naturaleza jurídica del esclavo y el contexto histórico en el cual se desarrolló.

Romero en su documento "Manumisión, ritualidad y fiesta liberal en la provincia de Cartagena durante el siglo XIX" hace referencia en su investigación el análisis que al respecto expone Dockes e indica que:

Clásicamente se ha entendido la esclavitud como la dominación permanente y violenta de personas enajenadas de nacimiento; como el derecho de propiedad que ejerce un individuo sobre otro con sus tres componentes: Usus, Frutus y Abusus. En este sentido, esclavo es aquel 
o aquella persona que se encuentra bajo la dominación absoluta de un amo, por nacimiento, donación, compra, herencia o guerra. (2005, p. 126)

El origen de la palabra esclavo que expone Romero en su documento permite vislumbrar no solo la realidad del esclavo en la colonia, sino el legado que preside al Trabajo Doméstico, al indicar que:

La palabra esclavo (servus) significó inicialmente aquel cuya vida ha sido conservada (servatus) por gracia". Al momento del perdón, al esclavo se le da la vida pero se le retiene la libertad. Biológicamente seguirá vivo, pero socialmente estará muerto. De allí que los historiadores y teóricos de la esclavitud antigua hayan definido al esclavo como un muerto viviente, un muerto en prórroga, un muerto social. Al continuar la investigación se observa como en la actualidad y pese a los avances sociales, políticos y económicos la discriminación se perpetúa en este tipo de labores. (2005, p. 126) (Subrayado fuera de texto original)

Los dueños de esclavos los empleaban para trabajar en los campos, las minas y en el desempeño de labores domésticas en las casas señoriales, al respecto Navarrete en su libro Génesis y desarrollo de la esclavitud en Colombia siglos XVI y XVII, dilucida las labores domésticas en la época de la colonia e indica cuan especializada llegaba a ser:

(E)n el más alto rango estaban las sirvientas personales de las familias ricas, conocidas como mucamas que permanecían finamente vestidas y supervisaban el trabajo del resto de los esclavos domésticos. Después de las mucamas, que hacían las veces de amas de llaves y de cría, estaban los esclavos niños del señor. Estos casi siempre crecían en la casa con los hijos legítimos del amo y les servían como niñeros y compañeros de juego. Al crecer, las niñas eran entrenadas en los oficios de la casa y los niños como pajes o valets. Otros esclavos del servicio domésticos cualificados, de ambos sexos, eran los que atendían la cocina y los que realizaban las compras... En las casas señoriales había por lo menos una esclava propia, en otras más modestas, alquilada, que lavaba, almidonaba y aplanchaba la ropa. En estas casas de las familias más ricas había esclavos o esclavas especializados como lavadores, almidonadores o aplanchadores que trabajaban bajo la supervisión de la mucama. En el rango más bajo de los esclavos domésticos estaban los asignados a tareas como limpiar, llevar el 
agua, atender la mesa, trabajar en la cocina y botar los recipientes con los desechos humanos. (2005, p.188)

A diferencia de los nativos, los esclavos y libertos nunca contaron con una legislación que les brindara algún tipo de protección, en contraposición se encontraban algunos criollos quienes contando con poder económico no podían acceder a cargos que eran solamente otorgados a españoles, generando disgusto entre los criollos; con la traducción e infiltración de la Declaración de los Derechos del Hombre y el Ciudadano de 1789 realizada por Antonio Nariño a la sociedad criolla, se vislumbra como la Teoría ius naturalista alimentó la ideología independista que propendía por la libertad del hombre y los derechos del ciudadano, si bien, se reservó a las altas esferas sociales Neogranadinas, este pensamiento fue el que gestó la lucha de independencia, que conllevó a la desvinculación con la corona española y otorgó la libertad de aquellos esclavos que se unieron a la gesta.

\subsection{El trabajo Doméstico en la Independencia}

Con la independencia de las colonias se inició la pugna interna y no se hicieron esperar los conflictos de intereses entre liberacionistas y esclavistas, que impedían la libertad de los esclavos que habitaban la naciente república. Atendiendo a que los esclavistas consideraban que los esclavos eran objetos, los primeros se resistieron al cambio y crearon dilaciones y distracciones con el fin de retardar el proceso de emancipación y abolición de la esclavitud.

Con la sanción de la Ley 7 del 21 de julio de 1821, sobre la libertad de los Partos, manumisión y abolición del tráfico de esclavos, que tenía como propósito el cambio de paradigma nacional, se contemplaba que los hijos de las esclavas podían adquirir la libertad después de haber cumplido los dieciocho años, pero en la realidad podían pasar muchos años más sin que se concretara el derecho. Los argumentos esclavistas se radicalizaron, más por las connotaciones económicas en cuyo trasfondo se encontraba:

La defensa de un patrimonio y del principio de la propiedad privada que se erigían como obstáculos a toda pretensión idealista de otorgar por razones humanitarias la libertad a los negros. Los amos buscaron defender a sus esclavos de las pretensiones políticas y ante la 
fuerza de los hechos optaron por plantear su libertad, pero con indemnización. (Tovar, 1994. Recuperado de: http://www.banrepcultural.org/node/123392)

Tovar en "La manumisión de esclavos en Colombia, 1809- 1851, Aspectos sociales, económicos y políticos" explica como aun después de expedida la Ley 7 de 1821 la misma no se concretaba, pese a que había reglamentado a su vez:

Las Juntas de Manumisión, para que llevaran a cabo los procesos de liberación, compuestas por el Juez del lugar, el cura, dos vecinos y un tesorero. Igualmente se establecían sus rentas, que en general provendrían de las mortuorias. Los fondos se depositarían al tesorero, nombrado por el gobernador de la provincia. El hecho es que las Juntas no funcionaron y que el número de esclavos manumitidos no fue significativo. El poder de los amos era muy grande como para suponer que se iba a poner en marcha un proceso que afectaba la agricultura, la ganadería y la minería. (1994. Recuperado de: http://www.banrepcultural.org/node/123392)

Como se indicó anteriormente, Tovar expone que para 1839 la esclavitud prevaleció en Colombia pese a que el 21 de julio de este año entraba en vigencia la Ley de Partos y consigo el otorgamiento de la libertad de los hijos nacidos en 1821, pero no fue concedida la manumisión, en parte por la presión de los amos y por otra parte debido a la incapacidad de Gobierno de hacer eficaz la norma, en atención lucha que debía hacer frente contra rebeldes al sur del país.

El fin de la guerra sólo alentaba vías conciliatorias por parte del gobierno que dictó la ley de 29 mayo de 1842, que prolongaba la dependencia de los esclavos otros 7 años mediante el concierto o lo que se llamó el aprendizaje. La ley era en apariencia generosa, pero fue una manera de preservar la esclavitud, ya que vino acompañada de disposiciones represivas como la de tratar a los concertados que se fugaran como vagos y en consecuencia ser perseguidos y enviados a formar parte de los ejércitos de la República.

Estas medidas garantizaban la esclavitud, al menos hasta el 21 de julio de 1846, y fueron acompañadas de otras disposiciones represivas contra la agitación, como las que autorizaban las ventas de esclavos al exterior. La ley de aprendizaje y concierto puso sobre la mesa la cuestión de los malos tratos de los amos, la corrupción de funcionarios del gobierno tolerando 
ventas ilícitas y la alianza de las autoridades oficiales con los esclavistas. Todo ello se tradujo en una desautorización a los jueces que intentaron hacer cumplir las leyes vigentes sobre la manumisión.(5)

Finalmente la "abolición de la esclavitud sobrevino cuando la mayor parte de los afroamericanos eran ya libres. Como los últimos esclavos eran casi todos servidores domésticos, los recién emancipados no se marcharon ni se instalaron como campesinos... se establecieron en el mercado urbano, ya fuere para desempeñar labores especializadas o no”. (Klein, 2013, p. 255)

\subsection{Esclavitud y el contrato de arrendamiento de servicio doméstico:}

Al examinar el legado de la esclavitud en el ámbito jurídico, se advierte como su desarrollo histórico lleva al surgimiento de los contratos laborales de los trabajadores domésticos en la actualidad. El estudio del Derecho Romano, su legado e influencia en el derecho Latinoamericano deja ver la conexión entre la labor de los esclavos y la labor de los hombres libres, en las teorías que examina Alemán (1996, p.31) sobre el surgimiento de los contratos de arrendamientos de servicio, se observa que "el nacimiento de la locatio conductio operarum, surge en la necesidad de regular las prestaciones de trabajo de un hombre libre, bajo una modalidad distinta de aquéllas otras en donde el rasgo dependencia era inminente."Alemán en su investigación analiza la figura jurídica y adopta una posición frente al surgimiento de los contratos de locatio operarum y expresa al respecto que:

Un amplio sector doctrinal opina que el origen de la locatio operarum hay que buscarlo en la locatio conductio rei, y dentro de ésta, en aquella res particular que es el esclavo. Así para Martini el origen de la locatio conductio operarum ésta en la locatio servi, variedad de la locatio conducto rei; esto es, lo mismo que fue arrendando el animal de trabajo para su uso a cambio de una retribución, ocurrió en relación al esclavo. Por tanto, dentro del contexto del derecho romano era viable la instrumentalización del contrato de arrendamiento al trabajador libre que, a pesar de las contradicciones derivadas de la situación fáctica, aparece reglada por un principio de economía de medios. En este sentido, De Robertis afirmaba su derivación directa del arrendamiento de las cosas. 
De otro lado, Elguera sostiene que el contrato de arrendamiento toma su forma de la locatio conductio rei institucionalmente protegida por el pretor, con singularidad: la locatio de cosas muebles -esclavos, animales y objetos-. Posteriormente, esta protección se extiende a las cosas inmuebles y también a los supuestos de arrendamiento de obra -locatio conductio operis-, esto es, para realizar un trabajo determinado en una cosa entregada a estos efectos. Tenemos así dos formas de arrendamiento que contempla el derecho: locatio conducto rei y locatio conductio operis. Sin embargo, el trabajo de un hombre libre prestado en forma indeterminada, sin referencia a una obra específica que ejecutar es una modalidad que no se contempla en el aludido contrato. (1996. p. 32)

En definitiva, opinamos que el origen de la locatio conductio operarum está en el arrendamiento del esclavo; locatio conductio que nace de la locatio conductio rei, consiste en la entrega de una cosa para su uso y disfrute a cambio de una retribución, restituyéndose a la terminación del contrato. En efecto, entre las cosas que se daban en arrendamiento por el dominus se encontraba el esclavo, que era prestado a otra parte a cambio de una retribución. En virtud de esta singularidad permuta contractual, el dominus recibe la merces y el otro contratante disfruta de la prestación de una servicios, con la insoslayable obligación de pagar y restituir a su término. Por tanto, la locatio conductio resultaba idónea para la prestación de servicios retribuidos de un hombre libre, dando lugar, en este caso, al nacimiento de locatio conductio operarum. (1996. p. 39)

Lo expuesto por Alemán permite vislumbrar como del arrendamiento de la res (animales, cosas y esclavos) del derecho romano, surgen los contratos de arrendamiento de servicio de los hombres libres, así mismo respecto a los contratos de trabajo en la actualidad y el precedente jurídico de los mismos, Martínez y otros en su investigación expresan: "el contrato de trabajo no surgió de la nada, sino que es heredero directo del viejo contrato civil de arrendamiento de servicios” (2006. Pág. 57). Lo anterior lleva a uno de los precedentes jurídicos del derecho laboral colombiano y al observar el estudio de Batiza se logra establecer e1 vínculo entre el derecho romano y el colombiano por medio del derecho francés:

Según los tratadistas del derecho civil francés, las fuentes principales en la redacción del Código Civil fueron el derecho romano, el derecho consuetudinario, las ordenanzas reales y 
las leyes de la revolución; según estos autores, el derecho romano se utilizó sobre todo en materia de propiedad, obligaciones, diversos contratos y régimen total. (1990. Pág. 456)

Este tipo de contratos de arrendamiento de servicios cumplían con características específicas como lo indica Neves, al ser contratos de tipo civil tienen características particulares:

Las partes se "someten a sus valores de igualdad y libertad de los contratantes, que les han permitido establecer los derecho y obligaciones que les corresponden. El problema se presentó cuando se aplicaron dichos valores a relaciones en las cuales la disparidad era manifiesta, la cuestión no fue tan grave en los tiempos del derecho romano e incluso en las primeras décadas de aplicación del Código Civil Francés de 1804, porque la población que realizaba un trabajo por cuenta ajena y libre era reducida, respecto de quienes se encontraban bajo la esclavitud o la servidumbre. Pero con la Revolución industrial la situación se modificó radicalmente. La utilización del contrato de arrendamiento de servicios empezó a masificarse. Allí se puso en evidencia que la inserción de esta figura en el Derecho Civil, conducía a la regulación de la relación laboral individual por la voluntad unilateral del acreedor de trabajo y, por tanto, al establecimiento de condiciones deplorables. (Neves, 2007. Pág. 27)

Al abordar el contrato de arrendamiento de las mucamas o sirvientas en Colombia, que se configuraría como el precedente jurídico para la regulación de las relaciones laborales de los trabajadores del servicio doméstico en el país, se observa que este legado se remonta al Código Francés o Napoleónico del 21 de marzo de 1804,transmitido a Latinoamérica a través de la traducción y redacción efectuada por Andrés Bello para la elaboración del Código Civil Chileno; y adoptado en Colombia en 1873 mediante la Ley 84.El contrato de arrendamiento de criados domésticos se trataba de una relación de asalariado bajo contrato entre amo y criado que se transmitió desde el código de Napoleón, hasta la herencia introducida en la regulación colombiana; atendiendo a la naturaleza jurídica del contrato civil se podría decir que eran contratos de prestación de servicios, lo cual se observa de la lectura del artículo 2045 del Capítulo VII de la Ley 84 de 1873 del arrendamiento de criados domésticos, que expresa: "En el arrendamiento de criados domésticos una de las partes promete prestar a la otra, mediante un salario, cierto servicio determinado por el contrato". (Como se cita en Avella, 2010, p. 28) 
Este tipo de contratos entraron en vigencia veintiún años después de la abolición de la esclavitud en la República lo cual demuestra el atraso jurídico en el que se encontraba el país, Means en su investigación indica que: "El sistema legal colombiano del siglo XIX se puede clasificar de subdesarrollado porque en ciertos aspectos estaba retrasado con respecto al de Francia o Inglaterra en ese mismo siglo." (Pág. 12) Pero para Means la definición de subdesarrollo jurídico se debe establecer en relación con la norma ideal, por cuanto un sistema legal plenamente desarrollado jamás ha existido. El subdesarrollo afecta la aplicación de las normas formales a la realidad legal, siendo mayor la divergencia en países latinoamericanos que en Europa y Estados Unidos. "Unos objetivos difíciles y una realidad social y económica inmanejable han contribuido a la divergencia, pero parte de la responsabilidad se debe atribuir al subdesarrollo jurídico.” (Means. 2011. Pág. 13)

Lo anterior conllevó a la continuidad de las estructuras sociales que se mantienen hoy en día como lo advierte Vargas quien expone:

Lo que se encuentra en la literatura es que esta forma de trabajo mantiene las estructuras de dicho tipo de esclavitud: continúa siendo una actividad marginal y con retribuciones precarias. Por esta razón, varios autores coinciden en señalar que la esclavitud es la precursora de lo que se conoce como el servicio doméstico. (Vargas, 2011, p. 15)

Lo afirmado por Vargas se consolida con la investigación sociológica que realiza Barragán, respecto al orden social en Colombia, entre los siglos XVIII y XIX, espacio de tiempo en el cual la sociedad colombiana pasa de la colonia a la República, este análisis permite corroborar los orígenes de la estigmatización social de los trabajadores que desempeñan labores domésticas al considerar que durante la transición "el capital económico no tenía la suficiente fuerza como garante de distinción social, y donde ésta estaba fundamentada en un orden aristocrático y cortesano que entraba en tensión con el ideal democrático de igualdad y con el lento ascenso de lo burgués, dar forma a un capital simbólico entorno a lo nacional permitía posicionarse como élite.” (Como se cita en Barragán, 2007, p. 240)

En el análisis que lleva a cabo Barragán advierte que: 
El orden racial derivado de la Colonia, se propone como orden social y se establece una continuidad entre la Colonia y la República, aunque algunas leyes modificaron estas divisiones, en las prácticas sociales se evidenciaban de manera latente. Esta división social en las prácticas sociales se concebía como natural, es decir en el proceso social cada grupo aceptaba de forma inconsciente. En la República, su papel en el orden social, el cual reproducían. Se presentaron resistencias populares, dado a que los dominantes se reconocían en el orden, pero no ocurría lo mismo con los dominados.” (2007, p. 240)

Esto conlleva a que continuidad de los procesos sociales, que identifica determinadas labores con un grupo particular de persona y a su discriminación.

Queda claro que la historia ha plasmado alrededor de las relaciones labores domésticas, la estigmatización, el desconocimiento y el abandono que ha incidido en todos los ámbitos sociales, en la política y la economía al igual que al interior de los hogares donde se desempeñan estas labores, pero lo más delicado es la falta de protección y regulación que a través del tiempo ha tenido este tipo de relaciones laborales. Aun cuando surgieron a nivel mundial toda serie de luchas en pro de los trabajadores, estas giraba en torno a la explotación laboral por cuenta de la revolución industrial y comercial donde se sometían hombres, mujeres y niños a largas jornadas laborales, abusos y enfermedades a cambio de salarios de miseria, pero fueron los niños y las mujeres quienes sufrieron en mayor medida de los abusos por parte de los industriales.

\subsection{El Trabajo Doméstico y las teorías económicas y sociológicas}

A partir del pensamiento marxista se desarrollan las Internacionales Obreras, que refuerzan dentro de sus políticas el mejoramiento social y luchan por la equidad, lo cual no solo llevó al incremento de la organización obrera, sino que así mismo conllevó a la creación de movimientos políticos que adquirieron poder en Europa y Norte América, a tal punto, que la iglesia católica vio en estos grupos una gran amenaza para las creencias y pensamiento católico.

En razón a lo anterior, tras varios intentos fallidos de crear grupos de trabajadores que fueran afines al ideal de Roma, el Papa León XIII, expidió en 1891 la encíclica Rerum Novarum, que pretende ilustrar la situación creada por la masificación del socialismo y la difícil 
condición económica de los trabajadores asalariados. El Papa León XIII realizó un análisis pormenorizado de la "solución socialista" al problema de la pobreza obrera. (Araya, 1998, p.171-173).

La Rerum Novarum aborda de un modo más sistemático los problemas del socialismo. La condena es absoluta y se basa en que el socialismo niega la propiedad privada (y por lo tanto daña al propio trabajador), siendo este un derecho fundamental de la misma naturaleza humana. La familia, como organización natural, queda destruida con la colectivización total de la propiedad. Insiste, también, en que es inadmisible y contrario al derecho natural la absoluta igualdad entre los hombres. (Gay, 2002, p. 59)

Pero ¿debían sentir temor los gobiernos y los capitalistas, que habían amasado sus fortunas a expensas del trabajo mal remunerado sustentado en las teorías económicas de Adam Smith, quien establecía el pago de salarios en observancia de los precios del mercado, fijados por la oferta y la demanda? Para Karl Marx y Friedrich Engels la lucha entre las clases sociales si era posible, de hecho era el mecanismo para llegar a la igualdad social.

\subsection{Mundialización y Globalización de los Derechos Laborales}

Los precedentes históricos que llevaron a la creación de las actuales organizaciones que propenden por la protección de los trabajadores, surgen de las necesidades sociales y económicas que trajo consigo la revolución industrial y las enormes concentraciones obreras, que vieron afectadas sus condiciones de vida y de trabajo. El industrial escocés, Roberto Owen, a principios del siglo XIX, presintió la necesidad de una reglamentación internacional del trabajo; así mismo, Daniel Legrand y el diputado suizo Frey, vieron la necesidad de reglamentar el tema en particular. Simultáneamente emerge en la sociedad el interés respecto a los problemas del trabajo, por cuanto se decía que tenían relación directa con el bienestar de gran parte de la población y con la paz social. (Poblete, 1958, p. 65)

Después que los países industrializados se percataran del poder que estaban adquiriendo las organizaciones de trabajadores, se llevó a cabo la primera conferencia y los parlamentos de algunos países europeos aprobaron las primeras leyes que salvaguardaban los derechos sindicales de los trabajadores, se hizo exigible la indemnización por accidentes de trabajo y se instituyó los 
seguros sociales, pero los principales logros llegaron con la creación de la Asociación Internacional para la Protección Legal de los Trabajadores, en Bélgica en el año 1901, al lograr el apoyo de juristas, sociólogos, profesores y hasta del gobierno suizo, este último fue el que convocó a la Conferencia Diplomática en Berna donde se expidieron los primeros convenios internacionales, (ibídem) esta Asociación fue el precedente para la constitución de la OIT en 1919, mediante el Tratado de Versalles, como una parte de la organización de la Liga de las Naciones. Así mismo el surgimiento de constituciones sociales tales como la Constitución Política del Estado de Querétaro Arteaga de 1917 en México y la Constitución de Weimar de 1919 en Alemania, son en conjunto el precedente histórico para la defensa de los derechos de los trabajadores.

Se observa en el texto del tratado de Versalles la naturaleza de la creación del organismo que establecería los parámetros mundiales para la conducción y mejoramiento de las relaciones con el proletariado, Poblete cita la Parte XIII del Tratado de Versalles que reza:

Considerando, que la paz universal y permanente no puede fundarse sino sobre la base de la Justicia Social; considerando, que existen condiciones de trabajo que implican un gran número de personas la injusticia, la miseria y las privaciones, lo cual engendra un descontento tal que pone en peligro la paz y la armonía universal; y considerando, que es urgente mejorar dichas condiciones, por ejemplo, en lo concerniente a la reglamentación de las horas de trabajo, a la fijación de la duración máxima de la jornada y de la semana de trabajo, al reclutamiento de la mano de obra, a la lucha contra el paro, a la garantía de un salario que asegure condiciones decorosas de existencia, a la protección del trabajo contra las enfermedades generales y profesionales y los accidentes del trabajo; a la protección de los niños de los adolescentes y de las mujeres, a las pensiones de invalidez y vejez, a la defensa de los intereses de los trabajadores ocupados en el extranjero, a la afirmación del principio de libertad de asociación sindical, a la organización de la enseñanza profesional y técnica, y a las otras medidas análogas. -Considerando que la no adopción por una nación cualquiera de un régimen de trabajo realmente humano, pone obstáculos a los esfuerzos de las demás naciones deseosas de mejorar la suerte de los trabajadores de sus países... (Poblete, 1958, p. 67) 
Al respecto Ordoñez expone como las motivaciones de tipo político y económico llevaron a la creación de la OIT en consideración a que si no se mejoraba su situación, los trabajadores, cuyo número crecía continuamente debido a la industrialización, darían origen a conflictos sociales, que podrían desembocar en una revolución, lo que indica que en principio la preocupación de los Estados radicaba no en las necesidades de proveer bienestar a los trabajadores, sino como mecanismo de evitar la sublevación y la perturbación del nuevo orden social. (1998, p. 18)

En Colombia los primeros impulsos para la creación de una legislación se registraron en los años entre los años de 1915 a 1930, dicha normatividad se planteó para la configuración de aspectos concernientes a la seguridad en el sitio de trabajo, la protección de los trabajadores, la prevención y solución de conflictos laborales temas que no solo le concernían al Estado colombiano sino que adquiría un papel importante en la configuración de un nuevo orden mundial. Su estudio y análisis consolidaron con posterioridad la creación de un organismo internacional capaz de brindar directrices que mejoraran la calidad de vida de los trabajadores y que luchara contra las peores formas de trabajo en el mundo. (Avella, 2010, p. 23)

Con la creación de la OIT en 1919, se dieron los primeros seis convenios, que serían ratificados por Colombia hasta el año de 1933 y que exigían el avance en los derechos de los trabajadores, estos convenios reglamentaron las horas de trabajo, lo relativo al trabajo nocturno de las mujeres, a la protección de la maternidad, se fijaba la edad mínima de admisión de los niños y su trabajo nocturno en la industria.

Cabe resaltar el análisis que respecto de estos primeros convenios hace Murray quien sostiene que:

El modelo de trabajadora que subyace a los primeros convenios de la OIT difería del trabajador típico. La trabajadora no era considerada un ciudadano como tal, ni en el trabajo ni en la sociedad en general. Su actividad fuera del contexto laboral la había encerrado en el ámbito doméstico no regulado. Además, a diferencia de los hombres, las mujeres no tenían derecho a reivindicar la adaptación de su trabajo a las necesidades familiares, ya que esos convenios estaban concebidos en términos de prohibición. (Rodgers, 2009, p. 125)

En cita que Avella (p. 30) realiza de Latorre se destaca que en agosto de 1919 se llevó a cabo en Colombia el Primer Congreso Jurídico Nacional, del cual trascendió un proyecto de ley que 
abarcaba el contrato de trabajo que incluía sistemáticamente distintos aspectos de la relación laboral: el contrato individual de trabajo, el contrato de aprendizaje, los trabajadores rurales, los sirvientes domésticos, el trabajo femenino e infantil, el salario, la jornada de trabajo y los descansos, y obligaciones de los patrones y los dependiente. Aun cuando el proyecto fue sometido a consideración de la Comisión Especial de Asuntos Sociales del Senado y se logró definir sobre la "Naturaleza del trabajo en sus diversas formas; varia condición de los trabajadores según el sexo, la edad, lugares y tiempos; carácter del salario; accidentes del trabajo; derechos y deberes recíprocos de patronos y obreros; descanso del trabajo; huelgas y paro; condición especial de los trabajadores de las fincas rurales y haciendas; educación obrera y campesina; instituciones de provisión, etc.”; no se expide un código laboral.

Contrario a lo que se podía esperar en el avance de las leyes laborales, el gobierno del Presidente Suarez propuso solamente el reconocimiento legal del derecho a la huelga, advirtiendo el precedente jurídico mexicano (la Constitución de Querétaro) así como los hechos que acontecían en el país como el aumento del número de sindicatos activos y lo que denominaría Urrutia como "la primera serie de grandes huelgas en la historia del país" que dio inicio en Bogotá en el año de 1916, cuando los trabajadores de forma espontánea iniciaron una manifestación que finalizó con varios trabajadores muertos y al menos quinientos fueron detenidos, esto desató una serie de huelgas en ciudades como Cartagena, Barranquilla y Santa Marta, donde también se presentaron perturbaciones del orden público. (Ibídem)

Las bases sindicales de las décadas de 1930 y 1940 reflejaban la debilidad de la industria moderna y el bajo peso de un proletariado estable dentro del conjunto de las clases trabajadoras. El pueblo urbano era un híbrido de familias de propietarios de pequeños almacenes y tiendas de comestibles, o de modestas casas en las que alquilaban habitaciones; de artesanos entre los que sobresalían sastres y modistas; panaderos, carpinteros y zapateros. Dentro de estos y otros oficios había dueños de almacenes o de talleres con varios obreros o con trabajadores a domicilio, que elaboraban el producto para diferentes patronos. Muchos trabajadores urbanos, hombres y mujeres, eran campesinos inmigrantes de primera generación, cuya baja calificación no era impedimento para engancharse en la industria de la construcción, o en talleres y fábricas no mecanizadas, y en los servicios, incluidos el servicio doméstico y la prostitución. (Palacios, 2005, p. 542) 


\subsection{Regulación y Reivindicación de los Derechos de los Trabajadores Domésticos.}

Mientras en el mundo y en Colombia se desarrollaban los derechos de los trabajadores de las industrias y el comercio, otros grupos fueron pasados por alto, tal como con sucedía con las personas que desarrollaban trabajos domésticos; considerando que la unión y sindicalización de los trabajadores de la industria y el comercio se facilitó en razón a su entorno laboral, la unión y sindicalización de los trabajadores de servicios domésticos siempre fue y será una tarea compleja, las condiciones particulares de su entorno laboral les ha dificultado la comunicación con sus pares y la unificación para la demandadle mejoramiento de sus derechos laborales, el aislamiento al cual son sometidos les impide, de hecho, el conocimiento pleno de sus derechos.

En la Conferencia de Ginebra de 1927 se introdujo el Convenio 024 relativo al seguro de enfermedad de los trabajadores de la industria, del comercio y del servicio doméstico, cuya entrada en vigor fue el 15 julio 1928.Si bien en Colombia se aprobó el Convenio 024, por medio de la ley 129 del 23 de noviembre de 1931, este solo fue ratificado hasta el año de 1933 con la aprobación de los primeros veintiséis convenios de la Organización Internacional de Trabajo.

En 1939 fue el año en que la OIT depositó "mayor interés en la promoción de la igualdad de la mujer, no sólo debido al creciente activismo de las organizaciones feministas, sino también a los cambios en cuanto a la incorporación de la mujer a la población activa; este movimiento llevó al desarrollo de estadísticas que permitieron analizar el trabajo femenino y el trabajo doméstico entre otros". Hasta este año se vuelve a hablar sobre trabajo doméstico y se revelan estadísticas, pero este se hizo solo entorno a la mujer, atendiendo los estereotipos sociales y de género de la época. (Rodgers, 2009, p. 64)

En Colombia se observa que "los sindicatos fueron creados, controlados o cooptados por los dos partidos, el clero y la izquierda marxista. En las grandes empresas textileras de Medellín los mismos empresarios y el clero atendieron el frente sindical. Las endebles maquinarias sindicales que representaron a los trabajadores en el plano de las reivindicaciones salariales y gremiales, pero no consiguieron inducirlos a cambiar sus lealtades políticas y a votar por tal o cual partido o candidato". (Palacios, 2005, p. 543) Un claro ejemplo del pensamiento del gobierno respecto al sindicalismo se ubica en el estudio que realiza la Comisión Especial de Asuntos Sociales del Senado que señaló: 
Aquí es donde campean con todo esplendor las enseñanzas del gran pontífice de los obreros, León XIII, cuyas encíclicas sobre la condición de ellos y organización de la democracia cristiana o cristianismo social contienen, aun según testimonios solemnes de escritores heterodoxos, la última, la más sabia y fecunda palabra de estas gravísimas cuestiones morales económicas. (Como se cita en Avella, 2010 p. 31)

A medida que en el mundo progresan los derechos de los trabajadores, surgen nuevas medidas que abarcan otros aspectos sociales de las relaciones laborales, de tal forma que para 1944 con la declaración de Filadelfia se "exponen diez objetivos programáticos de la OIT que abarca la mayoría de los elementos esenciales del progreso social: pleno empleo y elevación de los niveles de vida; satisfacción en el puesto de trabajo; formación; política salarial; derecho de negociación colectiva; seguridad social; protección de la seguridad y la salud de los trabajadores; protección de la infancia y de la maternidad; alimentación, vivienda, medios de recreo y cultura adecuados e igualdad de oportunidades educativas y profesionales". (Ordoñez, 1998, p. 15)

Las circunstancias sociales, políticas y económicas de Colombia en los años cuarenta rodearon la llegada del "segundo auge del desarrollo industrial capitalista y que definió lo que fue la crisis del frente laboral de la época. El crecimiento industrial basado en la importación de infraestructura industrial había elevado la composición orgánica de capital y provocando la ampliación de la clase trabajadora a niveles entonces desconocidos.” (Sousa y García, 2004, p. 229) Por su parte, Avella cita un recuadro de Silva Romero de 2005 que como se puede observar contiene el esquema del decreto 2350 de 1944, en ella desembocaron dos temas centrales el contrato de trabajo y la jurisdicción especial del trabajo, este sentó las bases para la Ley 6 de 1945. 
Tabla 4.

Avella cita a Silva Romero. 2010 (p. 62)

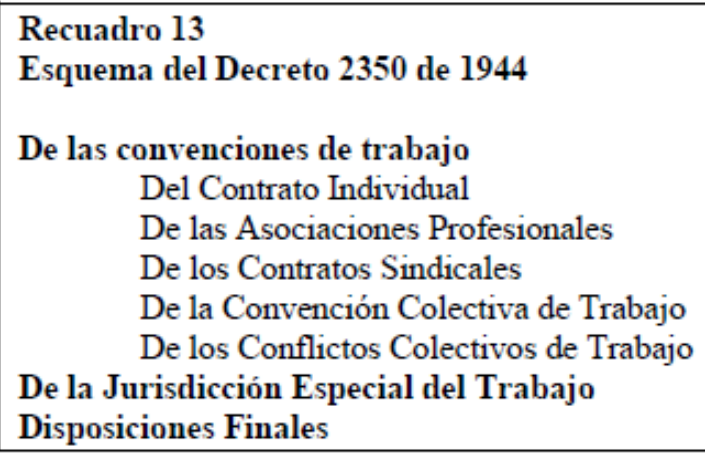

Fuente: Silva Romero (2005)

Indica Avella, que este fue un memorándum de los compromisos internacionales en materia laboral que había adquirido Colombia que obligaba la modernización de la legislación y bajo las facultades que otorga el estado de sitio, se expidió, una legislación que no había podido consolidarse en el congreso en tan corto tiempo. El Decreto Ley 2663 del 5 de agosto de 1950 preservó el espíritu orientado a favorecer la convergencia de los intereses del capital y del trabajo, que había caracterizado aquellos debates parlamentarios. (2010, p.62)

Los conflictos sociales no se hicieron esperar ante el aumento del desempleo a causa del desplazamiento de población rural a las ciudades por cuenta de la violencia bipartidista, que diera inicio en el país a mediados de los años cuarenta y que se agudizara con el Bogotazo del 9 de Abril de 1948. La sobreoferta laboral y la explotación, intensificó la confrontación capitaltrabajo asalariado, engendrándose en la sociedad la necesidad de una justicia laboral que dirimiera los crecientes conflictos obrero-patronales que desestabilizaban el sistema social. (Sousa y García, 2004, p. 229)

En Riesgos laborales, los precedentes jurídicos se remontan a la ley 57 de 1915 concerniente a las reparaciones por accidentes de trabajo, esta ley, según su artículo 10 de la misma, solo cobijaba a trabajadores específicos de las industrias y empresas como lo eran "las empresas de alumbrado público, de acueductos públicos, de ferrocarriles y tranvías, de licores, las fábricas de fósforos, de arquitectura o construcción de albañilería en que trabajen más de quince obreros, las minas y canteras, de navegación por embarcaciones mayores industriales servidas por 
maquinaria con fuerza mecánica, y las obras públicas nacionales y se estableció que los conflictos jurídicos serían de conocimiento de los jueces municipales sin importar la cuantía”.

Cabe resaltar lo revolucionaria que fue para la época esta ley por cuanto indicaba en qué casos admitía la responsabilidad de los empleadores, que tipo de accidentes amparaba, así mismo la norma contempla el tipo de daño y la compensación que ha de recibir el empleado por accidente de trabajo o sus herederos en caso de muerte. Esta norma es modificada por la ley 133 de 1931, seguida por leyes tales como la 37 de 1921 y la 32 de 1922 en las cuales el Estado prevé la necesidad que tienen las empresas industriales, agrícolas o de comercio de adquirir seguros colectivos obligatorios para cubrir los trabajadores. En atención a los problemas de sanidad de los trabajadores se requirió crear mecanismos para la protección de la salubridad y de las condiciones de vida de los trabajadores, por lo tanto se crea la Dirección General de Higiene para desempeñar el rol de supervisión, en observancia de la ley 46 de 1918, esta norma serían los precedentes jurídicos en Colombia de la salud ocupacional; y que más adelante sería reformada por las ley 61 de 1936, seguida de la ley 23 de 1940.

De los últimos derechos de los trabajadores que fueron desarrollados por la legislación colombiana se ubica el derecho colectivo, como expone Marcucci:

El derecho individual surge primero en el campo del derecho laboral y se apoya en principios del derecho común. El derecho colectivo es posterior y desciende del derecho común al público. En Colombia, este derecho vino a surgir legislativamente con la ley 78 de 1919 sobre los conflictos colectivos; con la ley 21 de 1920 sobre conciliación y arbitraje y, posteriormente, con la ley 83 de 1931 sobre organización de los sindicatos. (2005, p. 309)

En atención a lo anterior se hace alusión al pronunciamiento de la OIT del Informe IV de la Conferencia Internacional del Trabajo $N^{\circ} 99$ del 2010, que evidencia las dificultades que se han sostenido en el tiempo al establecer normativas que salvaguarden los derechos de los trabajadores domésticos:

Como hoy día a los trabajadores domésticos no se les suele reconocer una condición jurídica clara en la legislación del trabajo, se tiende a excluirlos de facto de las normativas oficiales y de su cumplimiento. Esto no presupone en modo alguno que su vida laboral carezca de estructura y control reglamentario. Antes bien, su vida y su trabajo están regulados por 
normas privadas estrictas relativas al trabajo desempeñado en la casa donde reside el empleador. Estas normas varían significativamente según el contexto cultural y son responsables de que los trabajadores domésticos figuren entre los más marginados, para los cuales el trabajo decente suele ser una aspiración difícil de alcanzar. Por consiguiente, la regulación del trabajo doméstico debe referirse a los empleadores individuales, las agencias de colocación y los beneficiarios de los cuidados, así como a los países de origen de los empleados domésticos y los países que los reciben. La actividad normativa debe abarcar a esta gama de agentes y políticas. (OIT, 2010, p. 12)

Lo expresado por la OIT se ajusta a los acontecimientos socio-jurídicos colombianos, ya que aun cuando se expidió normatividad para la protección de los derechos de los trabajadores, quienes desarrollaban labores domésticas se encontraron en total desventaja, atendiendo a las condiciones especiales de su sitio de trabajo y se les excluía de algunos derechos o prestaciones de tipo social y económico.

Se establece al estudiar el derecho colectivo de los trabajadores del servicio doméstico, que este por lo general estuvo influenciado por el sindicalismo católico, como se corrobora con el primer intento de consolidación del Sindicato del Servicio Doméstico, el cual actúo bajo la protección de la Obra Nazaret creada por frailes dominicos, atendiendo los designios del Papa León XIII en su Encíclica Rerum Novarum.

El 25 de marzo de 1938, el fraile dominico fray Eliécer Arenas Santos, solicitó el apoyo de varias mujeres que deseaban trabajar al servicio de la iglesia católica y quienes dieron inició formalmente a la Obra Social Nazareth y al Sindicato del Servicio Doméstico, que tenía como fin acoger a las trabajadoras domésticas que se encontraban cesantes; les ayudaban a encontrar trabajo, atendían a quienes se encontraban enfermas y, por último, ofrecían asilo a las ancianas. Los objetivos iníciales eran "laborar de modo permanente por el bien espiritual de las mujeres consagradas al servicio doméstico, atendiendo a su formación moral y religiosa, así como también al mejoramiento en todo sentido de su condición personal y de sus capacidades profesionales." (Plata, 2013, p. 33)

En el estudio realizado por Plata, sobre el sindicato del Servicio Doméstico y la Obra Nazareth, se expone como aun cuando la organización tenía el rótulo de "Sindicato", esta no se podía concebir como reivindicativa o emancipadora. No se luchaba por la búsqueda de una 
conciencia de clase entre las empleadas o la exigencia de sus derechos, sino que se resaltaba el valor del sufrimiento ofrecido a Dios como método para ganar el cielo y salvar a los pecadores, así mismo se enfatizaba en la sumisión de la trabajadora frente a la autoridad. Políticamente, el sindicato del servicio doméstico tuvo poca influencia. Sobre todo, por el tipo de personas que lo componían: mujeres de los sectores más humildes de la ciudad y del país, con muy poca formación académica. Las perspectivas del sindicato nunca fueron más allá de agrupar para fraternizar, educar en la doctrina cristiana y generar algún tipo de bienestar. Finalmente las disputas al interior de la Obra Nazaret y el posterior abandono del Sindicato lo dejo sin apoyo, que conllevó a su disolución. (2013, p. 34)

A partir de los años cuarenta aumenta el reconocimiento de derechos advirtiendo las transformaciones sociales ocurridas entorno de los conflictos laborales de la mitad del siglo XX. La Ley 6 de 1945 dictó:

Disposiciones sobre el contrato individual, a término fijo o a término indefinido; la jornada de trabajo; el salario mínimo legal; la remuneración de los días de descanso obligatorio; las indemnizaciones por accidentes de trabajo y enfermedades profesionales a cargo del patrono; las vacaciones de quince días por año de servicios; el auxilio de cesantía; el derecho de los trabajadores a asociarse libremente; la constitución de sindicatos de empresa, gremiales y de oficios varios; la definición del sindicato de empresa como base de la organización sindical y la restricción para que no exista más de un sindicato en una misma empresa; el establecimiento del fuero sindical; la convención colectiva; la definición de servicios públicos en los que se prohíbe la huelga; la institución de la Jurisdicción del Trabajo. (Avella, 2010, p.50)

Si bien la ley 6 no tocó el tema de los trabajadores del servicio doméstico, en el artículo 58, de su decreto reglamentario 2127 de 1945, se indicó que posteriormente se crearía un decreto separado que habría de regular entre otras modalidades de trabajo del servicio doméstico. Se resalta el hecho que incluso cuando se había estudiado en los diferentes proyectos de ley la regulación del trabajo doméstico, fue hasta el siguiente año con la expedición de la ley 90 de 1946 cuando se tendría en cuenta en una ley de la república, a los trabajadores del servicio doméstico. 
Como se aprecia históricamente en Colombia, la regulación laboral ha obedecido más a un mecanismo para evitar el conflicto y las manifestaciones de los trabajadores, así como para ejercer el control social de la población, al imponer leyes que en la mayoría de los casos buscan coartar el derecho de los ciudadanos a la libertad de expresión y los derechos colectivos de los trabajadores, tal es el caso del Decreto002 de 1918 expedido por el gobierno nacional bajo Estado de sitio, con el cual se prohibieron las reuniones de cualquier comité de huelga permanente.

Palacios expone al respecto que:

La idea según la cual las movilizaciones políticas representaban una amenaza para el sistema social y ponían en peligro el crecimiento ganó terreno entre dirigentes políticos y empresariales. Surge el autoritarismo político y un limitado nacionalismo económico que converge en formas de gobierno dictatoriales, inspiradas en el etéreo binomio Cristo y Bolívar. Apoyado en el Estado de sitio, se instituyó un nuevo modelo económico, más allá de la crítica ciudadana, de la fiscalización del congreso y de los funcionarios. Así mismo los gobiernos neoconservadores centraron sus políticas laborales en el papel benéfico del Estado y en la convivencia, pero al mismo aumentó la represión política al sindicalismo y la manipulación de las burocracias sindicales, la estigmatización de comunistas de los sindicatos, los relegaba y marginaba. (Palacios, 2005, p. 590)

Este fue el contexto histórico donde se desarrolló el decreto ley 2663 del 5 de Agosto de 1950, la desigualdad social y jurídica de los trabajadores es evidente en el articulado, un claro ejemplo es el artículo 171, con el cual se excluye el trabajo doméstico de la prohibición por medio de la cual se restringe el trabajo nocturno de menores de diez y seis (16) años, más adelante se excluye a este grupo de trabajadores del derecho a recibir remuneración por trabajo dominical, se exoneraba al empleador del pago de las indemnizaciones por accidente de trabajo y del auxilio monetario por enfermedad no profesional.

Como lo indica la OIT "pese a la inclusión expresa de los trabajadores domésticos en la legislación de muchos países, el trabajo doméstico remunerado sigue siendo prácticamente invisible como forma de empleo. Asociado como es el caso a nociones de familia y de trabajo no productivo, se considera que la relación de trabajo no «cuadra» claramente en el marco general 
de la legislación laboral existente, pese a derivarse de la relación entre «el amo y el sirviente». (2010, p.13)

Tal como acontecía en la sociedad Colombia, el análisis que lleva a cabo la OIT, permite advertir que aun cuando en algunos países se constituían los derechos de los trabajadores, el hecho de no expresarse específicamente sobre un grupo de trabajadores, conllevaba a la exclusión del mismo, lo cual genera que dichos grupos segregados pasen inadvertidos frente a la mayoría de los instrumentos legislativos. Caso como el que sucede al no ser contemplada la protección jurídica de las relaciones laborales de los trabajadores del servicio doméstico, quedando desamparados; porque al ser consideradas la norma, se justificaba la no protección de los derechos laborales por la no especificación normativa. (OIT, 2010, p.19)

Mediante la Resolución adoptada el 30 de Junio de 1948, en la Conferencia internacional del Trabajo, Sección 31, sobre las condiciones de empleo de los trabajadores domésticos, se puede ver como se insta a incluir en la agenda el tema referente a las condiciones de este grupo de trabajadores para su discusión, puesto que en la convención de Montreal de 1946, concerniente a la restricción del trabajo nocturno a los niños y jóvenes en trabajos no industriales, se excluye a los trabajadores del servicio doméstico, sin estudiar a fondo el estatus y condiciones de empleo de los trabajadores del servicio doméstico.

Pero fue hasta la Conferencia de 1965 donde se adoptaron medidas al respecto, en consideración a los resultados de la resolución sobre las condiciones del Trabajo Doméstico, de la segunda Conferencia Regional Africana, de la Organización Internacional del Trabajo, de 1964, en atención al estudió a fondo sobre las condiciones de empleo de los trabajadores domésticos, basados en las conclusiones de la Reunión de expertos en situación jurídica y condiciones de empleo de los trabajadores domésticos.

En la resolución de 1965 sobre condiciones de empleo de los trabajadores domésticos, como primera medida la Organización Internacional del Trabajo insta a los Estados Miembros a hacer todo lo posible para promover el establecimiento de medidas de protección a favor de los trabajadores domésticos, entre otros fines, para regular el horario de trabajo y demás condiciones de empleo, así como la formación profesional de estos trabajadores. Así mismo, la OIT opta por intensificar los estudios e investigaciones sobre los problemas de los trabajadores domésticos, se solicita a los Estados Miembros un amplio informe sobre las disposiciones legales que se refieren 
a los trabajadores domésticos, entre otras, las que tenían por objeto la adopción de un instrumento internacional para su protección.

La desactualización jurídica del derecho laboral colombiano con respecto al avance internacional en esta materia, llevó posteriormente a la expedición de decretos y leyes para regularlas. Se ubican así decretos como el 616 de 1954 que reformó los códigos sustantivos y procesal del Trabajo, en temas como estabilidad del trabajador a término fijo y contrato mínimo de cuatro meses. Con respecto a los derechos colectivos, aun cuando en 1948 se habían aprobado dos convenios para la protección de éstos, fue solo hasta 1976 que se aprobaron mediante la Ley 26, el Convenio Internacional del Trabajo (OIT, 1948) sobre libertad sindical y protección del derecho de sindicalización; y con la Ley 27 el Convenio Internacional del Trabajo (OIT, 1949) sobre aplicación de los principios del derecho de sindicalización y de negociación colectiva. No se deben dejar de lado Decretos que con anterioridad había expedido el gobierno nacional como fueron los decretos 2655 y 3111 de 1954, los cuales prohibieron a sindicatos ocuparse de política partidista y se creó el Consejo Nacional Sindical, respectivamente. (Avella, 2010, p.66)

Así mismo, se regularon temas importantes como el salario mínimo, creándose comisiones paritarias de empleadores y trabajadores por medio del decreto 1156 de 1955, más adelante la ley 187 de 1959 creó el Consejo Nacional de Salarios, al que se le asignó la fijación del salario mínimo, así mismo con el decreto 3506 de 1983, se logró la unificación del salario mínimo a nivel nacional; el decreto 180 de 1956, estableció que el subsidio familiar no es salario.

Posteriormente con la expedición del decreto 433 de 1971, se reorganizó el Instituto Colombiano de Seguros Sociales modificando la ley 90 de 1946, definiendo en el artículo primero que la seguridad social es un servicio público orientado y dirigido por el Estado. En el literal a del siguiente artículo se indicó que quienes mediante contrato de trabajo presten sus servicios a patronos de carácter particular, deben ser vinculados a la Seguridad Social.

El estudio del desarrollo histórico de la normatividad laboral en Colombia permite advertir cómo en principio sólo se encontraba dirigida a grupos particulares de trabajadores, excluyendo entre otros a los trabajadores del servicio doméstico, pero con el tiempo la regulación se plasmó de forma general como es el caso de la Ley 90 de 1946. Si bien quienes estudian los derechos de este grupo de trabajadores suelen dejar de lado esta norma, en atención a lo expresado por la OIT, se establece que a menos que se disponga la exclusión de determinado grupo de trabajadores todos hacen parte de la misma, por lo tanto, al no existir una exclusión explicita de 
los trabajadores domésticos, estos ya eran acreedores a los derechos consignados en dicha legislación.

\section{Armonización del Convenio 189 en la Legislación Colombiana}

El anterior estudio y análisis de la historia social y jurídica de los trabajadores del servicio doméstico, expone la necesidad de normatividad que se ajuste al caso particular de este grupo de trabajadores quienes se encuentran bajo estereotipos sociales, económicos y culturales. Es por esto que con la creación del Convenio 189 de la OIT, se busca fijar las reglas básicas para su protección. Su entrada en vigor en Colombia requirió el cumplimiento de procedimientos especiales como fueron: la aprobación por parte del Senado de la República, su correspondiente estudio de constitucionalidad en la Corte Constitucional colombiana y finalmente la aprobación en el Poder Ejecutivo.

El proceso de aprobación en el Senado de la República del Convenio 189, partió del Proyecto de Ley 230,radicado el 19 de abril de 2012 por la Ministra de Relaciones Exteriores María Ángela Holguín y el Ministro de Trabajo Rafael Pardo, en el Proyecto de ley se realizó una exposición de motivos donde se observó tanto el contexto general del convenio, como el internacional y el Nacional, en este último se examinó la legislación comparada entre el Convenio 189 y las leyes vigentes en el país, al incorporar el esbozo presentado por el Gobierno Nacional al estudio de Constitucionalidad que efectúa la Corte Constitucional de la Ley 1595 de 2012,mediante la sentencia C-616 de 2013, se logra contextualizar el Convenio 189 a la realidad jurídica de los derechos laborales para los trabajadores del servicio doméstico en Colombia. Previa observación del origen, desarrollo y entrada en vigor del Convenio.

Posteriormente se ha de examinar los diferentes pronunciamientos de los órganos colegiados en Colombia, como son la Corte Suprema de Justicia y Corte Constitucional, con el fin de establecer una línea jurisprudencial en cada uno de ellos, que nos permita examinar si sus pronunciamientos han garantizado el trabajo decente para los trabajadores del servicio doméstico en Colombia, $\mathbf{y}$, eventualmente, si estos pronunciamientos son acordes a lo establecido por el Convenio 189. 


\subsection{Convenio 189 de la OIT: Origen, desarrollo y entrada en vigor.}

La historia del trabajo doméstico remite a un punto culmen de su desarrollo, es decir, al Convenio 189 de la OIT, por medio del cual se busca reivindicar los derechos fundamentales de los trabajadores el servicio doméstico. Al examinar su origen y desarrollo en la Organización, se observa que ya en el Convenio 024 relativo al seguro de enfermedad, la OIT incluye a los trabajadores domésticos, pero fue el activismo femenino y su interés por la igualdad de la mujer el que a partir de 1939 hizo que el Organismo pusiera su mirada en las labores que desarrollaban las mujeres; igualmente se logra remontar desde la Resolución adoptada el 30 de Junio de 1948 como se expuso en el capítulo anterior. Pero la introducción del Informe IV (2A) de 2011 de la OIT indica precedentes más recientes y tendientes a crear protección específica para este grupo de trabajadores:

Los antecedentes de este tema se remontan a 2008, cuando el Consejo de Administración de la OIT, en su 301. reunión (marzo de 2008), decidió inscribirlo en el orden del día de la 99. ${ }^{a}$ reunión de la Conferencia Internacional del Trabajo, celebrada en 2010, para una doble discusión con vistas a la adopción de normas internacionales del trabajo sobre el trabajo decente para los trabajadores domésticos 1 . Se consideró que era necesario adoptar normas internacionales sobre esta cuestión habida cuenta de la exclusión histórica y continua de los trabajadores domésticos, principalmente mujeres y niñas, con respecto a las normativas de protección laboral. El establecimiento de nuevas normas sobre el trabajo doméstico brinda a la OIT una oportunidad sin precedentes para abordar la problemática de la economía informal y hacer realidad el trabajo decente para millones de trabajadores que se encuentran entre los más vulnerables del mundo. (OIT, 2011, pág. 1)

Se debe tener en cuenta que los antecedentes mencionados con anterioridad, no han sido los únicos estadios donde la OIT ha visto la necesidad de pronunciarse respecto a los derechos de este grupo de trabajadores, cabe resaltar que en 1948 en la $31^{\text {a }}$ Conferencia Internacional del Trabajo el delegado del Reino Unido, el Sr. Roberts instó a dar espacio en la agenda de 1950, la discusión sobre las condiciones de los trabajadores domésticos, la cual ya solicitada en la Convención de 1936,así como lo concerniente a la restricción del trabajo nocturno de niños y 
jóvenes trabajadores en ocupaciones no industriales, toda vez que en la Convención de 1946, los trabajadores domésticos fueron excluidos.

Fue en el año1965 que la CTI adoptó una resolución relacionada con las condiciones de trabajo del personal del servicio doméstico. Dicha resolución hacía hincapié en la necesidad urgente de dotar a estos trabajadores de los elementos básicos de protección capaces de garantizarles un mínimo nivel de vida, compatible con el respeto de la persona y la dignidad humana, que son esenciales a la justicia social.(D’Souza, 2010, p.2)

En el análisis que lleva a cabo D’Souza, se indica que la OIT y sus mandantes han abordado distintos problemas y que la Comisión de Expertos en Aplicación de Convenios y Recomendaciones han tramitado 207 observaciones y pedidos directos desde el 2002; así mismo se expresa que la Organización ha recibido cooperación técnica y de investigación, permitiendo abordar el tema del trabajo decente a partir de la igualdad de género, la protección de los trabajadores de la economía informal, los derechos de los trabajadores migrantes, la libertad de asociación, la eliminación del trabajo forzoso y la trata de personas, o la abolición del trabajo infantil, en especial de sus peores formas, todas ellas hay que resaltar, son políticas de Trabajo Decente.

Ya en 2006 especialistas de género de la OIT, elaboraron un Programa de diez años para la OIT sobre Trabajo Decente para el personal del servicio doméstico; para el 2007 se dio continuidad al tema celebrándose una reunión en la cual se discutió como reducir el déficit de trabajo decente en el sector, donde se consideró la evaluación de las políticas y los programas de la OIT y el plan para diseñar un programa mundial sobre trabajo doméstico. (D’Souza, 2010, p.4)

La OIT en su Recuperado de señala con respecto a la "Evolución del Convenio 189 y de la Recomendación 201" que:

El primer paso fue determinar la situación de la legislación y la práctica existentes en todo el mundo acerca de los trabajadores domésticos. La información fue presentada en el Informe IV(1), que fue enviado a los Estados miembros en 2009. Los comentarios recibidos como 
respuesta fueron publicados en el Informe IV(2). Estos dos documentos sirvieron de base para las discusiones en la Conferencia 2010.

Después de la Conferencia 2010, la Comisión de los Trabajadores Domésticos elaboraron el Informe IV(1), que contiene las conclusiones propuestas de las discusiones. El Informe presentó el primer proyecto de un convenio y una recomendación. Una vez más, los

mandantes fueron invitados a comentar, y sus respuestas fueron sintetizadas en el Informe IV(2A). Una versión revisada del convenio y de la recomendación propuestos (Informe IV(2B) ) fue publicada en marzo 2011, pocos meses antes de la Conferencia.

En junio 2011, los delegados de la OIT adoptaron por una mayoría abrumadora el Convenio sobre Trabajadores Domésticos (núm. 189) y la Recomendación (núm. 201), 2011, un conjunto de normas internacionales dirigidas a mejorar las condiciones de trabajo de millones de trabajadores domésticos en todo el mundo.

La participación activa y el compromiso de los gobiernos, los empleadores y los trabajadores, incluyendo a los mismos trabajadores domésticos, a lo largo del proceso de fijación de normas dio lugar a instrumentos que tienen un verdadero potencial de producir cambios en las vidas de los trabajadores domésticos. (6)

Como indica la OIT, al momento de la creación de estos instrumentos, ya algunos países contaban con normatividad que salvaguardaba los derechos de los trabajadores del servicio doméstico, Colombia no es la excepción, si bien, los trabajadores de este sector contaban con herramientas para su protección, no existía el concepto de Trabajo Decente bajo el cual cambia los paradigmas, pues con este nuevo principio se establecen lineamientos para la protección efectiva de los derechos de este grupo de trabajadores y asimismo se logra hacer visible un trabajo que a lo largo de la historia ha sido subvalorado y relegado.

\subsection{Armonización del Convenio 189 al Bloque de Constitucionalidad Colombiano}

El estudio que realiza la Corte Constitucional en sentencia C-067 de 2003 se indica como mediante los artículos 9, 93, 94, 214, 53 y 102 de la Constitución de 1991 se "definirían los parámetros de adopción de las normas internacionales en el orden interno”, pero más adelante con la sentencia C-401 de 2005 la corte profundizaría al efectuar el análisis concreto del modo 
en que los convenios internacionales del trabajo llegan a formar parte del bloque de constitucionalidad en Colombia, lo anterior a través de la exposición de la evolución del orden legal y constitucional que por medio de la jurisprudencia se le ha otorgado a nivel nacional a los convenios internacionales ratificados por el Gobierno Colombiano. Al respecto la Corte Constitucional deduce finalmente:

En un primer momento se enfatizó que todos los convenios internacionales del trabajo hacen parte de la legislación interna - en armonía con lo establecido en el inciso 4 del artículo 53 de la Constitución. Luego, varias sentencias empezaron a señalar que varios convenios de la OIT hacen parte del bloque de constitucionalidad y, posteriormente, se hizo una distinción entre ellos para señalar que algunos pertenecen al bloque de constitucionalidad en sentido estricto y otros al bloque de constitucionalidad en sentido lato.

No ofrece ninguna duda que todos los convenios internacionales del trabajo ratificados por Colombia fueron integrados a la legislación interna, por disposición expresa del inciso cuarto del artículo 53 de la Constitución. Esto significa que, de manera general, todos estos convenios adquieren el carácter de normas jurídicas obligatorias en el derecho interno por el solo hecho de su ratificación, sin que sea necesario que se dicten nuevas leyes para incorporar su contenido específico en el ordenamiento jurídico del país o para desarrollarlo.

La Corte considera que la inclusión de los convenios internacionales del trabajo dentro del bloque de constitucionalidad debe hacerse de manera diferenciada y fundamentada. Si bien todos los convenios internacionales del trabajo ratificados por Colombia forman parte de la legislación interna, varios integran también el bloque de constitucionalidad, en sentido lato o en sentido estricto.

En conclusión, es preciso distinguir entre los convenios de la OIT, puesto que si bien todos los que han sido "debidamente ratificados" por Colombia, "hacen parte de la legislación interna" (C.P., art. 53, inciso cuarto) -es decir, son normas jurídicas principales y obligatorias para todos los habitantes del territorio nacional, sin necesidad de que una ley posterior los desarrolle en el derecho interno- no todos los convenios forman parte del bloque de constitucionalidad (C.P., art. 93), en razón a que algunos no reconocen ni regulan derechos humanos, sino aspectos administrativos, estadísticos o de otra índole no constitucional. Igualmente, es claro que algunos convenios deben necesariamente formar parte del bloque de constitucionalidad, puesto que protegen derechos humanos en el ámbito laboral. 
Adicionalmente, la Corte Constitucional puede, como ya lo ha hecho, de acuerdo con criterios objetivos, indicar de manera específica qué otros convenios forman parte del bloque de constitucionalidad en sentido lato (C.P. art. 93, inciso 2), en razón a que son un referente para interpretar los derechos de los trabajadores y darle plena efectividad al principio fundamental de la protección del trabajador (C.P., art. 1) y al derecho al trabajo (C.P. arts. 25 y 53). Cuando algún convenio prohíba la limitación de un derecho humano durante un estado de excepción o desarrolle tal prohibición, corresponde a la Corte señalar específicamente su pertenencia al bloque de constitucionalidad en sentido estricto (C.P., art.93, inciso 1), como también lo ha realizado en sentencias anteriores. (Corte Constitucional, C-401 de 2005)

En atención a lo anterior y teniendo en cuenta que como elemento fundamental para su aplicación normativa a nivel nacional, la armonización del Convenio 189 al Bloque de Constitucionalidad Colombiano permite establecer el orden jurídico del mismo y en atención al artículo 53 de la Constitución Política de Colombia el convenio 189 de la OIT, se observa que este hace parte de la legislación nacional, tal como lo expone la Corte Constitucional:

La Corte advierte que los contenidos del tratado están unívocamente dirigidos a desarrollar los derechos laborales, muchos de ellos de índole constitucional, que tienen las trabajadoras y trabajadores domésticos. En lo que respecta al preámbulo del Convenio 189, la Corte advierte que cada uno de sus contenidos parte de premisas análogas a las explicadas anteriormente respecto de la invisibilidad y vulnerabilidad del trabajo doméstico y la necesidad correlativa de protección reforzada en lo que refiere a los derechos de las personas que lo ejercen. A su vez, el preámbulo del instrumento internacional acoge otros Convenios del Trabajo, ratificados por Colombia y que, en los términos del artículo 53 C.P., hacen parte de la legislación interna, lo que otorga un marco de constitucionalidad suficientemente preciso. (Corte Constitucional, C-616 de 2013)

Así mismo, en atención a lo expresado por la Corte en la Sentencia C-401 de 2005 se puede decir que el Convenio 189 es "un referente para interpretar los derechos de los trabajadores y darle plena efectividad al principio fundamental de la protección del trabajador" por lo tanto hace parte del bloque de constitucionalidad en sentido lato en atención a lo expuesto por la Corte en la Sentencia C-616 de 2013 que indica:

De otro lado, el mismo preámbulo refiere a que el Convenio está basado en el otorgamiento de eficacia a tratados que hacen parte del derecho internacional de los derechos humanos y 
que, en lo respecta al derecho interno, conforman el bloque de constitucionalidad. En ese sentido, desde el preámbulo del instrumento internacional resulta claro que sus contenidos no hacen nada distinto que establecer medidas concretas para la protección de los derechos humanos, asunto que, como es apenas natural, en nada riñe con la Constitución. (Corte Constitucional, C-616 de 2013) (Negrilla fuera de texto)

\subsection{Derecho al Trabajo Decente de los Trabajadores del Servicio doméstico en Colombia.}

Con la creación y posterior adopción del Convenio 189 del 16 de Junio de 2011, la OIT expresa el objetivo de éste, a través de su preámbulo:

El compromiso de promover trabajo decente para todos, de lograrla justicia social para una globalización equitativa; así mismo reconoce la contribución de los trabajadores domésticos a la economía mundial y considera que el trabajo doméstico sigue siendo infravalorado e invisible. Por lo tanto reconociendo las condiciones particulares en que se efectúa el trabajo doméstico se hace conveniente complementar las normas de ámbito general con normas específicas para los trabajadores domésticos, de forma tal que éstos puedan ejercer plenamente sus derechos. (Preámbulo. Convenio 189 de la OIT)

Al radicarse por parte del gobierno colombiano en el Senado de la República el proyecto de Ley 230 de 2012con el fin de iniciar el trámite legislativo que permitiera la aprobación del Convenio 189, se observa como en el Contexto General, argumentado para justificar la necesidad, estos fueron esbozados frente a la vulneración de los Derechos Fundamentales de dignidad e igualdad del grupo de trabajadores domésticos ya que:

Los riesgos de trato discriminatorio y de explotación hacia personas contratadas para cumplir labores domésticas, como aseo, cocina, lavado y planchado de ropa y demás actividades propias de un hogar; habían encontrado tradicional materialización, connivencia e indiferencia, en un rezago de la esclavitud y la servidumbre del pasado, manteniéndose la segregación social y las diferencias en las condiciones laborales. Esta situación ha venido cambiando el estado con el fin de proteger los derechos que tienen los trabajadores, ha incorporado en su legislación normas que regulan las condiciones de trabajo los trabajadores 
del hogar, parte de estos derechos han sido reconocidos gracias a la Jurisprudencia de la Corte Constitucional. (Congreso de la República, 2012, Proyecto de Ley 230)

Lo anterior reafirma las condiciones por las cuales en el país se han venido garantizando y equiparando los derechos de los trabajadores domésticos frente a los derechos de los demás trabajadores, encontrado así los primeros, en la acción tutela, la acción de constitucionalidad y en la vía jurisdiccional las únicas herramientas para la protección de sus derechos, lo anterior por no contar este grupo de trabajadores con políticas públicas efectivas que propendan por el Trabajo Decente, aun cuando en los mismos antecedentes del proyecto de ley se habla de la labor del Estado en la "promoción y prevención efectiva de los derechos de los trabajadores domésticos, así como, la promoción del cumplimiento y respeto de los principios y derechos fundamentales en el trabajo", la realidad de este grupo de trabajadores en Colombia dista mucho de lo que se sugiere en los antecedentes del proyecto de ley; ya que la desigualdad, la falta de control, de vigilancia e inspección de los lugares de trabajo, los hace a estos particularmente vulnerables por el ámbito privado en la cual se desarrolla la relación laboral, sumado a la falta de conocimiento de sus derechos y el abuso de la parte fuerte de la relación laboral (empleador).

Del estudio de constitucionalidad del Convenio 189 de la OIT realizado por la Sentencia C616 de 2013, podemos resaltar una serie de consideraciones hechas por la Corte constitucional que buscan darle armonía al articulado del convenio dentro del sistema jurídico colombiano, razón por la cual se hará una agrupación de derechos que tocan aspectos fundamentales del desarrollo de la relación laboral frente a este tipo de trabajadores.

\section{Derechos Laborales Individuales}

Con la aprobación del Convenio 189 de la OIT, mediante la Ley 1595 de 2012 y su posterior estudio de exequibilidad por medio de Sentencia C-616 de 2013, se efectúa el análisis comparativo entre el convenio, la norma vigente y los pronunciamientos de la Corte Constitucional, planteamientos de esta última, que busca brindar garantías y equiparar los derechos de los trabajadores domésticos. Ahora bien, con el fin de establecer lineamientos la Corte parte el estudio de la ley desde el elemento básico en el cual ha fundado sus decisiones: el principio de Dignidad Humana y su compaginación con otros derechos constitucionales que 
salvaguardan los derechos individuales de los trabajadores en Colombia. Expresa la Corte al respecto:

El artículo 25 C.P. determina que el trabajo es un derecho y una obligación social, el cual goza en todas sus modalidades de la especial protección del Estado. De igual modo, la misma norma prescribe que toda persona tiene derecho a un trabajo en condiciones dignas y justas. Del mismo modo, el artículo 53 C.P. identifica los principios mínimos fundamentales del trabajo, que operan como condiciones indispensables para el desarrollo legislativo ulterior. Estos principios versan sobre:

(i) igualdad de oportunidades para los trabajadores; remuneración mínima vital y móvil;

(ii) proporcional a la cantidad y calidad de trabajo;

(iii) estabilidad en el empleo;

(iv) irrenunciabilidad a los beneficios mínimos establecidos en normas laborales;

(v) facultades para transigir y conciliar sobre derechos inciertos y discutibles;

(vi) situación más favorable al trabajador en caso de duda en la aplicación e interpretación de las fuentes formales de derecho;

(vii)primacía de la realidad sobre formalidades establecidas por los sujetos de las relaciones laborales;

(viii) garantía a la seguridad social, la capacitación, el adiestramiento y el descanso necesario; $\mathrm{y}$

(ix) protección especial a la mujer, a la maternidad y al trabajador menor de edad.

Igualmente, la norma superior en comento determina tres reglas constitucionales específicas, relativas a (i) la obligación estatal de garantizar el derecho al pago oportuno y al reajuste periódico de las pensiones legales; (ii) la pertenencia a la legislación interna de los convenios internacionales del trabajo debidamente ratificados; y (iii) la prohibición que la ley, los contratos, los acuerdos y convenios del trabajo menoscaben la libertad, la dignidad humana o los derechos de los trabajadores.

La Corte encuentra que en relación con la garantía de los derechos de los trabajadores domésticos, la jurisprudencia constitucional ha fijado reglas definidas sobre el particular, las cuales versan en sus aspectos esenciales acerca de (i) la existencia de un mandato constitucional de equiparación, en lo que respecta al goce y ejercicio de los principios 
mínimos del trabajo, de que trata el artículo 53 C.P. entre los trabajadores domésticos y los demás trabajadores. Esto en los diferentes planos de la protección laboral, entre los que se destacan los aspectos salariales y prestacionales, de la seguridad social, las condiciones físicas del empleo compatibles con la dignidad de la persona; la protección de la estabilidad laboral de la mujer embarazada, etc. (ii) el reconocimiento que la relación laboral de los trabajadores y particularmente los trabajadores domésticos está signada por una particular forma de subordinación jurídica hacia el empleador, merced de la labor efectuada y las condiciones en que se desarrolla, sumado al hecho que el servicio es usualmente prestado por mujeres de escasos recursos e instrucción; en consecuencia (iii) la necesidad de otorgar a las relaciones laborales en comento un marco reforzado de protección de los derechos del trabajador, lo cual incluso permite fijar discriminaciones a su favor, compatibles con la condición de vulnerabilidad en que suelen encontrarse las trabajadoras y trabajadores domésticos. (Corte Constitucional, C-616 de 2013)

Por otra parte en lo referente a derechos humanos, como

Como se observa en el preámbulo presentado por la Corte Constitucional en la sentencia C616 de 2013, el Convenio 189 se ajustaría en gran medida a los pronunciamientos efectuados por el cuerpo colegiado en torno a la Constitución y las leyes colombianas. En el marco de la investigación que se está desarrollando, se puede decir que el análisis que realiza la Corte, permite tomar en consideración los vacíos legales, jurisprudenciales y la deficiente política pública sobre Trabajo Decente, específicamente para los trabajadores del servicio doméstico.

Así mismo, se puede observar como en Colombia previa adopción del Convenio, ya se venía gestando un claro avance en protección desde el ámbito constitucional, legal y jurisprudencial, de los derechos laborales para los trabajadores del servicio doméstico. La labor de la Corte Constitucional desde sus pronunciamientos se sustenta en el Principio de Dignidad Humana, pero este principio no es suficiente para garantizar la efectiva protección de estos trabajadores, al estudiar los elementos que componen el Trabajo Decente y realizar el cotejo con las garantías que ofrece la Constitución y la Ley, se evidencia la necesidad de políticas públicas eficientes que garanticen la plena protección de este grupo de trabajadores, como a continuación lo indica el cuerpo colegiado:

...la norma internacional impone un deber específico para los empleadores y para el Estado, consistente en la disposición de mecanismos adecuados y suficientes para las 


\section{trabajadoras y trabajadores domésticos sean debidamente informados sobre sus} derechos y obligaciones en virtud de la relación laboral. Tales mecanismos, a su vez, deberán tener en cuenta las particulares condiciones de dichos trabajadores, especialmente su grado de instrucción, la situación de vulnerabilidad en que suelen encontrarse y el tipo de subordinación jurídica que se predica respecto del empleador, conforme se explicó en apartados anteriores de esta sentencia. (Negrilla fuera del texto). (Corte Constitucional. C-616 de 2013)

\section{Preámbulo Convenio 189 de la OIT:}

La Conferencia General de la Organización Internacional del Trabajo: Convocada en Ginebra por el Consejo de Administración de la Oficina Internacional del Trabajo, y congregada en dicha ciudad el 1. ${ }^{\circ}$ de junio de 2011 en su centésima reunión;

Consciente del compromiso de la Organización Internacional del Trabajo de promover el trabajo decente para todos mediante el logro de las metas establecidas en la Declaración de la OIT relativa a los principios y derechos fundamentales en el trabajo y en la Declaración de la OIT sobre la justicia social para una globalización equitativa;

Reconociendo la contribución significativa de los trabajadores domésticos a la economía mundial, que incluye el aumento de las posibilidades de empleo remunerado para las trabajadoras y los trabajadores con responsabilidades familiares, el incremento de la capacidad de cuidado de las personas de edad avanzada, los niños y las personas con discapacidad, y un aporte sustancial a las transferencias de ingreso en cada país y entre países;

Considerando que el trabajo doméstico sigue siendo infravalorado e invisible y que lo realizan principalmente las mujeres y las niñas, muchas de las cuales son migrantes oforman parte de comunidades desfavorecidas, y son particularmente vulnerables a la discriminación con respecto a las condiciones de empleo y de trabajo, así como a otros abusos de los derechos humanos;

Considerando también que en los países en desarrollo donde históricamente ha habido escasas oportunidades de empleo formal los trabajadores domésticos constituyen una proporción importante de la fuerza de trabajo nacional y se encuentran entre los trabajadores más marginados; 
Recordando que los convenios y las recomendaciones internacionales del trabajo se aplican a todos los trabajadores, incluidos los trabajadores domésticos, a menos que se disponga otra cosa;

Observando la especial pertinencia que tienen para los trabajadores domésticos el Convenio sobre los trabajadores migrantes (revisado), 1949 (núm. 97), el Convenio sobre los trabajadores migrantes (disposiciones complementarias), 1975 (núm. 143), el Convenio sobre los trabajadores con responsabilidades familiares, 1981 (núm. 156), el Convenio sobre las agencias de empleo privadas, 1997 (núm. 181), y la Recomendación sobre la relación de trabajo, 2006 (núm. 198), así como el Marco multilateral de la OIT para las migraciones laborales: Principios y directrices no vinculantes para un enfoque de las migraciones laborales basado en los derechos (2006);

Reconociendo las condiciones particulares en que se efectúa el trabajo doméstico, habida cuenta de las cuales es conveniente complementar las normas de ámbito general con normas específicas para los trabajadores domésticos, de forma tal que éstos puedan ejercer plenamente sus derechos;

Recordando otros instrumentos internacionales pertinentes, como la Declaración Universal de Derechos Humanos, el Pacto Internacional de Derechos Civiles y Políticos, el Pacto Internacional de Derechos Económicos, Sociales y Culturales, la Convención Internacional sobre la Eliminación de todas las Formas de Discriminación Racial, la Convención sobre la Eliminación de todas las Formas de Discriminación contra la Mujer, la Convención de las Naciones Unidas contra la Delincuencia Organizada Transnacional, y en particular su Protocolo para Prevenir, Reprimir y Sancionar la Trata de Personas, especialmente Mujeres y Niños, así como su Protocolo Contra el Tráfico Ilícito de Migrantes por Tierra, Mar y Aire, la Convención sobre los Derechos del Niño y la Convención Internacional sobre la Protección de los Derechos de todos los Trabajadores Migratorios y de sus Familiares;

Después de haber decidido adoptar diversas proposiciones relativas al trabajo decente para los trabajadores domésticos, cuestión que constituye el cuarto punto del orden del día de la reunión, y Después de haber decidido que dichas proposiciones revistan la forma de un convenio internacional, adopta, con fecha dieciséis de junio de dos mil once, el presente Convenio, que podrá ser citado como el Convenio sobre las trabajadoras y los trabajadores domésticos, 2011", 


\section{Artículo Primero:}

A los fines del presente Convenio:

(a) la expresión trabajo doméstico designa el trabajo realizado en un hogar u hogares o para los mismos;

(b) la expresión trabajador doméstico designa a toda persona, de género femenino o género masculino, que realiza un trabajo doméstico en el marco de una relación de trabajo;

(c) una persona que realice trabajo doméstico únicamente de forma ocasional o esporádica, sin que este trabajo sea una ocupación profesional, no se considera trabajador doméstico. (OIT, Convenio 189, 2011)

Con el análisis del preámbulo y del primer artículo del Convenio 189se establece el marco en el cual éste ha de desarrollarse y se observa la necesidad de salvaguardar los derechos de los trabajadores del servicio doméstico. Ante la definición del concepto del Trabajador Doméstico, la Corte encuentra la misma conforme a la Constitución, por cuanto se vincula la labor con el "hecho que sea realizada por toda persona en un hogar u hogares para los mismos y que, por ende, conforme una relación de trabajo", el estudio de la Corte se enfoca en el último literal del artículo primero, en el cual se hace énfasis en el Trabajador Doméstico por horas, para evitar una interpretación jurídica que transforme o modifique la naturaleza de las relaciones laborales que perjudique a este grupo de trabajadores.

En el artículo segundo la corte realiza el estudio del ámbito de aplicación del Convenio en el marco de la Constitución e indica que no se contrapone a la Carta Política, ajustándose a los principios de igualdad contemplados en la misma:

\section{Artículo Segundo:}

\section{El presente Convenio se aplica a todos los trabajadores domésticos.}

2. Todo Miembro que ratifique el presente Convenio podrá, previa celebración de consultas con las organizaciones más representativas de los empleadores y de los trabajadores, así como con organizaciones representativas de los trabajadores domésticos y organizaciones representativas de los empleadores de los trabajadores domésticos, cuando tales organizaciones existan, excluir total o parcialmente de su ámbito de aplicación a:

(a) categorías de trabajadores para las cuales esté previsto otro tipo de protección que sea por lo menos equivalente; $y$ 
(b) categorías limitadas de trabajadores respecto de las cuales se planteen problemas especiales de carácter sustantivo.

\section{Artículo tercero}

1. Todo Miembro deberá adoptar medidas para asegurar la promoción y la protección efectivas de los derechos humanos de todos los trabajadores domésticos, en conformidad con las disposiciones del presente Convenio.

2. Todo Miembro deberá adoptar, en lo que respecta a los trabajadores domésticos, las medidas previstas en el presente Convenio para respetar, promover y hacer realidad los principios y derechos fundamentales en el trabajo, a saber:

(a) la libertad de asociación y la libertad sindical y el reconocimiento efectivo del derecho de negociación colectiva;

(b) la eliminación de todas las formas de trabajo forzoso u obligatorio;

(c) la abolición efectiva del trabajo infantil; $y$

(d) la eliminación de la discriminación en materia de empleo y ocupación.(OIT, Convenio 189, 2011)

En atención a las reglas que se contemplan en el artículo tercero del Convenio, el Gobierno Nacional en el Proyecto de Ley 230 de 2012, expresa la existencia de promoción de los derechos laborales, pero es la Corte la que profundiza al expresar la constitucionalidad e indica que su contenido va dirigido a:

\section{La promoción y la protección efectiva de los derechos humanos de todos los} trabajadores domésticos; al respecto expone D'Souza "la explotación y el abuso que sufre parte del personal del servicio doméstico tiene su origen en la falta de reconocimiento de esta actividad como trabajo, el carácter privado e inaccesible del lugar de trabajo y la índole informal de la relación laboral.”(2010, p.1) En Colombia se observa que aun cuando han existido normas que hacen a este grupo de trabajadores acreedores a derechos laborales, la tendencia a infravalorar al mismo, ha sido la causa predominante de los abusos contra estos trabajadores; la evolución normativa a lo largo del tiempo ha ido equiparando los derechos laborales de los trabajadores en Colombia, pero el desconocimiento de la norma, la falta de promoción, 
vigilancia, inspección y control, son los obstáculos que impiden la protección efectiva de los derechos para quienes laboran en los quehaceres del hogar, tal es el caso que se presenta en Sentencia T-1078 de 2012, donde la accionante es víctima de servidumbre doméstica "esclavitud" como forma de trata de personas o de servicios forzosos, en el caso, debido a la falta de información, al miedo de la víctima, entre otras circunstancias, llevó al vencimiento de los términos para una acción laboral y penal, pero en atención a la Constitución, al principio a la dignidad humana, a la identidad y a la familia, la Corte toma medidas para restablecer los derechos de la accionante.

(ii) Eliminación de las peores formas de trabajo, en este punto la Corte se remite al artículo 17 de la Constitución Política que "prohíbe la esclavitud, la servidumbre y la trata de seres humanos en todas sus formas.

(iii) erradicación del trabajo infantil al respecto la Corte se remite a la sentencia C-170 de 2004 que:

Analizó varias normas legales en materia de autorización excepcional del trabajo por menores de edad, puso de presente cómo desde el derecho internacional de los derechos humanos concurren mandatos precisos, vinculantes para el Estado colombiano, referidos tanto a la progresiva eliminación del trabajo infantil, como a su validación excepcional, sometida a estrictas condiciones, tanto en lo relativo a qué labores pueden desempeñarse, como de edad mínima. (Corte Constitucional, 2004, C-170)

Igualmente la Corte hace énfasis en los convenios y leyes aprobadas que reafirman el compromiso del Estado Colombiano de salvaguardar los derechos de los niños y erradicar el trabajo infantil. La Ley 515 de 1999 aprueba el "Convenio 138 sobre la Edad Mínima de Admisión de Empleo", adoptada por la 58 ${ }^{\mathrm{a}}$ Reunión de la Conferencia General de la Organización Internacional del Trabajo, Ginebra, Suiza, el veintiséis (26) de junio de mil novecientos setenta y tres (1973). La ley 704 de 2001, aprueba el "Convenio 182 sobre la prohibición de las peores formas de trabajo infantil y la acción inmediata para su eliminación", adoptado por la Octogésima Séptima $\left(87^{\mathrm{a}}\right)$ Reunión de la Conferencia General de la Organización Internacional del Trabajo, O.I.T., Ginebra, Suiza, el diecisiete (17) de junio de mil novecientos noventa y nueve. 
Así mismo se hace referencia al Artículo 171 del Código Sustantivo del Trabajo; al Artículo 251 de la Ley 685 de 2001 y Artículo 35 del Código de la Infancia y la Adolescencia.

(iv) eliminación de la discriminación laboral; para la cual se hace alusión al principio de igualdad de oportunidades contenido en el artículo 53 de la Constitución Política.

\section{Artículo 4:}

1. Todo Miembro deberá fijar una edad mínima para los trabajadores domésticos compatible con las disposiciones del Convenio sobre la edad mínima, 1973 (núm. 138), y el Convenio sobre las peores formas de trabajo infantil, 1999 (núm. 182), edad que no podrá ser inferior a la edad mínima estipulada en la legislación nacional para los trabajadores en general.

2. Todo Miembro deberá adoptar medidas para asegurar que el trabajo efectuado por los trabajadores domésticos menores de 18 años pero mayores de la edad mínima para el empleo no los prive de la escolaridad obligatoria, ni comprometa sus oportunidades para acceder a la enseñanza superior o a una formación profesional.(OIT, Convenio 189, 2011)

El artículo cuarto es consecuente con el literal c del numeral 2 del artículo precedente, que regula sobre la edad mínima de trabajo contemplado en el Convenio, la Corte reafirma los compromisos ya adquiridos con la OIT, ya que la normatividad vigente y la posición jurisprudencial en Colombia, sobre edad mínima de trabajo y del trabajo en menores de edad, enfatizan sobre la protección de los derechos de los menores de edad, derecho a la educación y al desarrollo profesional.

El Gobierno Nacional indica al respecto en el Proyecto de ley en mención:

El Estado colombiano viene trabajando con especial atención y compromiso en la lucha por la erradicación del trabajo infantil, mediante diversas normas internas ha reconocido los derechos de los menores de edad, así como estableciendo la edad mínima de trabajo en 15 años. Viene paralelamente trabajando en la promoción y difusión de las peores formas de trabajo infantil siendo una de estas peores formas el trabajo doméstico. En Colombia, para los jóvenes entre 17 y 15 años, les está prohibido desempeñarse en cualquier forma de trabajo doméstico. 
El Estado colombiano ha determinado como una de las peores formas de trabajo infantil el trabajo doméstico, prohibiendo de forma expresa este tipo de actividad para los menores de 18 años. Para las personas mayores de 18, que se desempeñen en esta actividad, los ampara las normas de derechos plasmadas en la Constitución Política, Código Sustantivo del Trabajo, así como la legislación promulgada de protección al trabajador.

Colombia ha ratificado el Convenio 138 de la OIT, el cual fue ratificado por las Leyes 515 de 1999 y 1098 de 2006 en su artículo 17 la que indica en forma taxativa cuáles son los trabajos peligrosos y nocivos para los menores de 18 años y ordena que el Ministerio de la Protección Social junto con el Instituto Colombiano de Bienestar Familiar deberán establecer la clasificación de tales actividades, previa consulta con las organizaciones de empleadores y trabajadores, así como de las instituciones y asociaciones civiles interesadas. En el desarrollo de dicha obligación, el trabajo del servicio doméstico está prohibido y considerado como una de las peores formas de Trabajo Infantil.

En el estudio sobre ocupaciones y condiciones de trabajo riesgosas para la salud y el desarrollo de los menores en Colombia, que realizó el Ministerio con la Universidad del Rosario en el año 2004, se elaboró la lista de ocupaciones No calificadas para los menores, entre las que se incluyó el servicio doméstico.

Posteriormente en el año 2005 se reglamentó el artículo 23 del Código del Menor a través de la Resolución 4448 de 2005. (Congreso de la República, 2012, Proyecto de Ley 230).

\section{Artículo 5:}

Todo Miembro deberá adoptar medidas para asegurar que los trabajadores domésticos gocen de una protección efectiva contra toda forma de abuso, acoso y violencia. (OIT, Convenio 189, 2011)

Si bien, la corte no efectúa una mayor profundización en el análisis del artículo quinto y se limita a indicar la concordancia del mismo con los principios Constitucionales, desde el punto de vista de la investigación consideramos que este es uno de los artículo principales, por cuanto hace parte de uno de los elementos del Trabajo Decente. Por esto al hablar de protección efectiva contra toda forma de abuso, acoso y violencia, se busca no solo crear condiciones dignas y justas sino brindar al trabajador, oportunidades de desarrollo individual y profesional, de empleo, 
protección social, derechos de los trabajadores y diálogo social, componentes esenciales del Trabajo Decente y que requiere el Compromiso de las instituciones del Estado y sobre todo de los empleadores para la vigilancia, el control e inspección efectiva de los puestos de trabajo.

Al respecto el Gobierno Nacional indica la existencia de normas que no solo protege a los trabajadores del servicio doméstico, por ser generales salvaguardan a todos los grupos de trabajadores y enuncia las leyes existentes para la protección contra toda forma de abuso, acoso y violencia en el trabajo, como lo son la Ley 1010 de 2006, la Ley 1147 de 2007 y la Ley 1257 de 2008.

\section{Artículo 6:}

Todo Miembro deberá adoptar medidas a fin de asegurar que los trabajadores domésticos, como los demás trabajadores en general, disfruten de condiciones de empleo equitativas y condiciones de trabajo decente, así como, si residen en el hogar para el que trabajan, de condiciones de vida decentes que respeten su privacidad.(OIT, Convenio 189, 2011)

El artículo quinto es complementado y ampliado a través del "artículo sexto" del Convenio, en el cual la OIT, expresa la necesidad de crear un Trabajo Decente para los trabajadores del servicio doméstico, pero de igual forma la Corte solo hace referencia a su compatibilidad con la Constitución y específicamente con el artículo 53 y con los principios de orden laboral, omitiendo la profundización en el concepto de Trabajo Decente y su armonización con la Constitución, los principios laborales y las leyes del país.

Mientras el Gobierno Nacional expresa: "Respecto a los principios de no discriminación, pago de prestaciones sociales generales y especiales, tales como el reconocimiento y pago de la cesantía, intereses, vacaciones e indemnización por despido injustificado, aporte a pensión, salud y riesgos profesionales, les son aplicables, como se expresó anteriormente, a todos los trabajadores sin excepción, lo que indica que los principios y derechos fundamentales en el trabajo, se han ajustado en la legislación interna, reincorporando lógicamente los Convenios Internacionales, reiterándose entonces que las normas de carácter general son aplicables a hombres y mujeres que desempeñan la actividad de servicio doméstico, como así lo prevén los principios generales contenidos en el Código Sustantivo del Trabajo, en especial los artículos $1^{\circ}$, 13,14 y $16 . "$ 


\section{Artículo 7}

Todo Miembro deberá adoptar medidas para asegurar que los trabajadores domésticos sean informados sobre sus condiciones de empleo de forma adecuada, verificable y fácilmente comprensible, de preferencia, cuando sea posible, mediante contratos escritos en conformidad con la legislación nacional o con convenios colectivos, que incluyan en particular:

(a) el nombre y los apellidos del empleador y del trabajador y la dirección respectiva;

(b) la dirección del lugar o los lugares de trabajo habituales;

(c) la fecha de inicio del contrato y, cuando éste se suscriba para un período específico, su duración;

(d) el tipo de trabajo por realizar;

(e) la remuneración, el método de cálculo de la misma y la periodicidad de los pagos;

(f) las horas normales de trabajo;

(g) las vacaciones anuales pagadas y los períodos de descanso diarios y semanales;

(h) el suministro de alimentos y alojamiento, cuando proceda;

(i) el período de prueba, cuando proceda;

(j) las condiciones de repatriación, cuando proceda; y

(k) las condiciones relativas a la terminación de la relación de trabajo, inclusive todo plazo de preaviso que han de respetar el trabajador doméstico o el empleador. (OIT, Convenio 189, 2011)

El artículo séptimo del Convenio hace referencia "a la obligación de los Estados de adoptar medidas para que los trabajadores domésticos conozcan las condiciones del empleo de forma adecuada, verificable y fácilmente comprensible, preferente a través de contratos escritos de conformidad con la legislación nacional o los convenios colectivos. Precisa la Corte en la sentencia C-616 de 2013 frente al artículo séptimo que: 
No se busca transmutar la naturaleza consensual del contrato de trabajo, del modo en que lo comprende la legislación nacional y en desarrollo del principio mínimo del trabajo de la primacía de la realidad sobre las formalidades establecidas por los sujetos de las relaciones laborales. Con todo, también para el caso de los contratos consensuales de índole verbal, las condiciones de empleo deben ser suficientemente conocidas por el trabajador doméstico. (Corte Constitucional, Sent. C-616, 2013)

De igual forma el Gobierno Nacional expone que:

En lo relativo a la forma como se estipula el contrato, si bien es cierto en Colombia puede celebrarse en forma verbal como una de las modalidades para su celebración, no significa que para el servicio doméstico no se celebre en forma escrita, es decir, que se aplica para todos los trabajadores lo que significa que puede estipularse en forma verbal o escrita, hay libertad de estipular el periodo de permanencia, es decir, a término fijo o indefinido, como todos los contratos de trabajo, pero igualmente existe de ante mano la presunción en cuanto a que toda relación de trabajo será regida por un contrato de trabajo. (Artículos 37, 45, 46 y 24 de C. S. del T.).

Se hace énfasis en la creación de la figura jurídica en Colombia, la cual surge a mediados del siglo XX, cuando Colombia realizó grandes avances en materia laboral y bajo el gobierno de Mariano Ospina Pérez se promulgaron el decreto 3743 y el decreto legislativo 2663 de 1950 los cuales dieron origen al Código Sustantivo del Trabajo, recopilando las normas existentes en materia laboral y fijando los elementos y la estructura del contrato de trabajo basados en los requisitos de los contratos civiles del Código civil colombiano.

Aun cuando con estos instrumentos legales se excluía a los trabajadores del servicio doméstico de algunos derechos, estos estaban incluidos en las normas generales y contaban con la protección del Estado, la cual progresivamente se ha incrementado en atención a la labor desarrollada por los grupos de trabajadores y de la Organización Internacional del Trabajo que tienen como principal objetivo la igualdad de derechos laborales, hacer visible el trabajo doméstico y crear trabajo docente para los trabajadores y las trabajadoras del servicio doméstico. 
Como expone D'Souza “la explotación y el abuso que sufre parte del personal del servicio doméstico tiene su origen en la falta de reconocimiento de esta actividad como trabajo, el carácter privado e inaccesible del lugar de trabajo y la índole informal de la relación laboral."(2010) En Colombia se observa que aun cuando han existido normas que hacen a este grupo de trabajadores acreedores a derechos laborales, la tendencia a infravalorar el mismo ha sido la causa predominante de los abusos contra ellos.

Al observar las medidas que los Estados deben adoptar a través del convenio 189 en atención de los artículos dieciséis y diecisiete, concernientes al acceso a la administración de justicia, a los mecanismos alternativos de resolución de conflictos y la equidad en la accesibilidad a los entes administrativos que propendan por la protección e inspección de los derechos laborales de los trabajadores, expone la Corte que estos artículos son totalmente compatibles con la Constitución y se encuentra previsto en el orden Constitucional.

La Corte solo se detiene en el análisis de la necesidad de inspeccionar el lugar de trabajo, con el fin de corroborar las condiciones de los trabajadores. Se destaca el ámbito familiar e íntimo en el cual se desarrolla la relación laboral, el cual se entraría a examinar con el fin de no ir en contra de los principios constitucionales.

En análisis de la sentencia C 616 de 2013 de la Corte Constitucional, se observa como mediante la aplicación del principio de Dignidad Humana, la Corte protege los derechos de los trabajadores domésticos, no ahondando en el Concepto de Trabajo Decente introducido por el Convenio 189 de la OIT. Sin embargo, podemos decir que el estudio realizado por la Corte en la sentencia en mención, sobre los derechos laborales de los trabajadores colombianos se compagina con los derechos que emanan de la aplicación del convenio, para los trabajadores domésticos, con el fin de equipararlos en derechos con las demás profesiones y oficios, y que se exponen a continuación:

\section{- Derechos Colectivos de los Trabajadores del Servicio Doméstico}

El literal a del numeral 2 de artículo 3 del Convenio 189 indica:

“a) la libertad de asociación y la libertad sindical y el reconocimiento efectivo del derecho de negociación colectiva";

Igualmente el numeral 3 del artículo en mención: 
“3. Al adoptar medidas para asegurar que los trabajadores domésticos y los empleadores de los trabajadores domésticos disfruten de la libertad sindical y la libertad de asociación y del reconocimiento efectivo del derecho de negociación colectiva, los Miembros deberán proteger el derecho de los trabajadores domésticos y de los empleadores de trabajadores domésticos a constituir las organizaciones, federaciones y confederaciones que estimen convenientes y, con la condición de observar los estatutos de estas organizaciones, a afiliarse a las mismas."(OIT, Convenio 189, 2011)

En estos se expone la obligación que adquieren los Estados Contratantes en la adopción de medidas que propendan por (i) la protección y promoción de derechos sindicales, este es uno de los puntos que desde la investigación requiere especial atención por parte del Estado, pese a la existencia de normatividad y protección Constitucional (Art. 39 C.P.) del derecho sindical, la falta de apoyo a las organizaciones de trabajadores de servicio doméstico, impiden su desarrollo y labor en pro de los derechos de los trabajadores, tal como lo expresa la Señora Marlene Gómez Ruíz, Tesorera de la Asociación de Trabajadoras del Hogar de Bucaramanga, quien indica que por la falta de compromiso de los diferentes estamentos gubernamentales, la falta de apoyo en la promoción sindical y la falta de ayuda de tipo económico a las asociaciones.

En lo concerniente a los derechos colectivos para este grupo de trabajadores la OIT en el informe de trabajo decente para los trabajadores domésticos sostiene que:

Lograr el trabajo decente para los trabajadores domésticos depende en última instancia de la capacidad y las posibilidades que éstos tengan de sindicarse y de participar en acciones colectivas. Pese a existir numerosos obstáculos en este sentido, como las restricciones jurídicas y el aislamiento que para ellos supone estar encerrados en hogares particulares, estos trabajadores han tratado en todo el mundo de asumir el control de su actividad laboral sindicándose. (OIT, 2010, p.3)

En el caso colombiano se observa como a medida que la presión social e internacional exigía al gobierno la protección de la actividad sindical, su regulación cobijaba los demás sectores laborales, pese a los esfuerzos por crear normas que permitieran la actividad sindical, el rechazo social y la coerción de distintos grupos impedía la efectividad de los derechos colectivos de los trabajadores del servicio doméstico. Organizaciones de trabajadores del hogar fueron vinculadas 
y manejadas por instituciones de origen Católico y bajo los preceptos de solidaridad, humildad y caridad, se buscaba realmente socavar en las trabajadoras del hogar los pensamientos sindicalistas y comunistas de la época.

Posteriormente se creó el Decreto 2663 de 1950, en cuyos artículos 12, 353 y siguientes, se recopilaron los derechos colectivos de los colombianos, modificados por las leyes 11 de 1984, 50 de 1990,584 de 2000 y el artículo 39 de la Constitución, así como por decretos y sentencia de constitucionalidad, para ajustar la norma a los cambios y necesidades socio-jurídicas. Para garantizar este derecho implicaría más la voluntad del Estado, del compromiso para brindar el acompañamiento jurídico, político, económico y social que requiere este grupo de trabajadores.

\section{- El Derecho a la Seguridad Social}

En el resumen que presentó el Gobierno Nacional para el proyecto de ley en mención, se indica que el marco normativo de la seguridad social para los trabajadores domésticos en el país data de más de veinte años, pero el carácter general del derecho a la seguridad social se remonta a normas anteriores a la ley 100 de 1993, es decir, llegan a la Ley 6 de 1945 y la Ley 90 de 1946, indicativo claro que en principio los trabajadores del servicio doméstico adquirieron el mismo tipo de protección de las demás profesiones u oficios en Colombia, por cuanto la no exclusión normativa otorgaba automáticamente el derecho.

La equivoca interpretación de algunos juristas que consideran que solo con la entrada en rigor de la Ley 11 de 1988, los Trabajadores del Servicio Doméstico adquieren el derecho a la seguridad social, lo anterior conlleva a razonamientos errados como se evidencia en la sentencia T- 23954 de 2010, donde el apoderado del accionado afirma que la obligación de afiliación del personal del servicio doméstico solo nace con la vigencia de la norma, pretendiendo negar la existencia del derecho adquirido por la demandante.

En realidad la Ley 11 de 1988, consagra unas excepciones en el régimen del Seguro Social, para los Trabajadores del Servicio Doméstico, que tenía como objetivo salvaguardar a aquellos trabajadores que devengaban por debajo del salario mínimo mensual, pero en ningún caso el porcentaje de cotización podría ser inferior al 50\% del salario mínimo, lo que se intentó no fue otorgar el derecho a la seguridad social, puesto ya se había alcanzado, sino crear un mecanismo para la cobertura efectiva, subsidiada por el Estado hasta el cincuenta por ciento del seguro. Es 
por esto que con la creación del Decreto Reglamentario 824 de 1988, se establecieron los criterios de afiliación para este grupo de trabajadores.

En las interpretaciones jurídicas que se realizan sobre el derecho a la seguridad social para los trabajadores del servicio doméstico, muchas veces se deja de lado por parte de los abogados, jueces y de los investigadores del tema, el estudio y análisis jurídico a partir de la Ley 90 de 1946, donde se contempla la protección de este grupo de trabajadores, como se puede apreciar en el artículo 2 que reza: "Serán asegurados por el régimen del seguro social obligatorio, todos los individuos, nacionales y extranjeros, que presten sus servicios a otra persona en virtud de un contrato expreso o presunto, de trabajo o aprendizaje, inclusive los trabajadores a domicilio y los del servicio doméstico", se expone así el carácter obligatorio del pago de la seguridad social, con el fin de brindar la protección a todos los trabajadores.

La Ley 100 de 1993, da continuidad al subsidio establecido en la Ley 11 de 1988, por medio de los artículos 18 y 30, pero mediante el artículo 5 de la Ley 797 de 2003 y atendiendo al deber constitucional de igualdad, se modifica, equiparando la base mínima de cotización a este grupo de trabajadores, sin embargo el gobierno amplia el subsidio para quienes tengan ingresos inferiores al salario mínimo como se observa en el parágrafo 1 del artículo en referencia donde se advierte que:

Artículo 5: En ningún caso el ingreso base de cotización podrá ser inferior a un salario mínimo legal mensual vigente.

Las personas que perciban ingresos inferiores al salario mínimo legal mensual vigente, podrán ser beneficiarias del Fondo de Solidaridad Pensional, a efectos de que éste le complete la cotización que les haga falta y hasta un salario mínimo legal mensual vigente, de acuerdo con lo previsto en la presente ley. (Congreso de la República, 2003, Ley 797)

En sentencia C-967 del 2003 se estudió la inconstitucionalidad del aparte del parágrafo 1 del artículo 5 de la ley 797, que expresa: "En ningún caso el ingreso base de cotización podrá ser inferior a un salario mínimo legal mensual vigente", según el argumento del demandante, con la norma demandada los trabajadores del servicio doméstico perdieron el privilegio que les otorgaba la ley 11 de 1988; en el análisis de constitucionalidad llevado a cabo por la Corte Constitucional, el órgano colegiado indica: 
La reforma introducida por la norma, lejos de producir el desconocimiento del derecho irrenunciable a la seguridad social pretende garantizar su eficacia, vistas las circunstancias de crisis por las que atravesaba el modelo legal anterior, crisis determinada en parte por la vigencia de la excepción que disposición demandada derogó. En efecto, conocidos los antecedentes legislativos de la ley en general se tiene que no iba a ser posible asegurar a los afiliados al sistema de seguridad social la garantía de pensión mínima, y que los correctivos introducidos de manera general pretendieron remediar esa situación. Dentro de tales correctivos, se observa que la excepción que permitía a los trabajadores del servicio doméstico cotizar con base en salarios mensuales inferiores al mínimo legal mensual vigente, por el uso contrario a derecho de que venía siendo objeto, resultaba ser un factor de distorsión del equilibrio económico del sistema que hacía imperiosa su revisión. Conjurada esta posibilidad elusiva, se asegura una mayor transparencia y eficiencia en la utilización social y económica de los recursos financieros disponibles, para que los beneficios a que da derecho la seguridad social sean prestados en forma adecuada, oportuna y suficiente. Así pues, como se dijo, la reforma al régimen de los empleados del servicio doméstico contribuye a la eficacia de su derecho a la seguridad social, y de los derechos de los demás afiliados al sistema en general. (Corte Constitucional, Sent. C-967, 2003).

En el cuadro a continuación se observa los datos que indican la cantidad de trabajadores del servicio doméstico que se encuentran afiliados al sistema de seguridad social en Latinoamérica, según los datos presentado por la OIT en 2010, Colombia paso de $12.5 \%$ al $24 \%$ de afiliados de 1990 a 2003. Aun cuando se cuenta con normas que datan del año de mil novecientos cuarenta y cinco, en Colombia la tasa de trabajadores vinculados al sistema es demasiado bajo, lo cual indicaría que la falla no es de tipo normativo, sino de cumplimiento de las normas laborales por parte de los empleadores, la falta de información de los trabajadores de sus derechos y la falta de inspección gubernamental, tal como lo expresó María Roa en el Seminario Internacional de Economía del Cuidado de Octubre de 2014, ella indicó la falta de control por parte de la inspecciones a los hogares donde hay trabajadores del servicio doméstico. 


\section{Tabla 5 .}

Porcentaje de trabajadores domésticos que cotizan a la seguridad social en años seleccionados

\begin{tabular}{|c|c|c|c|c|c|c|}
\hline & \multicolumn{3}{|l|}{1990} & \multicolumn{3}{|l|}{$2003^{*}$} \\
\hline & Total & Hombres & Mujeres & Total & Hombres & Mujeres \\
\hline América Latina & 17,6 & 35,5 & 16,6 & 23,3 & 33,6 & 22,8 \\
\hline Argentina & 7,8 & 25,5 & 6,8 & 4,0 & 29,3 & 3,5 \\
\hline Bolivia & - & - & - & 5,5 & 8,1 & 5,4 \\
\hline Brasil & 24,9 & 44,0 & 24,1 & 29,7 & 40,4 & 29,1 \\
\hline Chile & 51,7 & 66,7 & 51,4 & 53,8 & 52,1 & 57,4 \\
\hline Colombia & 12,5 & 51,3 & 10,8 & 24,0 & 40,9 & 23,3 \\
\hline Costa Rica & 40,0 & 59,5 & 39,3 & 35,7 & 41,8 & 35,2 \\
\hline Ecuador & 17,8 & 20,8 & 17,5 & 11,3 & 8,3 & 11,5 \\
\hline México & 4,2 & 20,7 & 2,5 & 9,2 & 18,7 & 7,9 \\
\hline Nicaragua & - & - & - & 3,8 & 9,5 & 2,9 \\
\hline Panamá & - & - & - & 31,5 & 38,9 & 30,6 \\
\hline Paraguay & - & - & - & 20,5 & 6,8 & 21,2 \\
\hline Perú & 17,3 & 31,3 & 16,3 & 20,5 & 6,8 & 21,2 \\
\hline Uruguay & 44,8 & 42,1 & 44,8 & 97,9 & 99,4 & 97,8 \\
\hline República Bolivariana de & - & - & - & 23,4 & 49,3 & 22,4 \\
\hline \multicolumn{7}{|c|}{ "Bolivia - 2002, Chile - 2000.} \\
\hline \multicolumn{7}{|c|}{ Fuente: OIT: Panorama Laboral 2004, OT, Buenos Aires. } \\
\hline
\end{tabular}

Fuente: (OIT, 2010, p.68)

En la actualidad el porcentaje de trabajadores afiliados ha ido aumentando, pero continúan siendo bajos en comparación con otros países, cómo es el caso de Uruguay y Chile. De acuerdo a cita que la Revista Portafolio realiza del Ministerio del Trabajo, se expone que para el año 2013 en Colombia solo el 33\% por ciento de los Trabajadores del servicio doméstico se encontraban afiliados al Sistema de Seguridad Social, asimismo en el artículo de Portafolio señalan que:

Una estadística revelada por el Ministerio de Trabajo dice que son 753.333 trabajadores en el sector doméstico, de los cuales el 95 por ciento son mujeres (715.666) y el resto hombres (37.667).

Sin embargo, advierte que a pesar de contribuir con 3,5 por ciento de las ocupaciones totales en el país, que son cerca de 21,5 millones, las condiciones laborales de los oficios domésticos son deficientes, ya que solo el 8 por ciento de las personas tienen un contrato escrito, mientras que el porcentaje restante tiene un convenio verbal.

Y aunque el 88 por ciento de personas está afiliada o cotiza a la seguridad social, sólo el 33 por ciento lo hace a través del régimen contributivo. 
Otra muestra de la poca profundización de la formalización en el sector es que solo el 15 por ciento de personas cotizan a pensiones o se encuentran jubiladas, y el 5,5 por ciento están afiliados a una caja de compensación familiar.

Mintrabajo llama la atención de que a pesar de concentrarse en las personas mayores de 38 años, un 3 por ciento (22.600 personas) tienen entre 10 y 17 años, lo cual constituye trabajo infantil.

Las bajas condiciones laborales de la población también se reflejan en el ingreso. En 2012, el 68 por ciento percibía menos de un salario mínimo mensual legal, con un promedio salarial aproximado de 478.800 pesos.(7)

\section{- La Flexibilización a la Seguridad Social}

La adopción del Convenio 189 trajo una serie de retos para Colombia, una vez ratificado por el congreso se establecieron a su entrada en vigor (Septiembre de 2013) una serie de medidas para su cumplimiento eficaz. Uno de los principales retos se encuentra vinculado a la afiliación de los trabajadores al Sistema de Seguridad Social, que si bien los este tipo de trabajadores habían adquirido este derecho, el reto para el país era el cubrimiento del sistema para aquellos trabajadores dependientes que laboran por períodos inferiores a un mes y que así mismo cuentan con varios empleadores.

Por lo tanto se hizo necesario establecer una nueva normativa que se ajustara a las necesidades de este grupo de trabajadores y empleadores sin que esto diera pie a la desigualdad como sucedía con la ley 11 y el decreto 824 de 1988, pero que así mismo garantizará de manera efectiva la seguridad social, lo que tuvo ocurrencia con la expedición del Decreto 2616 de 2013, respecto del que se puede hablar de la flexibilización de las relaciones laborales de los trabajadores domésticos, quienes prestan sus servicios por días a diferentes empleadores, y al no disponer de un mecanismo en el sistema que permitiera cotizar por los días efectivamente laborados, omitían el pago a este sector de trabajadores quienes se encontraban desprotegidos frente a los derechos ciertos e irrenunciables que tiene cualquier trabajador.

El argumento jurídico que adoptó el gobierno nacional para la expedición del decreto en referencia, sin ir en contra de los precedentes jurisprudenciales de la Corte Constitucional (Sentencia C-967 de 2003) y de la misma Constitución, expresa que la Corte en sus decisiones no ha negado la posibilidad de realizar cotizaciones sobre una base inferior al salario mínimo, 
por lo que en el precepto que sostiene el desarrollo del asunto, se enfatiza no en el salario mínimo mensual, sino que este sistema de cotización se orienta al salario mínimo diario, por lo que teniendo en cuenta la proporción entre estos dos tipos de salario; para efectos de la norma, la cotización se divide en cuatro niveles como lo dispone el decreto 2616 de 2013 (hoy recopilación Decreto 1072 de 2015) en su artículo 6, con el fin de dar acceso a los sectores informales de la economía al sistema de seguridad social.

Artículo 6: -Monto de las cotizaciones al sistema general de pensiones, subsidio familiar y riesgos laborales. Para el Sistema General de Pensiones y del Subsidio Familiar, se cotizará de acuerdo con lo señalado en la siguiente tabla:

Días laborados en el mes Monto de la cotización

Entre 1 y 7 días Una (1) cotización mínima semanal

Entre 8 y 14 días $\quad$ Dos (2) cotizaciones mínimas semanales

Entre 15 y 21 días Tres (3) cotizaciones mínimas semanales

Más de 21 días Cuatro (4) cotizaciones mínimas semanales (equivalen a un salario mínimo mensual)

\section{- La Protección a la Maternidad}

En cuanto a la Protección a la Maternidad, en Colombia se regula a partir de la ley 48 de 1924. Pese a que la norma estaba dirigida a la protección de la infancia, esta brindaba consultas gratuitas a las mujeres gestantes y subsidios a los hospitales que demostraran que les prestaban servicios de salud. Por otra parte la norma instaba a las fábricas que contaran con más de 50 trabajadoras a fundar una o más salas-cunas destinadas a los hijos de esas trabajadoras, de igual forma se permite la asociación de empresas para la creación de las salas cunas. Así mismo la Ley 90 de 1945 trajo consigo la obligación de los empleadores de brindar protección a los trabajadores a través de un seguro obligatorio el cual cubría contra riesgos tales como enfermedades no profesionales y maternidad, invalidez y vejez, accidente de trabajo y enfermedad profesional, y en caso de muerte. Al entrar en vigencia la ley 11 de 1988 y el decreto 824 de 1988, se dio continuidad a los derechos adquiridos por los trabajadores del servicio doméstico en cuanto al tema de seguros sociales.

Al respecto en la sentencia C-616 de 2013 la Corte constitucional remite a la sentencia T-303 de 2007que indica: 
Según la jurisprudencia, las empleadas de servicio doméstico son personas que se encuentran en estado de indefensión y, especialmente, de subordinación en relación con sus empleadores, por el hecho de estar bajo sus órdenes, aunado a la carencia de los medios mínimos requeridos para repeler la eventual violación o amenaza a sus derechos fundamentales. Así mismo, que una mujer trabajadora se encuentre en estado de gravidez ratifica que se halla en "circunstancia de debilidad manifiesta" (art. 13 Const.) y hace presumir gran vulnerabilidad, requiriendo un ingreso que asegure la subsistencia propia y la del hijo que está por nacer, según está también garantizado en el artículo 43 de la Constitución, según el cual la mujer “durante el embarazo y después del parto gozará de especial asistencia y protección del Estado, y recibirá de este subsidio alimentario si entonces estuviere desempleada o desamparada. (Corte Constitucional, C- 616, 2013).

Ya en el proyecto de ley 230 de 2012 el Gobierno Nacional se remitía a las normas existentes para sostener la protección a la maternidad y la paternidad.

De acuerdo con la legislación nacional, existe la protección a la maternidad, esta población goza de fuero especial de tal manera que ninguna trabajadora puede ser despedida por razón de su embarazo accediendo de igual forma a la protección de la seguridad social, pago de incapacidad establecida en la Ley 100 de 1993 norma que es aplicable sin distinción por razón de su oficio, precisamente por la Universalidad de la ley, como principio rector.

La trabajadora tiene derecho a una licencia de maternidad equivalente a catorce (14) semanas, período durante el cual recibirá un subsidio en dinero equivalente al 100 por ciento del salario que devengue en el momento de entrar a disfrutar el descanso, cuyo pago está a cargo de la EPS a la que se encuentre afiliada. Si el empleador no tiene afiliada a la trabajadora, este debe pagar la correspondiente licencia de maternidad.

Si en el curso del embarazo la trabajadora sufre un aborto o un parto prematuro no viable, tiene derecho a una licencia de dos a cuatro semanas, remuneradas con el salario que devengaba en el momento de iniciarse el descanso, a cargo de la EPS a la que se encuentre afiliada. Si el empleador no tiene afiliada a la trabajadora, este debe pagar la correspondiente licencia. 
Es obligación del empleador conceder a la trabajadora dos (2) descansos de treinta (30) minutos dentro de la jornada laboral para amamantar a su hijo, durante los primeros seis (6) meses de vida, sin que proceda descuento alguno del salario y sin importar la jornada de trabajo.

Fuero de maternidad. Es la garantía de que la trabajadora no puede ser despedida por motivo de embarazo o lactancia, o en el tiempo de licencia por maternidad posterior al mismo. Para efecto del despido, el empleador necesita la autorización del Inspector del Trabajo o del Alcalde Municipal en los lugares donde aquel no exista. El permiso sólo se concede con fundamento en alguna de las justas causas que tiene el empleador para dar por terminado el contrato de trabajo (artículo $7^{\circ}$ del Decreto 2351 de 1965, aparte A). Sin esta autorización, el despido carece de todo efecto.

Licencia de paternidad. El trabajador cónyuge tiene derecho a disfrutar de la licencia de paternidad, que consiste en un descanso remunerado de ocho (8) días hábiles, periodo en el cual recibe un reconocimiento económico cuyo pago está a cargo de la Empresa Promotora de Salud a la que se encuentre afiliado.

El derecho a la licencia de paternidad se acredita con el Registro Civil de Nacimiento, el cual se deberá presentar a la EPS dentro de los 30 días siguientes a la fecha del nacimiento del menor.(Congreso de la República, Proyecto de Ley 230, 2012).

\section{- Seguridad y Salud en el Trabajo y Riesgos Laborales}

Con el decreto 2663 de 1950 se definió y se reguló lo referente al accidente de trabajo, la enfermedad profesional, así mismo, en artículo 223 se exoneró a los empleadores del pago a determinados grupos de trabajadores en el literal d del artículo se encontraban los trabajadores del servicio doméstico, quienes quedaban desamparados ante los accidentes y enfermedades de trabajo. Mediante sentencia C-823 de 2006 la corte expone que la expedición y posterior entrada en vigencia del Decreto 1295 de 1994, que determina la organización y administración del Sistema General de Riesgos Profesionales, quedan incluidos los trabajadores del servicio doméstico.

Por lo tanto, a partir de de la ley 1295 de 1994 en atención al Principio de Igualdad, la protección a este grupo de trabajadores se encuentra inmersa en todas las normas vigentes sobre 
riesgos laborales, como lo son la Ley 776 de 2002, la ley 1562 de 2012 y el Decreto 1443 de 2014 Decreto 472 de 2015

Cabe resalta lo expresado por el Gobierno Nacional en el proyecto de ley 230 de 2012, donde indica:

Los trabajadores domésticos que devenguen como mínimo un salario mínimo mensual legal vigente tienen el derecho a la afiliación en el Sistema General de Riesgos Profesionales, a cargo de las Administradoras de Riesgos Profesionales (ARP). La elección corresponde al empleador y la cotización está a cargo exclusivo de este.

En caso de accidente de trabajo o enfermedad profesional, la administradora de riesgos profesionales a la cual se encuentre afiliado el trabajador al momento de ocurrir el accidente o al momento de requerir la prestación por enfermedad profesional, asume las prestaciones asistenciales y económicas.

Los trabajadores del servicio doméstico que laboren con distintos empleadores cotizarán por intermedio de todos ellos sobre el salario devengado con cada uno, sin que la suma de los aportes mensuales pueda ser inferior a un salario mínimo legal mensual vigente. (Congreso de la República, Proyecto de Ley 230, 2012)

\section{- El Derecho a las Vacaciones}

Con respecto a las vacaciones no han existido normas que excluyan a los trabajadores del servicio doméstico de las leyes generales, por lo que se entiende la igualdad laboral con respecto a este tema, ciñéndose a lo establecido en el Decreto 2663 de 1950. El descanso dominical obligatorio se encuentra en el mismo decreto y se indica la obligación del patrono de dar descanso dominical remunerado a todos sus trabajadores, para algunos trabajadores se establece la excepción que permite laborar durante los días de descanso obligatorio, pero este se ha de retribuir o se ha de dar un descanso compensatorio remunerado, entre este grupo de trabajadores se encuentran excluidos igualmente los trabajadores del servicio doméstico.

\section{- El Derecho a la Dotación}

La norma es igualmente equitativa con los trabajadores del hogar en lo que concierne al calzado y vestido, ya que no son excluidos del artículo 232 del decreto 2663 de 1950 y normas 
subsiguientes, es decir que por el hecho de laborar permanentemente, el patrono se encuentra en la obligación de entregar al trabajador el vestuario que se ajuste a las necesidades del puesto de trabajo.

\section{- Derecho al Auxilio de Cesantías}

En cuanto al Auxilio de Cesantías, el decreto que trajo a la vida jurídica su reglamentación general, al mismo tiempo excluyó a algunos trabajadores tales como los accidentales y transitorios, igualmente a quienes desarrollaban labores para patronos que ejecutaran actividades sin ánimo de lucro, entre los que se ubican los trabajadores del servicio doméstico.

Los esfuerzos jurídicos y políticos para que se otorgara a los trabajadores del servicio doméstico el derecho a las Cesantías rindió sus frutos mediante la Sentencia C-051 de 1995, donde la Corte Constitucional, en su análisis de exequibilidad de los artículos 252 y 338 del Código Sustantivo del Trabajo, que comprendían los artículos 254 y 355 del Decreto 2663 de 1950 respectivamente, excluían directamente a estos trabajadores del derecho a las cesantías. En definitiva, con la sentencia de la corte se logra el cumplimiento de los principios constitucionales a la igualdad y a la dignidad humana, que como lo expresa el Magistrado ponente Arango, este último principio converge en el aspecto de crear condiciones dignas y justas para los trabajadores, que expone el artículo 25 de la Constitución.

\section{- Regulación de la Jornada Laboral}

El estudio de la regulación de la jornada laboral en Colombia remite a la OIT y su origen, Blanchard expone:

La OIT es, con la Sociedad de Naciones, el organismo internacional creado en 1919, fruto de la Conferencia de Paz que puso fin a la Primera Guerra Mundial. La creación de la OIT (su constitución figura en el capítulo XIII del Tratado de Versalles) respondía a las reivindicaciones del mundo obrero, impaciente por lograr algunas conquistas sociales después de los enormes esfuerzos que había tenido que soportar durante el largo conflicto. La conferencia respondía así, en el espíritu de muchos gobiernos, a la idea de frenar el avance del comunismo en Europa, inmediatamente después de la revolución de octubre. (1996, Pág. 11) 
Con el surgimiento de parámetros jurídicos que mejorara las condiciones laborales de los trabajadores, llega la regulación de la jornada laboral como uno de los primeros derechos por los cuales lucharon los trabajadores, y lográndosela reducción de la jornada laboral a ocho (8h) horas en las industrias.

Para el caso particular de los trabajadores del servicio doméstico, se evidencia el carácter especial y urgente de cambiar los preconceptos socio-culturales; la OIT en el informe que presenta sobre Trabajo Decente para los Trabajadores Domésticos, examina algunos ejemplos en el mundo sobre el manejo de la jornada laboral para quienes viven en el domicilio del empleador expresa:

Cuando los trabajadores domésticos se hallan alojados en el domicilio de su empleador, existe entre el trabajo y el hogar una zona gris que puede impedir que la legislación sobre las horas de trabajo logre su objetivo principal: reducir las largas jornadas de trabajo. Estos trabajadores deben estar disponibles para trabajar durante largos períodos e incluso a veces de forma continua. Un estudio ha demostrado que en España algunos empleadores consideran que los trabajadores domésticos «internos» deben estar disponibles a todas horas. En los Países Bajos, las investigaciones realizadas han revelado que de muchos trabajadores domésticos migrantes alojados en el domicilio de su empleador se espera que estén disponibles a cualquier hora y, a menudo, es incluso de prever que el empleador cambie o cancele su día de descanso. Hay constancia de que en Kuwait ciertos colectivos de trabajadores, como los cocineros, los chóferes, los guardias de seguridad y las empleadas de hogar, trabajan en promedio entre 78 y 100 horas semanales. Aunque en la mayoría de los sistemas nacionales examinados no se aborda esta cuestión de manera pormenorizada, se han registrado algunos esfuerzos por establecer entre las exigencias del trabajo en el hogar y el número de horas de trabajo un equilibrio acorde con las normas internacionales. (OIT, 2010, p. 52)

En Colombia el artículo 162 del decreto ley 2663 de 1950, adoptó la duración máxima de la jornada laboral, aun cuando se indica que la máxima es de 8 horas diarias y 48 horas a la semana, se establecen algunas excepciones, dentro de las que se resalta la jornada máxima de 12 horas diarias para quienes desarrollan labores de discontinuas o intermitentes y en las de simple vigilancia, pero el artículo siguiente de la norma excluye determinadas actividades donde figura los trabajadores domésticos. 
El primer esfuerzo para equiparar los derechos de los trabajadores domésticos con la norma general surgió con la Sentencia C-372 de 1998, que pese al salvamento de voto adoptado por el magistrado José Gregorio Hernández Galindo expuso la necesidad de establecer el mismo horario para cualquier tipo de trabajador sin discriminar a grupos o sectores de trabajadores más pequeños pese a lo cual la Corte actúa con discrecionalidad en su fallo situación que conlleva a declarar la exequibilidad condicionada de la norma, en el sentido de que especifica una jornada diferente para aquellos trabajadores que prestan el servicio en el hogar. Dicha determinación de la Corte Desemboca en la inseguridad e incertidumbre de este tipo de trabajadores al pasar por encima el Principio y derecho Fundamental a la Igualdad.

Por lo anterior podemos decir que los argumentos expuesto por la Corte Constitucional en la sentencia en cita declaran la necesidad de diferenciar entre los trabajadores que habitan en el domicilio del empleador de aquellos que desempeñando tareas domésticas sus condiciones laborales distan de los primeros, si bien la Corte aborda el principio constitucional de dignidad humana y expone la necesidad de brindar condiciones justas de trabajo a quienes desarrollan actividades del servicio doméstico, toda vez que una jornada laboral excesiva estaría en contravía del orden constitucional, lo expuesto en el estudio riñe con la decisión final de exequibilidad condicionada, en consideración que permite que los trabajadores que habitan en el domicilio del empleador tengan una jornada máxima de 10 horas diarias, sin excluirlas de la excepción del artículo 162 del Código sustantivo del trabajo.

En definitiva aun cuando la norma no contempla la jornada máxima de trabajo de los trabajadores domésticos, la jurisprudencia exhorta para que quienes desarrollen actividades domésticas y que no habiten en el domicilio del empleador se rijan por las reglas generales, mientras que todos aquellos que residen en la casa del empleador, cumplan una jornada máxima de 10 horas diarias.

La posición adoptada en el artículo Noveno continúa con el artículo décimo del Convenio donde se profundiza la necesidad de equiparar los derechos de los trabajadores del servicio doméstico a la norma general, con respecto a los tiempos de trabajo y descanso a los cuales tiene derecho. Se recuerda de nuevo que al respecto la corte ya había realizado un pronunciamiento, donde se equiparaba el trabajo doméstico al trabajo de dirección y confianza, en el cual las jornadas laborales se debían ajustar a las necesidades de la empresa, la sentencia C-372 de 1998, si bien no declaró la inexequibilidad de la norma, la condiciono la jornada laboral de los 
trabajadores que habitan en el hogar del empleador a 10 horas. La corte solo hace el análisis desde el punto de vista del artículo 53 de la Constitución y a expresar la compatibilidad, pero desde el punto de vista de la investigación y en atención al convenio, es deber del Estado, legislar con respecto a la jornada laboral de los trabajadores domésticos, con el propósito de no exceder la jornada laboral máxima general de 8 horas diarias.

\section{- La Intermediación Laboral}

La intermediación laboral y ocultamiento de las relaciones laborales es abordado por el Convenio 189 mediante el Artículo Quince que expresa:

Artículo 15: Para proteger efectivamente contra las prácticas abusivas a los trabajadores domésticos contratados o colocados por agencias de empleo privadas, incluidos los trabajadores domésticos migrantes, todo Miembro deberá:

(a) determinar las condiciones que regirán el funcionamiento de las agencias de empleo privadas que contratan o colocan a trabajadores domésticos, en conformidad con la legislación y la práctica nacionales;

(b) asegurar la existencia de un mecanismo y procedimientos adecuados para la investigación de las quejas, presuntos abusos y prácticas fraudulentas por lo que se refiere a las actividades de las agencias de empleo privadas en relación a los trabajadores domésticos;

(c) adoptar todas las medidas necesarias y apropiadas, tanto en su jurisdicción como, cuando proceda, en colaboración con otros Miembros, para proporcionar una protección adecuada y prevenir los abusos contra los trabajadores domésticos contratados o colocados en su territorio por agencias de empleo privadas. Se incluirán las leyes o reglamentos en que se especifiquen las obligaciones respectivas de la agencia de empleo privada y del hogar para con el trabajador doméstico y se preverán sanciones, incluida la prohibición de aquellas agencias de empleo privadas que incurran en prácticas fraudulentas y abusos;

(d) considerar, cuando se contrate a los trabajadores domésticos en un país para prestar servicio en otro país, la concertación de acuerdos bilaterales, regionales o multilaterales con el fin de prevenir abusos y prácticas fraudulentas en la contratación, la colocación y el empleo; $y$ 
(e) adoptar medidas para asegurar que los honorarios cobrados por las agencias de empleo privadas no se descuenten de la remuneración de los trabajadores domésticos.

2. Al poner en práctica cada una de las disposiciones de este artículo, todo Miembro deberá celebrar consultas con las organizaciones más representativas de los empleadores y de los trabajadores, así como con organizaciones representativas de los trabajadores domésticos y con organizaciones representativas de los empleadores de los trabajadores domésticos, cuando tales organizaciones existan.

Al respecto la Corte se limita a indicar en la sentencia C- 616 de 2013 que la norma es exequible en atención al marco normativo y Constitucional planteado: "Todas ellas son medidas protectoras de los derechos de los trabajadores domésticos, en las diversas facetas de la garantía del salario, la igualdad y el acceso a la administración de justicia, por lo que en nada se oponen a la Constitución.” (Corte Constitucional, C-616, 2013)

\section{- Cajas de Compensación Familiar}

Al examinar el derecho laboral junto a los derechos complementarios de la seguridad social, y que corresponde satisfacer las Cajas de compensación Familiar en cuanto los trabajadores del Servicio Doméstico se parte del fin social que la asistía, como se expuso en las consideraciones que tuvo en cuenta la Junta Militar para promulgar el Decreto 118 de 1957 que trae inmersos aumentos de salarios, establece el subsidio familiar y crea el Servicio Nacional de Aprendizaje, SENA.

Se resalta que entre las motivaciones para la expedición del decreto se encuentra la alteración de la normalidad económica de la época, el aumento en el costo de la vida, el deber gubernamental de atender las necesidades de las clases menos favorecidas económicamente y fomentar su mejoramiento, todo ello fundado ideológicamente en la doctrina social-católica, como fundamento para el establecimiento de normas laborales tendientes a mejorar la situación de los trabajadores con el fin de reducir el poder del socialismo en la clase trabajadora, para el caso se estableció el subsidio familiar como medio de fortalecimiento de la familia.

Con las leyes 25 de 1981 y 21 de 1982 se dio forma al régimen de subsidio familiar en Colombia con la creación de la superintendencia de Subsidio Familiar, sin embargo la desprotección jurídica en este ámbito de los trabajadores del servicio domésticos fue continuo 
hasta la expedición del Decreto 721 de 2013, por medio del cual se reglamentó el numeral $4^{\circ}$ del artículo $7^{\circ}$ de la ley 21 de 1982 y se reguló la afiliación de los trabajadores del servicio doméstico al sistema de compensación familiar. En el decreto se especifica que la mediada hace parte del cumplimiento del Convenio 189 de la OIT, para garantizar la igualdad y el Trabajo Decente para los trabajadores Domésticos.

- En Camino a la Igualdad de Derechos Laborales para todos: La Prima de Servicios

En cuanto al derecho a las primas de servicio, mediante Sentencia C-871 del 13 de noviembre de 2014 la Magistrada Calle Correa, en estudio de constitucionalidad del Artículo 306 del Código Sustantivo del Trabajo, donde los accionantes exponen la violación de los artículos 13, 25, 53 y 93 de la Constitución Política, debido a que excluye a los trabajadores del servicio doméstico del derecho a la prima de servicios.

La Corte decidió a partir de consideraciones y fundamentos jurídicos declarar exequible la norma, no sin antes "exhortar al Congreso de la República y al Gobierno Nacional para que adopten las medidas legislativas e implementen las políticas públicas necesarias para avanzar hacia la universalidad del derecho prestacional al pago de la prima de servicios en el caso de los trabajadores y las trabajadoras domésticas”. (Corte Constitucional, C-871, 2014)

La Corte establece tres criterios que deben ser tomados en cuenta por el Congreso y el Gobierno Nacional para la adopción de medidas legislativas y la implementación de políticas las derivadas de los mandatos constitucionales, a continuación se describen:

(i) deberá asegurarse que los estratos más altos reconozcan y paguen la prima de servicios;

(ii) deberá ampliarse progresivamente la obligación.

(iii) Los órganos políticos deberán diseñar mecanismos y políticas públicas que operen como incentivos para que las familias asuman el pago de la prima de servicios, bajo la evaluación de conveniencia y oportunidad que deben asumir tanto el Congreso de la República como el Gobierno Nacional. (Corte Constitucional, Sentencia C-871, 2014)

Mediante el Proyecto de Ley 003 de 2015 el Congreso de la República buscaba modificar el artículo 306 del Código Sustantivo del Trabajo, en atención a la exhortación que efectúo la Corte 
Constitucional en sentencia C-871 de 2014, pero en este no se realizó el estudio y análisis del entorno social y económico que se vería afectado, incumpliendo la solicitud de la Corte Constitucional, en el Proyecto de Ley 003 de 2015 la Cámara de Representantes, realiza la exposición de motivos limitándose a mencionar los aspectos expuestos por la Corte Constitucional en la Sentencia ya citada y por medio de la misma se desarrollan las premisas que contiene el espíritu de la ley para la "Universalización de la Prima de Servicios para las Personas que Prestan Servicios Domésticos":

Las personas que prestan el servicio doméstico deben gozar de los mismos derechos que los demás trabajadores, por lo tanto le son aplicables los principios mínimos fundamentales consagrados en la Constitución Política: Condiciones dignas y justas (artículo 25 C. P.); principios laborales fundamentales de remuneración adecuada, mínima y móvil; irrenunciabilidad de los derechos mínimos consagrados en las normas laborales, aplicación del principio de favorabilidad, de las fuentes del derecho laboral y del principio de primacía de la realidad sobre las formas (artículo 53 C. P.). Sin embargo, ¿afirma la Corte $i$ este importante marco constitucional que preside las relaciones de los trabajadores domésticos ha venido siendo conculcado por cuanto este sector laboral ha sido sometido a desigualdad y discriminación social la cual se encuentra asociada a causas y prejuicios históricos en torno al servicio doméstico, sea este remunerado o no; problema que presenta mayor gravedad en cuanto el trabajo doméstico remunerado, es prestado en su mayoría por mujeres, grupo el cual ha sido históricamente discriminado por razones de género.

Este problema, señalado por el tribunal constitucional, ha determinado la infravaloración con la que se miran los trabajos domésticos, que no han permitido reconocer adecuadamente el valor que dicho trabajo representa en la sociedad. (Cámara de Representantes, Proyecto de Ley 003, 2015)

Dentro de las premisas desarrolladas en el proyecto se hace alusión a la ley 1413 de 2010 que hace referencia a la economía del cuidado la cual regula su inclusión en el sistema de cuentas nacionales, esto para llegar a los reportes del DANE sobre los aportes que este sector aporta al PIB:

(...) que la economía del cuidado aporta en Colombia en promedio: un 20\% del PIB, lo que equivale en plata blanca a ciento veinte mil (120.000) millones de pesos, cifra que se asemeja 
a la presentada por la CEPAL que señala que en América Latina la economía del cuidado equivale entre el $25 \%$ y el $30 \%$ del PIB.

Luego entonces: afirmar que el trabajo doméstico no es una actividad que produce utilidades, resulta no ser una premisa consistente para defender una discriminación hacia los trabajadores de este sector económico. Razón por la cual, es necesario que el Congreso de la República en ejercicio de la cláusula general de competencias legislativas, proceda a corregir este yerro histórico que se ha cometido contras las personas que se desempeñan en trabajo doméstico remunerado, equiparando los derechos de estos trabajadores y erradicando la última barrera de discriminación legal que hoy queda vigente contra los trabajadores del servicio doméstico. . (Cámara de Representantes, Proyecto de Ley 003, 2015)

Este Proyecto de ley finaliza su exposición de motivos citando la Sentencia C-871 de 2014 de la Corte Constitucional que indica: "debe concluirse que la distinción entre trabajadores del servicio doméstico y otros trabajadores para el pago de la prima es abiertamente irrazonable, por lo tanto, violatorio del principio de igualdad".

A lo largo de los debates tanto en la Cámara de Representantes como en el Senado de la República, no se realizó el estudio del impacto socio económico que implicaría la aprobación de la prima, dejando de lado los criterios planteados por la Corte Constitucional en la misma Sentencia que es citada en el proyecto.

El 7 de julio de 2016 se aprobó en el Congreso de la República la Ley 1788, por medio de la cual se garantiza el acceso en condiciones de universalidad al derecho prestacional de pago de prima de servicios para los trabajadores y trabajadoras domésticos. Esta Ley reforma el artículo 306 del Decreto ley 2663 del 5 de agosto de 1950, Código Sustantivo del Trabajo, para garantizar la universalidad del derecho a la prima de servicios equiparando los derechos de los trabajadores en atención al Convenio 189 de la OIT. Por otra parte la Ley crea La Mesa de Seguimiento a la implementación del Convenio 189, la cual tendrá como “objetivo formular y desarrollar políticas públicas con la finalidad de promover el trabajo decente en el sector del trabajo doméstico remunerado".

\section{- La Nueva Visión del Trabajo Decente para los Trabajadores Domésticos}

Se reitera que con el fin de lograr un contenido normativo de acuerdo con el contexto internacional, que colmara las expectativas, las necesidades y los derechos de los trabajadores, 
surge el concepto de Trabajo Decente, en 1999 en 87ª reunión en Ginebra y más allá de crear solo condiciones dignas y justas para los trabajadores, buscaba, como indica Amartya Sen "promover oportunidades para que los hombres y las mujeres puedan conseguir un Trabajo Decente y productivo en condiciones de libertad, equidad, seguridad y dignidad humana". (2000, p.130)

Bajo este nuevo lineamiento la Organización Internacional del Trabajo, crea una agenda fundada en cuatro pilares fundamentales que son: i.) la creación de trabajo, ii) la garantía de los derechos de los trabajadores, iii) la ampliación de la protección social y por último iv) la promoción del diálogo social. La OIT expresa como el concepto de Trabajo Decente, pese a ser un concepto relativamente nuevo "ha logrado un consenso internacional entre gobiernos, empleadores, trabajadores y la sociedad civil sobre el hecho de que el empleo productivo y el Trabajo Decente son elementos fundamentales para alcanzar una globalización justa, reducir de la pobreza y obtener desarrollo equitativo, inclusivo y sostenible”. (OIT, 2014. Recuperado de: http://www.ilo.org/sanjose/programas-y-proyectos/derechos/WCMS_248006/lang-es/index.htm)

Con el Convenio 189 y la Recomendación 201 del 2011 de la OIT, dan cumplimiento a la agenda de la organización no solo respecto al concepto de Trabajo Decente, sino que se ponen al día con el tema de la protección de quienes históricamente han desarrollado las labores en los hogares y que a pesar de haber sido discutida su situación y su fragilidad que evidencia la obligación y el deber de crear las herramienta que se requieran para su especial amparo en atención a que ha sido infravalorado e invisible no solo por su medio laboral, sino por la economía y la política en general. Este convenio por lo tanto tiene como fin vincular y comprometer a los Estados miembros al mejoramiento de la calidad de vida de los trabajadores domésticos. Este compromiso en pro de la justicia social en un mundo globalizado, fue adquirido por Colombia al suscribir el Convenio 189 y posteriormente con la aprobación del Congreso de la República mediante Ley 1595 de 2012.

Al observar el desarrollo jurídico que ha tenido el trabajo doméstico en Colombia y la realidad en la aplicación de la norma se advierte que "El problema reside a veces en la discrepancia existente entre los derechos legalmente reconocidos y su aplicación en la práctica" (0IT, 2010). El análisis normativo en Colombia corrobora el hecho que los trabajadores del servicio doméstico no han estado del todo desvinculados de la norma laboral, las leyes para la protección de los derechos de los trabajadores existen, el vacío no radica en la ley, radica en los 
obstáculos sociales, económicos, administrativos y culturales, que impiden a este grupo de trabajadores el acceso a la justicia y al derecho. Como lo indica directamente el propio Ministerio de trabajo, en sus discursos, los porcentajes de trabajadores afiliados al sistema no han aumentado de forma significativa, porque en el fondo la problemática no se encuentra en las normas, se encuentra en el cumplimiento de la misma.

Se subraya que aun cuando el Estado ha implementado algunas medidas, estas no son suficientes, la Procuraduría en el documento sobre Trabajo Decente indica:

El porcentaje de trabajadores de servicio doméstico cotizando a pensiones es inferior en Colombia en 33 puntos porcentuales al promedio de América Latina. Esto sugiere que los trabajadores no asalariados en Colombia tienen una probabilidad significativamente menor de acceder a pensiones que un trabajador no asalariado de la región. (Procuraduría, 2011, p. 194)

Se resalta como a lo largo del estudio de constitucionalidad, la Corte expone la preexistencia jurídica en Colombia de varios puntos adoptados en el Convenio, pero se enfatiza el hecho, que pese a la existencia de la norma y de los mecanismos para su protección, estos en si son ineficaces e insuficientes tanto para el cambio de paradigma socio-económico como para el cumplimiento y protección de los derechos laborales de los trabajadores domésticos, no solo se resalta la falta de apoyo y compromiso por parte del Estado con las organizaciones de trabajadores del servicio doméstico, que impide el cumplimiento de socialización, acompañamiento y mejoramiento de sus derechos, elementos contenidos en el artículo 18 del Convenio y que obligan a los Estados su cumplimiento bajo la cláusula pacta sunt servanda.

Uno de los principales retos se encuentra en el mejoramiento y adecuación de las inspecciones de trabajo por cuanto la labor que se desarrolla en el momento no es suficiente, en atención a la falta de herramientas que les permita cumplir con su labor de inspección, vigilancia y protección de los derechos de los trabajadores, se requiere reforzar las políticas públicas y crear otras que cumplan con el convenio, la corte a lo largo de análisis de constitucionalidad, expuso como por medio del principio de dignidad humana se ha brindado la protección de los trabajadores del servicio doméstico, pero se requiere profundizar en el concepto de la OIT de Trabajo Decente, que aún no ha sido adoptado a cabalidad por las ramas del poder público y su función de Administración de Justicia por la Rama Judicial. 
Los Artículos subsiguientes del convenio comprenden a las "cláusulas de aplicación, modificación, vigencia y carácter vinculante del tratado, disposiciones que son usuales en todo instrumento de esa naturaleza y que se muestran acordes con las reglas del derecho internacional público, en especial las contenidas en la Convención de Viena sobre Derechos de los Tratados, así como en la Constitución de la OIT", como lo comprueba y expresa la Corte Constitucional en la sentencia.

\subsection{Desarrollo Jurisprudencial del Trabajo Decente para los Trabajadores Domésticas en las Cortes Constitucional y Suprema de Justicia de Colombia}

La historia del trabajo doméstico permite establecer el origen del problema socio- cultural y de los preceptos jurídicos que fundamentan el actual desarrollo jurídico en torno a los derechos de los trabajadores del servicio doméstico. En Colombia se observa que si bien, ya existía un desarrollo jurídico, el entorno social impide su protección efectiva.

En la Contextualización que se desarrolla por parte de la Corte Constitucional en Sentencia C616 de 2013 se observa que ya desde la Constitución, las leyes y los pronunciamientos de las Altas Cortes Colombianas, Corte Suprema y Corte Constitucional, se han adoptado posiciones frente a los derechos de este grupo de trabajadores, es por medio del análisis jurisprudencial de los Cuerpos Colegiados que se puede determinar la efectiva protección de sus derechos. Bajo el principio de dignidad humana, se observa el desarrollo en materia de jurisprudencia constitucional del Trabajo Decente.

\subsubsection{Línea Jurisprudencial Trabajo Decente para los Trabajadores Domésticas en la Corte Constitucional Colombiana.}

El estudio del Trabajo Decente para los trabajadores del servicio doméstico en Colombia, remite a la historia nacional de lucha constante de quienes han sido la fuerza laboral menos valorizada en la sociedad, con el fin de determinar la eficacia de los mecanismos que garantizan la salvaguarda de la dignidad de este grupo de trabajadores y sus derechos laborales, se parte del análisis de los pronunciamientos de los órganos colegiados colombianos. 
Como guardiana de la Constitución y las leyes la Corte Constitucional Colombiana se ha convertido en la máxima autoridad y referente en la aplicación y protección de los derechos fundamentales en el territorio nacional, por lo tanto parte del desarrollo de la investigación se centra en los precedentes jurisprudenciales que equiparan los derechos de los trabajadores del servicio doméstico a las demás labores y oficios que se desarrollan en el país.

Surge del trabajo de investigación, el siguiente problema jurídico a resolver mediante el análisis jurisprudencial a las sentencias de la Corte Constitucional: ¿Se garantiza en Colombia el Trabajo Decente para los trabajadores del servicio doméstico?

Al llevar a cabo el rastreo jurisprudencial de la Corte Constitucional, en materia de Trabajo Decente para los trabajadores del servicio doméstico fueron encontradas 43 sentencias (Tabla 1.) sobre las cuales se realizó el análisis jurisprudencial a 13de estas, atendiendo a la relevancia de las mismas frente al tema en mención.

Tabla 6.

Rastreo Jurisprudencial Trabajadores Servicio Doméstico.

\begin{tabular}{lllllllll}
\hline 1995 & 1997 & 1998 & 1999 & 2000 & 2001 & 2002 & 2003 & 2004 \\
\hline C- 051 & T-172 & C- 372 & SU- 062 & T- 092 & T- 298 & T- 101 & C- 967 & T- 480 \\
& & & T- 495 & T- 101 & T- 1042 & T- 849 & C- 1089 & T- 605 \\
& & & T- 730 & T- 868 & T- 1055 & T- 1043 & & T- 1014 \\
2005 & $\mathbf{2 0 0 6}$ & $\mathbf{2 0 0 7}$ & $\mathbf{2 0 0 8}$ & $\mathbf{2 0 0 9}$ & $\mathbf{2 0 1 1}$ & $\mathbf{2 0 1 2}$ & $\mathbf{2 0 1 3}$ & $\mathbf{2 0 1 4}$ \\
C- 1004 & T- 381 & C- 310 & T- 442 & T- 106 & T- 237 & T- 082 & C- 616 & C- 871 \\
T- 1282 & T- 387 & T- 056 & T- 528 & T- 704 & T- 387 & T- 1078 & & \\
& C- 823 & T- 303 & T- 552 & & & & & \\
& & & T- 1230 & & & & & \\
\hline
\end{tabular}

El término de Trabajo Decente surgió en la conferencia de la OIT de 1999, cuando Amartya Sen, en su discurso expuso la necesidad de "promover oportunidades para que los hombres y las mujeres puedan conseguir un Trabajo Decente y productivo en condiciones de libertad, equidad, seguridad y dignidad humana", bajo este concepto y atendiendo el Convenio 189 de la OIT, que hace el llamado a las naciones a promover el Trabajo Decente para los trabajadores del servicio doméstico se realiza el estudio y la profundización de la jurisprudencia de la Corte Constitucional Colombiana, para establecer si los principios básicos del Trabajo Decente propuestos por la OIT se han considerado en los pronunciamientos del cuerpo colegiado. 
Para el desarrollo de la línea jurisprudencial de la Corte Constitucional sobre el Trabajo Decente para los trabajadores del servicio doméstico, se parte del pronunciamiento en la sentencia Fundadora de Línea, Sentencia C-051 de 1995, donde se salvaguarda los principios constitucionales a la igualdad y la dignidad de los trabajadores domésticos, al proteger el derecho al pago de cesantías de este grupo de trabajadores; aun cuando dentro de la sentencia se argumenta la improcedencia del pago de la prima de servicios, esta sentencia da inicio al cambio de paradigma, al equiparar los derechos de los trabajadores del servicio doméstico al resto de trabajadores y otorgarle a este grupo el beneficio del pago de cesantías.

Como se ha expuesto la igualdad debe ser "real y efectiva", por lo que permite que la ley, en casos especiales, de un trato diferente a algunas personas, siempre y cuando ello se justifique.

Profundizando en los argumentos de La Corte en la sentencia C-051 de 1995, cuando las diferencias son razonables y no contradicen normas constitucionales, no puede hablarse de violación del principio establecido en el artículo 13 de la Constitución. Ahora bien, tratándose del trabajo, el artículo 53 se refiere a una de las aplicaciones concretas del artículo 13: la igualdad de oportunidades para los trabajadores. Esta igualdad implica que el trabajador, en lo relativo a su retribución, depende de sus habilidades y de la labor que desempeña, y no de las condiciones o circunstancias de su patrono. Este es el fundamento de una de las máximas del derecho laboral: a trabajo igual, salario igual.

En conclusión, la diferenciación establecida entre trabajadores cuyos patronos desarrollaran actividades sin ánimo de lucro y los trabajadores con otro tipo de patrono, ${ }^{* *}$ no es autorizada por la Constitución, pues la condición o las circunstancias particulares del patrono no pueden convertirse en factores de tratos desiguales, en perjuicio de los trabajadores.

Deben destacarse, en esta sentencia, dos aspectos:

El primero, la "especial protección" que el Estado debe otorgar al trabajador, para que en relación con él se garanticen "los principios, derechos y deberes consagrados en la Constitución". Principios entre los cuales cabe destacar el de la igualdad, ya examinado; derechos, como el que

\footnotetext{
*Se estudió la constitucionalidad del artículo 338 del Código Sustantivo del trabajo. Prestaciones sociales: 1.Los patronos que ejecuten actividades sin ánimo de lucro quedan sujetos a las normas del presente Código; pero para los efectos de las prestaciones sociales a que están obligados, el Gobierno puede efectuar la clasificación de estos patronos y señalar la proporción o cuantía de dichas prestaciones. "2. Lo dispuesto en este artículo no será aplicable a aquellas personas que, de acuerdo con el Concordato, están sometidas a la legislación canónica."

${ }^{*}$ Consecuentemente el decreto 53 de 1952 que reglamentaba el artículo 338 del CST establecía que los trabajadores cuyos patronos se dedicaran a actividades sin ánimo de lucro devengarían el 50\% de las prestaciones sociales de los demás trabajadores.
} 
tiene toda persona a un trabajo en condiciones dignas y justas; y deberes, como el de la solidaridad social, en virtud del cual todos estamos obligados a promover el bienestar general, que en alguna forma contribuye al bienestar de cada uno.

El segundo, el derecho a un trabajo en condiciones dignas y justas. La dignidad del trabajo se deriva de la dignidad propia del ser humano. Y si éste, en el plano jurídico, es igual a todos sus semejantes, no tiene sentido el que en abstracto las condiciones del trabajo, al hablar específicamente de su retribución, sean diferentes. Por tales razones;

1) Respecto de los patronos que ejecutan actividades sin ánimo de lucro: el Estado debe estimular determinadas actividades a su costa y no a costa de algunos individuos. Los incentivos tributarios, por ejemplo, corren finalmente por cuenta de toda la comunidad. Lo que no tiene justificación a la luz de la Constitución, es conceder ventajas a algunos patronos en desmedro de ciertos trabajadores. Pues, se repite, la retribución que el trabajador reciba, debe corresponder a sus aptitudes y a la labor que desempeña.

2) Al aplicar la unidad normativa, la Corte desarrolla la relación entre el artículo 338 y el 252 del CST:

\section{Artículo 252: <Aparte tachado INEXEQUIBLE>}

1. Los trabajadores del servicio doméstico, los de empresas industriales de capital inferior a veinte mil pesos (\$20.000) y los de empresas agrícolas, ganaderas o forestales de capital inferior a sesenta mil pesos (\$60.000) tienen derecho a un auxilio de cesantía equivalente a quince (15) días de salario por cada año de servicios y proporcionalmente por fracciones de añ; pero en lo demás quedan sujetos a las normas sobre este auxilio.

2. <Aparte tachado INEXEQUIBLE, CONDICIONALMENTE exequible el resto del numeral> Para la liquidación de cesantía de los trabajadores del servicio doméstico solo-se computará el salario que reciban en dinero.

\section{Artículo 338. Prestaciones Sociales.}

1. <Aparte tachado INEXEQUIBLE> Los \{empleadores\} que ejecutan actividades sin ánimo de lucro quedan sujetos a las normas del presente Código; pero para los efectos de las prestaciones sociales a que están obligados, el Gobierno puede efectuar la clasificación de estos fempleadores\} y señalar la proporción o cuantia de dichas prestaciones. 
2. 〈Numeral INEXEQUIBLE〉. Lo dispuesto en este artículo no será aplicable a aquellas personas que, de acuerdo con el Concordato, están sometidas a la legislación canónica.

De igual forma indica que las razones que se adujeron sobre la inconstitucionalidad de los apartes del artículo 338 llevan a afirmar los mismo en relación con las cesantías restringidas contenidas en el numeral 1 del artículo 252. En ese sentido, a) si el servicio doméstico es un lujo, quienes lo disfrutan deben pagarlo en forma semejante como se remunera a todos los trabajadores; y b) la limitación del auxilio de cesantía se opone a la elevación del nivel de vida de los servidores domésticos, elevación que es impuesta por la solidaridad social.

3) Sin embargo tratándose de la prima de Servicios, predica la Corte que de ella, se excluye a los trabajadores de servicio doméstico, pues es claro que el hogar, la familia, no es una empresa y no genera utilidades, por lo tanto no va en contra de la Constitución.

Mediante sentencia T-172 de 1997, la Corte da un paso atrás frente a los derechos fundamentales de las accionantes, quienes aluden a sus derechos constitucionales a una vivienda digna, igualdad, solidaridad y por su estado de indefensión. La decisión de revocar el fallo de segunda instancia que protegía los derechos fundamentales de las accionantes y confirmar el fallo de primera instancia donde se niega la tutela, es decisión que deja en estado de indefensión a las accionantes, si bien el argumento adoptado se apega a la norma, se pudieron haber adoptado medidas que salvaguardaran la dignidad de las tutelantes.

En la decisión indica la Corte que: "la solicitud formulada a ellas por la accionada en el sentido de desalojar la casa de habitación en donde venían prestando sus servicios hasta la terminación del contrato de trabajo, no puede considerarse como el desconocimiento o vulneración de ningún derecho, que frente a ellas la demandada tuviera la obligación de reconocer".

Como se expresó anteriormente, la Corte se acoge a la norma, pero desampara personas que no tienen hogar, dejándolas en estado de indefensión y vulnerabilidad sin brindar ninguna garantía de protección a los derechos fundamentales solicitados, por último se resalta la no aplicación por parte de la Corte del principio vinculante de solidaridad, atendiendo que las señoras eran adultas mayores, habían laborado para la tía de la accionada por varios años y se encontraban vulnerables y en estado de indefensión. 
Con la exequibilidad condicional declarada por la Corte de los literales a y b del artículo 162 del Código Sustantivo del Trabajo

\section{“Articulo 162. Excepciones En Determinadas Actividades.}

1. Quedan excluidos de la regulación sobre la jornada máxima legal de trabajo los siguientes trabajadores:

a). Los que desempeñan cargos de dirección, de confianza o de manejo;

b). <Literal CONDICIONALMENTE exequible> Los servicios domésticos ya se trate de labores en los centros urbanos o en el campo;”

En Sentencia C-372 de 1998, se observa la reserva con la que hasta ese instante la Corte se pronunciaba sobre los derechos laborales y constitucionales de los trabajadores del servicio doméstico, pero con esta sentencia se consolida la Línea Jurisprudencial:

1)Si bien los temas abordados remiten a varios artículos del Código Sustantivo del Trabajo, el análisis de la Corte se concentra en los temas concernientes a los trabajadores del servicio doméstico; en su análisis del artículo 162 referente a la excepción al régimen de jornada máxima para los trabajadores en mención, la Corporación consideró que el legislador sustrajo de dicho régimen la labor doméstica teniendo en cuenta que la familia no tiene las características de una empresa o de un patrono corriente o regular, pues la economía doméstica y la labor desempeñada en la misma poseen unos rasgos particulares que implican una disponibilidad de tiempo diferente y adecuada a las actividades familiares, que no son asimilables a las desplegadas en otros ámbitos del quehacer económico o social.

2)Una jornada laboral excesiva contradice los principios de la dignidad humana y las condiciones justas en que han de cumplirse las tareas domésticas, tornándose indispensable fijar un límite al período de trabajo que exceda de la jornada máxima ordinaria, límite por fuera del cual se quebrantarían las garantías mínimas del trabajador. De modo que aun cuando sea posible la exigencia de laborar durante un período de tiempo superior a la jornada máxima fijada legalmente, para la Corte lo razonable es que, en ningún caso, los trabajadores del servicio doméstico laboren más de 10 horas diarias, y en el evento de que se requiera el servicio más allá de tal límite, procedería entonces, el reconocimiento y pago de horas extras, en los términos de la legislación laboral. 
En el argumento expuesto por el Magistrado Hernández en el salvamento de voto indica como muy posiblemente el pronunciamiento del cuerpo colegiado y los razonamientos presentados en la providencia que profiere la exequibilidad condicionada de los literales ha de "generar inseguridad jurídica y hará que en la práctica resulten inútiles las buenas intenciones de la Corte".

La discreción con la cual actuó la Corte, como se indica en el salvamento de voto: "a pesar de reconocer, como lo hace en la parte motiva del Fallo, que es "indispensable fijar un límite al período de trabajo que exceda de la jornada máxima ordinaria, límite por fuera del cual se quebrantarían las garantías mínimas del trabajador" decide la Corte declarar exequible la norma.

Prosiguiendo con el análisis que realiza el magistrado en su salvamento de voto, se puede considerar que la Corte actuó atendiendo un argumento que deja de lado criterios de solidaridad, dignidad y equidad laboral para este grupo de trabajadores, en la motiva la Corte expone que la inexequibilidad "tendría un efecto perverso, generando desempleo y, eventualmente, la desaparición del trabajo doméstico", este frágil argumento implica el desamparo por parte del órgano colegiado de la protección y defensa de los derechos de los trabajadores del servicio doméstico, al no equiparar las horas laborales tanto de aquellos trabajadores que residan en la casa del empleador, como de quienes no residen en la misma.

La sentencia SU 062 de 1999, adoptada como sentencia reconceptualizadora de línea puesto que se observa el cambio de paradigma en el desarrollo de la línea jurisprudencial, en la medida en que la Corte establece los parámetros para salvaguardar los derechos fundamentales en los casos de indefensión de los trabajadores del servicio doméstico; si bien la Corte Constitucional indica cuál es el mecanismo idóneo para solicitar la protección de los derechos laborales, dejó clara la necesidad de salvaguardar una serie de derechos que generaría el desamparo a un grupo específico de personas que por su cualidades estarían en estado de indefensión de no ampararse sus derechos, mientras acude a las instancias judiciales pertinentes.

Posteriormente se ubicó la sentencia T-730 de 1999, con la cual continúa la tendencia de la Corte de salvaguardar los derechos fundamentales de los trabajadores que se encuentren desamparados y sin sistema de seguridad social, debido a la urgencia de la protección de los derechos de los accionantes, aun cuando se deba acudir a la jurisdicción laboral, se ampara en primera instancia mecanismo transitorio para la protección de los derechos fundamentales, que de no ser amparados, podrían generar un daño irreversible a la parte actora. 
En la Sentencia T-730 de 1999es claro que el hecho de que la trabajadora sea del servicio doméstico no excluye en absoluto la protección de los derechos ni afecta la igualdad y la dignidad del trabajo. "En conclusión, la Constitución no autoriza el que la condición o las particularidades del patrono se conviertan en factores de tratos desiguales, en perjuicio de los trabajadores. La Corte resalta que la igualdad es para todas las modalidades del trabajo, luego no queda excluido el servicio doméstico y por consiguiente quienes desempeñen tal labor tienen derecho a la seguridad social.

Hoy no tiene presentación que alguien que aparezca como trabajador del servicio doméstico sea excluido de la seguridad social. El mismo empleador tiene la obligación de afiliar a su trabajador del servicio doméstico, porque de lo contrario sería el empleador quien respondería por la seguridad social. Tampoco es constitucional que habiéndose cotizado se ordene anular esas cotizaciones, porque la cotización implica la obligación correlativa de prestar el servicio y, se repite, el derecho a la seguridad social es irrenunciable. Además, sobre el carácter de las cotizaciones ya la Corte Constitucional en Sentencia C-577 de 1995 dijo que eran contribuciones parafiscales con todas sus consecuencias. Si alguien cotizó y ello constituyó una contribución parafiscal, no puede después de recibirse un buen número de cotizaciones venirse a anularlas y a quitarles toda proyección jurídica.

La Ley 797 de 2003 trajo consigo cambios en el sistema de cotización a la seguridad social no solo para los trabajadores del servicio doméstico, como lo expone la Corte Constitucional en

\section{Sentencia C-967 de 2003:}

La propuesta legislativa que se concretó en la Ley 797 de 2003 incorporó una serie de medidas que constituyen una respuesta integral a la situación de desequilibrio e inequidad detectada. Entre estas se encuentran algunas que interesan especialmente para el asunto de que se ocupa ahora la Corte, cuáles fueron las que modificaron la operatividad del principio de solidaridad al reformar de manera general la base salarial de cotización, el régimen de los subsidios y la destinación de los mismos; entre estas medidas están principalmente las siguientes:

- Se mantuvo el fondo de solidaridad pensional, destinado a ampliar la cobertura del sistema mediante el subsidio a los grupos de población que, por sus características y condiciones socioeconómicas, no tienen acceso a los sistemas de seguridad social, tales como 
trabajadores independientes o desempleados, artistas, deportistas, madres comunitarias y discapacitadas. Se creó una subcuenta de subsistencia de dicho fondo, destinada a la protección de las personas en estado de indigencia o de pobreza extrema, mediante un subsidio económico.

- Se focalizó el subsidio a la cotización reservándolo a los trabajadores con ingresos inferiores a un salario mínimo que sean mayores de 55 años y a los vinculados a los fondos de pensiones mayores de 58 .

- Para alimentar el Fondo de Solidaridad Pensional se dispuso un aumento del uno por ciento sobre la base de cotización a cargo de los afiliados al sistema general de pensiones cuya base de cotización sea igual o superior a cuatro (4) salarios mínimos legales mensuales vigentes. Con el mismo propósito se estableció también que los afiliados con ingreso igual o superior a 16 salarios mínimos mensuales legales vigentes tendrán un aporte adicional sobre su ingreso base de cotización, así: de 16 a 17 smlmv de un $0.2 \%$, de 17 a 18 smlmv de un $0.4 \%$, de 18 a 19 smlmv, de un $0.6 \%$, de 19 a 20 smlmv, de un $0.8 \%$ y superiores a $20 \mathrm{smlmv}$ de $1 \%$ destinado exclusivamente a la subcuenta de subsistencia, del Fondo de Solidaridad Pensional.

- $\quad$ El límite máximo de la base de cotización se amplió a 25 salarios mínimos. (Antes 20). Se agregó que cuando se devenguen mensualmente más de veinticinco (25) salarios mínimos legales mensuales vigentes, la base de cotización será reglamentada por el Gobierno Nacional y podrá ser hasta de 45 salarios mínimos legales mensuales.

- Se estableció, en la norma que ahora se examina, que en ningún caso el ingreso base de cotización podría ser inferior a un salario mínimo legal mensual vigente, derogándose la excepción que permitía al servicio doméstico cotizar sobre bases salariales inferiores.

- Se dispuso, a partir de 2004, un incremento general en la tasa de cotización. Este incremento pretende capitalizar las reservas del ISS y de los fondos de pensiones privados, en especial el de garantía de pensión mínima del sistema de ahorro individual.

Además de estas medidas referentes concretamente a la reforma de los mecanismos de operatividad del principio de solidaridad dentro del régimen general de seguridad social en pensiones, la Ley 797 de 2003 pretendió eliminar hacia futuro ciertos privilegios concedidos a una mínima parte de los servidores públicos cobijados por regímenes exceptuados o 
especiales y aumentó las semanas de cotización requeridas para acceder a la pensión, así como la edad para adquirir el derecho, en ciertos casos.

Además de las anteriores reflexiones, relativas a la situación de crisis e inequidad por la que atravesaba el sistema de seguridad social en pensiones y a las medidas legales que se adoptaron para tratar de remediarla, otra serie de consideraciones resultan importantes a la hora de examinar la constitucionalidad de la norma acusada, especialmente frente a la operatividad práctica del principio de solidaridad: En primer lugar, no puede perderse de vista que como causa de la expedición de la norma acusada está el hecho de que el legislador detectó la presencia de una reiterada práctica social contraria al principio de buena fe, consistente en cotizar con fundamento en la excepción legal que permitía al servicio doméstico hacerlo con base en ingresos menores al salario mínimo legal mensual, a pesar de no ser el cotizante empleado de esta categoría, ni estar percibiendo una remuneración inferior a dicho salario mínimo; lo que lo llevó a concluir que resultaba necesario cerrar esta posibilidad elusiva, que contribuía a la inviabilidad financiera del sistema general de pensiones y a su inequidad práctica.

La mencionada práctica elusiva significaba un menoscabo de los principios de solidaridad y eficiencia del sistema de seguridad social en pensiones, en la medida en que impedía que los recursos destinados a subsidiar a las clases económicamente más débiles efectivamente las beneficiaran a ellas, y en cuanto no facilitaba la razonable utilización social y económica de los recursos financieros disponibles. Ante esta situación generalizada se estimó menos lesivo de dichos principios el restringir el subsidio a la cotización del servicio doméstico con ingresos inferiores al salario mínimo, reservándolo para los que fueran mayores de 55 años, si se trata de personas afiliadas al ISS, o de 58 si son vinculados a alguno de los fondos de pensiones.

De otro lado, tampoco pierde de vista la Corte que la eliminación de la excepción que permitía a los trabajadores del servicio doméstico cotizar con base en ingresos inferiores al salario mínimo legal mensual, si bien significa para ellos elevar el monto de su cotización, grava de manera especial a sus empleadores, habida cuenta de que la nueva ley mantiene la regla conforme a la cual los empleadores pagarán el $75 \%$ de la cotización total y los trabajadores el $25 \%$ restante. En esta forma, a pesar del mayor sacrificio exigido a los 
empleados domésticos, se mantiene en cierta medida el principio de solidaridad, pues el sacrificio total será asumido en un $75 \%$ por dicho empleador.

En el mismo sentido resalta la Corte que la reforma introducida, si bien exige el sacrificio adicional comentado, no elimina de manera absoluta el principio de solidaridad, toda vez que las pensiones futuras de quienes cotizan con base en el salario mínimo se verán subsidiadas en aproximadamente un 49.1\%." (Corte Constitucional en Sentencia C-967, 2003, punto VI.G.1.12)

El accionante en la sentencia en mención, el Sr.Alejandro Escovar Rodríguez considera que apartes del Artículo 5 (parcial) de la Ley 797 de 2003, que modificó el inciso $4^{\circ}$ y parágrafo del artículo 18 de la Ley 100 de 1993, violaron derechos constitucionales de este grupo de trabajadores, quienes contaban con un subsidio del Estado para la cotización al sistema de seguridad social.

Señala la Corte Constitucional en sentencia C- 967 del 2003, al resolver demanda contra la ley 797, que la reforma "lejos de producir el desconocimiento del derecho irrenunciable a la seguridad social pretende garantizar su eficacia", atendiendo a la crisis del sector y con el fin de asegurar y garantizar los derechos de los afiliados al sistema así como el derecho a una pensión mínima, el Legislativo efectuó los análisis correspondientes para llevar a cabo los correctivos necesarios para el sostenimiento del sistema de seguridad social.

Dentro de tales correctivos, se observa que la excepción que permitía a los trabajadores del servicio doméstico cotizar con base en salarios mensuales inferiores al mínimo legal mensual vigente, por el uso contrario a derecho de que venía siendo objeto, resultaba ser un factor de distorsión del equilibrio económico del sistema que hacía imperiosa su revisión. Conjurada esta posibilidad elusiva, se asegura una mayor transparencia y eficiencia en la utilización social y económica de los recursos financieros disponibles, para que los beneficios a que da derecho la seguridad social sean prestados en forma adecuada, oportuna y suficiente. Así pues, como se dijo, la reforma al régimen de los empleados del servicio doméstico contribuye a la eficacia de su derecho a la seguridad social, y de los derechos de los demás afiliados al sistema en general. (Corte Constitucional en Sentencia C-967, 2003, punto VI.G.3.15) 
Para complementar lo anteriormente expuesto por la Corte, es importante hacer referencia a la intervención del Ministerio Público para el caso planteado, donde advierte que:

A pesar de recibir una parte de la remuneración en especie, el trabajador doméstico nunca puede recibir menos del salario mínimo, salario sobre el cual sólo debe pagar el $25 \%$ de la cotización, ya que el otro $75 \%$ le corresponde al empleador. En este sentido, antes que ir en contravía de la realidad nacional, el legislador persigue que en el futuro nadie sea remunerado por debajo de la cifra considerada mínima. (Corte Constitucional en Sentencia C-967, 2003, punto V.)

Si bien con la demanda, se buscaba salvaguardar el derechos con los que el Estado auxiliaba ${ }^{*}$ los trabajadores del servicio doméstico, la Corte en la parte motiva señala las razones por las cuales con la norma el Estado busca garantizar la eficacia del sistema de seguridad social, la equidad y la formalización de la labor desarrollada por estos trabajadores al pretender fomentar su remuneración justa, ya que a lo largo del tiempo han sido discriminados en virtud de las labores desempeñadas en el hogar. Claramente este pronunciamiento de la Corte está acorde con los preceptos de la OIT en cuanto a la progresividad en lo concerniente a la protección social.

Continua la Corte desarrollando su jurisprudencia en la Sentencia C- 967 de 2003 con respecto a los trabajadores domésticos en el sistema de seguridad social, inicia el análisis de la norma ${ }^{*}$ ya cita y decanta en el artículo 145 de Código Sustantivo del trabajo, el cual desarrolla el artículo 53 de la Constitución del cual concluye la Corte que "todos los trabajadores colombianos deben obtener una remuneración equivalente al salario mínimo legal vigente. En efecto, de conformidad con esa norma el salario mínimo es el que todo trabajador tiene derecho a percibir para subvenir a sus necesidades normales y a las de su familia, en el orden material, moral y cultural. Ahora bien, dice el artículo 132 del mismo estatuto laboral que el empleador y el trabajador pueden convenir libremente el salario en sus diversas modalidades, como por unidad

\footnotetext{
"Decreto 824 de 1988: Artículo 13. El trabajador del servicio doméstico que devengue una remuneración inferior al salario mínimo legal, cotizará para el seguro social sobre la base de dicha remuneración, sin que en ningún caso el porcentaje de la cotización pueda aplicarse sobre una cuantía inferior al 50\% del salario mínimo legal. Será de cargo del Gobierno Nacional, la diferencia existente entre el valor resultante del cálculo efectuado por el Instituto sobre la base del salario mínimo legal vigente y el valor de los aportes cubiertos por los patronos y trabajadores, conforme lo establecido en el artículo anterior.

*Artículo 5 (parcial) de la Ley 797 de 2003, que modificó el inciso 4º y parágrafo del artículo 18 de la Ley 100 de 1993.
} 
de tiempo, por obra, o a destajo y por tarea, etc., "pero siempre respetando el salario mínimo legal”; y el artículo siguiente agrega que "se denomina jornal el salario estipulado por días y sueldo el estipulado por períodos mayores".

Consecuentemente concluye La Corte que es posible contratar un trabajador por días, estipulando un jornal diario, pero que en todo caso la remuneración de cada día de trabajo debe respetar la noción de salario mínimo. Es claro que según la ley todo trabajador debe ser remunerado con un salario igual o superior al mínimo legal, sin embargo, por efecto de la remuneración por jornal, cuando no trabaje todos los días laborales de la semana, el monto total acumulado de lo que recibe durante un mes puede resultar inferior al salario mínimo legal mensual vigente.

En el caso de empleados del servicio doméstico que, por trabajar algunos días de la semana, no devengan mensualmente el salario mínimo mensual legal vigente, a pesar de ser remunerados conforme a la ley con el salario mínimo legal diario vigente. No obstante, el artículo $5^{\circ}$ de la Ley 797 de 2003, en el aparte acusado, los obliga a cotizar a salud como si recibieran efectivamente el salario mínimo mensual legal diario vigente.

Debe resaltarse que la situación en la que se encuentran los trabajadores del servicio doméstico que laboran por días sólo algunos días de la semana, puede darse también respecto de otra clase de trabajadores cuya remuneración se haya convenido por jornal. No obstante, estos últimos no estaban cobijados anteriormente por la excepción que se ha hecho referencia.

Los pronunciamientos de la Corte Constitucional continúan en la línea de dignificar la labor desarrollada por los trabajadores del servicio doméstico, aún cuando en las decisiones de la Corte Constitucional no se habla de Trabajo Decente, si se observa que estas se encuentran encaminadas a salvaguarda los derechos Constitucionales de los trabajadores del servicio doméstico; en el análisis de la sentencia C-1004 de 2005,se centra en el principio de igualdad que tienen los trabajadores del servicio doméstico, en relación a los demás grupos de trabajadores, se destaca que en la demanda el accionante acusa apartes de los Artículos 223 y 229 de la Ley 141 de 1961, pero que para efectos de la investigación el enfoque se realizará respecto al artículo 229, puesto la Corte se ha declarado inhibida debido a la derogatoria tácita del artículo 223.

En la Sentencia C-1004 de 2005 La Corte cita el artículo 206 de la ley 100 de 1993, considerando que en el caso de incapacidad para desempeñar labores, ocasionada por 
enfermedad no profesional la norma expresa que "el trabajador tiene derecho a que el Sistema General de Seguridad Social en Salud le pague un auxilio monetario hasta por ciento ochenta (180) días, así: las dos terceras (2/3) partes del salario durante los noventa (90) días y la mitad (1/2) del salario por el tiempo restante." Mientras que en el artículo 229 Literal d del C.S.T. establece que en la misma situación, por excepción, los trabajadores del servicio doméstico tienen derecho al pago íntegro de su salario hasta por un (1) mes.

Ante ello La Corte observa “... un aspecto desfavorable, concerniente al valor del auxilio monetario en relación con el tiempo de su reconocimiento, en cuanto la regla general otorga el auxilio hasta por ciento ochenta (180) días y la excepción lo confiere hasta por un (1) mes.” El fin del trato diferente y desfavorable para los trabajadores del servicio doméstico era favorecer la economía familiar de los empleadores, pues el pago estaba a cargo del patrono atendiendo al artículo 227 de C.S.T.

Lo anterior permite deducir la no discriminación de los trabajadores del servicio doméstico ya sea de forma favorable o desfavorable, frente a los demás grupos de trabajadores, como se observa en el artículo objeto de estudio de constitucionalidad, señala la Corte que considerando que la norma fue expedida con el fin de favorecer a los patronos, quienes debían pagar directamente el auxilio monetario por enfermedad no profesional a los trabajadores, pero advirtiendo que este fin ya no existe, “en virtud de las disposiciones de la Ley 100 de 1993 del reconocimiento y pago de dicho auxilio está a cargo del Sistema General de Seguridad Social en Salud, con base en la afiliación correspondiente del trabajador, de carácter obligatorio para todo empleador".

Del estudio que al respecto realiza la Corte Sentencia C-310 de 2007seresalta, la percepción socioeconómica y jurídica que se ha tenido de la actividad doméstica. Para La Corte el trabajo en el hogar es una actividad invisible para el resto de la sociedad. Aun cuando contribuyen a la producción y a la reproducción social y económica no se le ha dado la importancia que requiere y por el contrario se a subvalorado dicha labor.

Por lo tanto establece el ente colegiado que "el tratamiento que prodiga la norma acusada es discriminatorio, lo cual se hace aún más evidente al comparar el caso de los trabajadores domésticos con la situación de los conductores de vehículos de una familia, a quienes la ley laboral ordena aplicar las disposiciones establecidas para los domésticos, pero les reconoce el 
régimen ordinario de liquidación en materia de cesantía, vacaciones remuneradas y auxilio en caso de enfermedad no profesional" (Corte Constitucional, 2007)

En efecto, si conforme con los dictados superiores el salario en especie también es salario, hoy en día no se explica cómo el legislador desconoce su naturaleza retributiva, afectando de paso el ingreso del trabajador doméstico, quien por disposición de la norma acusada, Artículo 252, numeral 2 del C.S. del Trabajo, se ve privado de contar con la totalidad de su remuneración, como base, a fin de poder satisfacer necesidades esenciales en los aspectos ya referidos. Consecuentemente el auxilio de cesantía para trabajadores del servicio doméstico debe pagarse en dinero y en ningún caso será inferior a un salario mínimo legal mensual vigente, por cada año de servicios y proporcionalmente por fracciones de año.

El argumento esgrimido se contrapone al presentado por los magistrados que realizaron tanto aclaración como salvamento de voto, quienes indican la clara discriminación e inequidad con la cual se tratan a este grupo de trabajadores. El magistrado Jaime Araujo Rentería fundamentó su salvamento de voto en el principio de interpretación conforme con el fin de ajustarse a la Constitución e indicó “que la restricción para el computo de la cesantía sólo con base en el salario pagado en dinero, es inconstitucional" añadió que "el cálculo de la cesantía para trabajadores del servicio doméstico, debe realizarse de un lado, con base en el salario en dinero, el cual no podrá ser menor a un salario mínimo legal vigente por año y, respecto del salario en especie, el cual puede equivaler hasta un máximo del 30\% del salario mínimo pagado en dinero, porcentaje que debe sumarse al monto de cesantía calculado respecto del salario en dinero."

El magistrado profundiza en una de las principales problemáticas que existe al interior de este grupo de trabajadores y parte del desmedro de los derechos laborales de los trabajadores hasta el encubrimiento de la esclavitud del nuevo siglo.

\section{Expresó el magistrado Jaime Araujo Rentería}

La cesantía se debe pagar siempre en dinero y en todo caso no debe ser inferior al salario mínimo legal vigente...es necesario señalar que la circunstancia de que la cesantía se paga siempre en dinero no significa que no pueda seguir existiendo un salario en especie que debe pagarse de acuerdo con las reglas legales y que se debe valorar también conjuntamente con el salario en dinero, que es el efecto que a mi juicio trae la declaratoria de inexequibilidad de la 
expresión "solo". (Corte Constitucional, Sentencia C-310, 2007, Aclaración de Voto M. Jaime Araujo Renteria, Punto 4.)

Concluye el magistrado "que en el fondo el reclamo contra la norma acusada radicaba en la reducción del valor de la cesantía de los trabajadores domésticos al no tener en cuenta el salario en especie, cuestión que no se soluciona del todo con la fórmula resolutiva de la presente sentencia, pues se declara inconstitucional el que el cálculo de las cesantías se realice solo con base en el salario pagado en dinero, se excluye el pago de cesantías en dinero y el que este pago sea inferior a un salario mínimo legal vigente por año de trabajo, pero no se condiciona también a que se contabilice para el cálculo de la cesantía los elementos del salario que se pagan en especie"

La acción de tutela como mecanismo subsidiario para la defensa de los derechos fundamentales de los colombianos brinda protección a los trabajadores del servicio doméstico se puede observar en sentencias T- 237 de 2011 y T-387 de 2011, donde la Corte observa la necesidad de proteger a personas que por su labor u oficio son discriminadas y se encuentran en estado de indefensión, la Corte hace referenciase refiere a los riesgos a los cuales se encuentran expuestos lo trabajadores del servicio doméstico, por parte de los empleadores, como lo es el sometimiento a acoso sexual o físico, violencia, retención de salarios y documentos, la subvaloración de las tareas realizadas hasta la no vinculación a la seguridad social. Por estas y otras razones, atendiendo a los pronunciamientos de la Organización Internacional del Trabajo, se considera que los trabajadores domésticos están en situación de vulnerabilidad y demandan, por lo tanto, la protección del Estado.

Considera la Corte que la subsidiaridad como característica de la acción de tutela ante la existencia de otros mecanismos de defensa judicial torna en principio improcedente la acción, pero considerando el artículo 86 de la Constitución, se puede actuar ante la presencia de un perjuicio irremediable y por ende proceder al amparo transitorio del derecho. Estos pronunciamientos dignifican la labor desarrollada por este grupo de trabajadores que bajo los nuevos lineamientos de la OIT, se ven amparados, no solo por los conceptos internacionales de Trabajo Decente, sino que se observa como los órganos nacionales propenden por el respeto, la protección y la dignificación de los derechos laborales de los trabajadores (as) del servicio doméstico. Así en la sentencia T-237 de 2011 con la tutela se propende por proteger a los 
trabajadores del servicio doméstico de omisiones del patrono, por ejemplo en la afiliación a seguridad social del trabajador son graves y comprometen su responsabilidad personal, por tal razón y ante la vulnerabilidad del trabajador La Corte considera idónea a la tutela como medio para el reconocimiento y pago de incapacidades laborales. Indica la Corte que "ha señalado reiteradamente que el pago de tales incapacidades suple el salario durante el tiempo en el cual el trabajador se encuentra forzosamente al margen de sus labores, de manera que se garantice no sólo su satisfactorio restablecimiento, sino una subsistencia en condiciones dignas, en concordancia con el artículo 53 superior”.

También es el caso de la sentencia T-180 de 2012 con la cual se busca salvaguardar a este grupo de trabajadores que se encuentren en estado de vulnerabilidad ante las misiones diplomáticas, las cuales alegan la protección del derecho internacional y la Convención de Viena con el fin de evadir, en algunos casos, sus responsabilidades en los países donde desarrollan sus actividades diplomáticas, en este caso se busca salvaguardar los derechos fundamentales y la estabilidad laboral reforzada de mujer en embarazo.

La Corte establece que mediante el estudio del caso se busca:

Determinar el alcance de las obligaciones de las misiones diplomáticas en materia de estabilidad laboral frente a mujeres en estado de embarazo es un asunto que trasciende al caso concreto y proyecta sobre el mismo un interés desde la dimensión objetiva de los derechos fundamentales, ya que las garantías laborales de un grupo laboral frente a cuerpos diplomáticos constituye un asunto de interés general en materia de derechos fundamentales, en la medida en que atañe a la forma social del Estado colombiano, donde el trabajo constituye un principio fundante, y la protección de grupos vulnerables es un mandato imperioso derivado del principio de igualdad material. (Corte Constitucional, Sent. T-180, 2012, punto, II.3. párrafo12)

La Corte señala en su parte motiva los artículos XXXI Y XXXIII de la Convención de Viena sobre relaciones Diplomáticas de 18 de abril de 1961, adoptada en Colombia por la Ley 6 de 1972, por la cual se aprueba la "Convención de Viena sobre Relaciones Diplomáticas" hecha en Viena el 18 de abril de 1961 e indica: 
Por interpretación restrictiva de los tratados, los agentes diplomáticos de las misiones o delegaciones acreditas en un país extranjero, no gozan de inmunidad de jurisdicción laboral. Esta situación se armoniza con el hecho de que el artículo XXXIII de la Convención dispone que los agentes diplomáticos deberán cumplir las normas que en materia de Seguridad Social imponga el Estado receptor a los empleadores, con respecto a los "criados particulares" que presten servicios exclusivos a un agente diplomático, siempre y cuando los trabajadores sean (i) nacionales del Estado receptor, o (ii) tengan su residencia permanente en dicho Estado. En el caso concreto, la parte accionada indica que la señora Luz Andrea Sana, ciudadana colombiana, fungió como empleada personal en el hogar del señor ex Embajador Ahmad Parbaja, lo que, en los términos de la Convención sería equivalente a afirmar que laboró como “criada particular" del señor ex Embajador Ahmad Pabarja, en su momento, jefe de la misión de la Embajada de la República Islámica de Irán en Colombia. (Corte Constitucional, Sent. T180, 2012, punto, II.4.2.1. Párrafo 15)

En el análisis que efectúa la Corte respecto del caso en concreto, apuntan a examinar a quien prestaba directamente sus servicios la actora, toda vez que ella indica que fue contratada por la embajada y el representante legal de la embajada y el embajador indican que fue contratada, con el fin de colaborar a la Señora Fátima con la organización de las cosas para el viaje. La Corte expresa que debido a que el contrato no fue claramente pactado por duración de obra ni por término fijo (en cuyo caso debería constar con escrito), de manera que las reglas aplicables a este trámite son las del contrato a término indefinido. La Corte se determina que:

El señor ex Embajador Ahmad Pabarja en calidad de agente diplomático de la Embajada de la República Islámica de Irán, vulneró el derecho fundamental a la estabilidad laboral reforzada de la ciudadana colombiana Luz Andrea Sana, quien fungía como su "criada particular," al dar por terminado su contrato de trabajo, estando embarazada y desconoció las normas internas sobre Seguridad Social, que en virtud del artículo XXXIII de la Convención de Viena sobre Relaciones Diplomáticas de 1961, adoptada en Colombia por la Ley 6 de 1972, deben ser acatadas por los agentes diplomáticos de las misiones o delegaciones extranjeras acreditas en nuestro país.(Corte Constitucional, Sent. T-180, 2012, punto, II.7. Párrafo 1) 
Por último se examina la sentencia T-1078 de 2012con la cual se logra demostrar la delgada línea que divide el desarrollo de la labor de servicio doméstico con la trata de personas y la esclavitud. Si bien con la sentencia no se pretende la protección de derechos laborales si busca salvaguardar el principio de dignidad y devolver a la accionante su nombre, su pasado y establecer la verdad y la justicia, todo lo cual concuerda con el articulado del Convenio 189, que busca que el Estado se comprometa con la erradicación de trabajos denigrantes, trabajos forzosos y el trabajo infantil.

Observa la Corte que ante el caso en particular las acciones de tipo laboral, civil y penal han prescrito, pero "a juicio de la Sala, de un lado, la prescripción y caducidad de las acciones no puede ser imputadas a la demandante, de otro lado, tales acciones no eran en todo caso idóneas para la protección de los derechos fundamentales de la peticionaria."(Corte Constitucional, T1078, 2012, punto, 2.5.2.2. Párrafo 1)

Argumenta la Corte que para el caso "no puede declararse improcedente la tutela bajo el argumento de que Amalia dejó caducar y prescribir los mecanismos judiciales que tenía a su alcance, pues tal argumento desconoce la complejidad de los fenómenos de trata de personas y sometimiento a trabajo forzoso, en particular la dificultad que tienen las víctimas para auto reconocerse como tales y superar su miedo frente a los perpetradores para denunciar." (Corte Constitucional, T-1078, 2012, punto, 2.5.2.2. Párrafo2)

Al respecto se trae a colación lo expresado por la OIT en el 2011 respecto al trabajo infantil:

El trabajo infantil doméstico (TID) en casa de terceros es una de las formas más comunes y tradicionales de trabajo infantil. Son "trabajadores invisibles", ya que sus labores son efectuadas al interior de casas que no son las suyas, sin ningún sistema de control y lejos de su propia familia. Este grupo es probablemente el más vulnerable y explotado así como el más difícil de proteger. Trabajo infantil es toda actividad económica realizada por niños y niñas que están por debajo de la edad mínima permitida por la legislación nacional. Para el caso de adolescentes (sobre la edad mínima pero menores de 18 años) son consideradas como trabajo infantil las actividades que interfieren con su educación, que se realizan en ambientes peligrosos y/o en condiciones que afecten su desarrollo psicológico, físico, social y moral, es 
decir, todo trabajo que les priva de su infancia, su educación y su dignidad. (OIT, Nota No.3, 2011, p.1)

Con esta sentencia la Corte rompe precedentes y salvaguarda los derechos fundamentales de la accionante, al incorporar los conceptos de la OIT sobre trabajo infantil y trata de personas, se establece la necesidad de volver visible un flagelo que viola derechos humanos y principios Constitucionales en el territorio nacional y que así mismo es un flagelo que trascienden fronteras, esta es la razón por la cual la OIT busca el compromiso de los gobiernos para la generación de Trabajo Decente y erradicar la trata de personas, el trabajo infantil y las formas degradantes de trabajo, se observa como por medio de sus pronunciamientos el órgano colegiado cumple con las nociones de la OIT en lo referente al Trabajo Decente y lo aplica a los trabajadores del servicio doméstico.

Cabe indicar que la Procuraduría General de la República (2011), desarrollo una investigación sobre Trabajo Decente y Digno en Colombia y con respecto al trabajo forzoso expresó que:

Sobre el tema no existen indicadores que den cuenta de prácticas de trabajo forzoso en el país. Cabe recordar que estas prácticas no se limitan solo al trabajo que se ejerce por coacción física a favor de un tercero, sino también a otras formas más sutiles que utilizan los empleadores para exigir a los individuos la realización de un trabajo o la prestación de un servicio, bajo la amenaza de una pena cualquiera, sin que la persona se haya ofrecido voluntariamente.

Entre estas prácticas se encuentra la servidumbre por deudas, el trabajar horas extras de manera obligatoria y sin consentimiento del empleado, la trata de personas, el trabajo no remunerado o la realización involuntaria de un trabajo en determinadas circunstancias como forma de condicionar la continuidad en el empleo. Muchas de estas prácticas hacen parte de la cotidianidad de los trabajadores, en parte porque existen barreras al acceso a la justicia o a los mecanismos de denuncia para combatirlas. Al respecto, la inspección laboral del Ministerio de la Protección Social debería incorporar formas de identificar estas prácticas para diseñar así una política que logre erradicarlas definitivamente. (Procuraduría General de la Nación, 2011, p. 61) 
Se determina que la Sentencia C-616 de 2013, es la sentencia arquimédica por ser la que reúne los conceptos emitidos con anterioridad por la Corte Constitucional, en el análisis que realiza de la adopción del Convenio 189 su análisis encuentra total concordancia entre el convenio 189 con la Constitución, en la sentencia la Corte lleva a cabo el análisis de cada uno de los artículos y su concordancia con la norma interna y con los pronunciamientos en los cuales ya la Corte ha venido adelantando la protección de ese tipo de derechos.

Contrario con lo expresado por la Corte en sentencia C-372 del 1998 donde indicaba la posibilidad de generar un impacto socio-económico negativo que llevaría al desempleo en este grupo de trabajadores con la declaratoria de inexequibilidad de la norma demandada, la OIT mediante convenio 189, crea un argumento totalmente diferente pues como lo expresa el profesor Jorge Eliécer Manrique Villanueva en su intervención por la Universidad Externado de Colombia, con el fortalecimiento de las normas laborales para este grupo de trabajadores se podrá:

(i) crear trabajo; (ii) garantizar los derechos de los trabajadores; (iii) extender la protección social; y (iii) promover el diálogo social. Por ende, el objetivo general del tratado no es otro que extender cada uno estos tópicos para el caso particular de las trabajadoras y trabajadores domésticos, quienes están por lo general vinculados a través de mecanismos informales que no garantizan las condiciones laborales mínimas. (Corte Constitucional, Sent. C-616, 2013, punto III.3.4.)

Si bien el carácter unificador que el Convenio 189 trae a la normatividad colombiana, para brindar seguridad jurídica y comprometer a los gobierno en mejorar los mecanismos de protección de los trabajadores del servicio doméstico, cabe resaltar que por la naturaleza del trabajo doméstico, como ya se ha indicado en varias ocasiones por la Corte, tiende a ser ocultado en la sociedad, por lo tanto el alcance de la norma queda en la simple buena voluntad sin generar un impacto real en la sociedad que permita transformar el trabajo del hogar en un trabajo digno y decente para todas aquellas personas que lo realizan.

Es esencial que para el fortalecimiento de los derechos fundamentales y laborales de los trabajadores del servicio doméstico, se gesten por intermedio de estas normas, políticas públicas que permitan volver visible esta labor, con el fin de fomentar el empleo, mejorar la calidad de 
vida y erradicar consigo las formas denigrantes de trabajo, el trabajo infantil, el trabajo forzoso y la esclavitud.

Finalmente con la sentencia C- 871 de 2014, la Corte Constitucional dio el último gran paso en el cumplimiento no solo de la Constitución y las Leyes sino de los Convenios Internacionales firmados, en particular el Convenio 189 de la OIT, al exhortar al Gobierno Nacional y al Congreso de la República para la creación de la norma tendiente a equiparar los derechos laborales de los Trabajadores del Servicio Doméstico en el marco del Trabajo Decente. A partir del salvamento de voto propuesto por el Magistrado Jorge Iván Palacio Palacio, se hace un llamado a la igualdad, a la protección, a valorar y a hacer visible la labor doméstica, es claro que la declaratoria de inexequibilidad, transformaría la realidad jurídica de las primas de servicio para este grupo de trabajadores, pero concuerdo con la corte cuando prevé el posible impacto económico de la norma, por lo tanto es prudente un análisis económico del derecho, para determinar el modelo que se aplicaría mejor para salvaguardar el derecho de los trabajadores del servicio doméstico al pago de la prima de servicios.

Se resalta en la sentencia las posiciones de las entidades que se pronunciaron al respecto que fueron el Ministerio del Trabajo y la Procuraduría, los dos organismos instan al órgano colegiado a declararse inhibida para pronunciarse sobre al tema en cuestión, la posición adoptada argumenta básicamente que la Corte ya se había pronunciado con anterioridad con relación al artículo en mención. Lo que no queda claro es como estas dos entidades que han llevado actividades en pro de los derechos de los trabajadores del servicio doméstico, se opongan a la creación de políticas públicas que en definitiva brinde a estos trabajadores la protección e igualdad constitucional definitiva y en el marco del Convenio 189 de la OIT.

A continuación se presenta la tabla donde se aprecia la Línea Jurisprudencial. 


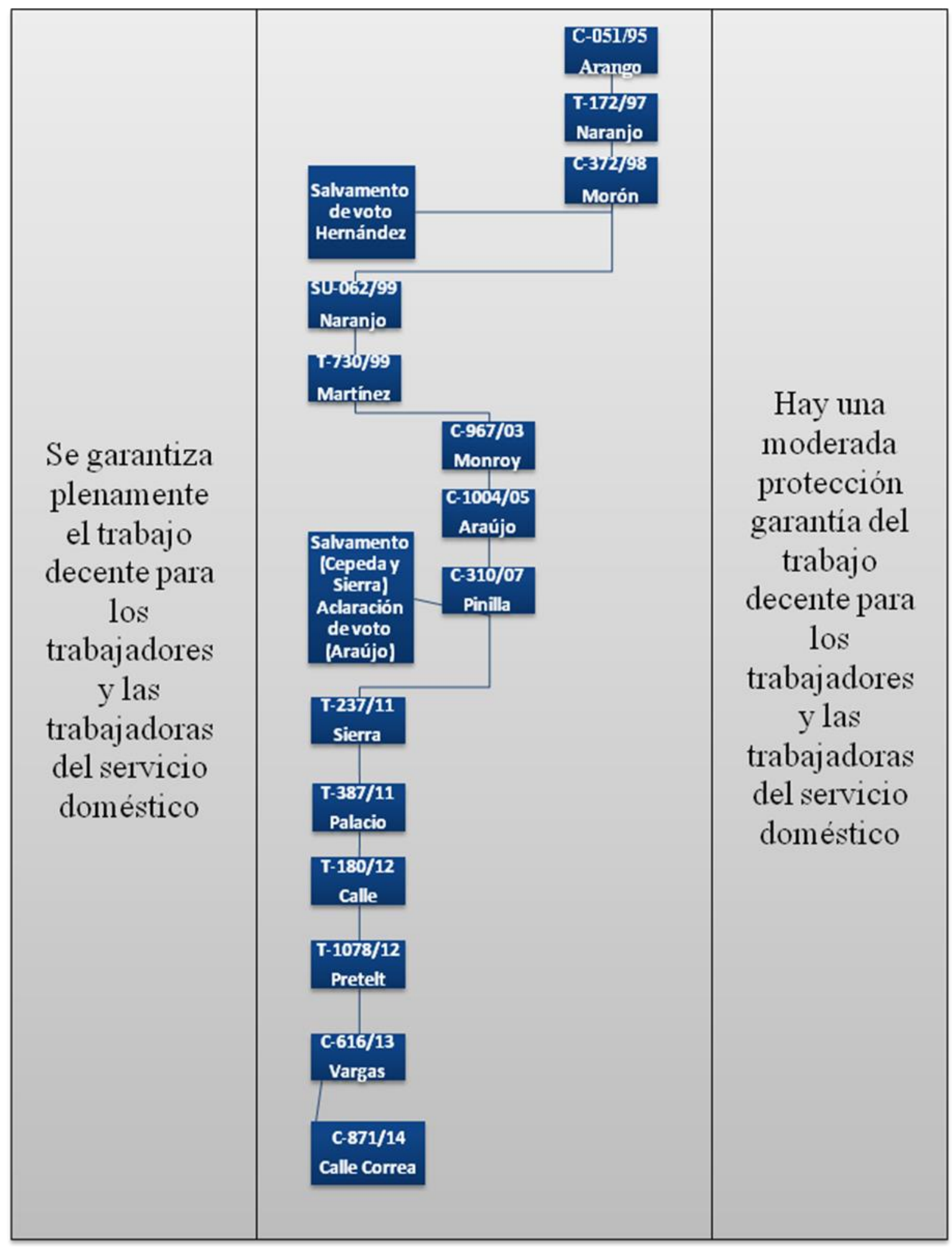

Figura 5. Línea Jurisprudencial 


\subsubsection{Línea Jurisprudencial Trabajo Decente para los Trabajadores Domésticos en la Corte Suprema de Justicia}

Estudiada la línea jurisprudencial que indica si, por parte de la Corte Constitucional se garantiza el Trabajo Decente para los trabajadores domésticos, se procede a la investigación de las sentencias de tutela relevantes para el análisis jurisprudencia del trabajo decente para los trabajadores domésticos del periodo de 1990 hasta 2013, emanadas por la Corte Suprema de Justicia, y que cuentan como sujetos de derecho las personas que laboran en el servicio doméstico.

Al examinar las sentencias de tutela de la Corte Suprema de Justicia relacionadas con este grupo de trabajadores y la garantía de un Trabajo Decente, se lograron rastrear o ubicar22 acciones de tutela, de las cuales al estudiar su contenido se consideraron viables para el desarrollo de una posible línea jurisprudencial, tan solo10. El común denominador del noventa por ciento de estas sentencias fue el derecho fundamental del debido proceso, solo en la sentencia T-34350 de 2013, no se habla de este, ya que estaba dirigido a la protección de derechos laborales ante misiones diplomáticas.

Por ejemplo en el expediente sentencia con radicado 4377de 1999 respecto de la negación al acceso a la salud a una empleada del servicio doméstico, alegando la indebida afiliación expresada en el literal b, artículo 5 del decreto 824 de 1998, al observar el caso se encuentra la diferencia entre los pronunciamientos de la Corte Constitucional y la Corte Suprema de Justicia. Los pronunciamientos de la segunda se ciñen totalmente a la norma sin realizar mayor análisis o apreciación entre el derecho vulnerado, la norma y la Constitución.

Tal es el caso del argumento esgrimido por la Corte Suprema de Justicia respecto al derecho a la salud, definiéndolo como un derecho programático y que por lo tanto, no puede ser calificado como un derecho fundamental; esta tesis difiere a la posición adoptada por la Corte Constitucional en sentencia T-730 de 1999, que al analizar el caso desde la órbita constitucional, en atención al espíritu de la norma, pasa de negar el derecho a la salud, a buscar alternativas para el cumplimiento por parte de la cotizante y su empleador, con el fin de evitar el fraude al sistema, sin vulnerar los derechos de la trabajadora.

Al efectuar el planteamiento que estuvo presente en el análisis de la línea jurisprudencial de las sentencias de tutela de la Corte Suprema de Justicia, tendiente a establecer si se garantiza en 
Colombia el Trabajo Decente para los trabajadores del servicio doméstico, se puede llegar a dos conclusiones:

La primera, parte del común denominador de las sentencias analizadas, si bien son pocas, todas tienen algo en común y es el sentimiento de vulnerabilidad de los accionantes, dentro de los procesos ordinarios, que conduce a instaurar la correspondiente acción de tutela, toda vez, que no vieron salvaguardados sus derechos constitucionales y legales, lo anterior llevaría a plantear otro tipo de investigación con el fin de estudiar el fenómeno del Trabajo Decente para los trabajadores domésticos, ya no desde la acción de tutela, sino enfocado en el mecanismo jurisdiccional idóneo creado para salvaguardar las leyes y la correcta administración de justicia laboral.

El planteamiento anterior se presenta a partir del sentir de las accionantes, quienes ven que mediante el proceso ordinario les fueron vulnerados sus derechos, en la mayor parte de los argumentos presentados se habla en específico sobre la valoración de la prueba que los jueces realizan para la adopción de la postura frente a las pretensiones de la parte actora y finalmente dictaminar la subsecuente sentencia. Para estos casos, el derecho procesal es el que brinda a los jueces las herramientas de análisis para cumplir con su labor de administrar justicia, por lo tanto en sus sentencias es poco común que medie otro tipo de intereses, más que el cumplimiento de los parámetros jurídicos, esta razón es esgrimida por la Corte Suprema en las Sentencias de tutela, con el fin de negar la acción constitucional.

En los casos concretos de las sentencias analizadas, se observa que la Corte Suprema no profundiza en el análisis de los hechos, solo observa los argumentos presentados por las accionantes.

En la Sentencia Radicado No.23504 de 2010 seniega la procedencia de la tutela contra la decisión judicial de segunda instancia que revocó la decisión de primera instancia que ordenaba el pago de las cotizaciones de pensión a la demandante trabajadora del servicio doméstico. Si bien en el argumento presentado por la Corte Suprema se observa que el órgano, parte su motiva desde la óptica procesal al indicar que la accionante no agotó los recursos procesales para acudir a un mecanismo que por su naturaleza de subsidiariedad, se invoca cuando se han agotado los demás mecanismos, se debe resaltar que su función como mecanismo expedito y de sencillo manejo, permite la protección de quien ve vulnerados sus derechos fundamentales. 
Atendiendo las funciones constitucionales y legales del juez de tutela, se cita para el caso el Auto 053 de 2002 de la Corte Constitucional que expresa al respecto:

En esta medida lo dispuesto por la Constitución Política es un mecanismo que le confía a los jueces la función de verificar el efectivo cumplimiento de los mandatos constitucionales de protección y primacía de los derechos inalienables de la persona y cuando encuentre configurada la vulneración o amenaza de un derecho fundamental, por acción o por omisión, imparta las órdenes de inmediato cumplimiento necesarias para salvaguardar efectivamente el derecho vulnerado. Una actuación superficial y formalista pone en peligro el derecho de acceso a la justicia al dejar desprotegido a quien solicita la protección constitucional de sus derechos fundamentales y por lo mismo desconoce el mandato del artículo 86 superior. (Corte Constitucional, 2002, Auto 053)

Que la Corte Suprema en su función de juez de tutela, solo fundamente su argumento en el procedimiento, sin desarrollar el aspecto subjetivo del caso en concreto y salvaguardar los derechos fundamentales de los ciudadanos, deja de manifiesto el estado de vulnerabilidad de este grupo de trabajadores, quienes no solo se encuentra en clara desventaja, debilidad e indefensión frente a sus empleadores sino que no cuentan con protección efectiva y eficaz de sus derechos fundamentales.

Lo anterior permite presentar la segunda conclusión y tiene que ver con los resultados arrojados de las sentencias en las cuales se observa con respecto a los casos planteados por trabajadores del servicio doméstico, que no hay una protección especial ni garantía de Trabajo Decente, en atención a lo particular de su relación laboral y al ámbito privado en el cual se desarrolla, los jueces en los análisis planteados no hacen referencia a este hecho en particular, lo cual es un indicativo de la inexistencia de la protección de este grupo de trabajadores.

Es la falta de garantías y la ineficacia en la protección de los derechos a este grupo de trabajadores la razón que desmotiva a los mismo a presentarse ante la jurisdicción a reclamar sus derechos, puesto el desconocimiento de las leyes y en particular del derecho procesal, lo que conlleva a falla en la recolección de las pruebas que sustente sus derechos laborales y constitucionales. 
En el caso tratado en la Sentencia Radicado No. 28774 de 2012, la accionante laboró como empleada doméstica y durante el tiempo señalado laboró de lunes a domingo, bajo la continuada subordinación de su empleadora, a la accionante nunca le fueron pagadas las prestaciones sociales a las que tiene derecho, ni fue afiliada al sistema general de seguridad social. En sentencias proferidas en primera y segunda instancia, se resolvió desfavorablemente, expresándose la falta de evidencia que determinara la existencia de una relación laboral ni los extremos de la relación.

La Corte Suprema de Justicia sostuvo que la acción de tutela contra sentencias judiciales es procedente en casos de grave amenaza o vulneración de derechos fundamentales por acción u omisión de la autoridad. La Corte realizó el estudio del caso y observó que los órganos accionados, cumplieron con su labor, estableciendo que no hubo vía de hecho, así mismo la sala reitera que el juez constitucional le está vedado interferir en asuntos del exclusivo resorte de los jueces naturales.

La posición que adopta la Corte Suprema de Justicia respecto a la acción de tutela frente a sentencias judiciales, deja de lado el estado de vulnerabilidad que les asiste a los trabajadores del servicio doméstico, la difícil consecución de la prueba, esta posición de la Corte Suprema en su rol de Juez Constitucional, deja entre dicho algunos principios del derecho laboral y constitucional, como lo son el principio de primacía de la realidad sobre las formas, el principio del juez como director del proceso, principio ultra petita, principio protector (norma más favorable, condición más beneficiosa y pro operario), el de interpretación de la norma, de aplicación suplementaria y el principio de protección al trabajo. Si bien es claro que el juez no puede transgredir los derechos de la otra parte, el juez constitucional tiene facultades más allá de la excusa planteada de seguridad jurídica, para no examinar los hechos de forma exhaustiva y corroborar que la falta de apreciación de la prueba puede conllevar de igual forma al menoscabo de los derechos legítimos y constitucionales.

Tal es el caso de los procesos de Radicado No. 27112 Acta No. 36 y Radicado No. 28774 Acta No. 16, donde no se realiza la condena por estimarse que no se logró establecer los extremos temporales de la relación laboral, es preciso que si se logra establecer la existencia del contrato, se condene al empleador, quien por su falta de colaboración con la justicia, debería ser sancionado por no actuar de buena fe e indicar efectivamente las fechas en las cuales se dio la relación laboral, por el contrario, se premia la actitud del empleador a quien se exonera del pago 
y se sanciona al trabajador quien aun después de demostrar la relación laboral, le son menoscabados sus derechos por no probar los extremos temporales.

Aun cuando en los casos seleccionados se niega la acción constitucional y se argumenta la inviabilidad por atentar contra los principios de autonomía, independencia, seguridad jurídica y vigencia del Estado Social de Derecho, se observa que en los casos de extremos laborales no precisa que el actor los pruebe, el juez como director del proceso tiene el deber de análisis tal como el Magistrado Ponente Carlos Ernesto Molina Monsalve en Sentencia SL-905-2013 Radicado No. 37865Acta No.40 expone:

Al respecto, en sentencia del 22 de marzo de 2006 Rad. 25580, reiterada en decisiones del 28 de abril de 2009 Rad. 33849 y 6 de marzo de 2012 Rad. 42167, dijo la Sala:

La jurisprudencia adoctrinada de esa Sala ha fijado el criterio según el cual, en estos casos, en que no se conocen con exactitud los extremos temporales, se podrían dar por establecidos en forma aproximada, cuando se tenga seguridad sobre la prestación de un servicio en un determinado período, para así poder calcular los derechos laborales o sociales que le correspondan al trabajador demandante. Al respecto, en sentencia de la CSJ Sala Laboral del 22 de marzo de 2006 Rad. 25580, reiterada en decisiones del 28 de abril de 2009 Rad. 33849 y 6 de marzo de 2012 Rad. 42167, se dijo:

“(...) Aunque no se encuentra precisada con exactitud la vigencia del contrato de trabajo, esta podría ser establecida en forma aproximada acudiendo a reiterada jurisprudencia sentada desde los tiempos del extinto Tribunal Supremo del Trabajo, según la cual cuando no se puedan dar por probadas las fechas precisas de inicio y terminación de la relación laboral, pero se tenga seguridad de acuerdo con los medios probatorios allegados sobre la prestación del servicio en un periodo de tiempo que a pesar de no concordar exactamente con la realidad da certeza de que en ese lapso ella se dio, habrá de tomarse como referente para el cálculo de los derechos laborales del trabajador.

En sentencia de 27 de enero de 1954, precisó el Tribunal Supremo:

Si bien es cierto que la jurisprudencia de este Tribunal ha sido constante en el sentido de que cuando quien debe demostrar el tiempo de servicio, y el salario devengado, no lo hace, no hay posibilidad legal para condenar al pago de prestaciones, salarios o indemnizaciones, es también evidente que cuando de las pruebas traídas a juicio se puede establecer sin lugar a 
dudas un término racionalmente aproximado durante el cual el trabajador haya servido, y existan por otra parte datos que permitan establecer la cuantía del salario devengado, es deber del juzgador desentrañar de esos elementos los hechos que permitan dar al trabajador la protección que las leyes sociales le garantizan>." (Negrilla fuera de texto)

En tales condiciones, si se trata de la fecha de ingreso, teniendo únicamente como información el año, se podría dar por probado como data de iniciación de laborales el último día del último mes del año, pues se tendría la convicción que por lo menos ese día lo trabajó. Empero frente al extremo final, siguiendo las mismas directrices, sería el primer día del primer mes, pues por lo menos un día de esa anualidad pudo haberlo laborado.

Cuando el trabajador demandante no precisa o no logra probar con exactitud la totalidad del tiempo servido a su empleador, no implica que deba perder el derecho a percibir los salarios o prestaciones sociales correspondientes al lapso de la actividad que logró demostrar judicialmente y, por tanto, la totalidad del tiempo servido es el que resulte probado en la litis. (CSJ, Sala Laboral, SL-905-2013 Radicado No. 37865Acta No.40, 2013, p. 12)

Si bien, no es una acción de tutela, se habla de impedir que pierda el trabajador el derecho, lo cual se debe de aplicar de forma contundente cuando está ante una relación laboral especial, como lo es el trabajo desarrollado por los trabajadores domésticos, que el juez constitucional indique que no hay una grave amenaza a los derechos fundamentales del trabajador, cuando no le fueron canceladas las acreencias, que hacen parte de su derecho al mínimo vital y móvil, a la seguridad social, a las prestaciones sociales y al derecho humano al trabajo, parece ser un argumento poco valido ante la clara violación de los derechos Constitucionales del accionante.

Hay que dejar claro que en algunos de los casos presentados, los hechos exponen una clara violación de derechos constitucionales, el desconocimiento de la norma lleva a los accionantes a presentar su inconformismo, ante los resultados del fallo y la no adquisición de los resultados esperados, esto no significa la violación de los derechos de orden constitucional.

El análisis presentado arroja como resultado, el desconocimiento del Trabajo Decente para los trabajadores del servicio doméstico, por parte de la jurisdicción ordinaria, lo cual indica la necesidad de capacitación del personal para el manejo de este tema en general, cabe resaltar que si bien, el concepto se desarrolla solo en el marco del Convenio 189 de la OIT, este no puede ser desconocido por la jurisdicción ordinaria en sus especialidades laboral y de seguridad social por 
cuanto comprende una política de orden público, que se debe tener presente en atención a los convenios y compromisos adoptados por Colombia con la Organización Internacional del Trabajo.

\subsubsection{Confrontación del Análisis Jurisprudencial Corte Constitucional y Corte Suprema de Justicia}

Una vez evidenciados los diferentes conceptos jurídicos de las altas cortes (Corte Suprema de Justicia y Corte Constitucional) en los puntos anteriores, frente al Trabajo Decente aplicado a las Relaciones laborales que se suscitan en el desarrollo del servicio doméstico, procederemos a analizar ya confrontar las diferencias conceptuales que arrojaron las líneas jurisprudenciales que se elaboraron a estos dos Cuerpos Colegiados. Al respecto cabe resaltar lo expresado por Molina quien indica que: "Desde los comienzos de la Constitución de 1991 ha habido diferencias entre la Corte Suprema de Justicia y la Corte Constitucional, pues se ha considerado dejan en entredicho uno de los principios esenciales del Estado de Derecho, como es el de la seguridad jurídica." (2003, pág. 68)

Lo expuesto por Molina deja de lado el concepto constitucional de Estado, instituido por la Carta de 1991, este punto de vista puede observarse en los pronunciamientos de tutela por parte de la Corte Suprema de Justicia, que al adoptar su fuero de juez constitucional no abandonó el antiguo concepto de Estado de Derecho con el fin de sostener el Principio de Seguridad jurídica sin atender al contemplado en el Artículo Primero de la Constitución de 1991 que precisa que Colombia es un Estado Social de Derecho, lo anterior implica un sustancial cambio de paradigma del papel que debe cumplir la rama judicial como lo expone Barreto:

La jurisprudencia de la Corte ha sido enfática en enunciar el nuevo y más comprometido papel del juez en los conflictos que conoce, como uno de los factores primordiales que diferencia las relaciones de poder en el Estado Social de Derecho, en contraposición con el Estado de derecho. Este nuevo papel del juez, en gran medida, es consecuencia apenas previsible de la necesidad de repartir justicia a individuos concretos: "la finalidad del Estado Social del derecho tiene como base para su interpretación finalística al ser humano, visto de manera concreta, esto es, con contenido, encontrándose con individuos materiales y no con 
entes abstractos". Incluso la Corte en la sentencia T-571/92 opta por un modo de concebir el contenido de tal individuo, como parámetro de interpretación judicial: "lo anterior se traduce en la prevalencia del ser sobre el tener o el haber dentro de un contexto que debe presidir las acciones de quienes son los encargados de administrar justicia en sus distintos niveles. Deberá tratarse a todas las personas sin distinción alguna, de acuerdo con su valor intrínseco. La integridad del ser humano constituye razón de ser, principio y fin del Estado

En un país como Colombia, donde la democracia formal y la estabilidad institucional han subsistido de la mano junto con una violencia recalcitrante, el juez constitucional, bajo los postulados del Estado Social de Derecho, ha llegado a optar por una visión de los poderes públicos que, según la Corte, es más inestable y conflictiva que la institucionalizada en el Estado de Derecho. En efecto, en el período del Estado liberal clásico "el poder legislativo asume un claro predominio sobre los demás, mientras el poder judicial es, en la práctica, políticamente neutralizado”. Esta actitud del juez en el Estado social de derecho sufre un cambio radical. Para demostrar esta afirmación, la clásica sentencia T-406/92, es quizás el mejor paradigma guía. Este fallo prescribe como cambio cualitativo fundamental del Estado social la "pérdida de la importancia sacramental del texto legal entendido como emanación de la voluntad popular y mayor preocupación por la justicia material y por el logro de soluciones que consulten la especificidad de los hechos", así ello vaya en detrimento de la seguridad jurídica. En otra decisión, la T-505/92, el juez se refieren a "la naturaleza social que identifica al ordenamiento jurídico [...] en la superación de la crisis del Estado de derecho como sinónimo de la legalidad abstracta". Como se ve, la ley ocupa un puesto de máxima importancia en el Estado de Derecho, lugar del cual es desplazado por la justicia material en el Estado social de derecho. (1999. Pág. 95)

Pese al cambio de paradigma que trajo consigo la Constitución de 1991, se observa que en la Corte Suprema de Justicia y la justicia ordinaria laboral se preserva el concepto de Estado de Derecho así como el Principio de Seguridad Jurídica como lo expone Molina; en contra posición se puede apreciar la constitucionalización del derecho expuesto por Barreto y que es adoptado por la Corte Constitucional en sus pronunciamientos los cuales consignan la protección de los derechos fundamentales del individuo, separándose de una Seguridad jurídica social, tal y como se observa en el fallo de tutela T-1078 de 2012, donde la Corte Constitucional, bajo el principio a 
la dignidad humana, de derecho a la identidad y a la familia, toma las medidas necesarias para restablecer los derechos de la accionante.

Por lo anterior es fundamental que para la protección de los derechos de los trabajadores del servicio doméstico y la garantía de trabajo decente, se unifiquen posiciones tal como lo expone el Consejo Superior de la Judicatura en el Módulo Sobre la Integración del Código General del Proceso al Proceso del Trabajo y de la Seguridad Social, de la Escuela Judicial Rodrigo Lara Bonilla, aquí se presenta un extracto del documento que platea la necesidad de salvaguardar derechos fundamentales aun sobre principios procesales como lo es el Principio de Congruencia:

Anteriormente ya se discutió si la extra y ultrapetita consagrada en el CPT y SS es una excepción al principio de congruencia, terminando en dos posiciones, unos que consideran que sí, pues el juez falla por fuera o más allá de lo pedido, y la otra, que no, porque la naturaleza de las obligaciones laborales es genérica y no específica como en el derecho civil. Pero hay más, lo más importante, derechos fundamentales:

Mientras en el artículo $7^{\circ}$ del Código General del Proceso hay una referencia a los derechos fundamentales constitucionales a los que debe acudir el juez cuando tenga dudas sobre la interpretación de sus normas, en la ley 1149 de 2007 se le ordena tomar todas las medidas necesarias para garantizar el respeto de los derechos fundamentales, aún así esas medidas no hayan sido solicitadas en la demanda, o en su contestación, pues son de oficio, insoslayables y obligatorias.

El reconocimiento del juez como ser humano, único e indivisible, conllevó al mandato del artículo $7^{\circ}$ de la ley 1149 de 2007, de juntar en una sola sus dos personalidades jurídicas, la de juez ordinario con la del juez constitucional. Poco a poco irá desapareciendo que un juez es dos, es decir uno ordinario y otro constitucional, lo que ha debido admitirse, contra toda lógica, por la necesidad de recrear la tutela como un mecanismo para consolidar el respeto a los principios y derechos de la Constitución de 1991 ante la férrea oposición de la tradición que solo le atribuía facultades para resolver los litigios. Las funciones separadas, por un lado de operador del proceso reglado en los códigos y, por el otro, de juez de tutela, implican una aceptación de doble personalidad contra natura que obviamente produce efectos ruinosos para los ciudadanos, cuando sus decisiones deben ser integrales, es decir basarse en el monismo, o 
sea el derecho es un solo que abarca desde la normatividad internacional, pasando por la constitucional hasta las disposiciones legales internas del país.

El respeto a los derechos fundamentales es la obsesión de los sectores más avanzados de la sociedad en el siglo XXI y tiene toda la preeminencia del caso. O como se expresó antes, sobre derechos fundamentales no puede haber litigio, pues el juez debe protegerlos inmediatamente conozca de su violación, sin esperar siquiera querella de parte.

Bajo este razonamiento, así no se haya pedido en la demanda el reconocimiento de un derecho fundamental, el juez debe ordenar su protección o cumplimiento, se halle el proceso en instancias o en el trámite del recurso de casación. Este desenvolvimiento lo había percibido ligeramente el legislador de lo social cuando estatuyó la sentencia extra y ultrapetita en Colombia y en otros países, como México, la suplencia de la demanda.

La diferencia del manejo del principio de congruencia en el campo civil frente al laboral radica que en el primero los derechos fundamentales sirven para obtener una correcta interpretación de una norma, mientras que en el segundo obligan a la acción y al cambio de las situaciones que generan su violación. Así el llamado principio de congruencia debe doblegarse frente a la corrección de la violación de los derechos fundamentales. (C.S. de la Judicatura, 2013, p.111. Recuperado: http://www.ejrlb.com/docs2016/modulo_laboral_cgp2015.pdf)

Del estudio de las anteriores Líneas Jurisprudenciales de Trabajo Decente para los Trabajadores del Servicio Doméstico, es posible observar como desde la Corte Constitucional quien en aplicación del Principio Fundamental de Dignidad Humana desarrolla la protección a este grupo de trabajadores; mientras que del estudio de la línea jurisprudencial de las sentencias de tutela provenientes de la Corte Suprema de Justicia, se observa y se logra evidenciar el desconocimiento del Trabajo Decente y los Derechos Fundamentales de los trabajadores del servicio doméstico; por eso es que se considera que tal posición que adopta la Corte Suprema de Justicia en sus decisiones se ajusta a los expuesto por Barreto quien referencia que estos fallos se basan en los preceptos jurídicos que traía consigo la jurisdicción ordinaria basada en conceptos de la Constitución de 1886, dejando de lado más de 20 años de cambio jurídico que trajo la Constitución de 1991. 
Lo anterior lleva a reforzar el análisis del Consejo de Estado al Proceso Laboral y se propone implementar en la jurisdicción ordinaria laboral, medidas que salvaguarden los derechos fundamentales de los trabajadores del servicio doméstico, tales como el desarrollo de talleres, seminarios y conferencias que provean de herramientas constitucionales a los jueces ordinarios y que les permita cumplir con el mandato Constitucional, así como el Convenio 189 de la OIT y garantizar Trabajo Decente para este grupo de trabajadores.

\section{Las Políticas Públicas y la Reivindicación de los Derechos Laborales para los Trabajadores del Servicio Doméstico}

Con el devenir de la historia, en el ámbito internacional y nacional, se evidencia que la lucha de los trabajadores del servicio doméstico por la reivindicación de sus derechos, ha sido una labor ardua y marcada por la estigmatización social, pero que con el tiempo dicha labor por salvaguardar sus derechos, ha dado sus frutos. Pues a partir de la reivindicación de derechos emanados de la relación laboral generó un gran impacto social, económico y político a nivel mundial; llevando a organismos internacionales como lo es la OIT, a reivindicar y socializar el derecho de este grupo de trabajadores por intermedio de la creación y socialización de políticas de trabajo decente que al día de hoy se encuentran enmarcadas en el Convenio 189.

Se observa que en un principio los avances en materia laboral se presentaron en los grandes sectores productivos de la economía y sus efectos se han extendido a los demás grupos de trabajadores; para efectos de la valoración de los mercados, se considera que con las políticas de globalización de la economía, las telecomunicaciones y la tecnología, relaciones laborales que a los ojos de las sociedades capitalistas pasaban desapercibidas, desestimadas, ignoradas, subvaloradas e invisibles adquieren un nuevo contexto y pasan a formar parte del sistema productivo de los Estados, como es el caso del trabajo doméstico, hoy por hoy incluido en el cálculo del Producto Interno Bruto Nacional, por solicitud de la OIT, con el propósito de hacer visible este grupo laboral.

El mayor logro para el mejoramiento de la calidad de vida de los trabajadores del servicio doméstico como ya se ha venido exponiendo surgió con la expedición del Convenio 189 de la Organización Internacional del Trabajo, aprobado en Colombia mediante ley 1595 de 2012, pero 
el gran reto no es solo la creación de normas. La verdadera misión se encuentra en el cambio de los paradigmas socio-culturales arraigados en un mundo con profundas raíces clasistas y esclavistas sustentadas también en el servilismo, razón que lleva a requerir de forma urgente el fortalecimiento de las instituciones encargadas del control, cumplimiento y vigilancia, así como en la creación de Políticas Públicas contundentes para la protección de este tipo de trabajadores que deben concretarse por intermedio de corrientes socio-económicas y enmarcadas en los postulados del Trabajo Decente.

Con el fin de contextualizar la realidad de este grupo de trabajadores, para efectos de la investigación, se consideró importante extraer la percepción de la labor que desarrollan y lo que para ellos significa el Convenio 189 y su contextualización en el ámbito nacional; pero por el entorno privado, es decir en los hogares, en el cual desarrollan su actividad, dificulta el acceso a cada uno de ellos. Debido a la imposibilidad de sacar una muestra clara y precisa que arrojará datos estadísticos efectivos, para extraer una visión de la realidad, se optó por realizar algunas entrevistas a organizaciones como la FUNDACIÓN MUJER Y FUTURO, LA ASOCIACIÓN DE TRABAJADORAS DEL HOGAR DE BUCARAMANGA, UTRAHOGAR, UTRASD y HABLEMOS DE EMPLEADAS DOMÉSTICAS.

Todas ellas, personas jurídicas, relacionadas directamente con el ejercicio y defensa de los trabajadores domésticos. Algunas de estas organizaciones son fundaciones y otras son organizaciones sindicales, pero todas con un fin común, que no es otro que el de salvaguardar los derechos de los trabajadores domésticos, por ser estos unos de los menos protegidos y de los más disgregados. Es a través de la información suministrada por estas organizaciones, que se logra advertir la escasa labor del Estado para establecer políticas públicas de Trabajo Decente para los trabajadores del servicio doméstico y se limita a la expedición de normatividad y de cartillas informativa.

Por otra parte, no existe acompañamiento a las organizaciones, se destacan que la labor que se ha desarrollado, ha sido por cuenta propia, en algunos casos asesorados por otras organizaciones, como es el caso de la FUNDACIÓN MUJER Y FUTURO, LA ESCUELA NACIONAL SINDICAL y UTRAHOGAR, que realizan labores de apoyo a organizaciones como UTRASD, LA ASOCIACIÓN DE TRABAJADORAS DEL HOGAR DE BUCARAMANGA y HABLEMOS DE EMPLEADAS DOMÉSTICAS. 
Si bien es cierto no existen políticas públicas claras por parte del estado para la implementación del convenio 189, UTRAHOGAR resalta la ayuda que recibieron del Estado para desplazarse y hacerse participes de las conferencias 99 y 100 de la OIT, en donde su asistencia consistió en la representación de los Trabajadores del Servicio Doméstico de Colombia ante el organismo internacional. De igual forma la FUNDACIÓN MUJER Y FUTURO expresa haber recibido el apoyo por parte del Ministerio del Trabajo en la promoción de los derechos de las trabajadoras del servicio doméstico.

Otro punto importante que se destaca de las entrevistas es la imposibilidad que tiene el Ministerio del Trabajo para llegar a cada uno de los hogares donde existe una relación de laboral de servicio doméstico. Aunado a la falta de eficacia y eficiencia del Estado en la protección de estos derechos.

Se puede cotejar de estas entrevistas que pese a existir reciente normatividad referente al trabajo doméstico, el estado se ha quedado corto en la promoción, divulgación y capacitación sobre políticas públicas tendientes a que tanto empleadores y trabajadores conozcan los deberes y derechos que tienen las partes de dicha relación laboral, así como la sanción a la explotación laboral de los trabajadores domésticos. Lo anterior en atención a la ratificación del convenio 189 de la OIT y la posterior expedición de la ley 1595 de 2012 así como del decreto 1072 de 2015 y cuyo objetivo conlleva a la disminución de las brechas sociales y de la pobreza en el país.

En lo concerniente al cambio social, las organizaciones entrevistadas coinciden, que debe ser tenidas en cuenta para el desarrollo de políticas públicas, por cuanto su inclusión estaría orientada a consolidar el cumplimiento y protección de los derechos de los trabajadores domésticos, al fortalecimiento de su actividad y a la expansión del conocimiento de sus derechos y obligaciones, además del reconocimiento social del trabajo en el hogar, creando instrumentos de asesoría y acompañamiento a las partes y por lo tanto servir de apoyo al Gobierno para el cumplimiento de las normas preexistente y del Convenio 189.

Por último, se destaca la propuesta de Andrea Londoño coordinadora de "HABLEMOS DE EMPLEADAS DOMÉSTICAS" quien en la entrevista expone que para el fortalecimiento de los derechos de este grupo de trabajadores se hace necesario el: "establecimiento de alianzas público privadas para la capacitación escolar, cívica y laboral de las empleadas"; en este mismo sentido indicó también la necesidad de crear: "Programas a través de organismos del Estado como el SENA y las Cajas de Compensación Familiar para capacitar a las empleadas”. (Apéndice, 9.1.4) 
Estas propuestas concuerdan con las consideraciones hechas por la Organización Internacional del Trabajo y que ya hacen parte de las políticas públicas de algunos Estados o que las organizaciones de trabajadores ya están poniendo en práctica. Es por esto que se considera que mediante unos programas de educación no formal, que a futuro se convirtiera en educación formal, se puede llegar a la profesionalización de dicha actividad, desarrollando en este tipo de trabajadores una serie de conocimientos especializados que terminarían dándole un valor agregado como actividad laboral. Esto permitiría que el servicio doméstico saliese de la sombra lo cual conllevaría a la implementación directa de los principio del derecho del trabajo y del Trabajo Decente.

\subsection{Propuesta final: Desarrollo profesional de los trabajadores domésticos para un Trabajo Decente}

El estudio socio jurídico del Trabajo Decente para los Trabajadores del Servicio Doméstico arroja como conclusión principal la equiparación jurídica formal de los derechos Constitucionales y Laborales para los Trabajadores Domésticos; al respecto en Colombia la brecha que existe no es muy amplia en el reconocimiento de derechos laborales para este grupo de trabajadores y los esfuerzos jurídicos del Estado para disminuirla nos llevan a la sentencia C871 de 2014 con la cual la Corte Constitucional exhortó al Congreso de la República y al Gobierno Nacional para que adopten las medidas legislativas e implementen las políticas públicas necesarias para avanzar hacia la universalidad del derecho prestacional (para el caso pago de la prima de servicios), constituyéndose en el último elemento para alcanzar la igualdad formal desde lo jurídico en materia de derechos laborales para los trabajadores domésticos.

Que exista la normatividad no es garantía ni del cumplimiento de la misma ni de su efectividad, se requiere de una serie de medidas que brinden el reconocimiento fáctico de los derechos de los trabajadores del servicio doméstico, sin dejar de lado los mecanismos de investigación, inspección, vigilancia y control por parte del Estado. Pero una propuesta a fondo debe estar encaminada al cambio de paradigma socio cultural respecto a la labor del servicio doméstico, y si bien es muy pronto para hablar de carreras tecnológicas si se puede hablar de capacitación y certificación del personal doméstico. 
Partiendo de los elementos que fundan el concepto de Trabajo Decente, la propuesta está encaminada a fortalecer los cuatro elementos que lo componen y que constituyen el pilar para el desarrollo del Convenio 189:

Por medio del Proceso de Formación Profesional de los Trabajadores del Servicio Doméstico se busca el mejoramiento de las Oportunidades de empleo y su especialización, que conllevaría al incremento de sus ingresos cumpliendo con el primer elemento del Trabajo Decente. "Contra la arraigada concepción de que el trabajo doméstico es un «trabajo de mujeres» que no requiere ningún tipo de conocimientos, cualificaciones o formación reales, la OIT y sus mandantes han reafirmado el valor que tiene el trabajo doméstico tanto para las familias y los trabajadores interesados, como para la economía doméstica y la economía más en general” (OIT, 2010)

La formación académica de los trabajadores, proyecta ampliar los conceptos jurídicos de derecho laboral, que les permita tomar conciencia de sus derechos individuales y colectivos, así como de sus obligaciones con el sistema, con el propósito de generar un cambio en el paradigma socio-cultural del empleo en el hogar, es claro que al ofrecer a los trabajadores, una formación que les genere conciencia del cumplimiento y promoción de la profesionalización del gremio, convergiría en los elementos del Trabajo Decente Oportunidades de empleo e ingresos, Derechos de los trabajadores, Protección Social y Dialogo Social; advirtiendo que con el propio reconocimiento de la necesidad de la afiliación al Sistema de Protección Social, se garantizaría, se preservaría y se fomentaría la integridad física y psicológica de los trabajadores.

En consecuencia se darían elementos o factores propios hacia el dialogo social, toda vez que al conocer los trabajadores domésticos sus derechos, obligaciones y necesidades estarían capacitados para exponer ante el gobierno y los empleadores, soluciones negociadas a los conflictos; de esa manera se logra que el trabajo doméstico adquiera voz y este sea escuchado y tomado en consideración y que adquiera el valor que merece dentro de la economía nacional y global.

En la resolución de 1965 sobre condiciones de empleo de los trabajadores domésticos, se inició el dialogo sobre la necesidad de formación profesional de estos trabajadores y en el informe IV de la Conferencia 99 de la OIT, se expuso:

El desarrollo profesional es un elemento indispensable del trabajo doméstico para que éste se considere como algo más que una experiencia temporal que conlleva sacrificios y está mal 
remunerada; antes bien, debe ser el primer peldaño hacia el logro de un empleo más satisfactorio. Hubo un tiempo en que se creía que vivir con una familia más acomodada representaba una oportunidad de adquirir ciertas cualificaciones, y de hecho es cierto que algunos empleadores alentaban a los trabajadores domésticos a aprender un oficio. Sin embargo, una visión más contemporánea del desarrollo profesional, que se refleja cada vez más en las políticas y la legislación nacionales, consiste en reconocer las cualificaciones necesarias para realizar el trabajo doméstico y ofrecer a los trabajadores domésticos un futuro mejor promoviendo su instrucción básica y su formación profesional.

La legislación de varios países examinados, entre ellos Bolivia, Irlanda, México y Perú, otorga generalmente a los trabajadores domésticos el derecho de asistir a cursos de formación básica y desarrollo profesional, siempre que ello no interfiera en su trabajo. En el Paraguay se ha establecido el derecho de asistir a cursos nocturnos, mientras que en Suiza el artículo 10 del contrato de trabajo tipo aplicable en el Cantón de Ginebra prevé que los empleadores deben ofrecer a los trabajadores domésticos la mayor flexibilidad de horario posible para permitirles participar en cursos de formación. En Italia, el artículo 9 del convenio colectivo aplicable establece que los trabajadores con contrato de duración determinada que hayan trabajado durante más de 12 meses tienen derecho a 40 horas de formación profesional remunerada, además del derecho a estudiar, que se reconoce en el artículo 3.4 .4 de dicho instrumento.

Diversos Estados Miembros de la OIT han creado, al margen de la legislación, programas de generación de capacidad y otros programas de progresión profesional. Así, por ejemplo, el Perú facilita a los trabajadores domésticos información sobre la creación de capacidad. Desde 2005, el Brasil lleva a cabo un programa gubernamental de tres etapas centrado en las habilidades sociales y las cualificaciones profesionales a fin de mejorar el nivel educativo de los trabajadores domésticos y reforzar su capacidad de sindicación. De esta manera, ha logrado convertir en un asunto de política pública los derechos humanos, la salud, la lucha contra la violencia de la que son víctimas las mujeres y la lucha contra el trabajo infantil. El programa se ha llevado a cabo, en su primera fase, como proyecto experimental en siete regiones principales del Brasil, con la ayuda del Fondo de asistencia para los trabajadores y en colaboración con el Ministerio de Educación. Uno de sus primeros objetivos es movilizar los 
conocimientos que los trabajadores domésticos consiguen a través de su experiencia laboral o de programas de calificación.

En Sudáfrica, en 2008 se inició un gran proyecto de formación titulado «Proyecto de desarrollo de las calificaciones de los trabajadores domésticos», que financia el Fondo nacional para las calificaciones del Departamento de Trabajo, y con el que se pretende, durante un período de tres años, formar a 27.000 trabajadores domésticos en todo el país. La formación está supervisada por el sector servicios del organismo encargado de la educación y la formación, que ha creado una cámara especial para los servicios domésticos con sede en Port Elizabeth. Los aprendices recibirán un reconocimiento oficial de sus calificaciones. El proyecto está relacionado con un amplio conjunto de leyes y reglamentos sobre trabajadores domésticos, que incluye la Ley sobre la Educación y la Formación Básicas de Adultos, núm. 52, de 2000, la Ley sobre la Continuación de la Educación y la Formación, núm. 98, de 1998 y la Ley sobre Desarrollo de las Calificaciones, núm. 97, de 1998. (OIT, 2010, p.64)

\subsubsection{Esquema del Programa de Formación Académica de Entrenamiento Doméstico.}

El programa diseñado dentro del presente trabajo, es el sustento de la puesta en marcha de unas políticas públicas tendientes a profesionalizar a futuro las labores domésticas emanadas de un contrato de trabajo y si mismo obedece a las condiciones, limitaciones e insuficiencias del gremio de los Trabajadores Domésticos, es por ello que consideramos que con el fin de erradicar los preconceptos socio-culturales y transformar la concepción de informalidad de este sector laboral, a través de las herramientas con las cuales cuenta el Estado y que son fundamentales para el logro de los objetivos. El Estado ya cuenta con una infraestructura (Personal capacitado, bolsa de empleo, aulas, equipos y materiales) que ofrece el SENA (Servicio Nacional de Aprendizaje) a lo largo del territorio Colombiano y que permitiría la apertura el proyecto, brindando capacitación y certificación a los trabajadores del servicio doméstico. Esto permitiría a su vez obtener un censo de la población, la inclusión al Sistema de Seguridad Social, su organización Sindical y por último la vinculación a una bolsa de empleo confiable y sin intermediarios. 
En la Actualidad el SENA cuenta con Programas de formación titulada y complementaria, la formación titulada se encuentra dividida en:

- “Operarios y auxiliares: Son programas de formación profesional que permiten el desarrollo de competencias laborales específicas básicas, transversales y de desarrollo humano, relacionadas con las áreas de desempeño y el perfil idóneo para ejecutar funciones productivas. Duración: de 6 a 12 meses

- Técnicos: Programas de formación que buscan que los aprendices adquieran competencias motrices y cognitivas, socio-afectivas y comunicativas para desarrollar actividades determinadas y solucionar problemas en un rango definido de áreas funcionales con respuestas predecibles; que comprendan y apliquen el proceso productivo, que utilicen instrumentos y técnicas definidas, que ejecuten operaciones para obtener resultados concretos y responder por su propio trabajo. Duración: 12 meses

- Tecnológicos: programa de formación que buscan que los aprendices adquieran las competencias cognitivas, socio-afectivas y comunicativas para aplicar el conocimiento técnico y tecnológico que solucione problemas estratégicos del área, que coordine y supervise actividades interdisciplinarias en los campos de la técnica y la tecnología, que organice y maneje recursos, que gestione proyectos productivos, que comunique ideas, que responda por los resultados de su trabajo y de otros que estén bajo su control, y que asuma con ética los roles sociales y organizacionales propios de su entorno. Se orientarán igualmente a desarrollar las competencias necesarias para garantizar la interacción de lo científico con lo instrumental y lo operacional con el saber tecnológico. Duración: 24 meses." (SENA, 2014, Recuperado: http://portal.senasofiaplus.edu.co/index.php/ novedades /444-nuevos-programas-de-formaciasn-virtual)

Atendiendo las necesidades propias de este sector de trabajadores, se adoptaría un programa para operarios y auxiliares, puesto que la enseñanza estaría dirigida a la praxis y solo algunos subtemas serían de carácter teórico. La selección de temas que ubicamos en este proyecto formativo, se adelantó considerando los diferentes aspectos que se pueden suscitar y que así mismo existen en un hogar cualquiera, partiendo de las labores más esenciales hasta las de cuidado de menores y mayores adultos y por último aquellas que ofrecen un valor agregado al 
servicio. En un primer módulo se encuentra la capacitación en Servicios Primarios dentro de los cuales se ubica: Aseo General, Lavado y Planchado, Cocina y Jardinería; El segundo aspecto de la capacitación estaría enfocado al Servicio del Cuidado donde se formaría en: Cuidado de Adultos y Discapacitados, Cuidado de Menores de Edad y en Cuidado de Mascotas; Finalmente se establecería un módulo que daría un valor agregado a la enseñanza y tiene que ver con los aspectos de las relaciones humanas y estaría compuesto por: Formación en Trabajo Decente, Higiene y Salud, Protocolo y Urbanidad. 
Relación de Aspectos y Malla Curricular

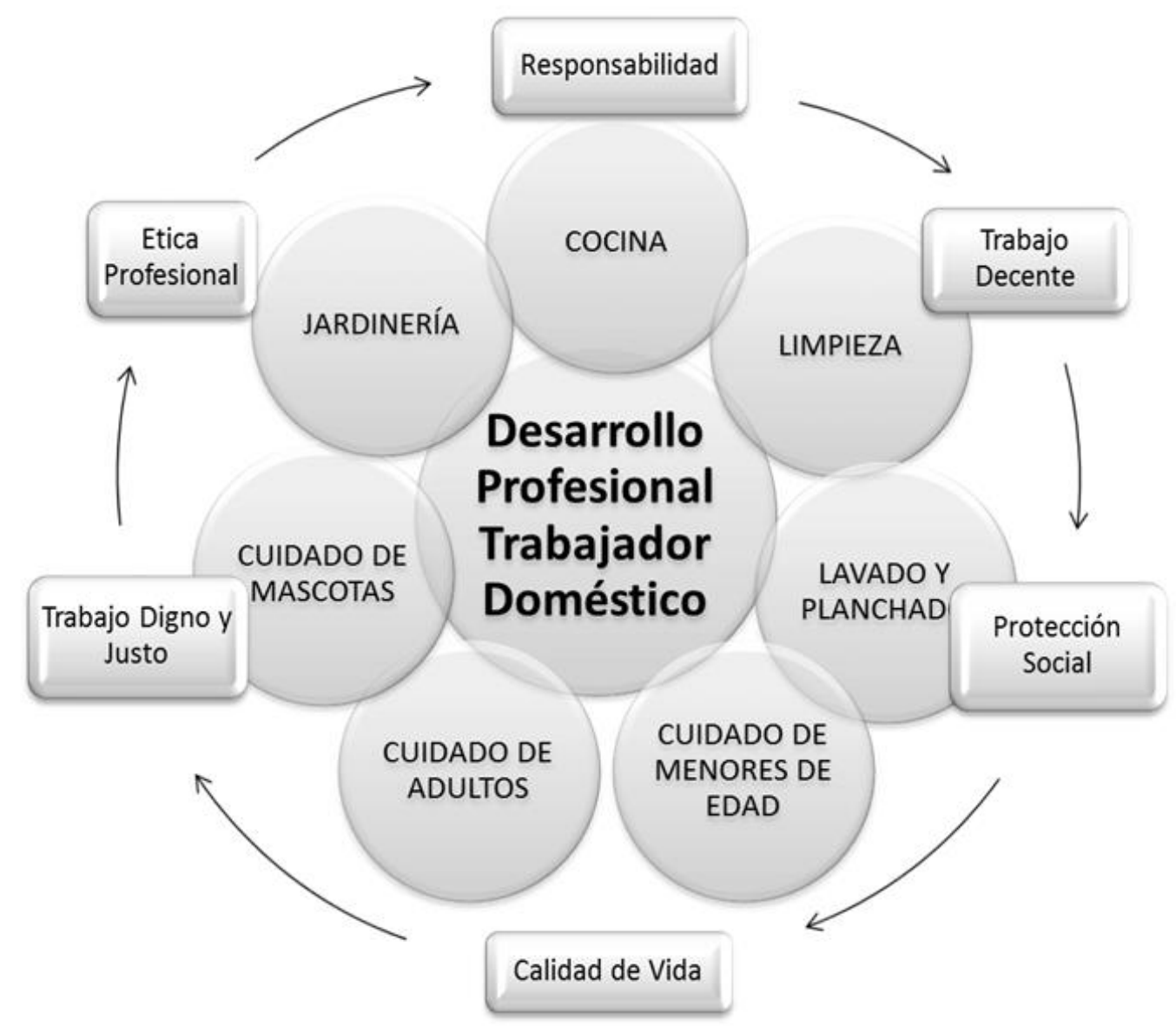

Figura 6. Relación de Aspectos 


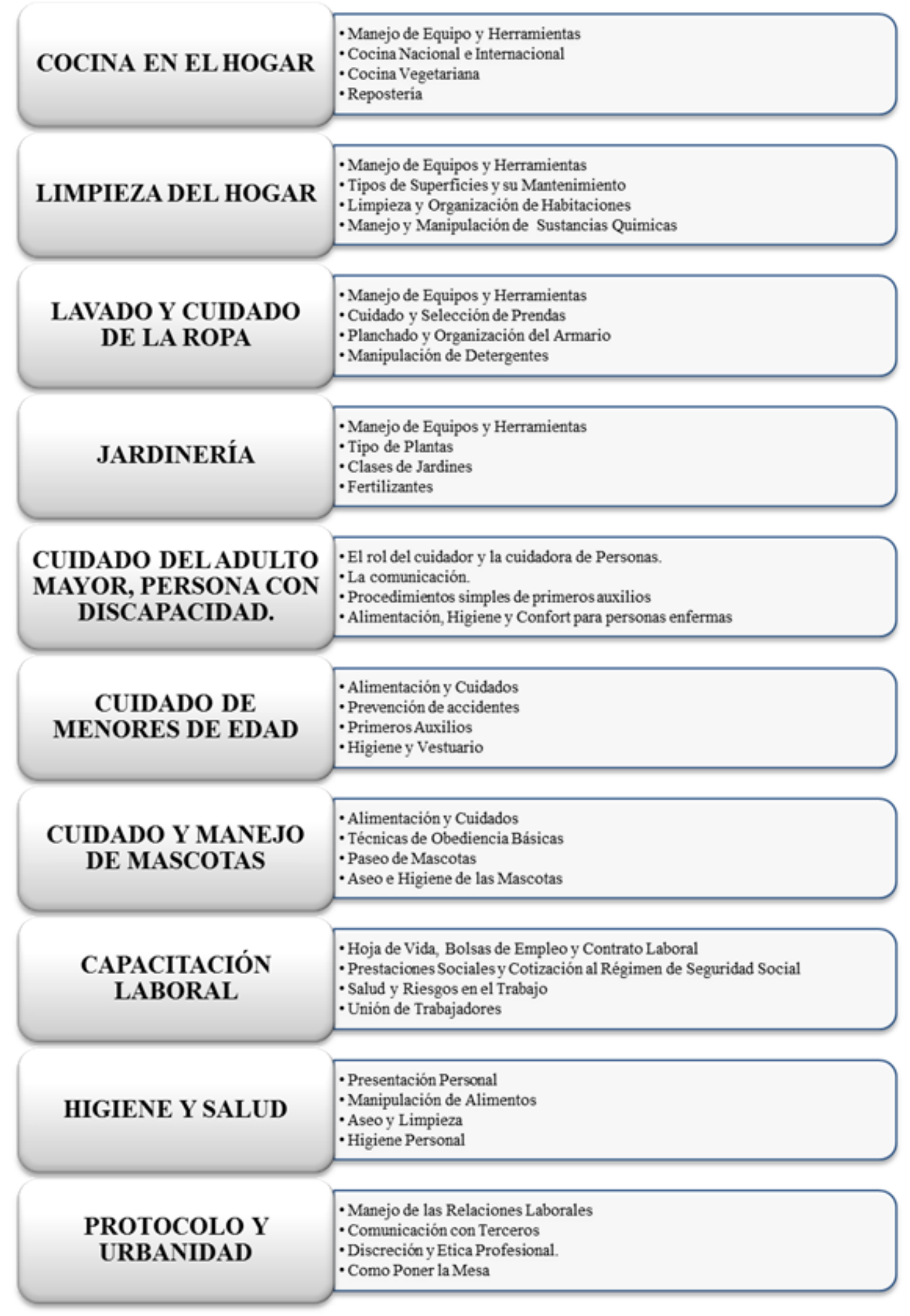

Figura 7. Malla Curricular 


\section{Objetivos:}

\section{Objetivo General}

Brindar herramientas de tipo académico y formación integral a los trabajadores del servicio doméstico que dignifique la labor que desarrollan en el hogar con el fin de cambiar el paradigma social y pasar de la informalidad de una labor subvalorada e invisible en la sociedad a una labor técnica que cumpla con las expectativas de las partes, adquiera el valor y posición que realmente debe tener en la economía nacional y global.

\section{Objetivos Específicos}

- Capacitar y formar a los trabajadores domésticos para que desempeñen a cabalidad su trabajo en el hogar.

- Brindar calidad a la labor desarrollada por los trabajadores del hogar.

- Tecnificar el trabajo doméstico.

- Darle el valor social que tiene el trabajo doméstico en la economía.

- Visibilizar el Trabajo Doméstico 


\section{Conclusiones}

La Contextualización del Convenio 189 de la OIT en Colombia, es el punto de partida que proyecta a nivel nacional el Trabajo Decente como un concepto estratégico de la OIT, desarrollado en 1999 por este órgano internacional que busca la promoción por intermedio de cuatro ejes estratégicos contenidos en: los Derechos fundamentales del trabajo; del empleo e ingresos; de la protección social y seguridad social; como último el dialogo social. La labor de crear Trabajo Decente para los trabajadores domésticos, surge de las precarias condiciones laborales de este grupo de trabajadores a través de los siglos, como se expuso en el Capítulo 4 de la contextualización histórica del trabajo decente para los trabajadores del servicio doméstico.

Es a partir del estudio del desarrollo histórico del trabajo doméstico en el mundo occidental y en Colombia, que se logró adquirir información precisa para así comprender como desde la esclavitud, se mantiene la estigmatización y subvaloración ya que por su naturaleza este tipo de labor se hace invisible social y culturalmente e incluso ante el Estado en su función protectora. Es así como se puede observar que el servus, quien ha conservado su vida por la gracia de su amo, pierde su capacidad jurídica como hombre libre, situación que genera toda una teoría de la muerte social del esclavo y por ende la de sus derechos, herencia que se ha transmitido a las labores que desarrollaba el siervo para su señor, como lo fue el trabajo doméstico. Y es en este marco socio-cultural arraigado donde se constituyeron los principales factores históricos que han llevado a que dicha labor, no sea reconocida, protegida y mucho menos remunerada equitativamente, conforme a la normatividad propia de la legislación del trabajo.

Consecuentemente se indagó el precedente jurídico del Contrato Laboral, el cual se remonta al Derecho Romano, específicamente al contrato de arrendamiento de la res (locatio conductio rei), en el que se incluía animales, cosas y esclavos, siendo este último de donde surge la variedad de locatio servi que como lo indican los autores citados en el capítulo respectivo, lleva a la creación de la locatio conductio operarum, antecedente jurídico de los contratos de arrendamiento de servicio de los hombres libres, y que derivaría en el contrato civil de arrendamiento de las mucamas o sirvientas, que llega a Colombia a partir del Código Civil Francés de 1804; lo anterior demuestra como mediante la norma y los arquetipos sociales se ha persistido en las estructuras de esclavitud, prolongándolas en el tiempo, lo cual permite deducir durante el proceso de investigación que esta figura es la precursora del trabajo doméstico y la 
raíz que lleva a que esta, se conserve como una actividad marginal, con remuneraciones precarias e incluso al desconocimiento de derechos laborales por la sociedad, muy a pesar de existir norma que protege sus derechos.

Posteriormente en el capítulo 5 referente a la armonización del convenio 189 en la legislación colombiana, se observan los primeros avances que desde la Organización Internacional del Trabajo se gestaron para eliminar los preceptos y/o estigmatizaciones que giran alrededor del desarrollo de la labor doméstica, al tiempo que el organismo internacional articulaba lo que sería el Convenio 189, que trajo consigo la reconsideración del trabajo doméstico desde lo social, lo económico y lo político.

La gestión para la equiparación de los derechos de los Trabajadores Domésticos, tiene como objetivo el cambio de paradigma de la sociedad frente a este sector precario de la economía. Los factores que afectan al grupo de los trabajadores del servicio doméstico, parten tanto de la necesidad de normas que regulen la actividad laboral, como de Políticas Públicas tendientes al cambio de arquetipo social, de un oficio erigido por siglos de desamparo, aislamiento y relegación. Con la armonización del convenio 189 con la norma colombiana que realiza la Corte Constitucional en Sentencia C-616 de 2013, permite visualizar la omisión del desarrollo normativo y jurisprudencial a nivel nacional del Concepto de Trabajo Decente que emana de la OIT; aun cuando en el estudio de Constitucionalidad del Convenio 189, la Corte declara la exequibilidad de cada uno de sus artículos y elabora un pequeño cotejo con la Constitución y las Leyes existentes, omite profundizar en este Concepto.

De acuerdo a lo anterior, consideramos que reflexionar en los elementos del Trabajo Decente, conllevan a advertir las falencias en las políticas públicas ejercidas por el Estado, para concretar el Convenio 189, pues al considerar sus componentes de empleo e ingresos; de Derechos humanos y del trabajo; y de protección social y de la seguridad social, se puede decir que Colombia cumple con casi todos estos, de hecho, con la reciente aprobación y sanción de la Ley 1788 de 2016, que garantiza la universalización del derecho a la prima de servicios a todo trabajador en el territorio nacional, logrando al respecto la equiparación de los derechos de los trabajadores domésticos con las demás profesiones u oficios.

Sin embargo la falta de políticas públicas por parte del Estado que brinde elementos y medios que garanticen la protección de derechos de este sector del trabajo, como es el fortalecimiento del Ministerio del Trabajo y de sus inspecciones del trabajo, las cuales son las encargadas del 
control y vigilancia; hace ineficiente e ineficaz la normatividad a aplicar, lo que conlleva a la omisión del Estado de los deberes y obligaciones adquiridos con la comunidad internacional, la OIT, la sociedad y los trabajadores. Debemos decir que de la investigación realizada frente a la contextualización del convenio 189 de la OIT, permite establecer que el porcentaje de trabajadores domésticos que reciben todas sus prestaciones sociales continúan siendo baja ya que la falta de de organización del Estado y de herramientas impide garantizar la calidad del empleo en este sector o brindan mecanismos de profesionalización o tecnificación del trabajo doméstico.

La investigación arroja como resultado, la falta de políticas públicas, la creación de la Mesa de Seguimiento a la implementación del Convenio 189, puede ser el punto de partida para el mejoramiento y garantía de los derechos de este grupo de trabajadores; así mismo se hace necesario e incluso indispensable, que el trabajo doméstico se tecnifique y si es posible se profesionalice, con el fin, que la prestación del servicio se haga competente y especializada, logrando así que este sector de trabajadores alcance el pleno desarrollo personal y laboral dentro de la sociedad.

De crearse políticas públicas tendientes a la tecnificación y profesionalización de la actividad, se lograría cumplir con otros aspectos como son la abolición efectiva del trabajo infantil en este sector, y el mejoramiento de las condiciones laborales a través de la implementación de políticas de salud ocupacional, hoy riesgos laborales.

Finalmente no debemos dejar a un lado el elemento del dialogo social, más aun cuando este sector de trabajadores, presta sus servicios, no dentro de una empresa, sino en el seno familiar, situación que los hace poco visibles y que dificulta la posibilidad de agremiarse como organismo sindical, razón por la cual estos quedan sin la posibilidad de expresar sus necesidades, frente a los demás gremios sindicales, frente al gobierno y frente a posible asociaciones de empleadores del servicio doméstico.

Del estudio y contextualización del convenio 189 frente a las normas nacionales, fue necesaria la observación del efectivo acceso a la administración de justicia mediante el análisis jurisprudencial de las Cortes Suprema de Justicia y Constitucional; es el desarrollo del punto 5.3, de la contextualización de dicho Convenio, donde queda expuesto el carácter imperativo del desarrollo normativo, jurisprudencial y doctrinal del Concepto de Trabajo Decente en Colombia, así mismo, de la capacitación de los administradores de justicia (jurisdicción ordinaria laboral y 
jueces constitucionales), que brinde herramientas jurídicas para consolidar el concepto de Trabajo Decente.

Aun cuando la Corte Constitucional presenta un cambio de paradigma humanístico sustentado en valores y principios que se diferencian de las interpretaciones exegéticas a las que el país estaba acostumbrado, el ente sigue actuando frente algunos derechos con discrecionalidad, lo cual deja inestabilidad jurídica; tal es el caso del horario laboral de las trabajadoras domésticas internas, donde se permite una jornada laboral de hasta 10 horas, en contravía de derechos conquistados por los trabajadores, donde la jornada laboral es de 8 horas diarias, discriminando este grupo de trabajadores. Por lo tanto, la unificación de la noción de trabajo decente, a los principios constitucionales del derecho laboral, significaría para el sistema jurídico nacional, la creación de un verdadero bloque jurídico tendiente a la efectiva protección de los derechos de todos los trabajadores incluyendo los trabajadores de esta actividad soterrada por la sociedad.

Podemos decir con certeza que el resultado de esta investigación demuestra claramente que el desarrollo jurídico del Concepto de Trabajo Decente en Colombia es nulo; al no estar contemplado en la Constitución y las leyes Colombianas, su noción e impacto no ha logrado el alcance que debería en el ámbito jurídico y en las decisiones de los jueces tanto de la Jurisdicción Ordinaria Laboral como de la Jurisdicción Constitucional. Solo bajo los principios de dignidad humana e igualdad es que se desarrolla en Colombia la protección eficaz y el amparo de los derechos de los Trabajadores del Servicio Doméstico.

Con el capítulo 6 se busca dar cumplimiento a varios aspectos del convenio 189 de la OIT mediante la promoción, desarrollo e implementación del Trabajo Decente y de políticas públicas por parte del Estado, para lograr la transformación del arquetipo social. La propuesta que se hace por medio de la presente investigación tiene como principal objetivo combatir la informalidad con la que se presta este tipo de trabajo, así como brindar herramientas a los trabajadores domésticos, que garantice su desarrollo dentro de la sociedad, a través de la capacitación técnica laboral, es decir, la profesionalización de la actividad y la adquisición de conocimientos teóricos y jurídicos, que conllevaría a la formalización de esta labor en el sector productivo colombiano y por ende el cumplimiento de los objetivos del Convenio 189 de la OIT.

Se agrega finalmente que la investigación arroja la necesidad y la obligación de difusión de los derechos de los trabajadores del servicio doméstico, la formalización y la tecnificación con el fin de hacer visible socialmente esta labor, actividad para la cual se requiere del acompañamiento 
y del apoyo por parte del Estado frente a la labor de los sindicatos, fundaciones y demás organizaciones que trabajan en favor del mejoramiento de la calidad de vida de los trabajadores domésticos. La entrada en vigencia del Convenio 189, conlleva a que el gobierno nacional, se esmere y esfuerce para mejorar algunos aspectos sociales, culturales y económicos de este grupo de trabajadores. 


\section{Referencias}

\section{Bibliográfica}

[1] Organizacion Internacional del trabajo OIT. El trabajo infantil doméstico afecta a 10 millones de niños. [En línea] 12 de junio de 2013. http://www.ilo.org/global/about-theilo/newsroom/news/WCMS_215187/lang--es/index.htm.

[2] OTI Naciones Unidas. Informe del Grupo de Delhi sobre estadísticas del sector no estructurado de la economía. [En línea] 08 de marzo de 2002. http://unstats.un.org/unsd/statcom/doc02/2002-14s.pdf.

[3] OIT Naciones Unidas . Conferencia Internacional del Trabajo, Memoria del Director General: Trabajo decente. [En línea] junio de 1999. http://www.ilo.org/public/spanish/standards/relm/ilc/ilc87/rep-i.htm.

[4] SENA. Actualización para periodistas - De la época precolombina a la conquista española. [En línea] 2007. http://www.banrepcultural.org/node/65064.

[5] [Tovar Pinzón, Hermes. La manumisión de esclavos en Colombia, 1809- 1851, Aspectos sociales, económicos y políticos. Revista Credencial Historia, (Bogotá - Colombia). Edición 59. [En línea] Noviembre de 1994. http://www.banrepcultural.org/node/123392.

[6] Organización Internacional del Trabajo OIT. Evolución del Convenio 189 y de la Recomendación $201 . \quad$ [En $\quad$ línea] 1996. http://www.ilo.org/global/docs/WCMS_211259/lang--es/index.htm.

[7] [Portafolio.co. En Colombia hay 750.000 trabajadores en el sector doméstico. [En línea] 13 de mayo de 2013. http://www.portafolio.co/economia/finanzas/colombia-hay-750-000trabajadores-sector-domestico-80708.

[8] Alemán Monterreal, A. (1996). El Arrendamiento de Servicios en Derecho Romano. (Página 32). Editorial Universidad de Almería, Servicio de Publicaciones. Almería. España.

[9] Araya, F. (1998). En el Eje del Tiempo: la explosión postmoderna. (Pág. 171) Primera Reimpresión. Editorial Universidad Estatal a Distancia. San José, Costa Rica. 
[10] Blanchard, F. (1996). Conferencia Inaugural: Los desafíos del Tripartidismo en la Oficina Internacional del Trabajo. (Págs. 11-19). El Trabajo en la Historia. Ediciones Universidad de Salamanca. Salamanca. España.

[11] Barragán Díaz, D. M. (2007). Orden Social en la Colombia de los Siglos XVIII y XIX. Revista Facultad de Ciencias Económicas: Investigación y Reflexión, vol. Núm. 2, diciembre, 2007, p 235-247. (Pág. 240) Universidad Militar Nueva Granada. Colombia.

[12] Barreto Rozo, A. (1999). Amparo Constitucional de los Derechos Sociales. A propósito del carácter social de la acción de tutela. Páginas 85-122. Derecho Constitucional Perspectivas Críticas. Ensayos, Líneas jurisprudenciales, Estadísticas de la Justicia Constitucional. Siglo del Hombre Editores. Universidad de los Andes. Bogotá, Colombia.

[13] Batiza, R. (1990). El Derecho Romano en el Código Civil Francés y en los Código Civiles Mexicanos de 1870, 1884 y 1928. (Págs. 455-479) Jurídica. Anuario del Departamento de Derecho de la Universidad Iberoamericana. 1990-1991 Número 20. Instituto de Investigaciones Jurídicas de la UNAM. México D.F. México.

[14] Cameron, E. (2006). El Siglo XVI. Historia de Europa Oxford. The Sixteenth Century was originally published in English in 2006. Traducción castellana para España y América: Crítica, S.L. Barcelona, España.

[15] Confederación Sindical Internacional (2010) Guía de Acción: Trabajo decente, vida decente para los trabajadores del hogar

[16] Domínguez Nafría, J.C. (1998). Influencias de la Conquista de América en la Doctrina sobre el Ius In Bello. Págs. 503- 546. (Pág. 512) Derecho y Administración Pública en las Indias Hispánicas: Actas del XII Congreso Internacional de Historia del Derecho Indiano. Ediciones de la Universidad de Castilla-La Mancha y de las Cortes de Castilla-La Mancha.

[17] Eugenio Martínez, M.A. (1977) Tributo y trabajo del indio en Nueva Granada (de Jiménez de Quesada a Sande). Editorial Consejo Superior de Investigaciones Científicas. Sevilla, España.

[18] Gay Bochaca, J. (2002). Capitalismo, Comunismo y Socialismo. Páginas: 53-64. (Pág. 59) Cuestiones Controvertidas del Cristianismo. Ediciones Palabra, S.A. Madrid, España.

[19] Klein, H.S. \&Vinson III, B. (2013). Historia mínima de la esclavitud en América Latina y en el Caribe. Primera Edición. El Colegio de México. México D.F. 
[20] López Medina, D.E. (2007). El Derecho de los Jueces. Tercera Edición. Legis Editores S.A. Bogotá, Colombia.

[21] Lorente, P. y Páez- Camino. (1984). Los Movimientos Sociales (hasta 1914). Historia del Mundo Contemporáneo. Ediciones Akal S.A. Madrid, España.

[22] Marcucci, C.R. (2005). Panorama Contextualizado del Derecho Laboral Sustancial Colombiano. Pág. 309. Editorial Universidad Cooperativa de Colombia Educc. Bogotá. Colombia.

[23] Martínez Girón, J.; Arufe Varela, A.; Carril Vázquez, X.M. (2006). Derecho del Trabajo. Segunda Edición. Editorial Netbiblo. España.

[24] Means, R.C. (trad. de Supelano, A.). (2011). Desarrollo y subdesarrollo del derecho. Corporaciones y derecho corporativo en la Colombia del siglo XIX. Universidad Externado de Colombia. Bogotá. Colombia.

[25] McNeill, W.H. (2000). La Civilización de Occidente: Manual de Historia. Tercera Edición. (Vélez, R.L. y Otros Trad.) Editorial de la Universidad de Puerto Rico. San Juan, Puerto Rico.

[26] Molino García, M.T. (1976). La Encomienda en el Nuevo Reino de Granada Durante el Siglo XVIII. Editorial Consejo Superior de Investigaciones Científicas. Escuela de Estudios Hispano-Americanos. Sevilla, España.

[27] Navarrete, M.C. (2005). Génesis y desarrollo de la esclavitud en Colombia siglos XVI y XVII. Primera Edición. Universidad del Valle, Programa Editorial. Cali, Colombia.

[28] Neves Mujica, J. (2007). Introducción al Derecho Laboral. Segunda reimpresión. Edición Fondo Editorial de la Pontificia Universidad Católica del Perú. Lima, Perú.

[29] Ordóñez Cifuentes, J.E.R. (1998). Cuadernos Constitucionales México-Centroamérica 30. La Opinión Consultiva de da Corte de Guatemala Sobre la Constitucionalidad del Convenio 169 de la OIT. Una Experiencia Constructiva en Favor de la Paz. Instituto de Investigaciones Jurídicas de la UNAM. México D.F. México.

[30] Palacios, M. Safford F. (2005). Colombia: País Fragmentado, Sociedad Dividida. (Págs. 542, 543 y 590). Traducción: García, A. Editorial Norma. Bogotá, Colombia.

[31] Poblete Troncoso, M. (1958). Comunidad Internacional Contemporánea. Relaciones y Organismos Internacionales. Editorial Jurídica de Chile. Santiago de Chile. Chile. 
[32] Procuraduría General de la Nación. (2011) Trabajo digno y decente en Colombia. Seguimiento y control preventivo a las políticas públicas. Diagramación e Impresión Rasgo y Color Ltda.

[33] Romano, R. (1996). Trabajo Compulsivo y Trabajo Libre en Nueva España (siglos XVI XVIII) (págs. 199- 209). El Trabajo en la Historia. Primera Edición. Ediciones Universidad de Salamanca. Salamanca. España.

[34] Sousa Santos, B de. y García Villegas, M. (2004). El Caleidoscopio de las Justicias en Colombia. Análisis Socio-Jurídico. Volumen 1. $1^{\text {a }}$ reimpresión. Siglo del Hombre Editores y Ediciones Universidad de los Andes. Bogotá, Colombia.

[35] Vargas Trujillo, E. (2011). Guía de Talleres. Trata de personas y servicio doméstico ¡Quitémonos las vendas, desatemos cadenas! Organización Internacional para las Migraciones. Bogotá D.C. Colombia.

\section{Electrónica}

[36] Abramo, L. (editora) (2006) Trabajo decente y equidad de género en América Latina. Chile, Santiago, Oficina Internacional del Trabajo. http://oit.org.pe/WDMS/bib/publ/libros /trabajo_decente_equidad_genero_al[la].pdf

[37] Arango, L. Posada, C. (2003). Determinantes de la probabilidad de tener servicio doméstico en Colombia. Banco de la República. Bogotá, Colombia. Recuperado de: http://www.banrep.gov.co/docum/ftp/borra269.pdf

[38] Avella Gómez, M. (2010) Las Instituciones laborales en Colombia. Contexto Histórico de sus Antecedentes y Principales Desarrollos hasta 1990. Borradores de Economía. Número 613. Banco de la República. (Págs. 23, 28, 30, 31, 50 y 62) Recuperado de: http://www.banrep.gov.co/docum/ftp/borra613.pdf

[39] Bernal, B. (1987). El Derecho Indiano. Revista OMNIA, Año 3, VII, México, 1987. (Págs. 1, 34 4) Recuperado de: http://www.posgrado.unam.mx/publicaciones/ant_omnia/07/02.pdf

[40] Cámara de Representantes. (23 de julio de 2015) Proyecto de Ley 003 de 2015 Cámara. por medio de la cual se garantiza el trabajo decente y en condiciones de igualdad para las personas que prestan servicios domésticos. Gaceta del Congreso No 507 de 2015. 
[41] Congreso de la República. (25 de abril de 2012) Proyecto de Ley 230 de 2012.por medio de la cual se aprueba el "Convenio sobre el Trabajo Decente para las Trabajadoras y los Trabajadores Domésticos, 2011 (N 189)”, adoptado en Ginebra, Confederación Suiza, en la $100^{\text {a }}$ reunión de la Conferencia Internacional del Trabajo, el 16 de junio de 2011. Gaceta del Congreso $N^{\circ} 176$, AÑO XXI.

[42] Consejo Superior de la Judicatura. Módulo sobre Integración del Código General del Proceso al Proceso del Trabajo y la Seguridad Social. Escuela Judicial Rodrigo Lara Bonilla. Recuperado de: http://www.ejrlb.com/docs2016/modulo_laboral_cgp2015.pdf

[43] D’Souza, A. (2010). Camino del trabajo decente para el personal del servicio doméstico: panorama de la labor de la OIT. (Pág. V). Recuperado de: http://www.ilo.org/wcmsp5 /groups/public/---dgreports/---gender/documents /publication/wcms_142907.pdf

[44] Departamento Administrativo de Estadísticas Nacionales. Principales Indicadores Del Mercado Laboral Septiembre de 2013. 31 de Octubre de 2013. Recuperado de: http://www.dane.gov.co/files/investigaciones/boletines/ech/ech/bol_ech_sep13.pdf

[45] Ghai, D. (2003) Trabajo decente. Concepto e indicadores.Revista Internacional del Trabajo, vol. 122, núm. 2.Páginas: 125 - 160. Recuperado de: http://www.ilo.org/public/spanish /revue/download/pdf/ghai.pdf

[46] Goldsmith, M. (1998) De Sirvientas a Trabajadoras. La Cara Cambiante del Servicio Doméstico en la Ciudad de México. Páginas: 85 - 96.Recuperado de: http://www.debatefeminista.com/PDF/Articulos/desirv487.pdf

[47] León, M. (2013). Proyecto de Investigación-acción: trabajo doméstico y servicio doméstico en Colombia. Revista de Estudios Sociales (No. 45) enero - abril de 2013 páginas: 198 211 http://res.uniandes.edu.co/view.php/833/view.php

[48] Molina Betancur, C.M. (2003) El Nuevo Gobierno Constitucional. Corte Constitucional: 10 Años, Balance y Perspectivas. Págs. 57 - 83. Centro Editorial Universidad del Rosario. Bogotá. Colombia.

[49] Organización Internacional del Trabajo (1999) Memoria del director general. 87a reunión. Ginebra. Recuperado de: http://www.ilo.org/public/spanish/standards/relm/ilc/ilc87/repi.htm

[50] Organización Internacional del Trabajo (2003) Directrices sobre una definición estadística de empleo informal, adoptadas por la Decimoséptima Conferencia Internacional de 
Estadísticos del Trabajo (noviembre - diciembre de 2003). Recuperado de: http://www.ilo.org/public/spanish/bureau/stat/download/guidelines/defempl.pdf

[51] Organización Internacional del Trabajo. (2006) Igualdad de género y trabajo decente Convenios y recomendaciones claves para la igualdad de género. Recuperado de: http://www.ilo.org/dyn/gender/docs/RES/500/F765069013/WEB\%20Promoting\%20Gende r\%20ESP.pdf

[52] Organización Internacional del Trabajo. (2012) Notas de la OIT: El Trabajo Doméstico Remunerado en América Latina y el Caribe. Recuperado de: http://ilo.org/americas/publicaciones/notas-trabajo-dom\%C3\%A9stico-remunerado/lang-es/index.htm

[53] Organización Internacional del Trabajo. (2010) Trabajo Doméstico Nota De Información 1: El Trabajo Doméstico Remunerado En América Latina. Recuperado de: http://www.ilo.org/wcmsp5/groups/public/@americas/@ro-lima/@srosantiago/documents/publication/wcms_178173.pdf

[54] Organización Internacional del Trabajo. (2011a.) Trabajo Doméstico Nota De Información 5: Una Jornada de Trabajo Decente para las Trabajadoras domésticas remuneradas. Recuperado

de:https://dgfss.files.wordpress.com/2015/03/notas_unajornadadetrabajodecenteparalastrab ajadorasdomesticasremuneradas_oit_2011.pdf

[55] Organización Internacional del Trabajo. (2011b.) Trabajo Doméstico Nota De Información 2: Salarios dignos para las trabajadoras del hogar. Recuperado de:http://ilo.org/wcmsp5/groups/public/---americas/---ro-lima/---srosantiago/documents/publication/wcms_178178.pdf

[56] Organización Internacional del Trabajo. (2011c.) Trabajo Doméstico Nota De Información 3: Erradicar el trabajo infantil doméstico. Recuperado de: http://ilo.org/wcmsp5/groups/public/---americas/---ro-lima/---srosantiago/documents/publication/wcms_178179.pdf

[57] Organización Internacional del Trabajo. (2011d.) Trabajo Doméstico Nota De Información 4: Trabajadores Domésticos: Estimaciones a Nivel Mundial y Regional. Recuperado de: http://www.ilo.org/wcmsp5/groups/public/---ed_protect/---protrav/--travail/documents/publication/wcms_159562.pdf 
[58] Organización Internacional del Trabajo. (2011e.) Trabajo Doméstico Nota De Información 7: El derecho a la organización de las trabajadoras domésticas remuneradas. Recuperado de: http://igenero.oit.org.pe/images/stories/documentos/Notas_OIT_7_VF.pdf

[59] Organización Internacional del Trabajo. (2013) Día Mundial contra en trabajo infantil. El trabajo infantil doméstico afecta a 10 millones de niños. Recuperado de: http://www.ilo.org/global/about-the-ilo/newsroom/news/WCMS_215187/lang-es/index.htm

[60] Organización Internacional del Trabajo. (2014). Proyecto PRO DERECHOS: Beneficiarios y papel de la OIT. Recuperado de: http://www.ilo.org/sanjose/programas-yproyectos/derechos/WCMS_248006/lang--es/index.htm

[61] Organización Internacional del Trabajo. Evolución del Convenio 189 y de la Recomendación 201. Recuperado de: http://www.ilo.org/travail/areasofwork/WCMS_211259/lang--en/index.htm

[62] Organización de las Naciones Unidas (2002) Informe del Grupo de Delhi sobre estadísticas del sector no estructurado de la economía. Consejo Económico y Social. Recuperado de: http://unstats.un.org/unsd/statcom/doc02/2002-14s.pdf

[63] Pedraza Gómez, Z. (2007). El trabajo infantil en clave colonial: consideraciones históricoantropológicas. Págs.: 80-90.Nómadas No. 26. Abril 2007. Universidad Central. Colombia. Recuperado de: http://www.ucentral.edu.co/images/editorial/nomadas/docs/nomadas_6_el_trabajo_sandra. pdf

[64] Plata Quezada, W.E. (2013) El Sindicato del Servicio Doméstico y la Obra Nazareth: Entre Asistencialismo, Paternalismo y Conflictos de Interés, Bogotá, 1938-1960. Revista de Estudios Sociales No. 45. Págs. 29-41. http://dx.doi.org/10.7440/res45.2013.03

[65] Revista Portafolio (2013) En Colombia hay 750.000 trabajadores en el sector doméstico. Pág. Web: http://www.portafolio.co/economia/finanzas/colombia-hay-750-000trabajadores-sector-domestico-80708

[66] Rodgers, G. Lee, E. Swepston, L. Van Daele, J. (2009). La Organización Internacional del Trabajo y la Lucha por la Justicia Social, 1919-2009. (Págs. 125 64) Primera Edición. Oficina Internacional del Trabajo. Ginebra. Suiza. Recuperado de: 
http://www.ilo.org/wcmsp5/groups/public/@dgreports/@dcomm/@publ/documents/public ation/wcms_104680.pdf

[67] Romero Jaramillo, D. (2005). Manumisión, ritualidad y fiesta liberal en la provincia de Cartagena durante el siglo XIX. Revista de Estudios Sociales (No. 29) enero - junio 2005, páginas: 125-147. Web: http://historiacritica.uniandes.edu.co/view.php/298/index.php?id=298

[68] Sen, A. (2000). Trabajo y derechos. Revista Internacional del Trabajo, vol. 119 (2000), núm. 2 (Páginas: $129 \quad$ - 139). Recuperado de: http://www.ilo.org/public/spanish/revue/download/pdf/sen.pdf

[69] SENA. (2007). Actualización para periodistas - De la época precolombina a la conquista española. Edición en la biblioteca virtual: Bogotá. Recuperado de: http://www.banrepcultural.org/blaavirtual/ciencias/sena/periodismo/precolom/indice.htm

[70] Servicio Nacional de Enseñanza. (2014). Programas de Formación. Recuperado de: http://www.sena.edu.co/oportunidades/formacion/Programas\%20de\%20Formacion/Pagina s/Programas-de-Formacion.aspx

[71] Tovar Pinzón, H. (1994). La manumisión de esclavos en Colombia, 1809- 1851, Aspectos sociales, económicos y políticos. Revista Credencial Historia. (Bogotá - Colombia). Edición 59. Noviembre de 1994. Recuperado de: http://www.banrepcultural.org/node/ 123392

[72] Universidad Externado de Colombia. (2014). Manual de Citación Normas Apa. Recuperado de: $\quad$ http://biblioteca.uexternado.edu.co/b1B11073k4/wpcontent/uploads/Manual-de-citaci\%C3\%B3n-APA-v7.pdf

[73] Vásquez Fernández, H. (Coord.) (2013) Informe Nacional del Trabajo Decente en Colombia del 2012. Ediciones Escuela Nacional Sindical. Medellín, Colombia. http://ens.org.co/apc-aa-files/4e7bc24bf4203c2a12902f078ba45224/TD_2012_ENS.pdf

\section{Jurídica}

[74] Congreso de la República de Colombia. ( 23 de junio de 1922). Ley 32 de 1922 (Junio 17) Que adiciona y reforma la 57 de 1915 y la 37 de 1921, sobre seguros de vida. Diario Oficial No 18.350. 
[75] Congreso de la República de Colombia. ( 5 de febrero de 1982). Ley 21 de 1982 (Enero 22) Por la cual se modifica el régimen del Subsidio Familiar y se dictan otras disposiciones. Diario Oficial 35939.

[76] Congreso de la República de Colombia. (11 de julio de 2012). Ley 1562 de 2012 (Julio 11). Por la cual se modifica el Sistema de Riesgos Laborales y se dictan otras disposiciones en materia de Salud Ocupacional. Diario Oficial No. 48.488.

[77] Congreso de la República de Colombia. (14 de diciembre de 1931). Ley 129 de 1931 (Noviembre 23) Por la cual se aprueban varias convenciones adoptadas por la Conferencia Internacional del Trabajo, en sus 1, 2, 3, 4, 7, 8, 9, 10 y 11 sesiones. Diario Oficial No 21.865 .

[78] Congreso de la República de Colombia. (15 de enero de 1990). Ley 25 de 1981 (Febrero 24) Por el cual se crea la Superintendencia del Subsidio Familiar y se dictan otras disposiciones. Diario Oficial No. 39.143.

[79] Congreso de la República de Colombia. (15 de Noviembre de 1915). Ley 57 de 1915 (15 de noviembre) Sobre reparaciones por accidentes de trabajo. Diario Oficial No. 15646.

[80] Congreso de la República de Colombia. (19 de Febrero de 1945). Ley 6 de 1945 (19 de Febrero) por la cual se dictan algunas disposiciones sobre convenciones de trabajo, asociaciones profesionales, conflictos colectivos y jurisdicción especial de trabajo Diario Oficial No. 25790.

[81] Congreso de la República de Colombia. (2 de diciembre de 1924). Ley 48 de 1924 (Noviembre 29). Sobre Protección a la Infancia. Diario Oficial No. 19.767.

[82] Congreso de la República de Colombia. (21 de diciembre de 2012). Ley 1595 de 2012 (Diciembre 21) Por medio de la cual se aprueba el "Convenio Sobre el Trabajo Decente Para las Trabajadoras y los Trabajadores Domésticos, 2011 (número 189)", adoptado en Ginebra, Confederación Suiza, en la 100ª reunión de la Conferencia Internacional del Trabajo el 16 de 2011. Diario Oficial No. 48.651.

[83] Congreso de la República de Colombia. (21 de enero de 1988). Ley 11 de 1988 (enero 19) Por lo cual se consagran unas excepciones en el régimen del Seguro Social para los trabajadores del servicio doméstico. Diario Oficial No 38.187. 
[84] Congreso de la República de Colombia. (23 de diciembre de 1993). Ley 100 de 1993 (Diciembre 23) Por la cual se crea el sistema de seguridad social integral y se dictan otras disposiciones. Diario Oficial No. 41.148.

[85] Congreso de la República de Colombia. (23 de Noviembre de 1918) Ley 46 de 1918 (23 de Noviembre) Por el cual se dicta una medida de salubridad pública y proveer a la existencia de habitaciones higiénicas a la clase proletaria.

[86] Congreso de la República de Colombia. (24 de Noviembre de 1921). Ley 37 de 1921(Noviembre 19) Que establece el seguro colectivo obligatorio. Diario Oficial No 17.998 y 17.999.

[87] Congreso de la República de Colombia. (29 de diciembre de 2011). Ley 1496 de 2011 (Diciembre 29) 'Por medio de la cual se garantiza la igualdad salarial y de retribución laboral entre mujeres y hombres, se establecen mecanismos para erradicar cualquier forma de discriminación y se dictan otras disposiciones. Diario Oficial No. 48.297.

[88] Congreso de la República de Colombia. (7 de enero de 1947). Ley 90 de 1946 (26 de Diciembre) Por la cual se establece el seguro social obligatorio y se crea el Instituto Colombiano de Seguros Sociales. Diario Oficial No 26.322.

[89] Congreso de la República de Colombia, (1 de enero de 1991). Ley 50 de 1990.Por la cual se introducen reformas al Código Sustantivo del Trabajo y se dictan otras disposiciones. Diario Oficial No. 39.618

[90] Congreso de la República de Colombia, (7 de julio de 2016). Ley 1788 de 2016. Por medio de la cual se garantiza el acceso en condiciones de universalidad al derecho prestacional de pago de prima de servicios para los trabajadores y trabajadoras domésticos. Diario Oficial No. 49.927.

[91] Corte Constitucional. Sentencia C-401 de 2005. Demanda de inconstitucionalidad contra el artículo 19 (parcial) del Código Sustantivo del Trabajo. Magistrado Ponente: Manuel José Cepeda Espinosa.

[92] Corte Constitucional. Sentencia C-067 de 2003. Demanda de inconstitucionalidad contra el artículo 21 (parcial) de la Ley 734 de 2002, Nuevo Código Disciplinario Único. Magistrado Ponente: Marco Gerardo Monroy Cabra

[93] Corte Constitucional. Sentencia C-616 de 2013. Revisión de constitucionalidad de la Ley 1595 del 21 de diciembre de 2012, "por medio de la cual se aprueba el "Convenio sobre el 
trabajo decente para las trabajadoras y los trabajadores domésticos, 2011 (Número 189)”, adoptado en Ginebra, Confederación Suiza, en la 100a reunión de la Conferencia Internacional del Trabajo el 16 de junio de 2011." Magistrado Ponente: Luis Ernesto Vargas Silva.

[94] Corte Suprema de Justicia, Sala Laboral. (4 de noviembre 2013). Sentencia SL-905-2013 Radicado No. 37865 Acta No.40 (2013) M.P. Carlos Ernesto Molina Monsalve.

[95] Decreto Ley 2663 del 5 de agosto de 1950 "Sobre Código Sustantivo del Trabajo", publicado en el Diario Oficial No 27.407 del 9 de septiembre de 1950, en virtud del Estado de Sitio promulgado por el Decreto Extraordinario No 3518 de 1949.

[96] Ley 50 de 1990 (diciembre 28) por la cual se introducen reformas al Código Sustantivo del Trabajo y se dictan otras disposiciones. Congreso de la República de Colombia.

[97] Ministro de Hacienda y Crédito Público y Ministro de Trabajo y Seguridad Social de la República de Colombia. (Junio 24 de 1994). Decreto Ley 1295 de 1994 (Junio 22). Por el cual se determina la organización y administración del Sistema General de Riesgos Profesionales. Diario Oficial No. 41.405.

[98] Organización Internacional del Trabajo. (1919). Convenio Número 1 (Nov. 1919). Convenio por el que se limitan las horas de trabajo en las empresas industriales a ocho horas diarias y cuarenta y ocho semanales. Primera Reunión CIT. Washington. Recuperado de:

http://www.ilo.org/dyn/normlex/es/f?p=NORMLEXPUB:12100:0::NO::P12100_INSTRU MENT_ID:312146

[99] Organización Internacional del Trabajo. (1919). Convenio Número 3 (Nov. 1919). Convenio relativo al empleo de las mujeres antes y después del parto. Primera Reunión CIT. Washington. Recuperado de:http://www.ilo.org/dyn/normlex/es/f?p=NORMLEXPUB:12100:0::NO:12100:P12100_ INSTRUMENT_ID:312148:NO

[100] Organización Internacional del Trabajo. (1919). Convenio Número 4 (Nov. 1919) Convenio Relativo al Trabajo Nocturno de las Mujeres. Primera Reunión CIT. Washington. Recuperado de: http://www.ilo.org/dyn/normlex/es/f?p=NORMLEXPUB:12100:0::NO:12100:P12100_IN STRUMENT_ID:312149:NO 
[101] Organización Internacional del Trabajo. (1919). Convenio Número 5 (Nov. 1919). Convenio por el que se fija la edad mínima de admisión de los niños a los trabajos industriales. Primera Reunión CIT. Washington. Recuperado de: http://www.ilo.org/dyn/normlex/es/f?p=NORMLEXPUB:12100:0::NO:12100:P12100_IN STRUMENT_ID:312150:NO

[102] Organización Internacional del Trabajo. (1919). Convenio Número 6 (Nov. 1919). Convenio relativo al trabajo nocturno de los menores en la industria Primera Reunión CIT. Washington. Recuperado de: http://www.ilo.org/dyn/normlex/es/f?p=NORMLEXPUB:12100:0::NO:12100:P12100_IN STRUMENT_ID:312151:NO

[103] OrganizaciónInternacionaldelTrabajo. (1948)Resolution concerning the conditions of employment of domestic workers, submitted by Mr. Roberts, Workers delegate, United Kingdom. Resolutions Adopted by the International Labour Conference at its 31st Session.Sanfrancisco. (June - July 1948). Geneva Recuperado de: http://www.ilo.org/public/ libdoc/ilo/P/09734/09734(1948-31).pdf

[104] Organización Internacional del Trabajo. (1965). Resolución Sobre las Condiciones de Empleo de los Trabajadores Domésticos. Adoptada el 23 de junio de 1965, Conferencia Internacional del Trabajo, 49a Sesión, 1965.

[105] Organización Internacional del Trabajo. (2010a). Conferencia Internacional del Trabajo, 99a reunión, 2010. Informe IV. Trabajo decente para los trabajadores domésticos. Primera Edición. Recuperado de: http://www.ilo.org/wcmsp5/groups/public/---ed_norm/--relconf/documents/meetingdocument/wcms_104703.pdf

[106] Organización Internacional del Trabajo. (2011a). Conferencia Internacional del Trabajo, $100^{a}$ reunión, 2011. Informe IV(2A). Trabajo decente para los trabajadores domésticos. Primera Edición. Recuperado de: http://www.ilo.org/wcmsp5/groups/public/---ed_norm/--relconf/ documents /meetingdocument/wcms_153167.pdf

[107] Poder Público Rama Ejecutiva Nacional. Junta Militar de Gobierno. (24 de julio de 1957). Decreto 118 (21 de Junio) Por el cual se decretan aumentos de salarios, se establece el subsidio familiar y se crea el Servicio Nacional de Aprendizaje, SENA. Diario Oficial No 29.441 . 
[108] Presidente de la República de Colombia. (11 de Septiembre de 1945). Decreto 2127 (28 de Agosto) Por el cual se reglamenta la ley 6a. de 1945, en lo relativo al contrato individual de trabajo, en general. Diario Oficial No. 25933.

[109] Presidente de la República de Colombia. Decreto 721 (15 de Abril) Por medio del cual se reglamenta el numeral $4^{\circ}$ del artículo $7^{\circ}$ de la Ley 21 de 1982 y se regula la afiliación de los trabajadores del servicio doméstico al Sistema de Compensación Familiar.

[110] Presidente de la República de Colombia. Decreto 824 de 1988 (abril 29). Se expide el Decreto Reglamentario de la Ley 11 de 1988.

[111] Recopilación de leyes de la Nueva Granada. (1845). Secretaria de Estado del Despacho de lo Interior, Sección $2^{\circ}$. 22 de febrero de 1845. Imprenta de Zoilo Salazar, Por Valentín Martínez. Bogotá. 


\begin{abstract}
Anexos
Anexo A. Entrevistas a Organizaciones que trabajan en pro de los derechos de los trabajadores del hogar.
\end{abstract}

\title{
9.1.1. POLÍTICAS PÚBLICAS Y LA REIVINDICACIÓN DE LOS DERECHOS INDIVIDUALES Y COLECTIVOS DE LOS TRABAJADORES Y LAS TRABAJADORAS DEL SERVICIO DOMÉSTICO
}

\section{MALENE GÓMEZ RUÍZ}

TESORERA

Asociación de Trabajadoras del Hogar de Bucaramanga

En el transcurso de la historia nacional e internacional, la lucha de los trabajadores por la reivindicación de sus derechos ha sido una labor ardua manchada por la violencia y la estigmatización social, pero finalmente la labor por salvaguardar los derechos de los trabajadores y trabajadoras han brindado sus frutos al crearon gran impacto social, económico y político a nivel mundial.

En la actualidad el Departamento Administrativo Nacional de Estadísticas incluye el trabajo doméstico en el Producto Interno Bruto Nacional indicando la importancia que esta fuerza laboral ha adquirido y su aporte a la economía Nacional; pero la mayor conquista llegó con la expedición y aprobación en Colombia del Convenio 189 de la Organización Internacional del Trabajo.

La sola aprobación del convenio no es evidencia del cumplimiento de la misma, se requiere el fortalecimiento de las instituciones encargadas de su implementación, así como la creación de políticas públicas contundentes para la protección del trabajo decente para los trabajadores y las trabajadoras del servicio doméstico.

Atendiendo su labor social con la Asociación de Trabajadoras del Hogar de Bucaramanga, se agradece la colaboración con el cuestionario a continuación 
1. En este orden de ideas, ¿cómo nació la idea de una la Asociación de Trabajadoras del Hogar de Bucaramanga y cuál es la labor que desarrollan para combatir la estigmatización de los grupos sindicales?

Nación en 1985 por medio de un grupo de estudiantes del Colegio la Presentación, que pasaron por las casas diciéndonos a nosotras, que las empleadas podíamos asistir a una reunión; que nos iban a enseñar a leer, escribir, a hacer la primaria, el bachillerato y a hacer manualidades. Hay a través de esto estaba la doctora Patricia, doctora María del Rosario, de CENALDI. Hay se dio inicio y por medio de esas reuniones, llegaban muchas empleadas y se nos hablaba de los derechos, de las prestaciones sociales, de los intereses, las horas de trabajo; uno se tenía que levantar desde las 4 y acostase a las 9 o 10 de la noche. Se dio inicio al revolcón. Se formó una fundación, a través de esta, se inició el proceso para adquirir la personería jurídica de la ASOCIACIÓN, en el año de 1991, pero mientras, se asistía a reuniones de trabajadoras del servicio doméstico, en Cali, en Bogotá, para adquirir el derecho a la seguridad social, gracias a Dios, a esta labor que se desarrolló, muchas adquirieron seguro y muchas ya se pensionaron.

2. En el desarrollo de la labor de la Asociación de Trabajadoras del Hogar de Bucaramanga, ¿cuáles han sido los principales retos que han afrontado tanto en la creación de la organización, como para su existencia?

El principal reto fue como agrupar personas, poder que tuvieran el derecho a las prestaciones, muchas eran discriminadas, por medio de las charlas, fue que se aprendió. Se logró la independencia de las trabajadoras, que no estuvieran encerradas, que salieran arrendaran su habitación, su casa. Si bien hay quienes aún trabajan de internas, ya no hay el mismo trato de antes.

3. ¿Cuál es el enfoque de trabajo de la Asociación para crear un trabajo decente para las trabajadoras del servicio doméstico?

Es como puedan ellas tener, su seguridad, tener sus prestaciones, sus vacaciones, sus derechos, en fin es trabajar por los derechos de las trabajadoras. 
4. ¿Ha mostrado interés el gobierno nacional o regional en la labor que desarrolla la Asociación para la protección de los derechos de las trabajadoras del servicio doméstico?

En Bogotá, lo que se hace desde allá y de ahí nos favorecemos todas. Pero a nivel regional, no se ha recibido el apoyo por parte de ningún ente del gobierno.

5. ¿Desde la creación de la organización a la actualidad, han recibido ayuda por parte del estado?

No

6. Teniendo en cuenta la ratificación por parte de Colombia del Convenio 189 de la OIT sobre trabajo decente para los trabajadores y las trabajadoras de servicio doméstico, en su labor

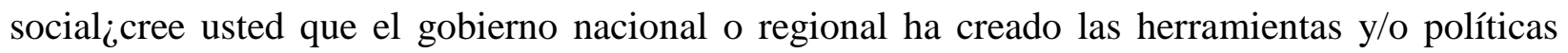
públicas idóneas para la protección de este grupo de trabajadores?

Lo que se hace por medio del gobierno nacional, y el cumplimiento de las leyes, pero estas no se cumple, solo si el patrono las cumple o la trabajadora las pide, pero si las pide las echa. Falta concientización y socialización de la norma para su cumplimiento.

7. ¿Conoce usted de políticas públicas que propendan por el trabajo decente para los trabajadores y las trabajadoras del servicio doméstico? De ser afirmativa la respuesta puede indicar ¿Cuáles son?

En el momento no se tiene conocimiento.

8. En su opinión ¿Cuáles son las herramientas o los mecanismos que se requiere a nivel nacional o regional para una óptima protección y garantía de los derechos de los trabajadores del servicio doméstico?

Irse uno a las calles a protestar, por algo que uno quiere. La única herramienta es parar hacerse escuchar, hoy en día vuelven muchas empleadas a quedarse sin seguro, porque se debe afiliar a una caja de compensación y muchos empleadores no quieren pagar, muy pocos son los que están pagando todo. De hecho hay quienes no pagan más de quinientos mil pesos, tres cientos cincuenta mil externas, ¿puede usted creer? Y las trabajadoras, lo aceptan por no quedarse en la casa. Hace falta políticas de concientización, tanto para los empleadores como para las empleadas. 
9. ¿Tiene conocimiento de otras organizaciones del orden nacional o regional que trabajen a favor de los derechos de los trabajadores y las trabajadoras del servicio doméstico?

En Bogotá SINTRASEDOM. De Cali, Medellín.

10. Como organización ¿han presentado propuestas a algunos de los estamentos del orden nacional o regional para la implementación de políticas públicas que propendan por el trabajo decente para los trabajadores y trabajadoras del servicio doméstico?

Si se han presentado propuestas, Se le envió una a la esposa del presidente URIBE, para que nos dieran un lugar donde reunirnos y donde realizar las actividades de la Asociación; nos contestó y nos dijo que no tenía para darnos casa, buscáramos casa casas que estuvieran desalojadas, pero esas casas tienen personas que cobran arriendo, lo que se quería era que nos colaboraran con una casa, y nos mandaron a las partes más feas más horribles, entonces no nos sirvió.

Después se pasó otro proyecto a la Gobernación, Tan poco nos quiso aprobar nada.

La idea es tener algo, para arrancar, aquí no se pueden hacer reuniones, Lo que se busca es un sitio donde alojar a las trabajadoras, para formalizar y hacer reunión.

NO HAY CONTROL POR PARTE DEL GOBIERNO DEL CUMPLIMIENTO DE LAS NORMAS POR

NECESITAN LA AYUDA A ALGUIEN QUE LES COLABORE A IMPULSAR LA ASOCIACIÓN

SENSO PARA SABER CUANTAS EMPLEADAS DEL SERVICIO DOMÉSTICO HAY EN LA CIUDAD Y CUAL ES LA SITUACIÓN LABORAL. 


\subsubsection{POLÍTICAS PÚBLICAS Y LA REIVINDICACIÓN DE LOS DERECHOS INDIVIDUALES Y COLECTIVOS DE LOS TRABAJADORES Y LAS TRABAJADORAS DEL SERVICIO DOMÉSTICO}

\section{ISABEL ORTIZ PÉREZ}

Auxiliar

Fundación Mujer y Futuro

En el transcurso de la historia nacional e internacional, la lucha de los trabajadores por la reivindicación de sus derechos ha sido una labor ardua manchada por la violencia y la estigmatización social, pero finalmente la labor por salvaguardar los derechos de los trabajadores y trabajadoras han brindado sus frutos al crear un gran impacto social, económico y político a nivel mundial.

En la actualidad el Departamento Administrativo Nacional de Estadísticas incluye el trabajo doméstico en el Producto Interno Bruto Nacional indicando la importancia que esta fuerza laboral ha adquirido y su aporte a la economía Nacional; pero la mayor conquista llegó con la expedición y aprobación en Colombia del Convenio 189 de la Organización Internacional del Trabajo.

La sola aprobación del convenio no es evidencia del cumplimiento de la misma, se requiere el fortalecimiento de las instituciones encargadas de su implementación, así como la creación de políticas públicas contundentes para la protección del trabajo decente para los trabajadores y las trabajadoras del servicio doméstico.

Atendiendo su labor social con la Fundación Mujer y Futuro, se agradece la colaboración con el cuestionario a continuación:

1. ¿Ha mostrado interés el gobierno nacional o regional en la labor que desarrolla con las trabajadoras del servicio doméstico?

Consideramos que ha existido muy poco interés y apoyo por la labor en favor de los derechos laborales de las trabajadoras del servicio doméstico. Pero es importante también aclarar que actualmente la FMF, realiza muy poco trabajo con esta población. 
2. ¿Desde la creación de la organización a la actualidad, han recibido ayuda por parte del Estado?

En 1992-1995 realizamos acciones en coordinación con el Min de Trabajo y hubo apoyo al reconocer la labor que adelantábamos de difusión de los derechos de las TSD. Apoyo económico no ha habido.

3. Teniendo en cuenta la ratificación por parte de Colombia del Convenio 189 de la OIT sobre trabajo decente para los trabajadores y las trabajadoras de servicio doméstico, en su labor social ¿cree usted que el gobierno nacional o regional ha creado las herramientas y/o políticas públicas idóneas para la protección de este grupo de trabajadores?

No se han creado herramientas ni políticas idóneas para la protección de este grupo de trabajadoras. Consideramos que la situación de precariedad de las mujeres TSD, es muy grave y requiere con urgencia protección estatal.

4. ¿Conoce usted de políticas públicas que propendan por el trabajo decente para los trabajadores y las trabajadoras del servicio doméstico? De ser afirmativa la respuesta puede indicar ¿Cuáles son?

Lo que conocemos es la obligatoriedad de vinculación al Sistema de seguridad social y a las cajas de compensación familiar de las TSD. También la obligatoriedad de ser liquidadas las prestaciones sociales como cualquier trabajador. Pero desafortunadamente no hay herramientas que garanticen su efectivo cumplimiento.

5. En su opinión ¿Cuáles son las herramientas o los mecanismos que requiere el estado para una óptima protección de los derechos de los trabajadores del servicio doméstico?

Realizar seguimiento a los empleadores en el cumplimiento de la legislación laboral, realizar difusión a empleadas y patronos sobre derechos laborales de TSD.

6. ¿Tiene conocimiento de otras organizaciones del orden nacional o regional que trabajen a favor de los derechos de los trabajadores y las trabajadoras del servicio doméstico? Si, en Cali, 
Taller Abierto realiza un trabajo de apoyo organizativo. En Bogotá, hay el sindicato de TD. Pero son muy pocas las organizaciones que adelantan acciones de apoyo a este sector.

7. Como organización ¿han presentado propuestas a algunos de los estamentos del orden nacional o regional para la implementación de políticas públicas que propendan por el trabajo decente para los trabajadores y trabajadoras del servicio doméstico?

No lo hemos realizado. 


\subsubsection{POLÍTICAS PÚBLICAS Y LA REIVINDICACIÓN DE LOS DERECHOS INDIVIDUALES Y COLECTIVOS DE LOS TRABAJADORES Y LAS TRABAJADORAS DEL SERVICIO DOMÉSTICO}

\section{LUZ DARY CAMAYO COMETA}

Secretaria

Unión de Trabajadoras del Servicio Doméstico

En el transcurso de la historia nacional e internacional, la lucha de los trabajadores por la reivindicación de sus derechos ha sido una labor ardua manchada por la violencia y la estigmatización social, pero finalmente la labor por salvaguardar los derechos de los trabajadores y trabajadoras han brindado sus frutos al crear un gran impacto social, económico y político a nivel mundial.

En la actualidad el Departamento Administrativo Nacional de Estadísticas incluye el trabajo doméstico en el Producto Interno Bruto Nacional indicando la importancia que esta fuerza laboral ha adquirido y su aporte a la economía Nacional; pero la mayor conquista llegó con la expedición y aprobación en Colombia del Convenio 189 de la Organización Internacional del Trabajo.

La sola aprobación del convenio no es evidencia del cumplimiento de la misma, se requiere el fortalecimiento de las instituciones encargadas de su implementación, así como la creación de políticas públicas contundentes para la protección del trabajo decente para los trabajadores y las trabajadoras del servicio doméstico.

Atendiendo la labor social que desarrolla, se agradece de antemano la colaboración con el cuestionario a continuación

1. En este orden de ideas, ¿cómo nació la idea de la Unión de Trabajadoras del Hogar?

La experiencia organizativa de UTRAHOGAR se inicia en 1.988, a través de un proyecto de promoción de los derechos de las mujeres de casas de familia, desarrollado por el Centro de Atención Integral para las Mujeres - CAMI de Cali.

Entre 1993 y 1997, UTRAHOGAR obtiene la personería jurídica, prestando de manera autónoma el servicio de asesoría a patrones/ patronas y empleadas, así como el de liquidación de 
prestaciones sociales. Este trabajo fue reconocido por la Oficina Regional del Trabajo del Ministerio de la Protección Social, de donde nos enviaban personas para ser atendidas. Para esta época también se mantiene una comunicación permanente con la Confederación Latinoamérica y del Caribe de las Trabajadoras en Casas de Familia CONLACTRAHO, lo que permitió el intercambio de experiencias y una ampliación de la perspectiva de la organización. Desde sus inicios las integrantes de UTRAHOGAR han contribuido con sus propios recursos al sostenimiento de la organización.

2. Indique por favor, ¿Cuál ha sido su labor en el ámbito de los derechos de los trabajadores y las trabajadoras del servicio doméstico?

En 1988, UTRAHOGAR participó activamente junto con otras organizaciones en la movilización para la aprobación de la Ley 11 de 1988 de Seguridad Social para las Trabajadoras Domésticas, que abrió las posibilidades para su afiliación, cotizando con el salario real que devengaban (menos del salario mínimo).

Participación a la 99 y 100 Conferencia de la OIT para la discusión del convenio 189.

Desde el ámbito Latinoamericano estamos afiliadas a la Confederación Latinoamericana y del Caribe de las trabajadoras del hogar, desde este escenario hemos podido intercambiar experiencias y aportar para la creación de leyes en los países que en la actualidad están gestionando aprobación de leyes al respecto.

En el ámbito local, se realizan talleres y asesorías sobre los derechos y deberes de manera permanente. Elaboración de liquidación de prestaciones sociales.

En la actualidad, se está fortaleciendo la bolsa de empleo como estrategia para que las mujeres accedan a empleos en condiciones favorables y con la información pertinente.

3. ¿Ha mostrado interés el gobierno nacional o regional en la labor que desarrolla con las trabajadoras del servicio doméstico?

En 2004 se participa de la jornada informativa sobre afiliación a seguridad social, evento organizado por la Secretaria de Salud, El Ministerio de la Protección Social y el Centro Integral 
para la Mujer y la Familia - Taller Abierto, como estrategia para la difusión de los derechos y deberes del gremio.

Desde el Ministerio de Trabajo hay apoyo facilitando las inspectores de trabajo para que nos actualicen en las leyes a las socias de UTRAHOGAR, también facilitan el material (cartillas) relacionadas a información pertinente al gremio.

4. ¿Desde la creación de la organización a la actualidad, han recibido ayuda por parte del estado?

Desde e Ministerio de Trabajo Nacional facilitaron los recursos económicos para participar en la 99 y 100 Conferencia en la OIT, únicos recursos que nos han facilitado.

5. Teniendo en cuenta la ratificación por parte de Colombia del Convenio 189 de la OIT sobre trabajo decente para los trabajadores y las trabajadoras de servicio doméstico, en su labor social ¿cree usted que el gobierno nacional o regional ha creado las herramientas y/o políticas públicas idóneas para la protección de este grupo de trabajadores?

Desde la legislación colombiana existe leyes en favor del gremio desde antes del Convenio, la dificultad para garantizar los derechos está relacionada con que la precariedad laboral hace que las mujeres acepten las condiciones desfavorables que imponen los empleadores y los recortes presupuestales estatales hace que los funcionarios nombrados en las entidades no den abasto para resolver/solucionar casos.

Así mismo, el trabajo doméstico sigue siendo una labor estigmatizado socialmente lo que hace más compleja la relación laboral como tal.

6. ¿Conoce usted de políticas públicas que propendan por el trabajo decente para los trabajadores y las trabajadoras del servicio doméstico? De ser afirmativa la respuesta puede indicar ¿Cuáles son?

A la fecha los decretos solo complementan lo existe, por ejemplo el 721 del 2013 que obliga a los empleadores a que afilien a sus empleadas a las cajas de compensación, pero una política como tal no existe.

7. En su opinión ¿Cuáles son las herramientas o los mecanismos que requiere el estado para una óptima protección de los derechos de los trabajadores del servicio doméstico? 
Los mecanismos están claros frente a los derechos que tiene el gremio de las trabajadoras domésticas, lo que sigue siendo muy débil son los procesos al momento de garantizarlos. Ejemplo, si las trabajadoras se acercan para establecer alguna queja ante el ministerio, éste solo hace una conciliación pero no obliga al cumplimiento de la acción, lo que genera desmotivación y desprotección para la trabajadora.

Por las mismas condiciones laborales en las que desarrollan las actividades, las mujeres tienen poco o nada de acceso a información sobre el tema y las instituciones que hacemos este tipo de labor no somos apoyadas económicamente para hacer más de lo que está en nuestras agendas anuales.

8. ¿Tiene conocimiento de otras organizaciones del orden nacional o regional que trabajen a favor de los derechos de los trabajadores y las trabajadoras del servicio doméstico? De ser afirmativo, puede indicar ¿cuáles?

SINTRASEDOM en Bogotá.

9. Como organización ¿han presentado propuestas a algunos de los estamentos del orden nacional o regional para la implementación de políticas públicas que propendan por el trabajo decente para los trabajadores y trabajadoras del servicio doméstico?

Como organización solo hemos hecho trabajo mancomunado con la Central Sindical CGT con sede en Bogotá para trabajar sobre lo que ya existe. 


\subsubsection{POLÍTICAS PÚBLICAS Y LA REIVINDICACIÓN DE LOS DERECHOS INDIVIDUALES Y COLECTIVOS DE LOS TRABAJADORES Y LAS TRABAJADORAS DEL SERVICIO DOMÉSTICO}

\section{ANDREA LONDOÑO SÁNCHEZ}

Coordinadora

Hablemos de Empleadas Domésticas.

En el transcurso de la historia nacional e internacional, la lucha de los trabajadores por la reivindicación de sus derechos ha sido una labor ardua manchada por la violencia y la estigmatización social, pero finalmente la labor por salvaguardar los derechos de los trabajadores y trabajadoras han brindado sus frutos al crear un gran impacto social, económico y político a nivel mundial.

En la actualidad el Departamento Administrativo Nacional de Estadísticas incluye el trabajo doméstico en el Producto Interno Bruto Nacional indicando la importancia que esta fuerza laboral ha adquirido y su aporte a la economía Nacional; pero la mayor conquista llegó con la expedición y aprobación en Colombia del Convenio 189 de la Organización Internacional del Trabajo.

La sola aprobación del convenio no es evidencia del cumplimiento de la misma, se requiere el fortalecimiento de las instituciones encargadas de su implementación, así como la creación de políticas públicas contundentes para la protección del trabajo decente para los trabajadores y las trabajadoras del servicio doméstico.

Atendiendo su labor social que desarrolla como coordinadora de Hablemos de Empleadas Domésticas en Medellín, se agradece la colaboración con el cuestionario a continuación

11. En este orden de ideas, ¿cómo nació la idea de Hablemos de Empleadas Domésticas?

En el año 2010 y luego de años de cuestionamientos personales y profesionales sobre la precariedad de los derechos laborales de las empleadas domésticas, ofrecí a la Escuela Nacional Sindical - ENS, ONG que realizaba en ese momento una investigación sobre las empleadas domésticas afro en Medellín, mis servicios como profesional de las comunicaciones, con el objetivo de visibilizar el abuso laboral y personal que sufren las 750.000 empleadas domésticas en Colombia. Yo sabía ya del poder de las redes sociales y había creado @Empleadas_hogar en Twitter, con buena acogida por parte, sobre todo, de los colegas de los medios masivos. La 
investigación de la ENS y el proyecto correspondiente fueron las bases del nacimiento del sindicato UTRASD - Unión de Trabajadoras del Servicio Doméstico en Colombia, grupo que también empezó a ser divulgado y apoyado a través de la cuenta en Twitter. Simultáneamente encontré en la agencia de publicidad MoralesCom, asesoría en comunicación pública para el objetivo que traía. Con la agencia llegamos a la conclusión de que los empleadores tienen profundamente instaladas en su mente a las empleadas domésticas como sujetos no merecedores de derechos laborales plenos, y al trabajo doméstico como una actividad despreciable de la economía nacional. Cruzamos los dramáticos resultados de la investigación de la ENS en la cual se daba cuenta de la deficiente garantía de derechos laborales de las empleadas, (no pago del salario mínimo, carencia de prestaciones sociales plenas, y por supuesto la discriminación de género, racional y laboral, entro otros resultados), con las expresiones de afecto de los empleadores (ejemplo: "Es la persona más importante de la familia”) y entendimos que hay una brecha grande entre lo que los empleadores dicen y lo que creen o sienten sobre las empleadas. A este tipo de certezas las llamamos Creencias, y como tales deben ser enfrentadas. De este análisis nace Hablemos de empleadas domésticas, cuyo objetivo es convocar a los dos grandes grupos de interés en este problema: empleadores y empleadas, y convocarlos de una forma más neutral, más abierta, para permitir que la sociedad "desembuche" todo lo que siente y piensa de ellas, para llegar al cumplimiento de la ley de manera efectiva. En ese momento creamos también la cuenta de Facebook Hablemos de Empleadas Domésticas y el sitio Web Hablemos de Empleadas Domésticas.

12. Indique por favor, ¿Cuál ha sido su labor en el ámbito de los derechos de los trabajadores y las trabajadoras del servicio doméstico?

Visibilizar y posicionar en la agenda mediática y pública el tema del trabajo doméstico, y de las empleadas domésticas como uno de los grupos sociales más discriminados, y al mismo tiempo, valiosísimo para el país. Hablemos de Empleadas Domésticas ha trabajado en cuatro frentes:

- Apoyo al sindicato Utrasd - Unión de Trabajadoras del Servicio Doméstico, mediante la visibilización de su trabajo ante la comunidad local, nacional e internacional y la gestión para buscar que las mujeres del sindicato reciban capacitación. El sindicato es apoyado por la Escuela Nacional Sindical - ENS. 
- Seguimiento al gobierno nacional - advocacy -, a través de las redes sociales digitales, para buscar el cumplimiento de los compromisos del Convenio 189, la reglamentación de la legislación, y la exigencia de campañas públicas y mecanismos que impulsen la puesta en práctica de la legislación.

- Sensibilización a los empleadores en particular y a la ciudadanía en general, sobre esta problemática, a través de la realización de eventos de reflexión y del posicionamiento del tema en redes sociales digitales así como el suministro de información especializada en el sitio web.

- Suministro de información a medios de comunicación, para posicionar el tema en la esfera pública nacional e internacional.

13. ¿Ha mostrado interés el gobierno nacional o regional en la labor que desarrolla con las trabajadoras del servicio doméstico?

Hemos encontrado tres tipos de respuesta por parte del gobierno.

- En la cuenta de Twitter hemos tenido algunas interlocuciones con el Ministerio de Trabajo y concretamente con los Ministros Rafael Pardo y Luis Eduardo Garzón, y los Viceministros Mauricio Olivera, David Luna y Juan Carlos Cortés.

- La Alcaldía de Medellín por petición nuestra, dictó, de manera muy comprometida, un curso básico de apropiación digital a 25 empleadas del sindicato, a través de su programa Medellín Inteligente. Estamos a la espera del diseño del segundo módulo.

- El Viceministerio de Trabajo anunció a la Escuela Nacional Sindical que apoyaría la campaña de información y sensibilización sobre los derechos laborales de las empleadas y la nueva reglamentación. Se han tenido tres reuniones con ellos en un lapso de 6 meses.

14. ¿Desde la creación de la organización a la actualidad, han recibido ayuda por parte del estado?

No.

15. Teniendo en cuenta la ratificación por parte de Colombia del Convenio 189 de la OIT sobre trabajo decente para los trabajadores y las trabajadoras de servicio doméstico, en su labor social ¿cree usted que el gobierno nacional o regional ha creado las herramientas y/o políticas públicas idóneas para la protección de este grupo de trabajadores? 
El gobierno nacional ha motivado la creación de tres normas fundamentales consistentes con el Convenio 189:

- Ley 1595 de 2012 (Derechos Laborales de las Empleadas del Servicio Doméstico) que aprueba el Convenio 189 de la OIT, en la cual se expresa la voluntad del gobierno nacional de velar por sus derechos laborales y se adquieren compromisos frente al ente internacional regulador de las relaciones entre empleados, empleadores y gobiernos.

- Decreto 721 del 15 de abril de 2013, del Ministerio de Trabajo, "por medio del cual se reglamenta el numeral 4 del artículo $7^{\circ}$ de la Ley 21 de 1982 y se regula la afiliación de los trabajadores del servicio doméstico al Sistema de Compensación Familiar."

- $\quad$ Decreto 2616 del 20 de noviembre de 2013, del Ministerio de Trabajo, "por medio del cual se regula la cotización a seguridad social para trabajadores dependientes que laboran por períodos inferiores a un mes, se desarrolla el mecanismo financiero y operativo de que trata el artículo 172 de la ley 1450 de 2011 y se dictan disposiciones tendientes a lograr la formación laboral de los trabajadores informales".

Pese a que las normas descritas eran el primer paso necesario para restablecer los derechos laborales de las empleadas, su implementación no ha contado con las políticas públicas y herramientas necesarias para su ejecución. Una de las grandes dificultades para cualquier intervención sobre el problema, es la disgregación de estas trabajadoras: cada una está en una unidad productiva o de trabajo (casa) distinta y distante geográficamente, y las posibilidades de ejercer presión de grupo ("la unión hace la fuerza") son más remotas que en el caso de las unidades productivas empresariales, por ejemplo. Esta misma dificultad la encuentra el Gobierno a la hora de ejercer deberes de inspección, fiscalizadores o judiciales sobre los empleadores. En otras palabras, las empleadas del servicio doméstico en Colombia están hoy a merced de su empleador (ellas dicen que en la mayoría de las veces su empleador es la patrona).

El gobierno nacional y los gobiernos departamentales y locales, están en mora de implementar programas para la ejecución de la legislación existente.

16. ¿Conoce usted de políticas públicas que propendan por el trabajo decente para los trabajadores y las trabajadoras del servicio doméstico? De ser afirmativa la respuesta puede indicar ¿Cuáles son?

No. 
17. En su opinión ¿Cuáles son las herramientas o los mecanismos que requiere el estado para una óptima protección de los derechos de los trabajadores del servicio doméstico?

- Inspección a las casas de los empleadores (hasta hace 6 meses teníamos noticia de que el gobierno nacional había realizado cinco inspecciones en todo el país).

- Campañas publicitarias de divulgación de la legislación existente.

- Establecimiento de alianzas público privadas para la capacitación escolar, cívica y laboral de las empleadas.

- Estímulos para los empleadores que afilien a la empleada doméstica, por más del mínimo, puede ser un peso, pero garantizaría la formalización laboral.

- Programas a través de organismos del Estado como el SENA y las Cajas de Compensación Familiar para capacitar a las empleadas.

- Agilización de los trámites de vinculación laboral, son aún muy engorrosos.

- Presión a las Cajas de Compensación Familiar para realizar campañas de afiliación y divulgación de la legislación sobre empleadas domésticas.

18. ¿Tiene conocimiento de otras organizaciones del orden nacional o regional que trabajen a favor de los derechos de los trabajadores y las trabajadoras del servicio doméstico? De ser afirmativo, puede indicar ¿cuáles?

- Tengo conocimiento de que en Bogotá, Yenny Hurtado ha liderado Sintrasedom, otro sindicato de empleadas domésticas, sin embargo, sólo hace unos meses entramos en contacto con ella y sólo hemos tenido algunas conversaciones telefónicas.

- En Medellín hemos trabajado apoyando al sindicato Utrasd.

- También en Medellín hemos encontrado a la Corporación Carabantú que trabaja con población afro, y ellos han sido muy cercanos a las empleadas y al sindicato.

19. Como organización ¿han presentado propuestas a algunos de los estamentos del orden nacional o regional para la implementación de políticas públicas que propendan por el trabajo decente para los trabajadores y trabajadoras del servicio doméstico? 
A través de Twitter hemos pedido apoyos concretos al Ministerio de Trabajo, como la actualización de la Guía Laboral del Trabajo Doméstico, la cual está desactualizada; Se nos ha respondido desde hace un año y medio, que están en proceso.

A través de la Escuela Nacional Sindical se ha entrado en contactos para la elaboración de una campaña publicitaria nacional conjunta sobre los derechos laborales de las empleadas, pero aún no hay ningún proceso formal en marcha.

Con Medellín Inteligente, dependencia de la Alcaldía de Medellín encargada de programas TIC, estamos en el diseño del segundo módulo de capacitación básica en tecnologías TIC.

Atentamente,

Andrea Londoño S.

14 de octubre de 2014. 
Anexo B. Análisis Jurisprudencial Sentencia C-616 de 2013 Sobre la Exequibilidad de la Ley 1595 de 2012 Por Medio de la Cual se Aprueba EI Convenio 189.

\section{ANÁLISIS JURISPRUDENCIAL SENTENCIA C-616 DE 2013 SOBRE LA EXEQUIBILIDAD DE LA LEY 1595 DE 2012POR MEDIO DE LA CUAL SE APRUEBA DEL CONVENIO 189.}

Número de sentencia Sentencia C-616 del 2013

Tipo de sentencia Revisión de Constitucionalidad

Fecha de sentencia Corte Constitucional: 04 de septiembre del 2013

Magistrado ponente Dr. Luis Ernesto Vargas Silva

Hechos o elementos Con base en lo dispuesto en el artículo 241 numeral 10 de la Carta fácticos Política, mediante oficio fechado el 26 de diciembre de 2012 y radicado en la Secretaría General de esta Corporación el 11 de enero de 2013, la Secretaria Jurídica de la Presidencia de la República remitió copia auténtica de la Ley 1595 de 2012, para efectos de su revisión constitucional.

El Magistrado Sustanciador, mediante auto del 7 de febrero de 2013, avocó el conocimiento del proceso y dispuso la práctica de pruebas. Recibidas estas, a través de providencia del 20 de marzo del mismo año, se ordenó continuar el trámite del mismo y, en consecuencia, fijar en lista el proceso por el término de 10 días con el fin de permitir la intervención ciudadana, así como dar traslado al Procurador General de la Nación para el concepto correspondiente y comunicar la iniciación del proceso al Presidente de la República, al Presidente del 
Congreso de la República, así como a los Ministros de Interior, de Relaciones Exteriores, de Trabajo, y de Salud y Protección Social.

\section{Normas}

constitucionales

Artículo 241 numeral 10

objeto

de

pronunciamiento

Problema jurídico de

la sentencia

¿Cumple la Ley 1595 de 2012 con los requisitos Constitucionales y de Ley para la adopción del Convenio 189 de la OIT sobre el Trabajo decente para las trabajadoras y los trabajadores domésticos?

¿Responde La ratificación del convenio 189a las necesidades sociojurídicas que salvaguarden el trabajo decente para los trabajadores y las trabajadoras del servicio doméstico en Colombia?

Procedimientos La Corte Constitucional en la sentencia realiza las consideraciones anteriores concernientes al procedimiento mediante el cual se adopta el Convenio 189 de la OIT sobre el trabajo decente para las trabajadoras y los trabajadores domésticos, atendiendo a lo pronunciado por la Corte se hace referencia a los siguientes puntos:

Constitucionalidad del trámite legislativo

La descripción del procedimiento surtido por el proyecto de ley permite a la Corte concluir que la norma de la referencia es exequible desde su aspecto formal. 


\section{- La revisión por el aspecto formal}

- Representación del Estado, suscripción del tratado y aprobación presidencial

El Ministerio de Relaciones Exteriores informó a esta Corporación que el Convenio 189 fue adoptado de acuerdo con el procedimiento previsto en el artículo 19 de la Constitución de la Organización Internacional del Trabajo.

- El trámite legislativo del proyecto de ley

El expediente legislativo enviado a la Corte por el Congreso de la República demuestra que el proyecto de ley $n .^{\circ}$ 230/12 Senado, 144/12 Cámara, que finalizó con la expedición de la Ley 1595 del 21 de diciembre de 2012 "por medio de la cual se aprueba el "Convenio sobre el trabajo decente para las trabajadoras y los trabajadores domésticos, 2011 (Número 189)”, adoptado en Ginebra, Confederación Suiza, en la 100a reunión de la Conferencia Internacional del Trabajo el 16 de junio de 2011.”

- Senado de la República

- El proyecto de ley correspondiente fue presentado al Congreso de la República por los ministros de Relaciones Exteriores y de Trabajo.

- Su texto fue publicado en la Gaceta del Congreso 176 del 25 de abril de 2012.

- El Secretario General del Senado hace constar que "[e]1 mencionado proyecto de ley fue aprobado en segundo debate con el lleno de los requisitos constitucionales, legales y reglamentarios, mediante votación ordinaria, conforme al artículo 129 de la Ley 5 de 1992, y un quórum de 92 votos afirmativos, cero negativos y centro abstenciones de 100 senadores". 
- Cámara de Representantes

- El proyecto de ley fue considerado y aprobado por la Comisión Segunda de la Cámara de Representantes el 7 de noviembre de 2012, por unanimidad y a través de votación ordinaria. Esto conforme lo expuesto en el Acta n. ${ }^{\circ} 19$ de la misma fecha, publicada en la Gaceta del Congreso 222 del 22 de abril de 2013.

- En sesión plenaria del 28 de noviembre de 2012, a la cual se hicieron presentes 152 Representantes, se consideró y aprobó por unanimidad y en votación ordinaria, el informe de ponencia para segundo debate, como el título y articulado del proyecto de ley, decisión consignada en el Acta n. ${ }^{\circ} 177$ de la misma fecha, publicada en la Gaceta del Congreso 83 del 12 de marzo de 2013.

- Sanción presidencial y remisión a la Corte Constitucional

La Ley 1595 fue sancionada por el Presidente de la República el 21 de diciembre de 2012, remitiéndose para su estudio a la Corte el 26 del mismo mes, a través de oficio suscrito por la Secretaria Jurídica de la Presidencia, cumpliéndose con ello el término de seis días al que refiere el artículo 241-10 de la Constitución.

\section{Aspectos de fondo}

En el análisis de fondo de la Corte Constitucional, se tuvo en cuenta los fallos que al respecto se han producido por el ente colegiado, para establecer un marco de referencia sobre las garantías mínimas que 
desde la Constitución poseen los trabajadores y las trabajadoras domésticas, con el fin de verificar la compatibilidad del convenio 189 con la Carta Política.

De lo pronunciado por la Corte se extraen los siguientes apartes:

"El artículo 25 C.P. determina que el trabajo es un derecho y una obligación social, el cual goza en todas sus modalidades de la especial protección del Estado. De igual modo, la misma norma prescribe que toda persona tiene derecho a un trabajo en condiciones dignas y justas. Del mismo modo, el artículo 53 C.P. identifica los principios mínimos fundamentales del trabajo, que operan como condiciones indispensables para el desarrollo legislativo ulterior. Estos principios versan sobre (i) igualdad de oportunidades para los trabajadores; remuneración mínima vital y móvil; (ii) proporcional a la cantidad y calidad de trabajo; (iii) estabilidad en el empleo; (iv) irrenunciabilidad a los beneficios mínimos establecidos en normas laborales; (v) facultades para transigir y conciliar sobre derechos inciertos y discutibles; (vi) situación más favorable al trabajador en caso de duda en la aplicación e interpretación de las fuentes formales de derecho; (vi) primacía de la realidad sobre formalidades establecidas por los sujetos de las relaciones laborales; (vii) garantía a la seguridad social, la capacitación, el adiestramiento y el descanso necesario; y (viii) protección especial a la mujer, a la maternidad y al trabajador menor de edad.

Igualmente, la norma superior en comento determina tres reglas constitucionales específicas, relativas a (i) la obligación estatal de garantizar el derecho al pago oportuno y al reajuste periódico de las pensiones legales; (ii) la pertenencia a la legislación interna de los convenios internacionales del trabajo debidamente ratificados; y (iii) 
la prohibición que la ley, los contratos, los acuerdos y convenios del trabajo menoscaben la libertad, la dignidad humana o los derechos de los trabajadores.

La Corte encuentra que en relación con la garantía de los derechos de los trabajadores y trabajadoras domésticos, la jurisprudencia constitucional ha fijado reglas definidas sobre el particular, las cuales versan en sus aspectos esenciales acerca de (i) la existencia de un mandato constitucional de equiparación, en lo que respecta al goce y ejercicio de los principios mínimos del trabajo, de que trata el artículo 53 C.P. entre los trabajadores y trabajadoras domésticos y los demás trabajadores. Esto en los diferentes planos de la protección laboral, entre los que se destacan los aspectos salariales y prestacionales, de la seguridad social, las condiciones físicas del empleo compatibles con la dignidad de la persona; la protección de la estabilidad laboral de la mujer embarazada, etc. (ii) el reconocimiento que la relación laboral de los trabajadores y particularmente los trabajadores domésticos está signada por una particular forma de subordinación jurídica hacia el empleador, merced de la labor efectuada y las condiciones en que se desarrolla, sumado al hecho que el servicio es usualmente prestado por mujeres de escasos recursos e instrucción; en consecuencia (iii) la necesidad de otorgar a las relaciones laborales en comento un marco reforzado de protección de los derechos del trabajador, lo cual incluso permite fijar discriminaciones a su favor, compatibles con la condición de vulnerabilidad en que suelen encontrarse las trabajadoras y trabajadores domésticos.

En lo que respecta al ámbito material del tratado, está conformado por reglas dirigidas a la protección de los derechos constitucionales de las trabajadoras y trabajadores domésticos, circunstancia que avala su exequibilidad. En consecuencia, la Corte declarará la 
constitucionalidad del instrumento internacional y de su ley aprobatoria."

El avanceen protección jurisprudencial de los derechos laborales para los trabajadores y las trabajadoras del servicio doméstico se apoya como se indica en la sentencia en el principio de dignidad humana que la Corte Constitucional Colombiana ha desarrollado,pero este principio no es suficiente para garantizar la efectiva protección de estos trabajadores, al estudiar los elementos que componen el trabajo decente y realizar el cotejocon las garantías que ofrece la Constitución y la Ley, se evidencia la necesidad de políticas públicas eficientes que garanticen la plena protección de este grupo de trabajadores al respecto indica la cuerpo colegiado:

“...la norma internacional impone un deber específico para los empleadores y para el Estado, consistente en la disposición de mecanismos adecuados y suficientes para las trabajadoras $y$ trabajadores domésticos sean debidamente informados sobre sus derechos y obligaciones en virtud de la relación laboral. Tales mecanismos, a su vez, deberán tener en cuenta las particulares condiciones de dichos trabajadores, especialmente su grado de instrucción, la situación de vulnerabilidad en que suelen encontrarse y el tipo de subordinación jurídica que se predica respecto del empleador, conforme se explicó en apartados anteriores de esta sentencia." (negrilla fuera del texto)

Al respecto en su intervención el Ministerio del Trabajo expresa:

“...que el Estado colombiano es “... conocedor de las dificultades y condiciones adversas que a nivel mundial enfrenta esta población, entendiendo que por décadas en muchos países han sido notorios los 
eventos de trato discriminatorio y de explotación hacia personas contratadas para cumplir labores domésticas como aseo, cocina, lavado y planchado de ropa y demás actividades propias de un hogar, que habían encontrado tradicional materialización, connivencia $e$ indiferencia, en un rezago de la esclavitud y la servidumbre del pasado a través del mantenimiento de la segregación social y las diferencias en las condiciones laborales". En ese sentido, la ratificación del Convenio se muestra útil para insertar a dichos trabajadores en los estándares internacionales del trabajo decente. Esto, a su vez, tendría un impacto significativo en la población laboral colombiana, pues los trabajadores y trabajadores domésticos ascienden a 500.000 personas en el país.” (negrilla fuera del texto)

Atendiendo el tema de investigación,se observa el análisis que efectúa la Corte sobre el artículo 14 del Convenioel cual corresponde ala adopción de medidas para la aplicación del mismo y expresa:

“...los Estados, luego de evaluar las características específicas del trabajo doméstico y actuando de conformidad con la legislación nacional, están obligados a adoptar medidas apropiadas para que los trabajadores domésticos disfruten de la protección de la seguridad social, incluida la maternidad, en condiciones análogas que los demás trabajadores. Para cumplir con estas obligaciones, se podrá hacer uso de un criterio de progresividad, en consulta con las organizaciones de trabajadores y empleadores, entre ellas las de los trabajadores domésticos si concurriesen. (negrilla fuera del texto)

Esta previsión es compatible con la Constitución, pues parte de la base del carácter universal e irrenunciable de la seguridad social, en los 
términos previstos en el artículo 48 C.P. Tales condiciones implican que, desde la Carta Política, el Estado está obligado a configurar las políticas y acciones tendientes a que los trabajadores domésticos accedan, en pie de igualdad, a las diferentes prestaciones del sistema de seguridad social, en sus distintas modalidades de riesgos."

El análisis de la sentencia refleja cómo en Colombia la protección a los trabajadores del servicio doméstico parte del desarrollo jurisprudencial de principios Constitucionales tales como la dignidad ylaigualdad,pero mediante la aplicación del principio de trabajo decente adoptado por la OIT en el Convenio 189 se busca que la protección de los derechos de los trabajadores del servicio doméstico, se desarrolle no solo por medio del aparato judicial sino que la generación de empleo, la plenagarantía de los derechos de los trabajadores, elaumentoala protección social y por último la promocióndel diálogo social esté presente en la sociedad mediante la formulación, creación y aplicación de políticas públicas efectivas.

Decisión

- DECLÁRASE EXEQUIBLE el "Convenio sobre el trabajo decente para las trabajadoras y los trabajadores domésticos, 2011 (Número 189)", adoptado en Ginebra, Confederación Suiza, en la 100a reunión de la Conferencia Internacional del Trabajo el 16 de junio de 2011.”

- DECLÁRASE EXEQUIBLE la Ley 1595 del 21 de diciembre de 2012, aprobatoria del instrumento internacional mencionado en el numeral anterior. 


\begin{abstract}
Anexo C. Análisis Jurisprudencial Sentencias de la Corte Constitucional Colombiana para establecer la Línea Jurisprudencial del Trabajo Decente para los Trabajadores del Servicio Doméstico.
\end{abstract}

Análisis Jurisprudencial de las Sentencias de la Corte Constitucional sobre el Trabajo Decente para los Trabajadores y las Trabajadoras Domésticas.

\title{
Sentencia C-051 de 1995
}

Tipo de sentencia: Acción de Constitucionalidad

Fecha de sentencia: Corte Constitucional: 16 de febrero 1995

Magistrado ponente: Dr. Jorge Arango Mejía

Actor o accionante Jaime Córdoba Triviño

Aspectos Jurídicos a estudiar:

- Facultades Extraordinarias del gobierno durante el estado de sitio.

- Patronos sin ánimo de lucro

- Concordato

- Prestaciones sociales complejas (Auxilio de cesantías) a empleados del servicio doméstico

- Pago de prima de servicio a trabajadores del servicio doméstico es improcedente

Norma Demandada:

Código Sustantivo del Trabajo

Artículo 338: Prestaciones sociales: 1.Los patronos que ejecuten actividades sin ánimo de lucro quedan sujetos a las normas del presente Código;pero para los efectos de las prestaciones sociales a que están obligados, el Gobierno puede efectuar la clasificación de estos patronos y señalar la proporción o cuantía de dichas prestaciones.

"2.Lo dispuesto en este artículo no será aplicable a aquellas personas que, de acuerdo con el Concordato, están sometidas a la legislación canónica."

Problema jurídico de la sentencia: 
1. ¿Puede el Gobierno nacional mediante facultades extraordinarias en virtud del estado de sitio legislar en asunto que conforme a la ley se encuentran reservados para el Congreso de la República?

2. ¿Mediante el artículo 338 del Código Sustantivo del Trabajo se violan los derechos a la igualdad y la protección del trabajo, toda vez que se crean dos categorías de trabajadores atendiendo a las calidades de los patronos reduciendo las prestaciones laborales a quienes prestan sus servicios a patronos que ejecutan actividades sin ánimo de lucro y a personas sometidas a legislación canónica según el Concordato?

3. ¿Garantiza la Corte Constitucional el trabajo decente para los trabajadores y las trabajadoras del servicio doméstico?

Decisión: La Corte Constitucional declara la inexequibilidad de:

1. Numeral 1 del artículo 338 del Código Sustantivo del Trabajo: "...pero para los efectos de las prestaciones sociales a que están obligados, el Gobierno puede efectuar la clasificación de estos patronos y señalar la proporción o cuantía de dichas prestaciones".

2. Numeral 2 del mismo artículo 338 del Código Sustantivo del Trabajo, que reza: "2. Lo dispuesto en este artículo no será aplicable a aquellas personas que, de acuerdo con el Concordato, están sometidas a la legislación canónica".

3. Numeral 1 del artículo 252 del Código Sustantivo del Trabajo, en la parte que dice:

"Los trabajadores del servicio doméstico, los de empresas industriales de capital inferior a veinte mil pesos (\$20.000) y los de empresas agrícolas, ganaderas o forestales de capital inferior a sesenta mil pesos (\$60.000) tienen derecho a un auxilio de cesantía equivalente a quince (15) días de salario por cada año de servicios y proporcionalmente por fracciones de año"..

Doctrina del caso concreto en la decisión mayoritaria (tesis):

1. Las facultades extraordinarias que el Gobierno se concede a sí mismo, por medio de un decreto dictado en virtud de la declaración del estado de sitio. Este es un primer vicio, porque ostensiblemente se excedían los límites de los poderes que el estado de excepción otorgaba al presidente. El, cuyas facultades se limitaban a la suspensión de las leyes incompatibles con el estado de sitio, no podía facultarse, en forma permanente, para legislar sobre asuntos reservados al Congreso, como éste sobre el cual versa la norma acusada.

Pero, además, ni siquiera el Congreso de la República habría podido otorgar una facultad extraordinaria como ésta, sin límite de tiempo para su ejercicio. 
Por estas razones, examinada, como corresponde hacerlo, a la luz de la Constitución vigente cuando se dictó, la norma es inexequible, y así habrá de declararlo la Corte en esta sentencia, sin perjuicio del examen de su contenido, comparándolo ya con la Constitución vigente.

2. Reflexiones del Artículo 13 Constitución (Derecho a la Igualdad): El inciso segundo de la norma mencionada, establece que el Estado promoverá "las condiciones para que la igualdad sea real y efectiva y adoptará las medidas en favor de grupos discriminados o marginados".

El que la igualdad deba ser "real y efectiva" permite que la ley, en casos especiales, de un trato diferente a algunas personas, siempre y cuando ello se justifique. La Corte ha sostenido que cuando las diferencias son razonables y no contradicen normas constitucionales, no puede hablarse de violación del principio establecido en el artículo 13.

En tratándose del trabajo, el artículo 53 se refiere a una de las aplicaciones concretas del artículo 13: la igualdad de oportunidades para los trabajadores. Esta igualdad implica que el trabajador, en lo relativo a su retribución, depende de sus habilidades y de la labor que desempeña, y no de las condiciones o circunstancias de su patrono. Este es el fundamento de una de las máximas del derecho laboral: a trabajo igual, salario igual.

En conclusión, la Constitución no autoriza el que la condición o las circunstancias particulares del patrono se conviertan en factores de tratos desiguales, en perjuicio de los trabajadores.

3. Artículo 25 de la Constitución (Derecho al trabajo): "El trabajo es un derecho y una obligación social y goza, en todas sus modalidades, de la especial protección del Estado, toda persona tiene derecho a un trabajo en condiciones dignas y justas".

Deben destacarse, en esta sentencia, dos aspectos: el primero, la "especial protección" que el Estado debe otorgar al trabajador. ¿Protección para qué? Para que en relación con él se garanticen "los principios, derechos y deberes consagrados en la Constitución". Principios entre los cuales cabe destacar el de la igualdad, ya examinado. Derechos, como el que tiene toda persona a un trabajo en condiciones dignas y justas. Y deberes, como el de la solidaridad social, en virtud del cual todos estamos obligados a promover el bienestar general, que en alguna forma contribuye al bienestar de cada uno.

El segundo aspecto es el derecho a un trabajo en condiciones dignas y justas. A este respecto, son pertinentes estos comentarios.

El calificativo de dignas que se da a las condiciones del trabajo, hay que entenderlo como derivado de la dignidad propia del ser humano. Y si éste, en el plano jurídico, es igual a todos sus 
semejantes, no tiene sentido el que en abstracto las condiciones del trabajo, en particular su retribución, sean diferentes. Ello implicaría el que la dignidad misma fuera mensurable, al punto de afirmar que unas personas tienen más dignidad que otras. Pretensión inaceptable a la luz de las leyes que nos rigen.

4. Patronos que ejecutan actividades sin ánimo de lucro: el Estado quiere estimular determinadas actividades, debe hacerlo a su costa, no a costa de algunos individuos. Los incentivos tributarios, por ejemplo, corren finalmente por cuenta de toda la comunidad. Y cuando se conceden a las personas jurídicas que trabajan al servicio de intereses generales, sin ánimo de lucro, tales incentivos son justos, tanto si se mira su finalidad como si se piensa en que a la postre los paga la comunidad, que es la beneficiaria de las tareas que se estimulan.

Lo que no tiene justificación a la luz de la Constitución, es conceder ventajas a algunos patronos en desmedro de ciertos trabajadores. Estos no tienen por qué pagar los favores que el Estado otorgue a sus patronos. Pues, se repite, la retribución que el trabajador reciba, debe corresponder a sus aptitudes y a la labor que desempeña.

5. Concordato: La Corte señala que el concordato aprobado por la ley 20 d 1974 no incluye lo concerniente a las relaciones laborales ente Iglesia y los trabajadores, por lo tanto no hay fundamento mediante el cual el artículo 338 sustente la referencia realizada al concordato.

5. Unidad Normativa: Artículo 252 Código Sustantivo del Trabajo (Cesantía restringida). La Corte desarrolla relación entre el artículo 338 y el 252 indicando que las razones que se adujeron sobre la inconstitucionalidad de los apartes del artículo 338 llevan a afirmar los mismo en relación con la restricción contenida en el numeral 1 del artículo 252.

Indica la Corte dos razones: La primera, que si el servicio doméstico es un lujo, quienes lo disfrutan deben pagarlo en forma semejante a como se remunera a todos los trabajadores.

La segunda, que la limitación del auxilio de cesantía se opone a la elevación del nivel de vida de los servidores domésticos, elevación impuesta por la solidaridad social.

6. Artículo 306 (Prima de Servicios): Predica la Corte que en lo concerniente a la prima de servicios la cual excluye a los trabajadores de servicio domésticos, indica que es claro que el hogar, la familia, no es una empresa y no genera utilidades. Por lo tanto no va en contra de la Constitución.

\section{Sentencia T-172 de 1997}

Tipo de sentencia: Acción de Tutela 
Fecha de sentencia: Corte Constitucional: 4 de abril de 1997

Magistrado ponente: Dr. Vladimiro Naranjo Mesa

Actor o accionante Dora Helena Aguilera y otras

Aspectos Jurídicos a estudiar:

- Acción de tutela contra particulares (Subordinación).

- $\quad$ Servicio doméstico (Alojamiento hasta la terminación del contrato)

- $\quad$ Estado de indefensión

- $\quad$ Contrato de servicio doméstico, desalojo vivienda por terminación.

- $\quad$ Derecho a la vivienda digna, circunstancias de debilidad manifiesta.

- $\quad$ Principio de solidaridad

Problema jurídico de la sentencia:

1. ¿Se vulneró los derechos fundamentales a las accionantes?

2. ¿Se encontraban las accionantes es estado de indefensión?

3. ¿Se encontraban las accionantes bajo subordinación?

4. ¿Garantiza la Corte Constitucional el trabajo decente para los trabajadores y las trabajadoras del servicio doméstico?

\section{Decisión}

Se niega el amparo toda vez que al morir el empleador y dar por finalizada la relación laboral, no hay vínculo que obligue que las trabajadoras continúen habitando el hogar del empleador.

Doctrina del caso concreto en la decisión mayoritaria (tesis)

1. Inexistencia de la subordinación: -“El concepto de subordinación, como sinónimo de sujeción a un sistema jerarquizado de expresión de órdenes, en principio concuerda más bien con el fundamento y razón de ser del contrato de trabajo. Y, aún allí, en el campo del derecho laboral, se admite la existencia de servicios personales -como, por ejemplo, las asesorías prestadas por abogados o contadores independientes-, claramente tipificables fuera del ámbito del Código Sustantivo del Trabajo.” (Sent. T- 003 de 1994, M.P. Jorge Arango Mejía).

La Corte después de citar jurisprudencia pre-existente sobre el caso expresa que "la relación de subordinación que se desprende del contrato de trabajo, cobija tan sólo el lapso de la vigencia del mismo. No se extiende ni al tiempo anterior al contrato, ni tampoco al tiempo subsiguiente al 
mismo. De igual manera, terminado por cualquier causa el contrato, la relación laboral de subordinación también desaparece.

Al respecto entiende la Sala que la obligación de suministrar alojamiento y alimentación a las empleadas del servicio doméstico que trabajan "internas" en la casa de sus patrones, es obligación que, como la de pagar el salario que se reconoce en dinero, culmina a la terminación del contrato de trabajo y no se extiende más allá en el tiempo. No es, por consiguiente, una obligación post-contractual, cuyo desconocimiento vulnere la igualdad o la intimidad de las antiguas trabajadoras. Así las cosas, no existe en este estadio y en relación con esa obligación, una real relación de subordinación que haga procedente la tutela en contra de particulares.

2. Estado de Indefensión: La Corte indica que el estado de indefensión se predica respecto del particular contra quien se interpone la acción. El particular es quien con su conducta activa u omisiva pone en peligro o vulnera un derecho fundamental del indefenso.

En el caso sub-exámine, puede pensarse que las demandantes de la tercera edad son personas que realmente están en situación de indefensión respecto de la protección de su derecho fundamental a gozar de una vivienda digna, derecho reconocido expresamente por el artículo 51 de nuestra Carta Política, y que es el que ellas reclaman por la vía de la tutela, puesto que lo que solicitan es permanecer en la vivienda que actualmente ocupan y que es la de sus antiguas patronas. Esta vivienda, a la fecha de la presente revisión, es de los herederos de éstas, por haberse íntegramente adelantado el trámite notarial de sucesión que culminó con la adjudicación y posterior registro del derecho de propiedad a nombre suyo, en común y proindiviso. (No pasa desapercibido para la Sala que aunque lo que consideran vulnerado es su derecho a la igualdad y a la intimidad, lo que en últimas pretenden es permanecer en la vivienda).

En efecto, como se desprende del acervo probatorio recogido en el expediente, en el caso de Carmen Rosa y María Eulalia Torres Sosa, se trata de personas de mucha edad, con graves alteraciones de salud puesto que una de ellas es invidente y la otra tiene muy disminuida la visión, quienes por lo avanzado de sus años tienen también recortadas sus facultades mentales y que son manifiestamente débiles desde los puntos de vista económico y cultural. Todo esto conduce a pensar que se trata de personas inmersas en un estado fáctico de indefensión.

3. Contrato de Trabajo (Alojamiento): La obligación de suministrar alojamiento y alimentación a las empleadas del servicio doméstico que trabajan "internas" en la casa de sus patrones, es obligación que, como la de pagar el salario que se reconoce en dinero, culmina a la 
terminación del contrato de trabajo y no se extiende más allá en el tiempo. No es, por consiguiente, una obligación post-contractual, cuyo desconocimiento vulnere la igualdad o la intimidad de las antiguas trabajadoras. Así las cosas, no existe en este estadio y en relación con esa obligación, una real relación de subordinación que haga procedente la tutela en contra de particulares.

No es posible pensar que en relación con el derecho fundamental a gozar de una vivienda digna, que es el derecho que las actoras reclaman, la demandada heredera sea una injusta agresora. Y ello por cuanto el contrato de trabajo que esta última puso a término, no confiere derecho alguno a exigir al antiguo patrón ningún derecho de habitación o cosa parecida. Tampoco confiere a las ex-empleadas la condición de poseedoras de la vivienda en que prestaban sus oficios, pues es obvio que nunca ejercieron la tenencia con ánimo de señoras y dueñas y que tampoco ahora lo hacen. Por lo tanto la solicitud formulada a ellas por la accionada en el sentido de desalojar la casa de habitación en donde venían prestando sus servicios hasta la terminación del contrato de trabajo, no puede considerarse como el desconocimiento o vulneración de ningún derecho.

\section{Sentencia C-372 de 1998}

Tipo de sentencia: Acción de Constitucionalidad

Fecha de sentencia Corte Constitucional: 21 de julio 1998

Magistrado ponente Dr. Fabio Morón Díaz

Magistrados que salvaron el voto José Gregorio Hernández Galindo

Actor o accionante Luis Álvaro Rodríguez Beltrán

Aspectos Jurídicos a estudiar

- Jornada laboral en cargos de dirección, de confianza y de manejo.

- Jornada laboral para servicio doméstico. Tiempo máximo.

\section{Norma Demandada}

Texto Acusado: “Artículo 162. Excepciones en determinadas actividades.

“1” Quedan excluidos de la regulación sobre jornada máxima legal de trabajo los siguientes trabajadores:

“a) Los que desempeñen cargos de dirección, de confianza o de manejo,

“b) Los del servicio doméstico, ya se trate de labores en los centros urbanos o en el campo.

“c) Los que ejerciten actividades discontinuas o intermitentes y los de simple vigilancia, cuando residan en el lugar o sitio de trabajo". 


\section{Problema jurídico de la sentencia}

1. ¿Mediante los literales a y b del artículo 162 se violan los principios constitucionales a la igualdad y la vida digna de los trabajadores exentos de la regulación sobre jornada máxima legal de trabajo?

2. ¿Garantiza la Corte Constitucional el trabajo decente para los trabajadores y las trabajadoras del servicio doméstico?

Decisión: $\quad$ En lo que respecta a las trabajadoras del servicio doméstico la Corte indicó:

1. Declarar EXEQUIBLES los literales a) y b) del artículo 162 del Código Sustantivo del Trabajo, y, en el caso del literal b) la exequibilidad se condiciona en el sentido de que los trabajadores domésticos que residen en la casa del patrono, no podrán tener una jornada superior a 10 horas diarias.

Doctrina del caso concreto en la decisión mayoritaria (tesis)

Si bien los temas abordados por la Corte en esta sentencia, remite a varios artículos del Código Sustantivo del Trabajo, el análisis de la motiva de la Corte se concentra en los temas concernientes a los trabajadores del servicio doméstico, materia de la investigación.

Al respecto la sentencia remite al análisis del artículo 162 que indica: "referente a las exclusiones de la regulación sobre jornada máxima legal de trabajo, el actor demanda los literales a) y b), relativos, en su orden, a los trabajadores que desempeñan cargos de dirección, de confianza o de manejo y a los del servicio doméstico, ya se trate de labores en centros urbanos o en el campo."

La protección al trabajo establecida por mandato del artículo 25 constitucional, incluye la fijación de jornadas máximas, dentro de las cuales los trabajadores presten los servicios propios de la relación laboral y estén sometidos a las órdenes del patrono, situación que se acompasa con el necesario descanso que es un derecho y que tiene como fines, entre otros, permitirle al trabajador "recuperar las energías gastadas en la actividad que desempeña, proteger su salud física y mental, el desarrollo de la labor con mayor eficiencia, y la posibilidad de atender otras tareas que permitan su desarrollo integral como persona.

Cabe precisar que los cargos de dirección, de confianza y de manejo revisten de una especial importancia en cualquier organización, resultando esenciales al cabal desarrollo de sus actividades, a la preservación de sus intereses fundamentales y a la realización concreta de sus fines. Por lo tanto, la consagración de estas actividades como una excepción a la regulación sobre jornada máxima legal de trabajo se inscribe dentro de la facultad que asiste al legislador 
para definir situaciones específicas en las que se justifique solicitarle al trabajador una disponibilidad diferente, toda vez que la responsabilidad aneja a actividades de esta índole es de mayor entidad que la originada en funciones corrientes.

En efecto, si esta especial categoría de trabajadores, creada por el legislador, obedece de manera esencial o fundamental a la necesidad de las empresas de proteger sus altos intereses, su propiedad o patrimonio, parece lógico deducir que las personas señaladas o escogidas por el patrono para realizar esas determinadas actividades o funciones, lo sean en atención a sus antecedentes personales, a su capacidad y moralidad, además de los conocimientos técnicos que el cargo requiera; esto hace suponer que debe tratarse de situaciones estables a las que de ordinario llega el trabajador bien sea por sus antecedentes y trayectoria en la prestación de servicios anteriores a la empresa, o porque sus calidades especiales de que es poseedor y de que seguramente tiene conocimiento el empleador, le permiten obtener esa clase de distinciones para desempeñar un cargo de dirección, de confianza o de manejo.

Referente a la excepción al régimen de jornada máxima para los trabajadores del servicio doméstico, la Corporación considera que el legislador sustrajo de dicho régimen la labor doméstica teniendo en cuenta que la familia no tiene las características de una empresa o de un patrono corriente o regular, pues es evidente que la economía doméstica y la labor desempeñada en la misma poseen unos rasgos particulares que implican una disponibilidad de tiempo diferente y adecuada a las actividades familiares, que no son asimilables a las desplegadas en otros ámbitos del quehacer económico o social.

En sentencia C 051 de 1995 la Corte indica que los trabajadores del servicio doméstico se encuentra excluido de la regulación de la jornada máxima, pero en esta sentencia la Corte profundiza e indica que, si bien es cierto que la familia tiene características singulares que no la asimilan a un patrono corriente, la Corte estima pertinente conciliar la protección que la Constitución brinda al núcleo familiar con las condiciones dignas y justas en que, de conformidad con la misma Carta Política, debe desarrollarse la actividad doméstica.

Una jornada laboral excesiva contradice los principios de la dignidad humana y las condiciones justas en que han de cumplirse las tareas domésticas, tornándose indispensable fijar un límite al período de trabajo que exceda de la jornada máxima ordinaria, límite por fuera del cual se quebrantarían las garantías mínimas del trabajador. 
La norma acusada puede ser exequible, de modo que aun cuando sea posible la exigencia de laborar durante un período de tiempo superior a la jornada máxima fijada legalmente, para la Corte lo razonable es que, en ningún caso, los trabajadores del servicio doméstico laboren más de 10 horas diarias, y en el evento de que se requiera el servicio más allá de tal límite, procederá entonces, el reconocimiento y pago de horas extras, en los términos de la legislación laboral.

Es así que la Corte condiciona en los términos establecidos, es la alternativa más razonable, ya que si llegara a declararse la inexequibilidad, bajo estrictas condiciones de solidaridad y dignidad del trabajador, no hay duda acerca de que ello tendría un efecto perverso, generando desempleo y, eventualmente, la desaparición del trabajo doméstico.

En lo que toca con los trabajadores del servicio doméstico que no viven con el patrono en forma permanente, la Corte estima que para ellos rigen las normas ordinarias en materia de garantías salariales y prestaciones sociales.

Salvamento de Voto:

El magistrado José Gregorio Hernández, se pronuncia en el salvamento de voto en lo concerniente a la JORNADA LABORAL PARA EL SERVICIO DOMÉSTICO y expresa su desacuerdo, lo tacha de estar ligado a la conveniencia sin ajustarse a la Carta Política, e indica: "Pienso que una norma legal a cuyo tenor todo un sector de trabajadores, sin justificación alguna, está excluido de la regulación sobre jornada máxima legal de trabajo, lo cual implica que estará expuesto de manera "lícita" a que se le exija laborar en forma continua durante veinticuatro horas al día, es abiertamente inconstitucional. Y esta Corte ha debido declararlo así de manera clara y contundente, retirando del sistema jurídico el literal b) del artículo 162 del Código Sustantivo del Trabajo. La Sentencia es contradictoria: declara la exequibilidad del precepto que excluye al aludido sector de trabajadores de la jornada máxima laboral, pero a renglón seguido la condiciona "en el sentido de que los trabajadores domésticos que residan en la casa del patrono no podrán tener una jornada superior a 10 horas diarias". En el fondo, aunque no lo dijera, la mayoría declaró la inexequibilidad de la norma acusada. Estoy de acuerdo, pero creo que ha debido hacerlo de manera explícita y sin incurrir en la inexplicable paradoja que señalo, lo cual muy posiblemente, al generar inseguridad jurídica, hará que en la práctica resulten inútiles las buenas intenciones de la Corte."

La Corte, a pesar de reconocer, como lo hace en la parte motiva del Fallo, que es "indispensable fijar un límite al período de trabajo que exceda de la jornada máxima ordinaria, límite por fuera 
del cual se quebrantarían las garantías mínimas del trabajador" (subrayado mío), expresa que el precepto "puede ser exequible" y así lo declara.

Expresa así mismo el Magistrado que la sentencia es contradictoria "en el sentido de que los trabajadores domésticos que residan en la casa del patrono no podrán tener una jornada superior a 10 horas diarias".

Finaliza su intervención indicando que el pronunciamiento debió "hacerlo de manera explícita y sin incurrir en la inexplicable paradoja, lo cual muy posiblemente, al generar inseguridad jurídica, hará que en la práctica resulten inútiles las buenas intenciones de la Corte.”

\section{Sentencia SU-062 de 1999}

Tipo de sentencia Acción de Tutela

Fecha de sentencia Corte Constitucional: 4 de Febrero de 1999

Magistrado ponente Dr. Vladimiro Naranjo Mesa

Actor o accionante María Cleofe Rodríguez Vda. de Ruíz

Aspectos Jurídicos a estudiar:

- Acción de tutela contra particulares (indefensión).

- Derecho a la Dignidad humana

- Derecho a la vida digna

- Servicio doméstico (Afiliación al régimen de pensiones)

- Derecho a la vida digna de personas de la tercera edad

- Derecho a la seguridad social de personas de la tercera edad.

Problema jurídico de la sentencia

1. ¿Se le vulneraron los derechos fundamentales citados por la accionante?

2. ¿Se encontraba la accionante es estado de indefensión?

3. ¿Garantiza la Corte Constitucional el trabajo decente para los trabajadores y las trabajadoras del servicio doméstico?

\section{Decisión}

La Corte tutela los derechos de la accionante, como mecanismo transitorio para la protección de los derechos fundamentales a la dignidad y la seguridad.

Doctrina del caso concreto en la decisión mayoritaria (tesis) 
1. Tutela contra particulares (estado de indefensión): Atendiendo al caso, la Corte hace referencia a la sentencia T-265 "El estado de indefensión se manifiesta cuando la persona ofendida por la acción u omisión del particular se encuentra inerme o desamparada, es decir sin medios físicos o jurídicos de defensa o con medios y elementos insuficientes para resistir o repeler la vulneración o amenaza de su derecho fundamental. El juez de tutela debe apreciar los hechos y circunstancias del caso a fin de establecer si se presenta la indefensión a que se refieren los numerales 4 y 9 del artículo 42 del decreto 2591 de 1991, para que proceda la acción de tutela contra particulares".

La Corte, continua y cita la sentencia T-172 de 1997 en lo concerniente al estado de indefensión: "De donde se ha concluido que el concepto de indefensión no es un predicado abstracto del cual puedan hacerse generalizaciones que se distancien de la realidad que ofrecen los hechos. Es por el contrario una "situación relacional, intersubjetiva en la cual el demandante es uno de los extremos y el demandado es otro. El primero ha sido ofendido o amenazado por la acción del segundo. Adicionalmente, el demandado no tiene posibilidades ni de hecho ni de derecho para defenderse de esta agresión injusta”.

A partir del análisis de las citas efectuadas, se indica en la sentencia que: "De esta manera, cuando un particular no tiene los medios físicos o jurídicos eficientes y suficientes para repeler las agresiones de las cuales viene siendo objeto por parte de un particular que atenta contra sus derechos fundamentales, la acción de tutela surge como el mecanismo judicial excepcional idóneo y efectivo que protege los derechos violentados, respecto de los cuales la agresión se hace ya incontenible. A lo anterior, han de agregarse las consideraciones subjetivas relativas a desprotección especial, a circunstancias económicas, sociales, culturales y los antecedentes personales de los sujetos procesales que deben ser valorados por el juez de tutela para determinar el grado de indefensión que hace procedente la acción.”

En el caso en particular la Corte hace énfasis en la edad de la accionante, grupo que cuenta con protección especial del Estado, el nivel socio-económico y cultural, elementos que conllevan a la dificultad de la accionante para acceder a medio de defensa judiciales idóneos y se configura el estado de debilidad manifiesta por cuanto se ve comprometido su mínimo vital al carecer de trabajo, de familia y de seguridad social quedando la accionante en una evidente situación de indefensión. 
2. Derecho Fundamental a la Vida en Condiciones Dignas: La Corte parte del análisis del artículo 1 de la Constitución e indica cómo nace del Estado Social de Derecho el cual se encuentra fundado en el respeto de la dignidad humana. En el entendido de la dignidad como el trato especial que tiene toda persona por el hecho de ser tal.

El desarrollo de los conceptos anteriores abarcan también las condiciones de vida correspondiente a la dignidad intrínseca del ser humano. Así mismo el derecho a la vida digna hace referencia al sustrato mínimo de condiciones materiales de existencia, acordes con el merecimiento humano, llamándolo mínimo vital de subsistencia.

3. Seguridad Social, Derecho fundamental por conexidad necesaria: La Constitución consagra la seguridad social como un derecho irrenunciable catalogado como económico y social. Su exigencia mediante la acción de tutela es efectivo si y solo si las circunstancia fácticas hacen que su reconocimiento sea imprescindible para la vigencia de otros derechos de carácter fundamental. Adicionalmente la Corte a definido que el alcance de la seguridad social como derecho fundamental, surge igualmente cuando quien pretende hacerlo valer es una persona que requiere de una especial protección por parte del estado, tal es el caso de los niños, personas de la tercera edad, mujeres cabeza de familia, entre otras.

4. Procedencia excepcional de la acción de tutela, no obstante la existencia de otros medios de defensa judicial:

““'Así, ha encontrado la Corte que puede tutelarse el derecho del trabajador a obtener el pago de su salario cuando resulta afectado el mínimo vital (Cfr. sentencias T-426 del 24 de junio de 1992, T-063 del 22 de febrero de 1995 y T-437 del 16 de septiembre de 1996); que es posible intentar la acción de tutela para que se cancelen las mesadas pensionales dejadas de percibir por una persona de la tercera edad en circunstancias apremiantes y siendo ese su único ingreso (Cfr. sentencias T-426 del 24 de junio de 1992, T-147 del 4 de abril de 1995, T-244 del 1 de junio de 1995, T-212 del 14 de mayo de 1996 y T-608 del 13 de noviembre de 1996); que cuando la entidad obligada al pago de la pensión revoca unilateralmente su reconocimiento, procede la tutela para restablecer el derecho del afectado (Cfr. Sentencia T-246 del 3 junio de 1996); que es posible restaurar, por la vía del amparo, la igualdad quebrantada por el Estado cuando se discrimina entre los trabajadores, para fijar el momento de la cancelación de prestaciones, favoreciendo con un pago rápido a quienes se acogen a determinado régimen y demorándolo indefinidamente a aquellos que han optado por otro (Cfr. Sentencia T-418 del 9 de septiembre de 
1996); que resulta admisible la tutela para eliminar las desigualdades generadas por el uso indebido de los pactos colectivos de trabajo con el objeto de desestimular la asociación sindical (Sentencia SU-342 del 2 de agosto de 1995. M.P.: Dr. Antonio Barrera Carbonell).

Visto que la presente situación involucra la afectación del mínimo vital de la demandante, la Sala encuentra es procedente la acción impetrada, no obstante existir otros medios judiciales de protección de los derechos cuyo amparo invoca."

\section{Sentencia T-730 de 1999}

Tipo de sentencia Acción de Tutela

Fecha de sentencia Corte Constitucional: 1 de octubre de 1999

Magistrado ponente Dr. Alejandro Martínez Caballero

Actor o accionante María Eugenia Arévalo Montenegro

Aspectos Jurídicos a estudiar

- Principio de continuidad en el servicio de salud.

- Sistema de seguridad social en salud

- Derecho a la salud del trabajador

- Derecho a la salud de la mujer trabajadora embarazada

- Derecho a la seguridad social de personal del servicio doméstico

Problema Jurídico:

1. ¿Se violaron los derechos constitucionales a la seguridad social y a la salud de la accionante?

2. ¿Garantiza la Corte Constitucional el trabajo decente para los trabajadores y las trabajadoras del servicio doméstico?

\section{Decisión:}

Se amparan los derechos de la accionante por cuanto existió violación a los derechos a la igualdad, la maternidad, a la vida y el trabajo en conexión estos dos últimos con los derechos a la salud y la seguridad social

Doctrina del caso concreto en la decisión mayoritaria (tesis)

1. Principios que rigen el sistema de seguridad social en salud: El análisis de la Corte parte del artículo 48 de la Constitución que establece: "Se garantiza a todos los habitantes el derecho irrenunciable a la seguridad social". Realiza así la Corte el siguiente análisis: "La misma norma 
señala como principios de la seguridad social: la eficiencia, la universalidad y la solidaridad. Además, "la seguridad social se ubica dentro de los principios constitucionales de la igualdad material y en la cláusula del Estado Social de Derecho". Por otro aspecto, la seguridad social es un servicio público, por lo tanto sobre él se proyecta el artículo 365 de la C. P.: "Los servicios públicos son inherentes a la finalidad social del estado. Es deber del estado asegurar su prestación eficiente a todos los habitantes del territorio nacional".

Enfatiza la Corte en el principio de la eficiencia en el sistema de seguridad social, indica que la continuidad del servicio está inmerso en el principio de la eficiencia, por lo tanto su interrupción se encuentra ligada a una causa legal que se ajuste a los principios constitucionales.

En Colombia la aplicación ineludible de los principios está basada en el artículo $2^{\circ}$ de la C. P. que señala como uno de los fines del estado "garantizar la efectividad de los principios". Luego, el principio de la continuidad en el servicio público de salud de los trabajadores dependientes no puede ser afectado ni siquiera cuando se incurre en mora superior a los seis meses, en el pago de los aportes, porque la disposición que permite suspenderle el servicio a quienes estén en esta circunstancia es una regla de organización dentro de la seguridad social establecida en la ley 100 de 1993 que no se puede extender a la "garantía de la seguridad social" establecida como principio mínimo fundamental en el artículo 53 de la C. P."

Cita la Corte el artículo 153 de la ley 100 de 1993, en lo concerniente al desarrollo del principio de la universalidad de la seguridad social, el artículo reza:

"Fundamentos del servicio público. Además de los principios generales consagrados en la Constitución Política, son reglas del servicio público de salud, rectoras del sistema general de seguridad social en salud, las siguientes:

1. Equidad. El Sistema General de Seguridad Social en Salud proveerá gradualmente servicios de salud de igual calidad, a todos los habitantes de Colombia, independientemente de su capacidad de pago. Para evitar la discriminación por capacidad de pago o riesgo, el sistema ofrecerá financiamiento especial para aquella población más pobre y vulnerable así como mecanismos para evitar la selección adversa.

2. Obligatoriedad. La afiliación al Sistema General de Seguridad Social en Salud es obligatoria para todos los habitantes en Colombia. En consecuencia, corresponde a todo empleador la afiliación de sus trabajadores a este Sistema y del Estado facilitar la afiliación a quienes carezcan de vínculo con algún empleador o de capacidad de pago. 
3. Protección integral. El Sistema General de Seguridad Social en Salud brindará atención en salud integral a la población en sus fases de educación, información y fomento de la salud y la prevención, diagnóstico, tratamiento y rehabilitación, en cantidad, oportunidad, calidad y eficiencia, de conformidad con lo previsto en el artículo 162 respecto del Plan Obligatorio de Salud.

4. Libre escogencia. El Sistema General de Seguridad Social en Salud permitirá la participación de diferentes entidades que ofrezcan la administración y la prestación de los servicios de salud, bajo las regulaciones y vigilancia del Estado y asegurará a los usuarios libertad en la escogencia entre las Entidades Promotoras de Salud y las Instituciones prestadoras de servicios de salud, cuando ello sea posible según las condiciones de oferta de servicios. Quienes atenten contra este mandato se harán acreedores a las sanciones previstas en el artículo 230 de esta ley......”.

Lo anterior permite a la Corte llegar a la conclusión que: dentro del sistema actual de la seguridad social en salud el objetivo es ampliar la cobertura y no restringirla, de ahí que es obligatorio para los empleadores incluir a sus trabajadores en el sistema, y el Estado no puede permitir la expulsión del sistema de persona alguna. Como corolario, hay que prestar a los afiliados la atención integral en sus fases de educación, información y fomento de la salud y la prevención, diagnóstico, tratamiento y rehabilitación de la enfermedad, incluido el suministro de medicamentos esenciales en su denominación genérica."

2. Especial protección a la salud de la trabajadora embarazada: La Corte hace referencia a la sentencia SU-62 de 1999 en la cual se señala a la acción de tutela como el mecanismo idóneo para salvaguardar los derechos de la seguridad social, no porque sea un derecho fundamental, sino que los elementos fácticos son los que le dan la connotación de fundamental y son aquellas personas que requieren de una especial protección del estado, para el caso en particular la mujer en embarazo.

Para este grupo de personas no cabe la renuncia o la exclusión de estos derechos, continua la Corte esgrimiendo los argumentos e indica, que en la mujer embarazada la protección no es solamente pos el derecho a la salud sino también para el nasciturus basados en los artículos 5, 13, 42, 43, 44 y 53 de la Constitución.

La Corte cita las sentencia C-372 de 1998 y la C-051 de 1995, donde deja establecido que el hecho de que la trabajadora sea del servicio doméstico no excluye en absoluto la protección de los derechos ni afectar la igualdad y la dignidad del trabajo, ya que sería violatoria de los 
artículos 13, 25 y 53. "En conclusión, la Constitución no autoriza el que la condición o las particularidades del patrono se conviertan en factores de tratos desiguales, en perjuicio de los trabajadores.

La Corte resalta que la igualdad es para todas las modalidades del trabajo, luego no queda excluido el servicio doméstico y por consiguiente quienes desempeñen tal labor tienen derecho a la seguridad social.

3. Prevalencia de la Constitución sobre normas de rango inferior: no se puede excluir del sistema de seguridad social a un trabajador dependiente: Debido a que el accionado argumenta la exclusión de la accionante, atendiendo a una norma de menor rango, la Corte se remite al acto legislativo N3 de 1911 el cual estableció que en Colombia en todo caso de incompatibilidad entre la constitución y la ley se aplicará aquella. A esto se le dio la denominación de excepción de inconstitucionalidad.

Por otra parte cita el artículo $4^{\circ}$ de la Constitución que establece: "La Constitución es norma de normas. En todo caso de incompatibilidad entre la Constitución y la ley u otra norma jurídica, se aplicarán las disposiciones constitucionales”.

"Es indudable que si una norma preconstitucional permite que se retire del sistema de seguridad social a una persona, esta norma se convierte en inconstitucional (inconstitucionalidad sobreviniente) porque actualmente todos los habitantes de Colombia tienen el derecho irrenunciable a la seguridad social (artículo 48 C.P.) y porque se garantiza a todas las personas el acceso a los servicios de promoción, protección y recuperación de la salud (artículo 49 C.P.), con mayor razón si se trata de mujer embarazada. Luego, el literal d) del artículo $5^{\circ}$ del decreto 824 de 1988 que dice: "Los parientes del patrono o de sus familiares hasta el quinto grado de consanguinidad, tercero de afinidad y primero civil, no pueden afiliarse como trabajadores del servicio doméstico", en cuanto la norma signifique exclusión de la seguridad social, no se compagina con la actual Constitución que protege al derecho al trabajo "en todas sus modalidades" (artículo 25 C.P.) y dentro de esa protección figuran entre los principios mínimos fundamentales: la garantía a la seguridad social y la protección especial a la maternidad (art. 53 C.P.). No es pues constitucional afirmar que por ser un empleador y una trabajadora familiares, esta circunstancia sea causa de retiro de la seguridad social.

Hoy no tiene presentación que alguien que aparezca como trabajador del servicio doméstico sea excluido de la seguridad social. El mismo empleador tiene la obligación de afiliar a su empleada 
del servicio doméstico porque de lo contrario sería el empleador quien respondería por la seguridad social. Tampoco es constitucional que habiéndose cotizado se ordene anular esas cotizaciones, porque la cotización implica la obligación correlativa de prestar el servicio y, se repite, el derecho a la seguridad social es irrenunciable. Además, sobre el carácter de las cotizaciones ya la Corte dijo que eran contribuciones parafiscales con todas sus consecuencias. Si alguien cotizó y ello constituyó una contribución parafiscal, no puede después de recibirse un buen número de cotizaciones venirse a anularlas y a quitarles toda proyección jurídica.

4. La cuota que debe pagar una trabajadora del servicio doméstico cuyo empleador es familiar: Al respecto la Corte argumenta: Se podría argüir que en realidad el literal d) del artículo $5^{\circ}$ del decreto 0824 de 1988 lo que impide es afiliarse como trabajador del servicio doméstico a la persona que sea familiar del empleador en los grados antes indicados, pero que la norma no impide que se afilie sin señalarse esa característica.

En esta situación habrá que leer la norma (artículo 5ºl decreto 824 de 1998, en su literal d-)) bajo la orientación de los principios de solidaridad, eficacia, continuidad y universalidad, propios de la seguridad social, y por consiguiente el mencionado literal d) del artículo $5^{\circ}$ del decreto 0824 de 1988, será simplemente una regla para que el I.S.S. pueda reclamar un mayor valor de cuota de afiliación del servicio doméstico, pero el citado artículo no podría tener la connotación de ser causal de exclusión del servicio de seguridad social.

En este orden de ideas, la norma indicada sería simplemente un instrumento para proteger el sistema de seguridad social en el sentido de que no se eluda el pago correcto de la cuota.

Tratándose del servicio doméstico, se tiene que el artículo 18 de la Ley 100 de 1993 dice: "En ningún caso la base de cotización podrá ser inferior al monto del salario mínimo legal mensual vigente, salvo lo dispuesto para los trabajadores del servicio doméstico conforme a la Ley 11 de $1988 "$.

Es decir, señala una excepción y se remite a los artículos $1^{\circ}$ y $2^{\circ}$ de la ley 11 de 1988 que señalan:

"ARTICULO $1^{\circ}$.- A partir de la vigencia de la presente Ley, el trabajador del servicio doméstico que devengue una remuneración en dinero inferior al salario mínimo legal vigente, cotizará para el Seguro Social sobre la base de dicha remuneración.

Parágrafo. En ningún caso el porcentaje de cotización podrá aplicarse sobre una cuantía inferior al 50\% del salario mínimo legal vigente. 
ARTICULO $2^{\circ}$.- El reconocimiento de las prestaciones de salud y la liquidación y reconocimiento de las prestaciones económicas para los trabajadores del servicio doméstico que tengan que cotizar en los términos señalados en el artículo $1^{\circ}$ de esta Ley, se efectuará de conformidad con lo establecido en los reglamentos generales del Seguro Social obligatorio.

Ninguna pensión que por razón de esta Ley se reconozca, podrá ser inferior al salario mínimo legal más alto vigente."

Son pues estas las normas en lo tocante al servicio doméstico, con el señalamiento de una presunción del mínimo. Lo anterior significa que, en principio, se tendría hoy como base para la liquidación del trabajador del servicio doméstico que no percibe el salario mínimo legal, el 50\% de dicho salario mínimo.

Pero si al literal d- del artículo 5 del decreto 824 de 1988, que desarrolló la ley 11 de 1988, se le da connotación de protección al sistema, para impedir un fraude (hacer figurar a un familiar como trabajador del servicio doméstico para pagar solo el 50\% de la cotización), entonces se concluye que en el caso especial del trabajador del servicio doméstico que es familiar de su empleador, no es posible aplicar el artículo $1^{\circ}$ de la ley 11 de 1988, sino que se deben aplicar las normas generales: en ningún caso la base de cotización puede ser inferior al salario mínimo legal, en razón de que se trata de trabajadores dependientes, salvo que la prueba demuestra lo contrario: que fueran trabajadores independientes, en cuyo caso la cotización será según el artículo 19 de la Ley 100 de 1993 y las disposiciones pertinentes.

\section{Sentencia C- 967 de 2003}

Tipo de sentencia Acción de Constitucionalidad

Fecha de sentencia Corte Constitucional: 21 de octubre 2003

Magistrado ponente Dr. Marco Gerardo Monroy Cabra

Actor o accionante Alejandro Escovar Rodríguez

- Aspectos Jurídicos a estudiar

- Principio de Solidaridad en seguridad social.

- Derecho a la seguridad social.

- Salario en especie

- Salario Mínimo

- Empleado del servicio doméstico 


\section{Norma Demandada}

1. El accionante acusa apartes del Artículo 5 (parcial) de la Ley 797 de 2003, que modificó el inciso $4^{\circ}$ y parágrafo del artículo 18 de la Ley 100 de 1993.

2. El artículo versa: Artículo $5^{\circ}$. El inciso 4 y parágrafo del artículo 18 de la Ley 100 de 1993 quedarán así:

"Artículo 18. Base de Cotización. La base para calcular las cotizaciones a que hace referencia el artículo anterior, será el salario mensual.

El salario base de cotización para los trabajadores particular es, será (sic) el que resulte de aplicar lo dispuesto en el Código Sustantivo del Trabajo.

El salario mensual base de cotización para los servidores del sector público, será el que señale el Gobierno, de conformidad con lo dispuesto en la Ley 4 a de 1992.

El límite de la base de cotización será de veinticinco (25) salarios mínimos legales mensuales vigentes para trabajadores del sector público y privado. Cuando se devenguen mensualmente más de veinticinco (25) salarios mínimos legales mensuales vigentes la base de cotización será reglamentada por el gobierno nacional y podrá ser hasta de 45 salarios mínimos legales mensuales para garantizar pensiones hasta de veinticinco (25) salarios mínimos legales.

Las cotizaciones de los trabajadores cuya remuneración se pacte bajo la modalidad de salario integral, se calculará sobre el $70 \%$ de dicho salario.

En todo caso, el monto de la cotización mantendrá siempre una relación directa y proporcional al monto de la pensión.

Parágrafo $1^{\circ}$. En aquellos casos en los cuales el afiliado perciba salario de dos o más empleadores, o ingresos como trabajador independiente o por prestación de servicios como contratista, en un mismo período de tiempo, las cotizaciones correspondientes serán efectuadas en forma proporcional al salario, o ingreso devengado de cada uno de ellos, y estas se acumularán para todos los efectos de esta ley sin exceder el tope legal. Para estos efectos, será necesario que las cotizaciones al sistema de salud se hagan sobre la misma base.

En ningún caso el ingreso base de cotización podrá ser inferior a un salario mínimo legal mensual vigente. Las personas que perciban ingresos inferiores al salario mínimo legal mensual vigente, podrán ser beneficiarias del Fondo de Solidaridad Pensional, a efectos de que éste le complete la cotización que les haga falta y hasta un salario mínimo legal mensual vigente, de acuerdo con lo previsto en la presente ley." 
Problema jurídico de la sentencia

1.

¿La norma acusada viola los derechos constitucionales de los empleados domésticos?

2. ¿Garantiza la Corte Constitucional el trabajo decente para los trabajadores y las trabajadoras del servicio doméstico?

\section{Decisión}

La Corte declara la exequibilidad de la norma demandada.

Doctrina del caso concreto en la decisión mayoritaria (tesis):

Para el desarrollo del análisis del problema jurídico que se atiende en esta sentencia la Corte precisa que aun cuando se plantea la inconstitucionalidad de una parte del último inciso del artículo 5, el accionante no tiene en cuenta el aparte subsiguiente donde indica que: “(1)as personas que perciban ingresos inferiores al salario mínimo legal mensual vigente, podrán ser beneficiarias del Fondo de Solidaridad Pensional, a efectos de que éste le complete la cotización que les haga falta y hasta un salario mínimo legal mensual vigente, de acuerdo con lo previsto en la presente ley". La expresión, indica la Corte, que pareciera dar a entender que, a pesar de que derogada la excepción que favorecía a los trabajadores del servicio doméstico cuyo salario fuera inferior al mínimo mensual legal vigente, tal categoría de trabajadores continúa favorecida de un beneficio que constituye que del fondo de solidaridad pensional se complete "la cotización que haga falta”. Así aunque de todas maneras tendría que cotizar con base al salario mínimo, no sería de su cargo sino del mencionado fondo.

Es mediante el análisis que hace la Corte de los siguientes artículos de la ley que le lleva a referirse al artículo 8 de la ley 797 de 2003, la cual como expresa la Corte es la que en últimas llevó a la derogación del artículo que permitía a los trabajadores del servicio doméstico cotizar por debajo del mínimo y les era subsidiado por parte del Estado, pero dicho subsidio se ha restringido y se reserva exclusivamente para aquellas personas mayores de 55 años.

Por lo tanto por no recaer sobre este último artículo la demanda la Corte no lo ha de considerar en la sentencia.

La Corte realiza el análisis de las pretensiones de la demanda y expresa: "Los argumentos en los cuales sustenta su acusación se orientan en el sentido de indicar que el principio superior de solidaridad obliga a dar una especial protección a los trabajadores que ganen menos del salario mínimo, especialmente a las mujeres que trabajan en estas condiciones como empleadas 
domésticas y a los niños que dependen de ellas, o a otros menores que igualmente se desempeñen como esta clase de trabajadores. No hacerlo, dice, quebranta las normas superiores que disponen la defensa de los niños contra toda forma de explotación laboral (C.P Art. 44), además de las relativas al derecho irrenunciable a la seguridad social (C.P Art. 48) y a la protección de las garantías laborales mínimas (C.P Art. 53). De otro lado, no dar esta protección, estableciendo que todos los trabajadores deben cotizar a pensiones tomando como base de cotización el salario mínimo mensual legal vigente, sin consultar su verdadera capacidad económica, desconoce el derecho a la igualdad a que se refiere el artículo 13 de la Constitución." Atendiendo a la normatividad derogada por la ley 797 de 2003 se expresa en la sentencia: “debe la Corte establecer si la libertad de configuración del legislador respecto del sistema de seguridad social en pensiones facultaba al legislador para derogar la norma que permitía a los trabajadores del servicio doméstico que no obtuvieran el salario mínimo mensual cotizar con base en lo realmente devengado, sin que esta base pudiera ser inferior al 50\% del salario mínimo legal mensual vigente, o si la situación de debilidad en que presuntamente se encuentran dichos empleados lo obligaba a adoptar normas que representaran un real subsidio a su capacidad de cotización."

Entrando en la materia de estudio la corte parte de los pronunciamientos que respecto a la seguridad social ha expresado. Sobre la doble naturaleza indica que: "es un servicio público de carácter obligatorio y esencial, prestado bajo la dirección, coordinación y control del Estado; y es, además, un derecho garantizado a todos los habitantes del Estado (art. 48). Considerada como derecho, la seguridad social implica que su prestación constituye una obligación exigible, hasta tal punto que, en los términos del artículo 48, no es posible renunciar a él.”

La seguridad social, en reiterada jurisprudencia de la Corte Constitucional, adquiere el carácter de derecho fundamental, atendiendo a las circunstancias del caso, que de no prestarse el reconocimiento puede poner en peligro otros derechos y principios fundamentales.

En lo atinente a la configuración legislativa en materia de los derechos que conforman el régimen de seguridad social, la Corte se ha referido al respecto indicando que debido a que la Constitución no opta por modelos concretos, esta materia la ha de determinar la ley, la cual ha de establecer los elementos estructurales atendiendo a las circunstancias de cada momento histórico. En sentencia C-789 de 2002 la Corte expresa: 
"La Constitución delega al legislador la función de configurar el sistema de pensiones, y le da un amplio margen de discrecionalidad para hacerlo, precisamente para garantizar que el sistema cuente con los "medios para que los recursos destinados a pensiones mantengan su poder adquisitivo constante," y para darle eficacia a los principios de universalidad, eficiencia y solidaridad, conforme al artículo 48 de la Carta. De tal modo, es necesario que el legislador pueda transformar las expectativas respecto de la edad y tiempo de servicios necesarios para adquirir la pensión, de tal forma que el Estado pueda cumplir sus obligaciones en relación con la seguridad social, a pesar de las dificultades que planteen los cambios en las circunstancias sociales."

"la Corte encuentra que, en principio, la facultad de modificar la base salarial con fundamento en la cual deben efectuarse las cotizaciones al régimen de seguridad social en pensiones cae dentro de la órbita de las prerrogativas legislativas. Por tal razón, puede el Congreso modificar el salario base de cotización. No obstante, la libertad de configuración del legislador en este punto se encuentra limitada por los valores y principios que soportan la noción de Estado Social, y por aquellos que el mismo constituyente ha entendido que deben presidir la organización del referido sistema, enunciados en el artículo 48 superior. Entre ellos están el principio de universalidad que implica la garantía de la protección para todas las personas, sin ninguna discriminación y en todas las etapas de la vida, y el de solidaridad que impone la práctica de la mutua ayuda entre las personas, las generaciones, los sectores económicos, las regiones y las comunidades bajo el principio del más fuerte hacia el más débil. Por eso, aunque en principio el legislador tenía competencia para reformar el salario base de cotización de los empleados del servicio doméstico, debe la Corte examinar si con dicho proceder no desconoció de manera absoluta el principio de solidaridad, el derecho a la igualdad, o la protección especial de las mujeres y los niños trabajadores, como lo afirma el demandante."

En cuanto al principio de solidaridad en el régimen de la seguridad social en materia de pensiones la Corte expresa que el objeto del régimen es garantizar a la población el amparo contra las contingencias derivadas de la vejez, la invalidez o la muerte, mediante el reconocimiento de pensiones y prestaciones que se determinan en la ley, cumpliendo previamente con ciertos requerimientos que la ley determina para acceder a los beneficios. En lo concerniente al principio de universalidad se pretende que se extienda a todos los habitantes del 
territorio nacional, por lo tanto en virtud de la afiliación al régimen hoy en día es obligatoria para todos los trabajadores dependientes e independientes."

"Como ha hecho ver esta Corporación, en materia de seguridad social el principio de solidaridad implica que todos los partícipes del sistema contribuyan a su sostenibilidad, equidad y eficiencia, lo cual explica que sus miembros deban en general cotizar, no sólo para poder recibir los distintos beneficios, sino además para preservar el sistema en su conjunto. Por ello, el sistema legal vigente prevé la existencia de fondos de solidaridad pensional y de garantía de pensión mínima que permiten de una parte asegurar a los afiliados el reconocimiento de una pensión mínima, y de otra ampliar la cobertura mediante el subsidio a los grupos de población que por sus características socio-económicas carecen de capacidad contributiva."

"Gracias a la existencia de los mecanismos de solidaridad es posible asegurar a quienes cotizan con base en el salario mínimo mensual legal vigente, que al cumplir con los requisitos legales tendrán derecho a una pensión equivalente a este mismo mínimo".

En lo concerniente a los trabajadores domésticos en el sistema de seguridad social la Corte inicia el análisis de la norma ya cita y decanta en el artículo 145 de Código Sustantivo del trabajo, el cual desarrolla el artículo 53 de la Constitución del cual concluye la Corte que "todos los trabajadores colombianos deben obtener una remuneración equivalente al salario mínimo legal vigente. En efecto, de conformidad con esa norma el salario mínimo es el que todo trabajador tiene derecho a percibir para subvenir a sus necesidades normales y a las de su familia, en el orden material, moral y cultural. Ahora bien, dice el artículo 132 del mismo estatuto laboral que el empleador y el trabajador pueden convenir libremente el salario en sus diversas modalidades, como por unidad de tiempo, por obra, o a destajo y por tarea, etc., "pero siempre respetando el salario mínimo legal"; y el artículo siguiente agrega que "se denomina jornal el salario estipulado por días y sueldo el estipulado por períodos mayores".

"De lo anterior se concluye que es posible contratar un trabajador por días, estipulando un jornal diario, pero que en todo caso la remuneración de cada día de trabajo debe respetar la noción de salario mínimo. Para esos efectos, el salario mínimo legal diario, para los trabajadores que laboran la jornada máxima legal, se debe determinar proporcionalmente a partir de la suma establecida como mínimo legal mensual; además, para quienes trabajan jornadas diarias inferiores a la máxima legal, debe calcularse también el salario mínimo en proporción al número de horas laboradas." 
En tal virtud, debe concluirse que ningún trabajador colombiano puede, según la ley, ser remunerado con un salario inferior al mínimo legal, pero que sí es posible que, por efecto de la remuneración por jornal, cuando no trabaje todos los días laborales de la semana, el monto total acumulado de lo que recibe durante un mes sea inferior al salario mínimo legal mensual vigente. Así las cosas, forzoso es concluir que puede darse el caso de empleados del servicio doméstico que, por trabajar (para uno o varios empleadores) sólo durante algunos días de la semana, no devengan mensualmente el salario mínimo mensual legal vigente, a pesar de ser remunerados conforme a la ley con el salario mínimo legal diario vigente. No obstante, el artículo $5^{\circ}$ de la Ley 797 de 2003, en el aparte acusado, los obliga a cotizar a salud como si recibieran efectivamente el salario mínimo mensual legal diario vigente.

Debe resaltarse que la situación en la que se encuentran los trabajadores del servicio doméstico que laboran por días sólo algunos días de la semana, puede darse también respecto de otra clase de trabajadores cuya remuneración se haya convenido por jornal. No obstante, estos últimos no estaban cobijados anteriormente por la excepción que se ha hecho referencia, que fue derogada por la norma bajo examen. Se pregunta entonces la Corte si esta disposición desconoce el principio de solidaridad o el de igualdad, el derecho irrenunciable a la seguridad social, o la protección especial a las mujeres o a los niños, como lo afirma la demanda, o si por el contrario el legislador, en uso de libertad de configuración, podía eliminar la excepción comentada.” A juicio de la Corte la reforma introducida por la norma que ahora se examina, lejos de producir el desconocimiento del derecho irrenunciable a la seguridad social pretende garantizar su eficacia, vistas las circunstancias de crisis por las que atravesaba el modelo legal anterior, crisis determinada en parte por la vigencia de la excepción que disposición demandada derogó. En efecto, conocidos los antecedentes legislativos de la ley en general se tiene que no iba a ser posible asegurar a los afiliados al sistema de seguridad social la garantía de pensión mínima, y que los correctivos introducidos de manera general pretendieron remediar esa situación. Dentro de tales correctivos, se observa que la excepción que permitía a los trabajadores del servicio doméstico cotizar con base en salarios mensuales inferiores al mínimo legal mensual vigente, por el uso contrario a derecho de que venía siendo objeto, resultaba ser un factor de distorsión del equilibrio económico del sistema que hacía imperiosa su revisión. Conjurada esta posibilidad elusiva, se asegura una mayor transparencia y eficiencia en la utilización social y económica de los recursos financieros disponibles, para que los beneficios a que da derecho la seguridad social 
sean prestados en forma adecuada, oportuna y suficiente. Así pues, como se dijo, la reforma al régimen de los empleados del servicio doméstico contribuye a la eficacia de su derecho a la seguridad social, y de los derechos de los demás afiliados al sistema en general.

Finalmente, la Corte no estima que la parte acusada del artículo $5^{\circ}$ de la Ley 797 de 2003 desconozca tampoco la protección especial que, en virtud de lo dispuesto por el artículo 44 de la Carta, merecen los niños contra toda forma de explotación laboral y contra la imposición de trabajos riesgosos. Ciertamente, si en algunos casos los menores son objeto de esta clase de explotación, ello no ocurre por efecto de lo que la norma actualmente dispone, dado que su objeto no es regular el trabajo infantil o juvenil, el cual se encuentra protegido por otras normas del ordenamiento. Entre ellas especialmente aquellas contenidas en el Código del Menor Decreto 2737 de 1989- que son específicas en proscribir la explotación económica de los niños y el desempeño de los menores en trabajos peligrosos para su salud física o mental, o que impidan su acceso a la educación. Adicionalmente, varios convenios suscritos por Colombia e incorporados a la legislación nacional, que por referirse a derechos fundamentales forman parte del llamado bloque de constitucionalidad, contienen mecanismos de prevención del abuso de los niños en materia laboral. Tales son, por ejemplo, la Convención de los Derechos del Niño, emanada de la Asamblea General de las Naciones Unidas y aprobada por el Congreso Nacional mediante la Ley 12 de 1991, que reconoce el derechos de los niños a ser protegidos contra el desempeño en labores riesgosas o la explotación laboral que obstaculice su educación y desarrollo, o el Convenio 138 sobre la edad mínima de admisión de empleo, adoptado por la $58^{\text {a }}$ Reunión de la Conferencia General de la Organización Internacional del Trabajo, y aprobado mediante la Ley 515 de 1999.

El artículo bajo examen no discrimina a los menores trabajadores ni tolera su explotación, pues lo que hace es establecer una norma general, aplicable también a ellos cuando se desempeñan como empleados domésticos o en cualquier otra actividad, norma que pretende regular las condiciones en que se debe cotizar para seguridad social en pensiones a fin de garantizar en el futuro el derecho correlativo. No existe pues una regulación específica que propicie o tolere respecto de ellos un trato legal diferencial. Por las mismas razones la Corte no estima que la norma que ocupa su atención desproteja particularmente a las mujeres que se emplean como trabajadoras domésticas, ni a los niños quede ellas dependen. Su objeto no es regular el trabajo doméstico femenino, sino una obligación derivada de éste, cuando es desempeñado por cualquier 
persona. En tal virtud no puede desproteger específicamente a la mujer empleada como trabajadora doméstica.

Finalmente la Corte aclara que toda vez que la expresión parcialmente acusada contenida en el último inciso del artículo $5^{\circ}$ de la Ley 797 de 2003 fue examinada exclusivamente en relación con su aplicación a los empleados del servicio doméstico que obtienen una remuneración mensual inferior al salario mínimo legal mensual vigente, los efectos de esta sentencia se limitan al a dicho cargo.

\section{Sentencia C-1004 de 2005}

Tipo de sentencia Acción de Constitucionalidad

Fecha de sentencia Corte Constitucional: 19 noviembre de 2003

Magistrado ponente Dr. Jaime Araujo Rentería

Actor o accionante Carlos Andrés Vásquez Velásquez

Aspectos Jurídicos a estudiar

- Inhibición de la Corte Constitucional.

- Sistema de riesgos profesionales

- Incapacidad por enfermedad no profesional de empleado de servicio doméstico

- Principio de Igualdad - Consagración en tratados internacionales ratificados por Colombia. Justificación del trato desigual.

- Empleado Del Servicio Doméstico-Justificación y objeto de la cotización mínima

\section{Norma Demandada}

Si bien en la demanda el accionante acusa apartes de los Artículos 223 y 229 de la Ley 141 de 1961, para efectos de la investigación el enfoque se realizara respecto al artículo 229, puesto la Corte se ha declarado inhibida debido a la derogatoria tácita del artículo 223.

El artículo 229 versa: "Excepciones. Las normas de este capítulo no se aplican:
a) A la industria puramente familiar;
b) A los trabajadores accidentales o transitorios;
c) A los artesanos que, trabajando personalmente en su establecimiento, no ocupen más de cinco (5) trabajadores permanentes extraños a su familia, y


d) A los criados domésticos, los cuales tienen derecho a la asistencia médica y farmacéutica corriente en caso de cualquier enfermedad y al pago íntegro de su salario en caso de incapacidad para desempeñar sus labores a consecuencia de enfermedad, todo hasta por un (1) mes."

Problema jurídico de la sentencia

1. ¿Viola el artículo 229 del Código sustantivo del trabajo el principio constitucional de igualdad, atendiendo a que los tienen derecho al pago íntegro de su salario en caso de incapacidad para desempeñar sus labores a consecuencia de enfermedad no profesional, hasta por un (1) mes, viola el principio de igualdad, teniendo en cuenta que por regla general se reconoce a los trabajadores un auxilio monetario hasta por ciento ochenta (180) días, así: las dos terceras (2/3) partes del salario durante los noventa (90) días y la mitad (1/2) del salario por el tiempo restante?

\section{Decisión}

La Corte declara inexequible la expresión "y al pago íntegro de su salario en caso de incapacidad para desempeñar sus labores a consecuencia de enfermedad, todo hasta por un (1) mes" contenida en el Art. 229, Lit. d), del Código Sustantivo del Trabajo".

Doctrina del caso concreto en la decisión mayoritaria (tesis)

Al efectuar el análisis la corte parte del Artículo 13 de la Constitución el cual enmarca el principio de la igualdad, así mismo se remite a varios artículos del texto constitucional que hacen alusión a la igualdad. Se remite la Corte a los tratados internacionales ratificados como son el Pacto de Derechos Civiles y Políticos suscrito en 1966 y a la Convención Americana sobre Derechos Humanos (Pacto de San José) suscrito 1969.

En el argumento de la Corte expone:

“que la regla general es la igualdad entre las personas o grupos de personas y que sólo por excepción puede dárseles un trato desigual, por lo cual cuando la ley o la autoridad política les dispensan un trato igual no tienen carga alguna de argumentación y, por el contrario, cuando les otorgan un trato desigual deben justificar su decisión en forma objetiva y razonable; de no existir tal justificación, el trato desigual será constitucionalmente ilegítimo o inválido y configurará una discriminación.

La Corte Constitucional ha señalado que la justificación de un trato desigual por parte del legislador requiere la concurrencia de los siguientes elementos:

i) La existencia de disposiciones o efectos jurídicos desiguales. 
ii) La existencia de un fin u objetivo del trato desigual, que debe ser válido a la luz de los valores, principios y derechos constitucionales,

iii) Que el medio previsto en la norma legal :

- no esté jurídicamente prohibido y sea en cambio permitido por el ordenamiento superior.

- sea también válido a la luz de los valores, principios y derechos constitucionales.

- sea adecuado o idóneo para la consecución del fin u objetivo.

- sea necesario, es decir, que no existan otros medios que no sacrifiquen los valores, principios o derechos constitucionales o que los sacrifiquen en menor medida.

- sea proporcional en sentido estricto, o sea, que sus beneficios sean superiores a la afectación de los valores, principios o derechos constitucionales.

La Corte cita el artículo 206 de la ley 100 de 1993, considerando el argumento del demandante, en el caso de incapacidad para desempeñar sus labores, ocasionada por enfermedad no profesional la norma expresa que "el trabajador tiene derecho a que el Sistema General de Seguridad Social en Salud le pague un auxilio monetario hasta por ciento ochenta (180) días, así: las dos terceras (2/3) partes del salario durante los noventa (90) días y la mitad (1/2) del salario por el tiempo restante.” Mientras que en el artículo 229 Literal d del C.S.T. establece que en la misma situación, por excepción, los trabajadores del servicio doméstico tienen derecho al pago íntegro de su salario hasta por un (1) mes.

Ante lo anteriormente expuesto declara la Corte: "Se observa que esta última disposición otorga un trato desigual a los trabajadores en ella contemplados, en dos aspectos: i) un aspecto favorable, relativo al valor del auxilio monetario en relación con el salario devengado, en cuanto la regla general otorga sólo una parte de éste y la excepción confiere la totalidad del mismo; ii) un aspecto desfavorable, concerniente al valor del auxilio monetario en relación con el tiempo de su reconocimiento, en cuanto la regla general otorga el auxilio hasta por ciento ochenta (180) días y la excepción lo confiere hasta por un (1) mes."

Considera la Corte que el fin de este trato diferente y desfavorable para los trabajadores del servicio doméstico era favorecer la economía familiar de los empleadores, puesto el pago estaba a cargo del patrono atendiendo al artículo 227 de C.S.T.

Asevera la Corte que dicho fin ya no existe, en virtud de la ley 100 de 1993, puesto el reconocimiento y pago de dicho auxilio está a cargo del sistema general de seguridad social en salud y teniendo en cuenta que la afiliación del trabajador es de carácter obligatorio para todo 
empleador. "Por consiguiente, el trato desigual establecido en la expresión analizada carece de una justificación objetiva y razonable y configura por ello una discriminación de los mencionados trabajadores".

\section{Sentencia C-310 de 2007}

Tipo de sentencia Acción de Constitucionalidad

Fecha de sentencia Corte Constitucional: 03 de mayo 2007

Magistrado ponente Dr. Nilson Pinilla Pinilla.

Magistrados que salvaron el voto Dr. Manuel José Cepeda Espinosa

Dr. Humberto Antonio Sierra Porto

Magistrados que aclararon el voto Dr. Jaime Araújo Rentería

Dr. Manuel José Cepeda Espinosa

Actor o accionante Claudia Milena Díaz Ulloa

Aspectos Jurídicos a estudiar

- Liquidación de Cesantía Empleado Doméstico.

- Derecho a la igualdad de empleado de servicio doméstico

- Incapacidad por enfermedad no profesional de empleado del servicio domestico

- Principio a trabajo igual salario igual

- Salario en especie

\section{Norma Demandada}

El accionante acusa el numeral 2 del Artículo 252 del Código Sustantivo del Trabajo por ir en contravía de los preceptos constitucionales.

El artículo versa: “Artículo 252 Cesantía restringida: ...

Para la liquidación del auxilio de cesantía de los trabajadores del servicio doméstico sólo se computará el salario que reciban en dinero.”

\section{Problema jurídico de la sentencia}

1. ¿El numeral 2 del artículo 252 de C.S.T. que indica que el auxilio de cesantía de los trabajadores del servicio doméstico solamente se liquidará con base en la parte de salario que reciben en dinero, vulnera los artículos 13, 25 y 53 de la Constitución Política?

\section{Decisión}


La corte Declara inexequible la expresión “sólo", contenida en el numeral $2^{\circ}$ del artículo 252 del Código Sustantivo del Trabajo. En el entendido que el auxilio de cesantía siempre se pagará en dinero y en ningún caso será inferior a un salario mínimo legal mensual vigente, por cada año de servicios y proporcionalmente por fracciones de año

\section{Doctrina del caso concreto en la decisión mayoritaria (tesis)}

\section{Protección constitucional del salario}

Al examinar la Corte desde el ámbito constitucional uno de los elementos fundamentales del contrato de trabajo, como lo es el salario, la Corte hace referencia a los artículos 25 y 53 de la carta política, con el fin de determinar los aspectos constitucionales y definiendo el salario como la "remuneración mínima vital y móvil, proporcional a la cantidad y calidad de trabajo". Ya en sentencia C-710 de 1996 la Corte define como salario "todo aquello que recibe el trabajador como contraprestación directa de su servicio, sin importar su denominación, es salario".

Hace igualmente alusión a distintas sentencias concernientes al salario como sobre la primacía de la realidad sobre las formas, la comprensión de aspectos tanto jurídicos del salario como de aspectos de tipo socioeconómico y político; destaca el salario como un derecho que busca no solo la satisfacción de las necesidades de mera subsistencia, este debe permitir la realización de los valores y propósitos de vida individuales; señala al salario y a las prestaciones como derechos subjetivos patrimoniales y los considera como remuneraciones protegidas constitucionalmente, es igualmente un derecho irrenunciable de carácter de derecho fundamental por estar conectado directamente a la subsistencia de las personas.

Indica la Corte "Es así como en ejercicio de esa facultad de configuración, el legislador ha fijado el alcance de la noción de salario en el artículo 127 del C. S. T. modificado por el artículo 15 de la Ley 50 de 1990, señalando que constituye salario no sólo la remuneración ordinaria, fija o variable, sino todo lo que recibe el trabajador en dinero o en especie como contraprestación directa del servicio, "cualquiera sea la forma o denominación que adopte". Excluye del concepto de salario, lo que recibe el trabajador "ocasionalmente y por mera liberalidad del empleador".

Hace referencia la Corte del artículo 129 del Código Sustantivo del Trabajo relativo al salario en especie del cual expresa: "De modo que para que los pagos en especie al trabajador adquieran la calidad de salario deben tener carácter retributivo, esto es, ser la contraprestación a los servicios personales del trabajador". Esto en lo concerniente a la configuración al salario y lo que representa dentro de la relación laboral. 


\section{Auxilio de cesantía}

Advirtiendo lo dispuesto por la Corte, se determina que como prestación social, la cesantía constituye un derecho irrenunciable, dado su carácter remuneratorio a una labor subordinada en desarrollo de un contrato de trabajo.

\section{Vulnerabilidad de los trabajadores del Servicio Doméstico}

Del estudio que al respecto realiza la Corte se resalta, la percepción socioeconómica y jurídica que se ha tenido de la actividad doméstica, como destaca la Corte, estudios especializados, algunos como los que se han resaltado en la investigación, indica que el trabajo en el hogar es una actividad invisible para el resto de la sociedad. Aun cuando contribuyen a la producción y a la reproducción social y económica no se le ha dado la importancia que requiere y por el contrario se a subvalorado dicha labor.

Mediante la parte motiva la Corte hace un recorrido por la jurisprudencia que hay respecto a los derechos de los trabajadores del servicio doméstico, así mismo hace alusión a los pronunciamientos de la Organización Internacional del Trabajo.

\section{Igualdad en materia laboral.}

Realiza la Corte mención de los principios y derechos constitucionales que rigen la materia y se remite al artículo 143 y en el estudio realizado expresa que: "no toda desigualdad o diferencia de trato constituye una vulneración de la Constitución, que sólo se convierte en discriminatoria cuando no obedece a causas objetivas y razonables que la justifiquen. Al respecto, la Corte ha manifestado que habrá discriminación "cuando ante situaciones iguales se da un trato jurídico diferente, por eso se proclama el principio a trabajo igual salario igual"

La Corte hace referencia a sentencias anteriores donde se ha determinado que no se puede discriminar al trabajado en razón de la condición particular del patrono, es decir que a la luz de la Constitución, no se justifica que se den ventajas a los empleadores en desmedro de los derechos de los trabajadores.

5. En Consideración a los puntos ya abordados, la Corte profundiza en el análisis de la norma acusada de inconstitucional y expresa que "es evidente que la norma acusada establece un tratamiento distinto para esa clase de trabajadores, pues sus cesantías se liquidan solamente con el salario que reciben en dinero, a diferencia de las otras personas que devengan parcialmente salario en especie, respecto de quienes no aplica tal restricción.” 
Agrega la Corte: "En relación con la hipotética desmejora de las condiciones de vida de dichos trabajadores, ante el temor de cuantificar todo lo que signifique salario en especie, también resultan válidas las anteriores consideraciones, pues de un lado, quien contrata trabajo doméstico no puede remunerarlo sólo en especie, sino en el porcentaje autorizado por la ley".

Por lo tanto establece el ente colegiado que "el tratamiento que prodiga la norma acusada es discriminatorio, lo cual se hace aún más evidente al comparar el caso de los trabajadores domésticos con la situación de los conductores de vehículos de una familia, a quienes la ley laboral ordena aplicar las disposiciones establecidas para los domésticos, pero les reconoce el régimen ordinario de liquidación en materia de cesantía, vacaciones remuneradas y auxilio en caso de enfermedad no profesional"

"Para la Corte no es justo que entre personas que tienen como empleador al jefe de hogar y desempeñen tareas para la familia, exista un tratamiento diferencial en lo concerniente a la liquidación de cesantías, por la simple circunstancia de que unas realizan labores "de aseo, cocina, lavado, planchado, vigilancia de niños, y demás labores inherentes al hogar" y otras se encarguen de conducir automotores. Tal distinción, se repite, es abiertamente discriminatoria, por carecer de una justificación objetiva y razonable.

Finalmente, también resulta ostensible la degradación en que incurre la norma acusada al negarle carácter salarial a la remuneración en especie que reciben los trabajadores del servicio doméstico, ya que la exclusión de ese concepto de la base de liquidación de la cesantía de dichos trabajadores implica, como bien advierten la demandante, el Procurador y algunos intervinientes, una sensible reducción de los ingresos de esos empleados hacia la eventualidad del desempleo o las necesidades de vivienda y educación, que corresponden a las finalidades asignadas legalmente a esa prestación social, según se analizó."

En efecto, si conforme con los dictados superiores el salario en especie también es salario, hoy en día no se explica cómo el legislador desconoce su naturaleza retributiva, afectando de paso el ingreso del trabajador doméstico, quien por disposición de la norma acusada se ve privado de contar con la totalidad de su remuneración, como base, a fin de poder satisfacer necesidades esenciales en los aspectos ya referidos.

En este sentido, la norma bajo revisión comporta igualmente una ostensible violación del derecho al trabajo (art. 25 Const.), del cual es expresión la remuneración, así como también del "principio de universalidad de las prestaciones sociales", como quiera que "dentro de las 
contingencias típicas cubiertas por un sistema contributivo de seguridad social, se encuentra el desempleo", que es una eventualidad que se busca precaver con la cesantía de los trabajadores. Por todo lo anterior, la Corte declarará la inexequibilidad de la expresión "sólo", contenida en el numeral $2^{\circ}$ del artículo 252 del Código Sustantivo del Trabajo y exequible en lo demás dicho numeral, en el entendido que el auxilio de cesantía siempre se pagará en dinero y en ningún caso será inferior a un salario mínimo legal mensual vigente, por cada año de servicios y proporcionalmente por fracciones de año."

Salvamento de Voto

Los magistrados que salvaron su voto expresan de forma respetuosa, que el argumento de la Corte que llevaron a la exequibilidad de la norma no constituyen criterios relevantes que justifiquen la diferencia del trato prevista en el aparte demandado, ni le restan respetabilidad ni valor jurídico a la labor desarrollada.

"Encontró el Pleno de la Corporación "degradante" "negarle carácter salarial a la remuneración en especie que reciben los trabajadores del servicio doméstico " y reconoce la decisión que la exclusión del salario en especie, de la base de liquidación de la cesantía, comporta "una sensible reducción de los ingresos dé esos empleados hacia la eventualidad del desempleo o las necesidades de vivienda y educación, que corresponden a las finalidades asignadas legalmente a esa prestación social (.) ".

Sin embargo, mediante la decisión de la cual disentimos, la Corte resolvió mantener la disposición en el ordenamiento avalando, en consecuencia, como lo expresamos en el pleno de la Corporación, la supervivencia en el ordenamiento de un rezago de la modalidad, por fortuna superada, que otorgaba a los señores poder sobre la retribución por los servicios que les eran prestados y determinación absoluta de la dedicación espacio temporal de sus siervos, en la labor desarrollada"

Para los magistrados la norma despoja de los efectos prestacionales la retribución en especie que reciben los empleados del hogar, y deja al arbitrio del patrono no solo fijar la remuneración sino la potestad de determinar la forma de la prestación del servicio.

Finalmente advierten los magistrados que salvaron su voto que la declaratoria de inexequibilidad de la palabra solo no corrige la discriminación contra los trabajadores domésticos, así mismo, no se corrige "en el entendido que el auxilio de cesantía siempre se pagará en dinero y en ningún caso será inferior a un salario mínimo legal mensual vigente" 


\section{Aclaración de Voto}

Para la aclaración del voto el magistrado Jaime Araújo Rentería hace referencia a las normas constitucionales y del código sustantivo del trabajo para exponer su posición frente a la sentencia:

"En este sentido y en lo que toca con la disposición demandada en esta oportunidad -numeral 2 del artículo 252 sobre cesantía restringida para los trabajadores del servicio doméstico-, considero que la interpretación más ajustada a la Constitución, de conformidad con el principio de "interpretación conforme", es en primer lugar, que la restricción para el computo de la cesantía sólo con base en el salario pagado en dinero, es inconstitucional; en segundo lugar, que el cálculo de la cesantía para trabajadores del servicio doméstico, debe realizarse de un lado, con base en el salario en dinero, el cual no podrá ser menor a un salario mínimo legal vigente por año y, respecto del salario en especie, el cual puede equivaler hasta un máximo del $30 \%$ del salario mínimo pagado en dinero, porcentaje que debe sumarse al monto de cesantía calculado respecto del salario en dinero.

Para el suscrito magistrado, como lo manifesté en Sala Plena, lo importante en este caso es señalar unas reglas claras que no dejen en la indefinición la determinación del salario en especie y sus implicaciones para el cálculo de las cesantías para los trabajadores del servicio doméstico, pues esta falta de claridad puede terminar en que no se suministre el pago de salario en especie o en que se cobre su valor en desmedro del salario mínimo de esos trabajadores pagado en dinero. Es en este sentido, que considero necesario que hacer claridad acerca de las disposiciones sobre el salario en especie de los trabajadores domésticos y su cálculo para las cesantías, ya que a mi juicio pueden tener un efecto perverso que desmejoraría la situación salarial de estos trabajadores, si se llegara a interpretar en el sentido de que lo pagado en especie debe descontarse del salario mínimo legal vigente que siempre debe pagarse en dinero, y en forma correspondiente para las cesantías.

De otra parte, debo expresar mi preocupación porque se sostenga que es necesario convenir el salario en especie, pues puede ocurrir que se den esos elementos del salario sin convenirlos y lo esencial, a mi entender, es que se contabilicen.

En síntesis y concordancia con lo anterior, es de observar que en materia laboral prima la realidad sobre la forma, y el pago en especie sería también parte del salario y debe tenerse en cuenta por tanto para el cálculo de las cesantías, sin desmedro de la cesantía pagada en dinero 
que no puede ser inferior a un salario mínimo legal vigente por año de trabajo. En mi criterio, la claridad interpretativa de estas disposiciones tiene que contribuir a eliminar formas veladas de esclavitud.

En este orden de ideas, para el suscrito magistrado resulta importante que la Corte precise que la cesantía siempre debe pagarse en dinero y que no puede ser inferior al salario mínimo legal. Por ello propuse en su momento dos aspectos acogidos en la presente sentencia, en relación a que la cesantía se debe pagar siempre en dinero y en todo caso no debe ser inferior al salario mínimo legal vigente. Así mismo, considero necesario señalar que la circunstancia de que la cesantía se paga siempre en dinero no significa que no pueda seguir existiendo un salario en especie que debe pagarse de acuerdo con las reglas legales y que se debe valorar también conjuntamente con el salario en dinero, que es el efecto que a mi juicio trae la declaratoria de inexequibilidad de la expresión "solo".

Finalmente, en criterio del suscrito magistrado la mejor opción de resolución del presente caso era la declaración de inexequibilidad de la disposición acusada. No obstante, concuerdo con la declaración de inexequibilidad de la expresión "solo", sin ningún condicionamiento, por cuanto tendrá el mismo efecto.

No obstante, me permito indicar que en el fondo el reclamo contra la norma acusada radicaba en la reducción del valor de la cesantía de los trabajadores domésticos al no tener en cuenta el salario en especie, cuestión que no se soluciona del todo con la fórmula resolutiva de la presente sentencia, pues se declara inconstitucional el que el cálculo de las cesantías se realice solo con base en el salario pagado en dinero, se excluye el pago de cesantías en dinero y el que este pago sea inferior a un salario mínimo legal vigente por año de trabajo, pero no se condiciona también a que se contabilice para el cálculo de la cesantía los elementos del salario que se pagan en especie"

Si bien en la sentencia hay otro salvamento de voto en este caso es del magistrado Manuel José Cepeda Espinosa, no se ha de tener presente para efectos del análisis, debidoque el magistrado se limita a exponer lo que a su juicio son las figuras de la aclaración de voto y el salvamento de voto, por lo tanto su intervención no profundiza en el caso en concreto.

\section{Sentencia T-237 de 2011}

Tipo de sentencia Acción de Tutela

Fecha de sentencia Corte Constitucional: 1 de abril de 2011 
Magistrado ponente Dr. Nilson Pinilla Pinilla

Magistrados que salvaron el voto Dr. Humberto Antonio Sierra Porto

Actor o accionante María Hildelgaer Sarmiento Miranda

Aspectos Jurídicos a estudiar

- Acción de tutela contra particulares (Indefensión).

- Trabajador Doméstico y situación del vulnerabilidad

- Incapacidad Laboral

- Derecho al pago de incapacidad laboral.

\section{Problema jurídico de la sentencia}

1. ¿Es la acción de tutela el mecanismo idóneo mediante el cual se puede solicitar el pago de incapacidades laborales?

2. ¿Vulnera el empleador los derechos fundamentales de la accionante, al no efectuar los pagos de las incapacidades laborales?

\section{Decisión}

La corte concede a la accionante la acción de tutela.

Doctrina del caso concreto en la decisión mayoritaria (tesis)

1. La acción de tutela como mecanismo de protección de derechos laborales, la Corte ha indicado en reiterada jurisprudencia que esta es procedente contra particulares:

“cuando el solicitante se halle en estado de subordinación o indefensión, porque así lo dispone expresamente el artículo 86 de la Carta Política, en concordancia con los numerales 1 a 9 del artículo 42 del Decreto 2591 de 1991.

La Corte ha entendido, y así lo ha expuesto en su jurisprudencia, que la indefensión hace referencia a una situación relacional que implica la dependencia de una persona respecto de otra, no tiene origen en la obligatoriedad derivada de un orden jurídico o social determinado se configura sobre situaciones de naturaleza fáctica en cuya virtud la persona afectada en su derecho carece de defensa por acción u omisión para proteger sus derechos conforme a las leyes que reglamentan su ejercicio; es decir que la indefensión es entendida como la posibilidad de dar respuesta efectiva ante la violación o amenaza de que se trate. Así mismo, ha dicho también esta Corte que el estado de indefensión o impotencia se analizará teniendo en cuenta las circunstancias del caso concreto, de las personas involucradas, de los hechos relevantes tales 
como las condiciones de desprotección, circunstancias económicas, sociales, culturales y los antecedentes personales de los sujetos procesales, por ello el concepto de indefensión es esencialmente relacional. Ello significa que el estado de indefensión en que se encuentra el ciudadano en relación con otros particulares habrá que determinarlo, por parte del juez de tutela de acuerdo al tipo de vínculo que existe entre ambas partes".

2. Situación de vulnerabilidad del trabajador doméstico

La Corte se refiere a la jurisprudencia que trata sobre los riesgos a los cuales se encuentran expuestos lo trabajadores del servicio doméstico, por parte de los empleadores, como lo es el sometimiento a acoso sexual o físico, violencia, retención de salarios y documentos, la subvaloración de las tareas realizadas hasta la no vinculación a la seguridad social. Por estas y otras razones, atendiendo a los pronunciamientos de la Organización Internacional del Trabajo, que consideran que los trabajadores domésticos están en situación de vulnerabilidad y demandan, por lo tanto, la protección del Estado.

3. La acción de tutela para el reconocimiento y pago de incapacidades laborales.

Indica la Corte que "ha señalado reiteradamente que el pago de tales incapacidades suple el salario durante el tiempo en el cual el trabajador se encuentra forzosamente al margen de sus labores, de manera que se garantice no sólo su satisfactorio restablecimiento, sino una subsistencia en condiciones dignas, en concordancia con el artículo 53 superior”.

"Entonces, no solamente se constituye en una forma de remuneración del trabajo sino en garantía para la salud del trabajador, quien podrá recuperarse satisfactoriamente, como lo exige su dignidad humana, sin tener que preocuparse por reincorporarse de manera anticipada a sus actividades habituales con el objeto de ganar, por días laborados, su sustento y el de su familia. Y es que el trabajador tiene derecho a que se le retribuyan sus servicios pero también a que se le otorgue justo trato durante el tiempo en que permanece involuntariamente inactivo por causa de perturbaciones en su salud"

Continúa la Corte indica que la posición jurídica permanece invariable, "respecto a la omisión del empleador de afiliar a sus trabajadores al Sistema de Seguridad Social, al entender que la misma afecta gravemente los derechos de éstos, comprometiendo la responsabilidad directa de aquél, en el sentido de asumir la totalidad de los costos inherentes a la preservación de la seguridad social de los trabajadores afiliados y de los beneficiarios de ellos". 
4. Para el caso en concreto la Corte encuentra viable la acción para obtener el pago de las incapacidades laborales, por encontrase comprometidos los derechos fundamentales de la actora, "su dificultad para volver a trabajar y la precariedad de los ingresos familiares, al vivir del salario mínimo percibido por el esposo, en buena parte gastado en la recuperación de la señora, todo ello exacerbado por la no cancelación de las incapacidades laborales, dispuestas médicamente".

\section{Tesis Salvamento de Voto}

Estima el Magistrado Humberto Antonio Sierra Porto, en el salvamento de voto, que la sentencia no se resolvió el caso de manera precisa ya que del relato de los hechos se observa que la accionante solicita por este medio subsidiario de defensa, el pago de unas incapacidades que dan un total de 240 días; sin embargo, las características del asunto permiten determinar que en este caso se debió resolver de una manera diferente a la efectuada en el fallo de la referencia. Continúa el análisis el magistrado e indica que en la sentencia se debió tener en cuenta:

“(i) el contrato laboral que surgió entre la accionante y el señor José Isidro Ferrucho no se perfeccionó conforme a lo dispuesto en las normas de Código Sustantivo Laboral (ii) la señora María Hildelgaer tuvo un accidente de trabajo, el cual no se encuentra calificado por ninguna ARP, ya que su empleador no la vinculó a la seguridad social ni en salud ni en pensión (iii) teniendo en cuenta que la accionante está reclamando el pago de 240 días de incapacidad en este caso debe existir una calificación de su enfermedad, ya que las incapacidades superan los 180 días a efectos de definir si tiene el derecho a una pensión de invalidez la cual debe ser asumida por el empleador ya que nunca la afilió a seguridad social en pensión."

Expresa por lo tanto el magistrado que el problema jurídico que se plantea "no sólo radica en el impago de las incapacidades laborales sino además en que por el hecho que éstas comprenden un total de 240 días entre junio de 2009 y febrero 3 de 2010 se genera una incapacidad permanente o parcial."

Continua el argumento del Dr. Sierra quien indica: "En este orden, es pertinente señalar que como el contrato de trabajo de la accionante se efectuó desprovisto de toda legalidad, no sólo al empleador le corresponde (i) asumir el pago de las incapacidades adeudadas, ya que éstas debían ser canceladas por la administradora de riesgos profesionales ARP teniendo en cuenta que la enfermedad según se resalta a folio 12 fue a causa de su ejercicio laboral, (ii) sino que es a través 
del juez natural quien determina si además tiene una incapacidad por causa de su enfermedad, situación que no fue contemplada en el fallo del cual me separo de la posición mayoritaria.

Además, lo anterior es preciso señalar que el fallo no hizo una distinción entre las causas de las incapacidades por enfermedad profesional y la enfermedad común a efectos de resaltar que las incapacidades surgieron por (i) una actividad con ocasión del trabajo y (ii) la ocurrencia del hecho, el cual produce "en el trabajador una lesión orgánica, una perturbación funcional, una invalidez o la muerte".

\section{Sentencia T-387 de 2011}

Tipo de sentencia Acción de Tutela

Fecha de sentencia Corte Constitucional: 17 de mayo de 2011

Magistrado ponente Dr. Jorge Iván Palacio Palacio

Actor o accionante Caso 1: María Lucila Rodríguez Hernández

Caso 2: María Soledad Albino Luna

Aspectos Jurídicos a estudiar

- Acción de tutela contra particulares (Estado de indefensión y subordinación de empleadas del servicio doméstico).

- Reconocimiento y pago de acreencias laborales

- Derecho fundamental a la seguridad social y el mínimo vital

- Servicio doméstico-Trato discriminatorio y situación de vulnerabilidad.

- Pensión provisional a empleada del servicio doméstico.

- Persona en circunstancias de debilidad manifiesta

\section{Decisión}

1. En el expediente T-2927616, la corte revoca la sentencia de tutela proferida en única instancia por el Juzgado Primero Laboral del Circuito de Tunja el (19) diecinueve de noviembre de 2010 y en su lugar CONCEDER el amparo invocado.

2. En el expediente T- 2931555, la corte revoca la decisión proferida por el Juzgado Primero Civil del Circuito de Girardot, Cundinamarca, el tres (3) de diciembre de 2010, que a su vez confirmó el fallo de primera instancia del Juzgado Tercero Civil Municipal de la misma ciudad y, en su lugar, conceder la protección de los derechos fundamentales invocados.

Doctrina del caso concreto en la decisión mayoritaria (tesis) 
Considera la Corte que la subsidiaridad como característica de la acción de tutela ante la existencia de otros mecanismos de defensa judicial torna en principio improcedente la acción, pero atendiendo el artículo 86 de la Constitución, el cual indica que ante la presencia de un perjuicio irremediable, procede el amparo transitorio del derecho.

Indica al respecto la Corte que en "materia laboral, específicamente en cuanto el pago de acreencias, reiterada jurisprudencia ha señalado que la acción de tutela no es el mecanismo idóneo para buscar la protección de derechos de esta naturaleza, ya que el interesado cuenta con una jurisdicción específica para obtener su protección. Sin embargo, de manera excepcional ha entendido, que en algunos casos se hace necesaria la intervención del juez de tutela. Entre ellos, cuando se está frente a la solicitud de un reconocimiento pensional que cobre relevancia constitucional, en el evento que los sujetos que la reclamen se encuentren en estado de indefensión".

En este orden de ideas en el razonamiento de la sentencia se indica que la "acción de tutela procederá para reclamar acreencias de tipo laboral, siempre y cuando se esté en presencia de un asunto que desborde el plano legal y adquiera especial relevancia por encontrarse en juego derechos de rango fundamental, tales como el mínimo vital, la vida en condiciones dignas y la salud, entre otros. En especial, cuando quien los reclama es una persona que se encuentra en estado de vulnerabilidad e indefensión y hace parte de la tercera edad, caso en el cual a pesar de la existencia de otros medios de defensa judicial, estos pueden tornarse poco idóneos e ineficaces para la protección de los derechos reclamados”

Así mismo se ha señalado en anteriores sentencias que la seguridad social es un derecho de rango fundamental, que se encuentra consagrado en los artículos 48 y 49 de la Constitución, y que por su naturaleza tiene connotaciones de derecho irrenunciable y de servicio público obligatorio.

Hace referencia la Corte reiteradamente sobre la situación de vulnerabilidad de los trabajadores del servicio doméstico y procede a realizar el estudio de los casos concretos.

\section{Sentencia T-180 del 2012}

Tipo de sentencia Acción de Tutela

Fecha de sentencia Corte Constitucional: 08 de marzo de 2012

Magistrada ponente Dra. María Victoria Calle Correa

Actor o accionante Luz Andrea Sana

Aspectos Jurídicos a estudiar 
- Acción de tutela temeraria (hecho nuevo).

- Legitimación por pasiva de misión diplomática (inmunidad diplomática en materia laboral)

- Convención de Viena Sobre Relaciones Diplomáticas-Inmunidad restrictiva de los Estados extranjeros en materia laboral

- Principio de inmunidad restringida en el ámbito laboral.

- Inmunidad relativa de los estados y de los agentes diplomáticos en materia laboral.

- Estabilidad laboral reforzada de mujer trabajadora embarazada

- Estabilidad laboral reforzada de mujer embarazada en misión diplomática.

Problema jurídico de la sentencia

En la presentación de caso, el magistrado ponente presenta la siguiente pregunta como problema jurídico:

1. ¿Vulnera un agente diplomático de una misión o delegación acreditada en Colombia el derecho fundamental a la estabilidad laboral reforzada de una trabajadora colombiana embarazada, al dar por terminado su contrato de trabajo aduciendo que la labor para la que fue contratada finalizó, pues las funciones diplomáticas por las cuales el agente se encontraba en el país también cesaron?

\section{Decisión}

1. La Corte revoca el fallo y ampara los derechos fundamentales de la peticionaria al trabajo y a la estabilidad laboral reforzada.

Doctrina del caso concreto en la decisión mayoritaria (tesis)

1. La Corte al desarrollar el estudio del caso tiene en cuenta que la actora ya había interpuesto una acción de tutela contra la Embajada, por lo tanto realiza el análisis de los argumentos de la parte accionada, que apunta a establecer una temeridad por parte de la actora al accionar bajo los mismos hechos; atendiendo a los argumentos presentados por el demandado, la Corte logra establecer:

"En el caso concreto, la Sala encuentra que las dos acciones presentadas por la peticionaria contra la Embajada de la República Islámica de Irán guarden estrecha similitud en los aspectos que orientan el análisis de la cosa juzgada. Así, si bien en ambas acciones se solicita protección a derechos constitucionales diversos (en la primera, la estabilidad laboral reforzada; y en la 
segunda, el debido proceso) y existe diversidad parcial entre las partes demandadas (en la primera, únicamente la Embajada de la República Islámica de Irán; en la segunda, la Embajada mencionada y dos Ministerios), la exposición de los hechos y de los fundamentos jurídicos coincide en ambos escritos, de manera que el problema jurídico que se desprende de las demandas es, prima facie, el mismo.

Sin embargo, la Sala observa que hay un hecho relevante que modifica la situación analizada en las decisiones de tutela iniciales, no seleccionada para revisión, y que podría constituir una razón que justifica la consideración del caso por parte de la Corte Constitucional. Antes de producirse la sentencia de primera instancia en el primer trámite de tutela, el señor Ex Embajador de la República Islámica de Irán decidió reincorporar a su trabajo a la peticionaria, de manera que al producirse esa decisión no existía un despido efectivo, una desvinculación real del servicio, o una terminación definitiva del contrato de trabajo.

La importancia del hecho es clara, pues en su intervención, el representante de la Embajada expresó que sólo se dio por terminado definitivamente el vínculo laboral una vez la parte accionada obtuvo lo que éste llama "autorización judicial" por parte del Juzgado 32 Civil Municipal de Bogotá, autorización que entiende fundamentada en la manifestación efectuada en la sentencia del 18 de junio de 2010, en la que el despacho sostuvo que el vínculo laboral con la peticionaria, terminó, pues la labor para la cual había sido contratada culminó definitivamente el 21 de junio de 2010, fecha en la cual el señor Ex Embajador y su familia regresaron a su país de origen.

Pero además, la Sala de Revisión tuvo la oportunidad de constatar un hecho adicional que se presentó al momento de escogencia de este expediente por parte de la Corte Constitucional. Si bien ese no fue un hecho que suscitara la interposición de la segunda demanda, sí supone una nueva configuración jurídica del conflicto, que amerita ser tenida en cuenta en este análisis, pues señala que existe la oportunidad de consolidar la interpretación sobre el sentido de las normas constitucionales aplicables a casos como este."

2. La Corte en su intervención hace alusión al fallo T-932 de 2010 de la cual indica: “mientras en ese caso se discutió si la suspensión del pago de la mesada de pensión de vejez a una ex trabajadora, nacional colombiana, y cuyo derecho pensional había sido previamente reconocido por la propia Embajada constituía una violación a sus derechos fundamentales al debido proceso y la seguridad social en pensiones, en este caso se plantea si una actuación del 
Jefe del cuerpo diplomático frente a una empleada contratada para el servicio personal que podría comprometer sus derechos fundamentales como mujer gestante, puede implicar la responsabilidad de la Embajada y si ello puede discutirse por la vía de la acción de tutela”.

Finalmente la Corte establece que mediante del estudio del caso se busca determinar: "el alcance de las obligaciones de las misiones diplomáticas en materia de estabilidad laboral frente a mujeres en estado de embarazo es un asunto que trasciende al caso concreto y proyecta sobre el mismo un interés desde la dimensión objetiva de los derechos fundamentales, ya que las garantías laborales de un grupo laboral frente a cuerpos diplomáticos constituye un asunto de interés general en materia de derechos fundamentales, en la medida en que atañe a la forma social del Estado colombiano, donde el trabajo constituye un principio fundante, y la protección de grupos vulnerables es un mandato imperioso derivado del principio de igualdad material".

3. Por lo tanto ante la existencia de un hecho nuevo no resuelto de manera definitiva en el primer proceso y que justificaría la interposición de una nueva acción de tutela, como sería la circunstancia del "segundo despido" de la accionante. Así mismo atendiendo que al momento de escoger el fallo se produjo un hecho jurídico nuevo que dota de especial trascendencia constitucional al asunto objeto de revisión. Esos argumentos, en su conjunto, permiten asumir la revisión del fallo y emitir un pronunciamiento de fondo, pese a que un problema jurídico parcialmente similar (en tanto existe una modificación normativa relevante, y un indicio de un hecho nuevo en este trámite) fue estudiado en decisiones de la jurisdicción constitucional no escogidas anteriormente.

En la consideración realizada por de la Corte del caso expresa: , para la Sala la sentencia T-932 de 2010 constituye un hecho jurídico que puede modificar sustancialmente los criterios adoptados por las distintas salas de selección al momento de escoger un expediente para estudio de la Corte pues si bien se trata de determinaciones carentes de motivación, para esta Sala es claro que tienen por objeto contribuir a la consolidación de la jurisprudencia constitucional y la unificación de la interpretación de los derechos fundamentales.

Con todo, no pasa por alto la Sala que la actuación de la demandante puede resultar opuesta a los principios que protege la prohibición de temeridad y, especialmente, al funcionamiento ágil y eficaz de la administración de justicia. Esa situación se desprende del hecho de que la peticionaria en efecto presentó acciones de tutela que plantean el mismo problema jurídico sin justificar adecuadamente la presentación de la segunda acción, y tomando en consideración que 
esa situación presumiblemente obedece a una errónea asesoría jurídica, pues ambas acciones poseen un sello del Centro de Atención Laboral de la Central Unitaria de Trabajadores, y un membrete de la misma.

Así, considerando que existen indicios sobre la ocurrencia de un hecho nuevo que podría justificar la interposición de la segunda tutela, pero estas no fueron acreditadas ni alegadas por la peticionaria; y, por otro lado, que en el caso concreto se produjo una decisión jurisprudencial que modifica el orden jurídico frente a este conflicto, que la misma tuvo lugar el mismo día de su escogencia, y que dota al caso de relevancia a la luz de la dimensión objetiva de los derechos fundamentales, la Sala (i) asumirá el estudio de fondo de la acción. Pero (ii) dictará órdenes de prevención a la peticionaria y al Centro de Atención Laboral de la Central Unitaria de Trabajadores para que se abstengan de presentar acciones de tutela

4. Con respecto a la Legitimación por pasiva: inmunidad restringida de los Estados Extranjeros en materia laboral respecto de los trabajadores que les presten sus servicios, siempre que aquellos sean nacionales colombianos, o residan de forma permanente en el país. Convención de Viena sobre Relaciones Diplomáticas de 1961, aprobada en Colombia por la Ley

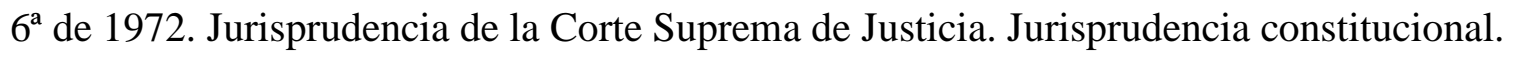

Al respecto la Corte expone: mediante auto del 30 de marzo de 2011, decidió vincular nuevamente al proceso a la Embajada de la República Islámica de Irán [aparte 5]. El fundamento que llevó a esta Sala a proceder con dicha vinculación, en contraposición a lo expuesto por la Sala de Casación Civil de la Corte Suprema de Justicia, parte de la interpretación que la Sala Laboral de la Corte Suprema de Justicia y la Corte Constitucional han dado a los artículos XXXI y XXXIII de la Convención de Viena sobre Relaciones Diplomáticas de 1961, adoptada en Colombia por la Ley 6 de 1972, en el caso radicado bajo el número No. 32096 de 2008, relativo a un proceso laboral iniciado por una ciudadana colombiana contra la Embajada del Líbano en Colombia; y la sentencia T-932 de 2010 (M.P. Luis Ernesto Vargas Silva) en la cual la Corte revisó el proceso de tutela de Isabel Francisca Cote Gómez contra la Misión Diplomática de la Embajada de la República Bolivariana de Venezuela en Colombia, y condenó a la misma a pagar a la ciudadana colombiana una suma de dinero provisional a título de pensión de vejez, hasta que la jurisdicción laboral resolviera de fondo la controversia en materia de derechos laborales. Así mismo la Corte señala los artículos XXXI Y XXXIII de la Convención de Viena sobre relaciones Diplomáticas de 18 de abril de 1961, adoptada en Colombia por la Ley 6 de 1972, por 
la cual se aprueba la "Convención de Viena sobre Relaciones Diplomáticas hecha en Viena el 18 de abril de 1961 e indica:

"Por interpretación restrictiva de los tratados, los agentes diplomáticos de las misiones o delegaciones acreditas en un país extranjero, no gozan de inmunidad de jurisdicción laboral. Esta situación se armoniza con el hecho de que el artículo XXXIII de la Convención dispone que los agentes diplomáticos deberán cumplir las normas que en materia de Seguridad Social imponga el Estado receptor a los empleadores, con respecto a los "criados particulares" que presten servicios exclusivos a un agente diplomático, siempre y cuando los trabajadores sean (i) nacionales del Estado receptor, o (ii) tengan su residencia permanente en dicho Estado. En el caso concreto, la parte accionada indica que la señora Luz Andrea Sana, ciudadana colombiana, fungió como empleada personal en el hogar del señor ex Embajador Ahmad Parbaja, lo que, en los términos de la Convención sería equivalente a afirmar que laboró como "criada particular" del señor ex Embajador Ahmad Pabarja, en su momento, jefe de la misión de la Embajada de la República Islámica de Irán en Colombia”

“Ahora bien, la competencia para conocer de tales conflictos, por disposición del artículo 235 de la Constitución Política radica en la Sala de Casación Laboral de la Corte Suprema de Justicia. Sin embargo, esa regla de competencia debe armonizarse con las disposiciones constitucionales, legales y jurisprudenciales que regulan el trámite de tutela y que permiten la intervención del juez constitucional en asuntos propios de otras jurisdicciones, siempre que ello sea necesario para amparar un derecho fundamental, ante la amenaza de un perjuicio irremediable".

5. En el análisis que efectúa la Corte hacia el caso en concreto apuntan a examinar a quien prestaba directamente sus servicios la actora, toda vez que ella indica que fue contratada por la embajada y el representante legal de la embajada y el embajador indican que fue contratada, con el fin de colaborar a la Señora Fátima con la organización de las cosas para el viaje. La Corte expresa que debido a que el contrato no fue claramente pactado por duración de obra ni por término fijo (en cuyo caso debería constar con escrito), de manera que las reglas aplicables a este trámite son las del contrato a término indefinido.

6. Desde el análisis efectuado por la Corte se logra determinar que: "El señor ex Embajador Ahmad Pabarja en calidad de agente diplomático de la Embajada de la República Islámica de Irán, vulneró el derecho fundamental a la estabilidad laboral reforzada de la ciudadana colombiana Luz Andrea Sana, quien fungía como su “criada particular," al dar por terminado su 
contrato de trabajo, estando embarazada y desconoció las normas internas sobre Seguridad Social, que en virtud del artículo XXXIII de la Convención de Viena sobre Relaciones Diplomáticas de 1961, adoptada en Colombia por la Ley 6 de 1972, deben ser acatadas por los agentes diplomáticos de las misiones o delegaciones extranjeras acreditas en nuestro país".

Al finalizar el estudio del caso la Corte indica: "por tratarse de hechos que sucedieron en aplicación de las normas que regulan las relaciones diplomáticas entre los Estados participes de la Convención de Viena sobre Relaciones Diplomáticas de 1961 y teniendo en cuenta que la actuación que vulneró los derecho fundamentales de la peticionaria se realizó durante el tiempo en que el señor ex Embajador Ahmad Pabarja fungía como representante de su país en Colombia, la Sala revocará el fallo de única instancia de la Sala Penal del Tribunal Superior de Bogotá, que declaró la improcedencia de las acción, y en su lugar, se ordenará la Embajada de la República Islámica de Irán o a quien haga sus veces, (i) vincular a la señora Luz Andrea Sana a un cargo de igual o similares condiciones al que venía desempeñando al momento de la terminación del contrato laboral, (ii) pagarle los salarios dejados de percibir, (iii) vincularla al Sistema de Seguridad Social, (iv) y reconocerle la licencia de maternidad conforme lo establece el artículo 236 y siguientes del Código Sustantivo del Trabajo, así como las demás prestaciones sociales a que haya lugar de acuerdo a la legislación colombiana vigente".

\section{Sentencia T-1078 de 2012}

Tipo de sentencia Acción de Tutela

Fecha de sentencia Corte Constitucional: 12 de diciembre de 2012

Magistrado ponente Dr. Jorge Ignacio PreteltChaljub

Actor o accionante Amalia

Aspectos Jurídicos a estudiar

- Víctima de servidumbre doméstica como forma de trata de personas o de servicios forzosos.

- Violencia Sexual, explotación y maltrato físico.

- Violación de derechos fundamentales.

- Derecho a la dignidad humana, a la identidad, a la familia. 
La Corte al iniciar su análisis expone el siguiente problema jurídico:

1. Determinar si los derechos de la peticionaria a la identidad, a la familia, a la justicia, a la verdad, a la reparación, a la libertad, a la integridad sexual y a la dignidad humana, entre otros, han sido vulnerados por Eunice Beltrán de Sánchez y Vitaliano Sánchez, al parecer por haberla extraído de su casa cuando era una niña de aproximadamente 7 años de edad, haberla forzado a realizar trabajo doméstico sin remuneración hasta aproximadamente la edad de 15 años, y por haberla sometido posiblemente a maltratos y hasta abusos sexuales.

Desde el punto de vista de la línea jurisprudencial el problema jurídico ha sido redactado de la siguiente forma:

2. ¿Los accionados violaron los derechos fundamentales de la accionante por la posible extracción de su hogar y posteriormente haberla forzado a realizar trabajo doméstico sin remuneración?

Decisión

1. La corte ampara los derechos de la tutelante: los derechos fundamentales a la identidad, a la familia, a la justicia, a la verdad, a la reparación, a la libertad, a la integridad sexual y a la dignidad humana, de la peticionaria.

Doctrina del caso concreto en la decisión mayoritaria (tesis)

1. Para el estudio del caso concreto, la Corte se remite al artículo 17 constitucional el cual cita e indica su vínculo con los "artículos 1 superior, según el cual uno de los fundamentos del Estado Social de Derecho colombiano es el respeto de la dignidad humana; el artículo 12 que proscribe la tortura y los tratos crueles, inhumanos o degradantes; el artículo 16 que garantiza el derecho al libre desarrollo de la personalidad; y el artículo 28 que reconoce el derecho a la libertad, entre otros."

Así mismo hace referencia a los tratados firmados y ratificados por Colombia consecuentes con el artículo 17:

“Convención sobre la Esclavitud de 1926, el Convenio sobre el Trabajo Forzoso de la OIT de 1930, el artículo 4 de la Declaración Universal de los Derechos Humanos de 1948 , la Convención suplementaria sobre la abolición de la esclavitud, la trata de esclavos y las instituciones y prácticas análogas a la esclavitud de 1956, la Convenio sobre la abolición del trabajo forzoso de la OIT de 1957, el artículo 8 del Pacto Internacional de Derechos Civiles y Políticos de 1966, el artículo 6 de la Convención Americana sobre Derechos Humanos de 1969 , 
el Protocolo para prevenir, reprimir y sancionar la trata de personas, especialmente mujeres y niños de 2000 -Protocolo de Palermo-, entre otros."

En concordancia con los artículos ya indicados por la Corte y en cumplimiento de las disposiciones de derecho internacional de los derechos humanos en las consideraciones se tiene igualmente en cuenta:

"En el caso de los niños, el artículo 44 superior ordena su protección específica “( ...) contra toda forma de abandono, violencia física o moral, secuestro, venta, abuso sexual, explotación laboral y económica y trabajos riesgosos". La obligación del Estado de proteger a los niños frente a este tipo de prácticas es también resaltada en el derecho internacional, por ejemplo, en los artículo 19 y 32 de la Convención sobre los derechos del niño y en el Convenio 182 de la OIT sobre las peores formas de trabajo infantil, el cual incluye en su artículo 3 entre las prácticas prohibidas: “(...) todas las formas de esclavitud o las prácticas análogas a la esclavitud, como la venta y el tráfico de niños, la servidumbre por deudas y la condición de siervo, y el trabajo forzoso u obligatorio, incluido el reclutamiento forzoso u obligatorio de niños para utilizarlos en conflictos armados"."

2. La Corte al realizar el análisis del artículo 17 constitucional del cual resalta Los Elemento que lo componen y examina las definiciones dadas por los instrumentos internacionales; de las consideraciones de la Corte se destaca:

Sobre la definición de esclavitud del artículo 1 de la Convención de 1926 sobre la esclavitud en donde se expresa que es: "el estado o condición de un individuo sobre el cual se ejercitan los atributos del derecho de propiedad o algunos de ellos”. Así mismo indica que es “(...) todo acto de captura, adquisición o cesión de un individuo para venderle o cambiarle; todo acto de cesión por venta o cambio de un esclavo, adquirido para venderle o cambiarle, y en general todo acto de comercio o de transporte de esclavos".

En la convención suplementaria sobre la abolición de 1956 se realizan precisiones correspondientes a las practicas análogas a la esclavitud, la Corte resalta la definición que expresa: "toda institución o práctica en virtud de la cual un niño o un joven menor de dieciocho años es entregado por sus padres, o uno de ellos, o por su tutor, a otra persona, mediante remuneración o sin ella, con el propósito de que se explote la persona o el trabajo del niño o del joven", atendiendo al caso en concreto sería una de las definiciones que más se asemeja y que se tendría en cuenta para efectuar la correspondiente analogía. 
De la OIT la Corte sustrae apartes del artículo 2 del Convenio sobre trabajo forzoso, el cual es definido como: "todo trabajo o servicio exigido a un individuo bajo la amenaza de una pena cualquiera y para el cual dicho individuo no se ofrece voluntariamente"

Por último la Corte se remite al artículo 3 del Protocolo de Palermo donde se define la trata de personas como: "la captación, el transporte, el traslado, la acogida o la recepción de personas, recurriendo a la amenaza o al uso de la fuerza u otras formas de coacción, al rapto, al fraude, al engaño, al abuso de poder o de una situación de vulnerabilidad o a la concesión o recepción de pagos o beneficios para obtener el consentimiento de una persona que tenga autoridad sobre otra, con fines de explotación", y entre las modalidades de trata se encuentra "explotación sexual, los trabajos o servicios forzados, la esclavitud o las prácticas análogas a la esclavitud, la servidumbre". Lo anterior vincula a los Estados a crear políticas y medidas dirigidas a combatir estos asuntos en particular.

3. En el estudio efectuado por la Corte se establece que el fundamento de la prohibición de la esclavitud, la servidumbre, los trabajos forzosos y la trata de seres humanos surge de la clara violación de los derechos fundamentales, es así que tales prácticas ameritan la respuesta estatal. En el análisis la Corte cita el auto 092 de 2008 concerniente al problema de la explotación y la trata de mujeres en el marco del conflicto armado, en el auto se resalta como "las mujeres en sociedades patriarcales como la nuestra están más expuestas al riesgo de servidumbre y explotación en labores domésticas, debido a los estereotipos sobre los roles y labores femeninas".

Se pronuncia la Corte respecto al derecho de los niños y hace referencia al artículo 44 de la Constitución y al artículo 9 de la Convención sobre los derechos de los niños, resaltando que la jurisprudencia ya ha indicado que es "la familia es la primera llamada a satisfacer las necesidades materiales, afectivas y psicológicas del niño y que el derecho de toda persona a recibir protección contra injerencias arbitrarias o ilegales en su familia, forma parte, implícitamente, del derecho a la protección de la familia”.

Otros de los derechos que a consideración de la Corte han sido vulnerados la integridad física, el derecho a la salud, a la alimentación, a la educación, el derecho al trabajo en condiciones justas y el derecho a elegir profesión u oficio, con respecto a estos dos últimos se especifica que en el caso de la servidumbre o trabajo forzoso, no hay remuneración, los horarios laborales son 
extenuantes, por otra parte la víctima es obligada a realizar trabajos en contra de su voluntad y en precarias condiciones.

4. En consideración de la Corte atendiendo el artículo 2 de la carta política sobre los fines del Estado, en el territorio nacional se debe garantizar la efectividad de los principios, derechos y deberes consagrados en la Constitución. Además, indica que las autoridades de la República están instituidas para proteger a todas las personas residentes en Colombia, en su vida, honra, bienes, creencias y demás derechos y libertades.

Los tratados internacionales sobre la trata de seres humanos, trabajo forzado y esclavitud, exhortan a los estados a generar legislación y políticas públicas tendientes a erradicar la esclavitud, la servidumbre, el trabajo forzado y trata de seres humanos.

5. Al realizar el análisis tanto de la normatividad vigente (Ley 985 de 2005, por medio de la cual se adoptan medidas contra la trata de personas y normas para la atención y protección de las víctimas de la misma), como de las instituciones encargadas del fortalecimiento de la lucha contra la trata de seres humanos la Corte indica, que aun cuando el gobierno nacional ha emprendido varias medidas al respecto, los estudios realizados por la Universidad de los Andes y la OIM demuestran que la situación en Colombia sigue siendo preocupante y se requiere de mayores medidas para combatir el problema.

6. En lo pertinente a la procedencia de la acción de tutela, la Corte argumenta que para el caso en concreto el estado de indefensión y atendiendo que la acción se dirige contra particulares: "En este caso, mientras la tutelante estuvo bajo el dominio de los peticionarios, dada su corta edad, su imposibilidad de dejar la casa y de autodeterminarse por el temor que sentía, su desconocimiento de la ciudad y la ausencia de una red de apoyo, se encontraba en una situación de desventaja desde el punto de vista material que le impedía gozar de sus derechos fundamentales y que, por tanto, puede calificarse como indefensión. En la actualidad, continúa en una situación de desventaja frente a los accionados derivada (i) del temor que parece aún prodigarles, y (ii) de la imposibilidad de lograr por otros medios que le suministren datos adicionales sobre su identidad y su familia, lo cual es aún más grave si se tiene en cuenta que solo ellos pueden proveer tal información.

Indica la Corte que la accionante no dispone de otros mecanismos judiciales de defensa. En la actualidad, como indicó el juez de primera instancia, las eventuales acciones penales que se hubieran podido adelantar contra los demandados ya prescribieron, y las acciones de 
responsabilidad civil ya caducaron. Sin embargo, a juicio de la Sala, de un lado, la prescripción y caducidad de las acciones no puede ser imputada a la demandante y, de otro lado, tales acciones no eran en todo caso idóneas para la protección de los derechos fundamentales de la peticionaria. En efecto, no puede declararse improcedente la tutela bajo el argumento de que Amalia dejó caducar y prescribir los mecanismos judiciales que tenía a su alcance, pues tal argumento desconoce la complejidad de los fenómenos de trata de personas y sometimiento a trabajo forzoso, en particular la dificultad que tienen las víctimas para auto reconocerse como tales y superar su miedo frente a los perpetradores para denunciar. Esa fue la situación de Amalia, quien en la declaración rendida ante esta Sala de Revisión, manifestó que aun siendo adulta sentía temor frente a Eunice Beltrán y le tomó muchos años llenarse de valor para denunciar lo sucedido. En el mismo sentido, los expertos de la Defensoría del Pueblo resaltaron que una manifestación del trauma por estrés postraumático que presenta Amalia, es su limitada conciencia de las consecuencias de las vivencias traumáticas que experimentó, lo que condujo a que tardara años en presentar la tutela y lo hiciera por sugerencia de terceros .

Además, debe tenerse en cuenta que cuando Amalia huyó del hogar de la familia Sánchez Beltrán, continuaba siendo una niña sin educación e ignorante de sus derechos y de las autoridades ante quienes podía acudir. Sobre este punto también llamaron la atención los expertos de la Defensoría del Pueblo, quienes resaltaron que la demandante creció sin sustento emocional y sin los elementos necesarios para reconocerse como sujeto de derechos, lo que explica su omisión en denunciar por tantos años. Por tanto, la supuesta inacción que reprochó el juez de primera instancia, no puede ser imputable a la peticionaria.

Por otra parte, expresa la corte que erró también el Juzgado Cuarenta Penal Municipal con Función de Garantía de Bogotá al sostener que la demandante debía haber acudido a la acción penal. Para la Sala, la acción penal no es el único mecanismo de defensa de los derechos de la demandante y tampoco el más idóneo, pues (i) la demandante no busca la condena penal de sus victimarios sino la tutela de sus derechos fundamentales, y (ii) la protección de la víctima en el proceso penal está supeditada a la comprobación de la existencia de un delito.

Adicionalmente, en criterio de la Sala, las acciones de reparación civil tampoco eran idóneas en este caso, pues su finalidad es simplemente reparatoria y suponen la existencia de daños ya causados, es decir, no sirven para poner fin a la amenaza o vulneración de derechos fundamentales con independencia de los daños acaecidos. 
Por último, la Sala advierte que tampoco es cierto lo señalado por el juez de segunda instancia en el sentido de que la tutela es improcedente por falta de inmediatez. En este caso, si bien es cierto la vulneración presunta de los derechos de la demandante comenzó en 1963 o 1964, lo cierto es que (i) algunas violaciones al parecer aún persisten -como en el caso del derecho a la identidady (ii) en todo caso los efectos en la salud emocional de la demandante de pasadas vulneraciones de derechos continúan."

\section{Sentencia C-871 del 2014}

Tipo de sentencia Acción de Constitucionalidad

Fecha de sentencia Corte Constitucional: 13 de Noviembre 2014

Magistrado ponente Dra. María Victoria Calle Correa

Magistrados que salvaron el voto Jorge Iván Palacio Palacio

Magistrados que aclararon el voto Luis Guillermo Guerrero Pérez

Actor o accionante MelhenJasmín Rodríguez Avellaneda, Laura María Avellaneda Montero y José Gregorio Esparza Garay.

Aspectos Jurídicos a estudiar

- Pago de prima de servicio a trabajadores del servicio doméstico.

Norma Demandada

\section{“CÓDIGO SUSTANTIVO DEL TRABAJO}

ARTÍCULO 306. PRINCIPIO GENERAL. 1. Toda empresa (de carácter permanente) está obligada a pagar a cada uno de sus trabajadores, excepto a los ocasionales o transitorios, como prestación especial, una prima de servicios, así:

a) Las de capital de doscientos mil pesos (\$200.000) o superior, un mes de salario pagadero por semestres del calendario, en la siguiente forma: una quincena el último día de junio y otra quincena en los primeros veinte días de diciembre, a quienes hubieren trabajado o trabajaren todo el respectivo semestre, o proporcionalmente al tiempo trabajado, siempre que hubieren servido por lo menos la mitad del semestre respectivo y no hubieren sido despedidos por justa causa.

b). Las de capital menor de doscientos mil pesos (\$200.000), quince (15) días de salario, pagadero en la siguiente forma: una semana el último día de junio y otra semana en los primeros veinte (20) días de diciembre, pagadero por semestres del calendario, a quienes hubieren trabajado o trabajaren todo el respectivo semestre; o proporcionalmente al tiempo trabajado. 
Siempre que hubieren servido por lo menos la mitad del semestre respectivo y no hubieren sido despedidos por justa causa.

2. Esta prima de servicios sustituye la participación de utilidades y la prima de beneficios que estableció la legislación anterior".

Problema jurídico de la sentencia

¿Viola el artículo 306 del CST, en el que se define la prima de servicios, los derechos a la igualdad y al trabajo, así como los principios mínimos fundamentales de las relaciones laborales y el bloque de constitucionalidad (artículos 13, 25, 53 y 93 de la Constitución Política, respectivamente), al excluir a las trabajadoras del servicio doméstico de su reconocimiento y pago?

\section{Decisión}

Si bien la Corte declara la exequibilidad de la expresión "toda empresa", contenida en el artículo 306 del Código Sustantivo del Trabajo, el ente colegiado exhorta al Congreso de la República y al Gobierno Nacional para que adopten las medidas legislativas e implementen las políticas públicas necesarias para avanzar hacia la universalidad del derecho prestacional al pago de la prima de servicios en el caso de los trabajadores y las trabajadoras domésticas

Doctrina del caso concreto en la decisión mayoritaria (tesis)

Al Considerar la Corte lo atinente a las normas señaladas por los accionantes, así como el análisis del Convenio 1892011 de la OIT de cual indica que al ser un tratado de derechos humanos y, más específicamente, un tratado de igualdad. $\mathrm{Su}$ propósito, claramente definido desde el Preámbulo, es el de lograr que el trabajo doméstico se desarrolle en condiciones decentes. Y para lograrlo, buena parte de sus artículos constituyen una concreción del principio de igualdad, en especial, sus artículos $3^{\circ}$ (aplicación de los principios fundamentales del derecho al trabajo) $6^{\circ}$ (igualdad en las condiciones de empleo, en comparación con otros trabajadores) , $10^{\circ}$ (igualdad en relación con la jornada máxima de trabajo, compensación por horas extras, período de descanso y vacaciones), artículo 11 (aplicación de las normas sobre salario mínimo) y 14 (igualdad en materia de seguridad social y maternidad).

La Corte al examinar la norma demandada, considera que al excluir a las trabajadoras y trabajadores del servicio doméstico del pago de la prima de servicios, genera un déficit de protección de este grupo social, y un trato desigual frente a los demás trabajadores. La Corporación consideró que si bien se ha argumentado que esta diferencia de trato es razonable, 
pues la prima de servicios nació como una forma de retribuir a los trabajadores por las utilidades de la empresa, esa posición ya ha sido revaluada y, además, preserva una concepción errónea del trabajo doméstico.

Así, explicó que (i) la prima de servicios sí se inspiró en una prestación que se denominaba "reparto de utilidades", pero no es idéntica a esta última, como lo demuestra el hecho de que el Legislador la definió en torno a criterios como el patrimonio de la empresa y el salario del trabajador (y no en relación con las utilidades de la unidad productiva); (ii) la prima de servicios puede concebirse entonces, de forma más amplia, como una retribución por los beneficios económicos y sociales que obtiene el empleador del trabajo; (iii) el trabajo doméstico genera beneficios económicos y sociales a las familias, pues (iii.1) les permite salir del hogar para generar ingresos y (iii.2) brinda cuidado a las personas más vulnerables del hogar (niños y ancianos). Finalmente, (iv) la distinción afecta a un grupo social vulnerable.

Considera la Corte que la premisa según la cual los hogares no generan utilidades (i) no es relevante, dado que la prima no corresponde al reparto de utilidades, y (ii) ese referente debe revaluarse para dar lugar a un concepto amplio de los beneficios que genera el trabajo para el empleador, que reconozca el valor económico y social que el trabajo doméstico reporta a la unidad familiar.

En consecuencia, la premisa según la cual los hogares no generan utilidades (i) es de poca relevancia, dado que la prima no es el reparto de utilidades, sino que apenas lo representa, mediante un mecanismo de cálculo que no depende de los dividendos de un ejercicio económico determinado; y (ii) debe revaluarse para dar lugar a un concepto amplio de utilidades, que reconozca el valor económico y social que el trabajo doméstico reporta a la unidad familiar.

A partir del análisis expuesto, y de la jurisprudencia reiterada en esta providencia, debe concluirse que la distinción entre trabajadores del servicio doméstico y otros trabajadores para el pago de la prima es abiertamente irrazonable y, por lo tanto, violatoria del principio de igualdad. (Negrillas fuera de texto)

\section{Salvamento de Voto}

La relatoría de la Corte en su comunicado No. 45 de Noviembre de 2014 presenta el siguiente salvamento de voto del Magistrado Jorge Iván Palacio Palacio:

“Al estimar que si bien la Corte reconoce en la parte motiva de la decisión la importancia del trabajo doméstico y su déficit de protección, tales consideraciones no se muestran congruentes 
con la parte resolutiva, ya que se limitan a declarar la exequibilidad pura y simple de la norma y a exhortar al Congreso para que avance hacia la universalización de la prima de servicios.

El Magistrado Palacio Palacio consideró que este tribunal ha debido extender el reconocimiento y pago de la prestación a través de una sentencia integradora, para así desterrar de una vez todo el acto discriminatorio contra este sector vulnerable de la población (arts. 13 y 53 superiores), hacer efectivos sus derechos fundamentales (art. $2^{\circ}$ superior) y alcanzar la justicia material (orden social justo, preámbulo de la Constitución).

La contribución significativa del trabajo doméstico a la economía del país, el déficit de protección por su infravaloración e invisibilidad, la necesidad de disfrutar de condiciones no menos favorables que de los trabajadores en general, el hecho que esta labor se cumple principalmente por mujeres y niñas, y finalmente que el concepto de "empresa" ha evolucionado hacia una concepción amplia gracias al dinamismo del derecho humano laboral, tornaban imperioso que la Corte desterrara toda interpretación inequitativa y excluyente que pudiera surgir de la norma acusada. Así se lo imponía la Constitución y el Convenio 189 de 2011 de la OIT. 
Anexo D. Análisis Jurisprudencial Sentencias de Tutela de la Corte Suprema de Justicia Colombiana para establecer la Línea Jurisprudencial del Trabajo Decente para los Trabajadores del Servicio Doméstico

\section{Análisis Jurisprudencial de las Sentencias de la Corte Suprema de Justicia sobre el Trabajo Decente para los Trabajadores y las Trabajadoras Domésticas}

\section{Sentencia Radicado 4377}

Fecha de Sentencia

25 de Octubre de 1999Corte Suprema de Justicia, la Sala de Casación Laboral

Magistrado Ponente Rafael Méndez Arango

Partes Ana Milena Guevara Gutiérrez VS Instituto de Seguros Sociales

Aspectos Jurídicos

- Derechos a la Vida y la Salud

- Afiliación fraudulenta al sistema de seguridad social

- Régimen especial Trabajadoras del Servicio Doméstico

Hechos o Elementos Fácticos Relevantes y Probados

- $\quad$ La tutelante solicitó al Instituto de Seguros Sociales practicarle una "cirugía de cataratas en el ojo derecho.

- Según la solicitante, el Instituto de Seguros Sociales ha violado sus derechos fundamentales a la vida y al debido proceso por no programar la cirugía que le fue ordenada el 25 de marzo de 1998 por el médico José Manuel Fernández, oftalmólogo perteneciente en ese entonces al Seguro Social.

- Mediante acción de tutela el Tribunal de Cali ordenó al Instituto de Seguridad Social ordenó que dentro de los 30 días siguientes a la notificación del fallo practicara la cirugía porque la accionada no respondió "la solicitud de información".

- $\quad$ En la impugnación el gerente seccional del Seguro Social afirma que debe ser revisada la decisión tomada por cuanto Ana Milena Guevara Gutiérrez aparece vinculada como empleada 
del servicio doméstico por Sara Rosa Arango Gutiérrez, tía de la solicitante, según ésta lo informó.

- $\quad$ Alega el impugnante que en razón del parentesco que existe entre la empleadora y Ana Milena Guevara Gutiérrez se presenta una situación de afiliación indebida prohibida en el literal d) del artículo $4^{\circ}$ del Decreto 824 de 1998, pues, según lo afirma, los aportes que pagan las empleadas del servicio doméstico se hacen tomando la mitad del salario mínimo legal vigente, por lo que dice que no puede "hacerse uso de esa forma de afiliación 'más económica' para facilitar el servicio de salud a terceros que además no tienen el carácter de empleadas de servicio doméstico.

\section{Problema Jurídico}

¿Se debe negar el acceso a la salud, a empleada del servicio doméstico, alegando la indebida afiliación expresada en el literal b, artículo 5 del decreto 824 de 1998 ?

\section{Tesis}

Se debe negar el derecho a la salud de empleada del servicio doméstico afiliada indebidamente atendiendo la prohibición especifica del decreto 824 de 1988.

Fundamento de las Tesis

Atendiendo a que el Tribunal de Cali tutela los derechos de la accionante, debido a la falta de contestación por parte de la accionada, queda por lo tanto el fundamento de la Tesis de la Corte la cual en la consideración de la sentencia expresa que la entidad accionada, no vulnera los derechos de la accionante, por cuanto hace prevalecer la norma existente se cita al respecto:

"El Instituto de Seguros Sociales se ha limitado a cumplir rigurosamente lo preceptuado en el artículo $5^{\circ}$ del Decreto 824 de 1988, por medio del cual, en ejercicio de la facultad otorgada en el artículo $3^{\circ}$ de la Ley 11 de 1988, el Presidente de la República estableció que no podrían afiliarse como trabajadores del servicio doméstico "los parientes del patrono o de sus familiares hasta el quinto grado de consanguinidad, tercero de afinidad y primero civil"'”.

Argumenta la Corte que el motivo por el cual no se efectúo la cirugía a la accionante fue la misma información suministrada por ella al indicar el parentesco con la supuesta empleadora.

Si bien, los fundamentos de la Corte radican en la información suministrada extemporáneamente por el gerente del Instituto de Seguridad Social, el cuerpo colegiado expresa que el juez debió 
examinar la presunción de veracidad y en sus facultades pudo averiguar si son o no ciertos los hechos aducidos para solicitar la tutela; y dado que el artículo 21 del mismo decreto permite fundar la decisión en cualquier medio probatorio, de lo informado por el gerente seccional del Seguro Social resulta que la negativa a practicar la cirugía está basada en una norma de obligatorio cumplimiento, como lo es el ya citado artículo $5^{\circ}$ del Decreto 824 de 1988.

Fuentes Decreto 824 de 1998

Constitución Política de Colombia

Ley 362 de 1997

Decreto 2591 de 1991

Decisión Revocar la sentencia dictada el 8 de septiembre de 1999 por el Tribunal de Cali y, en su lugar, negar la tutela solicitada por Ana Milena Guevara Gutiérrez contra al Instituto de Seguros Sociales

Salvamento de Voto No hubo salvamento

Aclaración del Voto No hubo aclaración

Posición Crítica La Corte Suprema deja de lado otras apreciaciones que si realiza la Corte Constitucional en sentencia T-730 de 1999, que expone un caso similar donde el Instituto de Seguros Sociales niega la prestación del servicio por incurrir en la misma prohibición del decreto 824 de 1988.

Para el caso la Corte Constitucional realiza el estudio de los derechos vulnerados e indica:

"Es indudable que si una norma preconstitucional permite que se retire del sistema de seguridad social a una persona, esta norma se convierte en inconstitucional (inconstitucionalidad sobreviniente) porque actualmente todos los habitantes de Colombia tienen el derecho irrenunciable a la seguridad social (artículo 48 C.P.) y porque se garantiza a todas las personas el acceso a los servicios de promoción, protección y recuperación de la salud (artículo 49 C.P... Luego, el literal d) del artículo $5^{\circ}$ del decreto 824 de 1988 que dice: "Los parientes del patrono o de sus familiares hasta el quinto grado de consanguinidad, tercero de afinidad y primero civil, no pueden afiliarse como trabajadores del servicio doméstico", en cuanto la norma signifique exclusión de la seguridad social, no se compagina con la actual Constitución que protege al derecho al trabajo "en todas sus modalidades" (artículo 25 C.P.). No es pues constitucional afirmar que por ser un empleador y una trabajadora familiares, esta circunstancia sea causa de retiro de la seguridad social. 
Hoy no tiene presentación que alguien que aparezca como trabajador del servicio doméstico sea excluido de la seguridad social. El mismo empleador tiene la obligación de afiliar a su empleada del servicio doméstico porque de lo contrario sería el empleador quien respondería por la seguridad social.

En esta situación habrá que leer la norma (artículo 5ºl decreto 824 de 1998, en su literal d-)) bajo la orientación de los principios de solidaridad, eficacia, continuidad y universalidad, propios de la seguridad social, y por consiguiente el mencionado literal d) del artículo $5^{\circ}$ del decreto 0824 de 1988, será simplemente una regla para que el I.S.S. pueda reclamar un mayor valor de cuota de afiliación del servicio doméstico, pero el citado artículo no podría tener la connotación de ser causal de exclusión del servicio de seguridad social.

En este orden de ideas, la norma indicada sería simplemente un instrumento para proteger el sistema de seguridad social en el sentido de que no se eluda el pago correcto de la cuota."

Al observar los dos casos se encuentra la diferencia con la cual los cuerpos colegiados manejan los mismos, mientras la Corte Superior se ciñe totalmente a la norma sin realizar mayor análisis o apreciación entre el derecho vulnerado, la norma y la Constitución que el argumento que expresa el hecho que la salud es un derecho programático y que por lo tanto no puede ser calificado como un derecho fundamental mientras la Corte Constitucional analiza el caso desde la órbita constitucional atendiendo al espíritu de la norma, pasa de obstaculizar el derecho a la salud a buscar alternativas para el cumplimiento por parte de la cotizante y su empleador, con el fin de evitar el fraude al sistema, sin vulnerar los derechos de la trabajadora.

\section{SentenciaRadicado No. 11182 Acta No. 92}

Fecha de Sentencia 04 de Noviembre de 2004Corte Suprema de Justicia, la Sala de Casación Laboral

Magistrado Ponente Francisco Javier Ricaurte Gómez

Partes María Giovanny González Castellanos VS Sala Laboral Del Tribunal Superior Del Distrito Judicial De Cundinamarca

Aspectos Jurídicos

- Acción de Tutela contra sentencias 
- Principio no reformatio in pejus

- Derechos adquiridos

- Vía de Hecho

- Vulneración al debido proceso

Problema Jurídico

¿Se debe declarar improcedente la acción de tutela contra pronunciamientos de última instancia, cuando se ven vulnerados derechos adquiridos y protegidos por la Constitución?

Tesis

La acción de tutela contra sentencias judiciales es improcedente.

Fundamento de las Tesis

Parte la Corte Suprema su consideración indicando que en múltiples oportunidades se ha sostenido que el aludido mecanismo constitucional de la acción de tutela, es improcedente cuando lo que se pretende es dejar sin validez sentencias y providencia judiciales. En su argumento la Corte Suprema cita apartes de la Sentencia C 543 de 1992, donde la Corte Constitucional Declara la Inexequibilidad del artículo 11 del decreto 2591 de 1991, el cual indicaba la procedencia y la caducidad de la acción de tutela contra sentencia judiciales. Bajo este precepto la Corte Suprema basa su argumento, para declarar la improcedencia de la acción de Tutela contra el Tribunal Superior de Cundinamarca.

Decisión

La Corte Suprema niega el amparo por improcedente la acción de tutela solicitada.

Posición Crítica

Se inicia el análisis dejando en claro que en los antecedentes de la sentencia, la Corte Suprema indica que la acción de tutela fue promovida contra la providencia del 9 de septiembre de 2004, de la Sala Laboral del Tribunal Superior de Cundinamarca, por cuanto en la primera instancia se falló a favor de la demandante y se condenó a los demandados al pago de las prestaciones sociales, sin embargo la demandante apela la decisión, con el propósito que en la segunda instancia el juez tuviera en cuenta las pruebas aportada en la primera, donde se demuestra que la relación laboral fue hasta el 20 de diciembre de 1998, atendiendo que el a quo falló la decisión hasta el 30 de noviembre de 1998, pero el ad quem, como se expresa en la sentencia de la corte, exonera a los demandados por considerar que actuaron de buena fe. 
Lo expuesto en los antecedentes contradice lo presentado por la Corte Suprema en las consideraciones donde indica que la Sala Laboral del Tribunal Superior de Cundinamarca confirma y adiciona el fallo absolutorio del Juzgado Civil del Circuito de Fusagasuga, la confusión expone irregularidades en la sentencia del ad quem, la clara violación al debido proceso y la vía de hecho en la cual incurrió lo cual conlleva a la demandante a instaurar la acción de tutela, para salvaguardar el reconocimiento de derechos laborales adquiridos y demostrados en el proceso de primera instancia.

Continuando con las observaciones a la Sentencia emitida por el órgano colegiado, se evidencia que el solo hecho de impulsar la acción de Tutela contra la decisión del Tribunal, sentó las bases para el pronunciamiento de la Sala Laboral de la Corte Suprema, por cuanto no se profundiza en los hechos de la demanda, se yerra en los hechos de la misma, así mismo no se estudia la estructura procesal, sino que el argumento expuesto se dirige directamente al argumento de la improcedencia de la demanda.

Al entrar a examinar el caso, la Corte Suprema cita en sus consideraciones la Sentencia C543 de $1^{\circ}$ de octubre de 1992, donde la Corte Constitucional declara inexequible el artículo 11 del decreto 2591 de 1991, para argumentar la improcedencia de la acción de tutela contra decisión de la Sala Laboral de Tribunal de Cundinamarca; pero se omite la sentencia T-231 de 1994, que "subrayó que todo el ordenamiento jurídico debe sujetarse a lo dispuesto por la Constitución en razón de lo dispuesto en el artículo 4 de la Carta Fundamental. Además, se resaltó que uno de los efectos de la categoría Estado Social de derecho en el orden normativo es que los jueces en sus providencias, definitivamente están obligados a respetar los derechos fundamentales" (Sent. T-094 de 2013) (negrilla fuera del texto)

Lo anterior permite argumentar la falta de profundización en el caso concreto, puesto se deja de lado no solo derechos fundamentales, como el debido proceso, la dignidad humana y la seguridad social, sino que ignora por completo el principio de no reformatio in pejus, lo cual lleva a retomar el error en el que incurre la Corte Suprema, en el desarrollo de los hechos que impide establecer de forma puntual el argumento de la Sala Laboral del Tribunal del Cund. para exonerar a los demandados y por lo tanto negar pretensiones ya adquiridas por la demandante en la primera instancia. 


\section{Sentencia Radicado No.23504 Acta No. 27}

Fecha de Sentencia 03 de Agosto de 2010Corte Suprema de Justicia, la Sala de Casación Laboral

Magistrado Ponente Elsy Del Pilar Cuello Calderón

Partes Ana Trinidad Ojeda Arias vs. Sala Laboral del Tribunal Superior del Distrito Judicial de Tunja.

Aspectos Jurídicos: -Derecho Fundamental al Debido Proceso

Problema Jurídico: ¿Se debe declarar improcedente la acción de tutela contra pronunciamientos judiciales, máxime cuando se ven vulnerados derechos laborales y fundamentales?

Tesis: La acción de tutela contra sentencias judiciales es improcedente.

Fundamento de las Tesis:La Corte Suprema en su consideración parte del argumento indicando que la acción de tutela como mecanismo constitucional es improcedente cuando lo que se pretende es dejar sin validez sentencias y providencia judiciales, "salvo que con las actuaciones u omisiones de los jueces, resulten violados, en forma evidente, derechos constitucionales fundamentales. Pero su procedencia está limitada, primero a aquellas situaciones en las cuales el afectado no disponga de otro medio de defensa judicial, caso en que se convierte en mecanismo principal y, segundo, cuando existiendo otro medio, se utiliza como mecanismo transitorio con el fin de evitar un perjuicio irremediable."

En su argumento la Corte Suprema adopta el principio de inmediatez para la procedencia de la acción de tutela, indica el órgano colegiado que "no existe justificación alguna que explique la inactividad de la accionante para solicitar el amparo constitucional, si se tiene en cuenta que la sentencia con la cual considera vulnerado su derecho se profirió el 6 de mayo de 2009, mientras que esta acción se recibió el 16 de julio de 2010, es decir, 1 año, 2 meses y 7 días después".

Finalmente expresa la Corte: "es claro que la acción de tutela resulta improcedente teniendo en cuenta que la accionante, debió utilizar las herramientas que el ordenamiento jurídico le concede para proteger sus derechos, es decir, el recurso extraordinario de casación, el cual no se interpuso a pesar de contar con interés jurídico para el mismo".

Decisión: La Corte Suprema niega la acción de tutela solicitada.

Posición Crítica: Si bien en el argumento presentado por la Corte suprema se observa que el órgano parte su motiva desde la óptica procesal al indicar que la accionante no agoto los 
recursos procesales para acudir a un mecanismo que por su naturaleza de subsidiariedad, se invoca cuando se han agotado los demás mecanismos, pero se debe resaltar que su función como mecanismo expedito y de sencillo manejo, permite la protección de quien ve vulnerados sus derechos fundamentales.

Atendiendo las funciones constitucionales y legales del juez de tutela, se cita para el caso el Auto 053 de 2002 de la Corte Constitucional que expresa al respecto:

"En esta medida lo dispuesto por la Constitución Política es un mecanismo que le confía a los jueces la función de verificar el efectivo cumplimiento de los mandatos constitucionales de protección y primacía de los derechos inalienables de la persona y cuando encuentre configurada la vulneración o amenaza de un derecho fundamental, por acción o por omisión, imparta las órdenes de inmediato cumplimiento necesarias para salvaguardar efectivamente el derecho vulnerado. Una actuación superficial y formalista pone en peligro el derecho de acceso a la justicia al dejar desprotegido a quien solicita la protección constitucional de sus derechos fundamentales y por lo mismo desconoce el mandato del artículo 86 superior".

En ningún aparte de la sentencia, la Corte Suprema se asegura de comunicarse con la accionante, para verificar la no afectación o vulneración de los derechos fundamentales, cabe resaltar que los trabajadores y las trabajadoras del servicio domésticos, son personas en estado de vulnerabilidad debido a las condiciones socio-económicas, por lo tanto requieren mayor vigilancia y protección.

Que la Corte en su función como juez de tutela, solo base su argumento en el procedimiento sin desarrollar el aspecto subjetivo del caso en concreto y salvaguardar los derechos fundamentales de los ciudadanos, deja de manifiesto el estado de vulnerabilidad de este grupo de trabajadores, quienes no solo se encuentra en clara desventaja, debilidad e indefensión frente a sus empleadores sino que no cuentan con protección efectiva y eficaz de sus derechos fundamentales.

\section{Sentencia Radicación $\mathbf{N}^{\circ} 32885$ Acta $\mathbf{N}^{\circ} 18$}

Fecha de Sentencia 14 de junio 2011Corte Suprema de Justicia, la Sala de Casación Laboral Magistrado Ponente Dr. Camilo Tarquino Gallego 
Partes María Orfilia Velásquez De González Vs. Sala Laboral Del Tribunal Superior Del Distrito Judicial De Medellín, Elena María Cafiel Ávila y Luis Fernando Marmol Mercado

Aspectos Jurídicos:-Derecho fundamental al debido proceso

Problema Jurídico: ¿Procede la acción de tutela contra pronunciamientos judiciales?

Tesis: La acción de tutela contra sentencias judiciales es procedente en casos de grave amenaza o vulneración de derechos fundamentales por acción u omisión de la autoridad.

Fundamento de las Tesis: Expresa la Corte:

"La posibilidad de controvertir las decisiones judiciales por medio de la tutela es de alcance excepcional y restringido, y se predica sólo de aquellos eventos en los que pueda establecerse una actuación del juzgador arbitraria, contraria al orden jurídico y violatoria de derechos fundamentales, pues, de no ser así, el Juez Constitucional, atentaría contra los principios de autonomía, independencia, seguridad jurídica y vigencia del Estado Social de Derecho"

La Corte indica que el argumento esgrimido por la parte accionante no "omite ilustrar el sentido del yerro en el cual incurrió el juzgado, dejando en evidencia que lo que asiste es una clara inconformidad con las resultas del proceso."

Decisión: La Corte Suprema niega el amparo constitucional solicitado por la accionante.

Posición Crítica: Ante el caso en concreto no existe información que aclare la decisión adoptada por el juez de única instancia, por lo tanto la posición crítica que se puede adoptar está dirigida a la falta de análisis que desarrolla la corte ante el hecho de no pago de la sanción, no profundiza las razones de la primera instancia, solo revisa el argumento esgrimido por la parte accionante, para hacer la solicitud del amparo.

\section{Sentencia Radicación No. 33885 Acta No. 63}

Fecha de Sentencia 22 de agosto de 2011Corte Suprema de Justicia, la Sala de Casación Laboral

Magistrado Ponente Dra. Elsy Del Pilar Cuello Calderón

Partes Diana Mónica Naranjo Zambrano vs Juzgado Segundo Laboral del Circuito de Florencia y Judith Perdomo Leiva

Aspectos Jurídicos: -Derecho fundamental al debido proceso 
Problema Jurídico: ¿Puede el juez constitucional reemplazar al ordinario al realizar valoración de los medios probatorios allegados?

Tesis: La acción de tutela contra sentencias judiciales es procedente en casos de grave amenaza o vulneración de derechos fundamentales por acción u omisión de la autoridad.

Fundamento de las Tesis: Expresa la Corte:

"La sentencia cuestionada, independientemente de que se comparta o no el criterio jurídico allí expuesto, es producto de la valoración que hizo el juzgador de las pruebas obrantes en el plenario, función que ejerció dentro del ámbito de autonomía que la misma Constitución Política reconoce en cabeza de los jueces, sin que la providencia pueda considerarse arbitraria, contrario a lo sostenido por la Sala Única del Tribunal Superior del Distrito Judicial de Florencia"

Esgrime así mismo la Corte Suprema: “independientemente de que dicha medio probatorio admita otra forma de valoración, no puede la queja constitucional irrumpir en el legítimo ejercicio que otorga el artículo 61 del Código Procesal del Trabajo y la Seguridad Social al Juez, amén de que al hacerlo se afectaría el orden jurídico, pues la instancia constitucional reexaminaría en un término por demás corto y perentorio las razones vertidas por las partes en el marco de un proceso ordinario. En esa medida y toda vez que, se reitera, no es admisible que en este estadio constitucional se le imponga al Juez una valoración de la prueba, a menos que se advierta contraria a las reglas jurídicas, que no es el presente caso, no es posible, desde ningún punto de vista anular una decisión"

Decisión: La Corte Suprema niega el amparo constitucional y revoca la decisión adoptada ad quem.

Posición Crítica: Este caso permite observar uno de los temas de los cuales se quejan los trabajadores del Servicio Doméstico y por el cual deciden no acceder a la rama, por cuanto en los procesos no obtienen la garantía y protección de los derechos que creen violados.

Se entiende de sobre manera la posición de la Corte Suprema de Justicia con respecto a la acción de tutela contra decisiones judiciales, pero más allá de escudarse en la seguridad jurídica, es deber de los jueces atendiendo la constitución y las leyes, proteger la parte débil de la relación laboral, la cual si se observa el análisis que lleva a cabo el tribunal se logra establecer que no se tuvo en cuenta en el acervo probatorio la constancia del Ministerio de Protección Social. 


\section{Sentencia Radicado No. 27112 Acta No. 36}

Fecha de Sentencia 25 de octubre de 2011Corte Suprema de Justicia, la Sala de Casación Laboral

Magistrado Ponente Dr. Jorge Mauricio Burgos Ruiz

Partes Marleny Calambás Morales Vs. Sala Laboral del Tribunal Superior del Distrito Judicial de Bogotá y Juzgado Dieciocho Laboral del Circuito

Aspectos Jurídicos:-Derecho fundamental al debido proceso

- Derecho a la Vida Digna

- Derecho a la Seguridad Social

Problema Jurídico: ¿Procede la acción de tutela contra pronunciamientos judiciales?

Tesis: La acción de tutela contra sentencias judiciales es procedente en casos de grave amenaza o vulneración de derechos fundamentales por acción u omisión de la autoridad.

Fundamento de las Tesis: Expresa la Corte:

"Esta Sala de la Corte ha sido del criterio que no procede la tutela contra providencias o sentencias judiciales, atendiendo los principios de la cosa juzgada, la independencia y autonomía de los jueces, y entre otras razones fundamentales, por ausencia de base normativa."

La Corte indica que "encuentra la decisión atacada arraigada en argumentos que consultaron reglas mínimas de razonabilidad jurídica y que, sin lugar a dudas, obedecieron a la labor hermenéutica propia del juez, sin que sea dable entonces al actor recurrir al uso de este mecanismo preferente y sumario, como si se tratase de una tercera instancia a la cual pueden acudir los administrados a efectos de debatir de nuevo sus tesis jurídicas y probatorias sobre un determinado asunto, que en su momento fue sometido a los ritos propios de una actuación judicial, con el único fin de conseguir el resultado procesal que le fue esquivo en su oportunidad legal."

Decisión: La Corte Suprema niega la acción de tutela solicitada.

Posición Crítica: Se continúa con la misma posición crítica por cuanto, el órgano judicial se sostiene en su concepto de independencia de los jueces y para el caso en concreto argumenta la libre formación de convencimiento. Expresa la corte que el argumento presentado por el órgano accionado, se ajusta a derecho, si bien se logra establecer la relación laboral, el juez como 
director del proceso invoca el principio del procedimiento civil "onus probando incumbitactori" y absuelve a la parte accionada.

Al estudiar otros pronunciamiento de la sala, se observa el criterio en el cual cuando " no se conocen con exactitud los extremos temporales, se podrían dar por establecidos en forma aproximada, cuando se tenga seguridad sobre la prestación de un servicio en un determinado período, para así poder calcular los derechos laborales o sociales que le correspondan al trabajador demandante" (SL-905-2013)

Aun cuando en el criterio de la corte se encuentra el análisis de los extremos temporales, en el estudio que se realiza no se especifica si ser aplico este parámetro, por lo tanto solo se puede partir del concepto que entrega la Corte en el sentido que pronunciamiento del juez se ajustó a derecho y que por lo tanto no existió la vulneración del derecho constitucional de la parte actora.

\section{Sentencia Radicado No. 28774 Acta No. 16}

Fecha de Sentencia 15 de Mayo de 2012Corte Suprema de Justicia, la Sala de Casación Laboral

Magistrado Ponente Dr. Rigoberto Echeverri Bueno

Partes Sonia Mireya Molina Vs. Sala Laboral de Descongestión del Tribunal Superior del Distrito Judicial de Bogotá y Juzgado Trece Laboral del Circuito de Bogotá.

Aspectos Jurídicos: -Derecho fundamental al debido proceso

- Derecho al mínimo vital

Problema Jurídico: ¿Procede la acción de tutela contra pronunciamientos judiciales?

Tesis: La acción de tutela contra sentencias judiciales es procedente en casos de grave amenaza o vulneración de derechos fundamentales por acción u omisión de la autoridad.

Fundamento de las Tesis:La Corte realiza el estudio del caso y observa que los órganos accionados, cumplieron con su labor, estableciendo que no hubo vía de hecho, así mismo la sala reitera que el juez constitucional le está vedado interferir en asuntos del exclusivo resorte de los jueces naturales.

Decisión:La Corte Suprema niega el amparo constitucional solicitado.

Posición Crítica:La corte suprema continua su posición respecto a la acción de tutela frente a sentencias judiciales, sin examinar la vulnerabilidad de los trabajadores del servicio doméstico, quienes por la situación particular de la prestación del servicio, se dificulta la 
consecución de la prueba, pero esto no es excusa para desamparar los derechos de la parte débil de la relación laboral.

\section{Sentencia Radicado No. 29774 Acta No. 28}

Fecha de Sentencia 14 de Agosto de 2012Corte Suprema de Justicia, la Sala de Casación Laboral

Magistrado Ponente Dr. Carlos Ernesto Molina Monsalve

Partes Consuelo Meneses Vs. Sala Laboral del Tribunal Superior del Distrito Judicial de Bogotá

Aspectos Jurídicos: -Derecho fundamental al debido proceso

Problema Jurídico:¿Procede la acción de tutela contra pronunciamientos judiciales?

Tesis:La acción de tutela contra sentencias judiciales es procedente en casos de grave amenaza o vulneración de derechos fundamentales por acción u omisión de la autoridad.

Fundamento de las Tesis:Enfatiza la Corte en su posición:

"que la tutela contra una decisión judicial, no es un recurso último o final, sino un remedio urgente para conjurar el quebrantamiento inminente de derechos de origen constitucional. En esta medida, es deber de la parte interesada, hacer uso diligente y oportuno de la protección constitucional, pues de no ser así, la firmeza de las decisiones judiciales estaría sujeta a la controversia constitucional que en cualquier momento, sin límite de tiempo, pudiera promover cualquiera de las partes. Escenarios como el descrito, impedirían tener seguridad sobre los derechos de cada uno y sobre el alcance de los mismos, con lo que se generaría una vulneración del derecho de acceso a la justicia y un clima de enorme inseguridad jurídica. Por ello, la necesidad de ejercer la acción de tutela en un lapso de tiempo cercano a la ocurrencia de los hechos que se considera vulneran los derechos fundamentales"

La Corte indica que el principio de inmediatez de la acción queda desestimado por cuanto pasa aproximadamente un año desde el fallo de la sentencia hasta la presentación de la acción de tutela de igual forma el juez llega a cabo el estudio del caso y expresa que aun "haciendo abstracción de la citada causal de improcedencia, esta Sala no encuentra capricho o arbitrariedad en la providencia objeto de censura. Por el contrario, la colegiatura accionada se apoyó en 
razonados procesos de interpretación, aplicación de normas y valoración de elementos de acreditación, que le permitieron proveer como viene indicado."

Decisión:La Corte Suprema niega a la accionante el amparo Constitucional solicitado.

Posición Crítica:Uno de los errores en los cuales incurren los asesores jurídicos, es no informar al usuario las diferentes posibilidades frente al caso, lo cual lleva al cliente a formar falsas expectativas con respecto al resultado del caso.

\section{Sentencia Radicación No. 42603 Acta No. 13}

Fecha de Sentencia 30 de Abril de 2013Corte Suprema de Justicia, la Sala de Casación Laboral

Magistrado Ponente Dr. Rigoberto Echeverri Bueno

Partes Marisol Rodríguez Rojas Vs. Juzgado Tercero Municipal De Pequeñas Causas Laborales Aspectos Jurídicos: -Derecho fundamental al debido proceso

- Derecho al trabajo

Problema Jurídico: ¿Procede la acción de tutela contra pronunciamientos judiciales?

Tesis: La acción de tutela contra sentencias judiciales es procedente en casos de grave amenaza o vulneración de derechos fundamentales por acción u omisión de la autoridad.

Fundamento de las Tesis: Expresa la Corte:

"Aunque se pudiera discrepar de las tesis admitidas por el juzgado de conocimiento en relación con los puntos anotados, esa disonancia no es motivo para calificar la referida sentencia como violatoria del derecho fundamental al debido proceso."

Continuando la Corte advierte: "que la pretensión de la parte accionante está dirigida a plantear una discusión eminentemente jurídica frente al fallo de única instancia, posición ésta que, como también lo ha sostenido esta misma Sala, resulta improcedente para fundamentar la solicitud de amparo constitucional en la medida que la acción de tutela no es una instancia más y, sobretodo, porque no le es permitido al juez constitucional entrar a controvertir las providencias judiciales, so pretexto de tener una opinión diferente, pues quien ha sido encargado por el legislador para dirimir el conflicto es el juez natural y su convencimiento debe primar sobre cualquier otro, salvo que se presenten las desviaciones protuberantes a que se ha hecho mención, que, se insiste, en este caso no se dan."

Decisión: La Corte Suprema niega el ampara constitucional. 
Posición Crítica:La corte ya tiene sentada la posición en la cual se intenta mediante la acción de tutela desvirtuar los fallos de procesos ordinarios, solo la afectación grave de derechos fundamentales, se le ha previsto el fuero de invalidar sentencias de procesos ordinarios.

En el caso en concreto, la corte hace un análisis más profundo de los antecedentes y de la postura del juzgado accionado, lo cual brinda luces respecto a las posturas y las decisiones adoptadas.

\section{Sentencia ATL387-2013Radicación No. 34350Acta No. 39}

Fecha de Sentencia 26 de Noviembre de 2013Corte Suprema de Justicia, la Sala de Casación Laboral

Magistrado Ponente Dr. Rigoberto Echeverri Bueno

Partes Luz Enith Montoya Hernández Vs. Embajada del Japón

Aspectos Jurídicos: -Acción de Tutela trabajadora doméstica, contra misión diplomática

Problema Jurídico:¿Procede la acción de tutela contra misión diplomática?

Tesis:La acción de tutela contra Misiones Diplomáticas solo procede en las excepciones contempladas en el artículo XXXI de la Convención de Viena sobre Relaciones Diplomáticas.

Fundamento de las Tesis: La Sala indica que continua con la posición adoptada en el auto del 21 de marzo de 2012, Radicado 37637, por cuanto la acción de tutela se encuentra incluida dentro del poder jurisdiccional frente al cual existe inmunidad y por no acreditarse alguna de las excepciones contempladas en el artículo XXXI de la citada Convención, ni haber operado una renuncia sobre tal beneficio.

Decisión:La Corte Suprema decide Rechazar In Limine la acción de tutela.

Posición Crítica: En este caso la Corte de nuevo deja de lado los antecedentes del caso y pasa a argumentar los motivos para el rechazo del proceso, por lo tanto se desconocen los detalles que sustentan la solicitud del amparo constitucional. 